\title{
ESTUDO DA REMOÇÃO BIOLÓGICA DE NITROGÊNIO VIA NITRITO UTILIZANDO FENOL COMO FONTE DE CARBONO OPERANDO UM REATOR EM BATELADAS SEQUENCIAIS (SBR) EM ESCALA PILOTO
}

\author{
Dissertação apresentada à Escola \\ Politécnica da Universidade de São Paulo \\ para obtenção do título de Mestre em \\ Engenharia.
}

Área de Concentração:

Engenharia Hidráulica e Sanitária

Orientador:

Prof. Dr. Pedro Alem Sobrinho 
A meu pai, Francisco Pataro, por tudo que faz por nós, a meu pequeno sobrinho Bernardo, certeza de que tudo se renova e à minha avó Maninha, exemplo de perseverança e tenacidade até hoje.

\section{Luciano Matos Queiroz}




\section{AGRADECIMENTOS}

Ao Prof ${ }^{\circ}$ Dr. Pedro Alem Sobrinho, por quem tenho especial deferência profissional e pessoal, pela confiança, ensinamentos, conselhos e orientação segura ao longo da realização deste trabalho.

Á Prof ${ }^{a}$ Dr $^{\mathrm{a}}$ Dione Mari Morita, pelas preciosas contribuições, generosidade e ensinamentos decisivos para qualidade deste projeto.

Aos Prof ${ }^{o s}$ Drs. Roque Piveli e Sidney Ferreira Filho pelos ensinamentos, apoio e contribuições a este trabalho.

Á colega Mariana Aun, pela sugestão do tema, paciência no ensino das técnicas de análises, confiança, apoio, conselhos, grande incentivo e amizade dispensada ao longo do curso.

Aos especiais colegas da turma de mestrandos de 2.004, Lúcia, Aline, Ruy, Érika, Godoy, Manuel, Hilton, Ari, Carlos e Max, pela amizade, companheirismo e incentivo ao longo desse período.

Aos demais colegas na convivência cotidiana do laboratório, Alexandre, Ricardo, Danielle, Nádia, Adriana, Simone, Adalberto, Sérgio, Mariane pelo apoio, amizade e convivência prazerosa.

Aos funcionários do Laboratório de Saneamento da Poli-USP, Fábio Campos e Laerte Carvalho, pela grande ajuda e principalmente pelo respeito e amizade dispensados.

Aos funcionários Ângela Mizuta, Iara Raposo, Odorico Borges e Ricardo Souza pela presteza com que sempre atenderam minhas solicitações.

À bibliotecária Elaine Gravva pela paciência e ajuda na procura dos artigos técnicos que contribuíram para realização deste projeto.

À CAPES pelo fornecimento da bolsa de auxílio.

A meu irmão Gustavo e minha cunhada Viviane pelo incentivo e apoio.

A meus padrinhos Tio Zé e Tia Tânia pela generosidade, abrigo, carinho, incentivo, conselhos e apoio; meus pais não podiam ter escolhido melhor.

Áos primos Juliana, Maurício, Roberta, Edvan, Daniela e Clarissa pelos momentos de descontração e apoio sejam no Rio ou em São Paulo.

À Tia Leila e Armando pelo carinho, apoio, conselhos e doação do acervo em Saneamento.

Á toda minha família, em especial Tia Bity e Tia Vanda, pelo carinho e incentivo para conclusão dessa etapa da minha carreira. 
Aos amigos de infância da diretoria, Rafa, Gugu, Guto, Binho, Fábio, Serginho, Zé e Lú Guerra, prova de que amigos de infância não têm defeitos.

Aos amigos baianos em saga paulistana, Saul, Raquel, Marcos César, Alessandra, Marco Antônio, Karina, Bruno, Marcela e em especial ao meu amigo de infância Marcus Mesquita, pelos momentos de prazerosa convivência e amizade.

Às grandes amigas Renata Soraya e Karina Silveira pelo incentivo, apoio e amizade.

Ao Dr. Adonai Guimarães e sua família pelo incentivo à minha carreira, respeito e amizade dispensada ao longo da nossa convivência.

A todos que torcem por mim e ajudaram de alguma forma para conclusão dessa importante etapa da minha formação profissional, porque a gente veio a terra para fazer amizade. 


\section{RESUMO}

QUEIROZ, L. M. Estudo da remoção biológica de nitrogênio via nitrito utilizando fenol como fonte de carbono operando um reator em bateladas seqüenciais (SBR) em escala piloto. 2006. 198 f. Dissertação (Mestrado) - Escola Politécnica, Universidade de São Paulo, São Paulo, 2006.

A presente pesquisa propôs avaliar a remoção biológica do nitrogênio pela via simplificada (nitritação) utilizando fenol como fonte de carbono na etapa anóxica (desnitritação) em um sistema de lodos ativados com biomassa em suspensão. Para tanto operou-se um reator piloto (volume útil de 20 litros) em bateladas seqüenciais alimentado com 5 (cinco) litros de água residuária sintética. A investigação foi caracterizada pela utilização do fenol (1.000 mg $\left.\mathrm{C}_{6} \mathrm{H}_{5} \mathrm{OH} / \mathrm{L}\right)$ e pelo aumento gradual da concentração de nitrogênio amoniacal no despejo líquido sintético (200; 300 e $500 \mathrm{mg}$ N/L) buscando as condições que permitissem a predominância do $\mathrm{N}_{-} \mathrm{NO}_{2}{ }^{-}$ao final da fase aeróbia dos ciclos de tratamento e utilização do fenol pelos microrganismos heterotróficos para redução do nitrogênio oxidado durante a fase anóxica.

Para a presente pesquisa as condições para predominância do $\mathrm{N}_{-} \mathrm{NO}_{2}{ }^{-}$na massa líquida do reator ao final da etapa aeróbia foram: $\mathrm{pH} \cong 8,3$ associado à extensão do período aeróbio do ciclo de tratamento que garantisse uma concentração mínima de amônia livre $\left(>0,3 \mathrm{mg} \mathrm{NH}_{3} / \mathrm{L}\right)$ no conteúdo do reator piloto. Com estas condições, a relação $\mathrm{N}-\mathrm{NO}_{2}^{-} /\left(\mathrm{N}_{-}-\mathrm{NO}_{2}^{-}+\mathrm{N}-\mathrm{NO}_{3}^{-}\right)$variou entre 89 e 99\%. Mantendo uma concentração de 1,0 mg $\mathrm{O}_{2} / \mathrm{L}$ no conteúdo do reator durante a fase aeróbia e tempo de residência hidráulico de três dias, as eficiências de remoção de $\mathrm{N}-\mathrm{NH}_{3}$ variaram entre: 89 e 98\% com concentrações no afluente próximas a $200 \mathrm{mg}$ N/L (nove ciclos de tratamento); 95 e 98\% para concentrações no afluente da ordem de $300 \mathrm{mg}$ N/L (cinco ciclos de remoção) e 95 e 97\% com concentrações no afluente próximas a $500 \mathrm{mg}$ N/L (três ciclos de tratamento). Para temperaturas entre 23,5 e $33^{\circ} \mathrm{C}$ e concentrações de sólidos em suspensão voláteis entre 3.420 e $2.175 \mathrm{mg}$ SSV/L no conteúdo do reator, a taxa de nitrificação específica variou entre 0,01 e $0,05 \mathrm{~kg} \mathrm{~N}-\mathrm{NH}_{3} / \mathrm{kg} \mathrm{SSV}$. dia. Concentrações máximas de amônia livre da

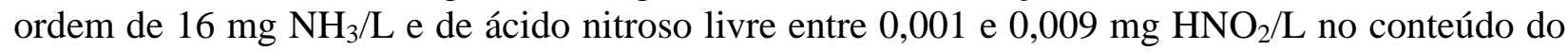
reator piloto não inibiram a oxidação biológica do nitrogênio.

Fenol, em concentrações no afluente próximas a $1.000 \mathrm{mg} \mathrm{C}_{6} \mathrm{H}_{5} \mathrm{OH} / \mathrm{L}$, mostrou-se adequado como única fonte de carbono para remoção de nitrogênio, via nitrito, para concentrações afluentes da ordem de 200 e $300 \mathrm{mg}$ N/L. As eficiências de remoção do nitrogênio oxidado variaram entre 97 e 100\%, utilizando taxas de aplicação volumétricas próximas a 0,03 kg fenol $/ \mathrm{m}^{3}$.hora.. As taxas de "desnitritação" específicas variaram entre 0,01 e 0,05 kg N-NO ${ }_{2}^{-} / \mathrm{kg} \mathrm{SSV}$ .dia; a relação alimento/microrganismo (A/M) esteve compreendida entre 0,06 e 0,13 kg fenol / kg SSV. dia; a relação fenol removido/N-NOx removido variou entre 2,1 e 3,2 g fenol removido / g NNOx removido e as eficiências de remoção do fenol, durante a etapa anóxica estiveram compreendidas entre 37 e 67\%. Taxas de aplicação volumétricas da ordem de 0,07 kg fenol $/ \mathrm{m}^{3}$.hora inibiram a "desnitritação" biológica. Os três ciclos de tratamento da etapa conduzida com concentração de $500 \mathrm{mg}$ N/L no afluente, foram marcados pela inibição da "desnitritação" e acúmulo de fenol, causados pelas elevadas concentrações de $\mathrm{N}-\mathrm{NO}_{2}{ }^{-}\left(\cong 80\right.$ a $\left.98 \mathrm{mg} \mathrm{N}-\mathrm{NO}_{2}^{-} / \mathrm{L}\right)$ na massa líquida do reator. Ainda durante essa etapa, a coleta de amostra na fase anóxica dos ciclos de remoção para realização de ensaios exploratórios, associando cromatografia gasosa e espectrometria de massa, detectaram a formação de 2 e 4 - nitrofenol no conteúdo do reator piloto. 


\begin{abstract}
QUEIROZ, L. M. Study of nitrogen biological removal via nitrite using phenol as carbon source operating a pilot scale sequence batch reactor (SBR). 2006. 198 f. Thesis (Master's) Escola Politécnica, Universidade de São Paulo, São Paulo, 2006.

This research proposes to evaluate an activated sludge system with suspended biomass in a pilot scale aiming to remove nitrogen by a simplified way (nitritation) using phenol as the carbon source of the anoxic phase (denitritation). A pilot reactor of 20-liters volume was operated in sequence batch stages fed with 5-liters of a synthetic wastewater. The investigation was characterized by the use of phenol $\left(1,000 \mathrm{mg} \mathrm{C}_{6} \mathrm{H}_{5} \mathrm{OH} / \mathrm{L}\right)$ and the gradual increase of ammonium nitrogen concentration in the synthetic wastewater (200, 300 and $500 \mathrm{mg}$ N/L) searching the conditions that allowed the prevalence of $\mathrm{N}^{-\mathrm{NO}_{2}}{ }^{-}$in the end of the aerobic phase of the treatment cycles and the use of phenol for the heterotrophic microorganisms to reduce the oxidized nitrogen during the anoxic phase.

To the present research, the conditions to $\mathrm{N}-\mathrm{NO}_{2}{ }^{-}$prevalence in the reactor liquid mass in the end of the aerobic phase were: $\mathrm{pH} \cong 8.3$ associated to the extension of the aerobic period of the treatment cycle which guarantees a minimum concentration of free ammonia $\left(>0.3 \mathrm{mg} \mathrm{NH}_{3} / \mathrm{L}\right)$

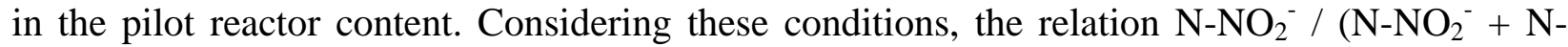
$\mathrm{NO}_{3}{ }^{-}$) varied between 91 and 99\%. Maintaining a concentration of $1.0 \mathrm{mgO} / \mathrm{L}$ in the reactor content and hydraulic residence time of three days, the removal efficiencies of $\mathrm{N}-\mathrm{NH}_{3}$ vary between: 89 and 98\% to influent concentrations near $200 \mathrm{mg}$ N/L (nine treatment cycles); 95 and $98 \%$ to influent concentrations of the order of $300 \mathrm{mg}$ N/L (five removal cycles) and 95 and $97 \%$ to influent concentrations near $500 \mathrm{mg} \mathrm{N} / \mathrm{L}$ (three treatment cycles). To temperature between 23,5 and $33^{\circ} \mathrm{C}$ and volatile suspended solid concentrations between 3,420 and 2,175 mg SSV/L in the reactor, the specific nitrification rate varied between 0.01 and $0.05 \mathrm{~kg} \mathrm{~N}-\mathrm{NH}_{3} / \mathrm{kg} \mathrm{SSV}^{-1}$. Maximum concentrations of free ammonia in the pilot reactor of the order of $16 \mathrm{mg} \mathrm{NH} / \mathrm{L}$ and nitrous acid between 0.001 and $0.009 \mathrm{mg} \mathrm{HNO}_{2} / \mathrm{L}$ didn't inhibit the nitrogen biological oxidation.

Influent phenol concentrations near $1,000 \mathrm{mg} \mathrm{C}_{6} \mathrm{H}_{5} \mathrm{OH} / \mathrm{L}$ showed to be adequate as single carbon source to nitrogen removal as nitrite to influent concentrations of the order of 200 and $300 \mathrm{mg}$ $\mathrm{N} / \mathrm{L}$. The oxidized nitrogen removal efficiencies vary between 97 and 100\%, using volumetric loading rates near $0.03 \mathrm{~kg}$ phenol/ $\mathrm{m}^{3}$.hour. The specific denitritation rates vary between 0.01 and

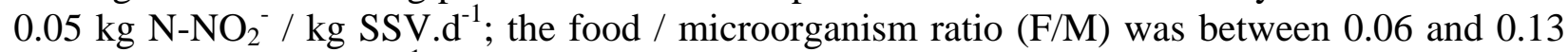
$\mathrm{kg}$ phenol / $\mathrm{kgSSV} . \mathrm{d}^{-1}$; phenol ${ }_{\text {removed }} / \mathrm{N}-\mathrm{NOx}_{\text {removed }}$ ratio varied between 2.1 and $3.2 \mathrm{~g}$ phenol $_{\text {removed }} / \mathrm{g} \mathrm{N}-\mathrm{NOx}_{\text {removed }}$ and phenol removal efficiencies during the anoxic phase were between 37 and $67 \%$. Volumetric loading rates of the order of $0.06 \mathrm{~kg}$ phenol $/ \mathrm{m}^{3}$.hour inhibited the biological denitritation. The three treatment cycles of the phase conducted with influent concentration of $500 \mathrm{mg}$ N/L showed denitritation inhibition and phenol accumulation caused by

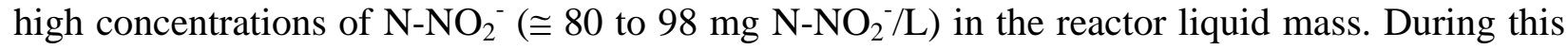
phase, the sampling of the anoxic phase of the removal cycles to the initial tests associating gas chromatography and mass spectrophotometer detected the formation of 2 and 4-nitrophenol in the pilot reactor content.
\end{abstract}




\section{SUMÁRIO}

1 INTRODUÇÃO 1

2 OBJETIVO 3

2.1 OBJETIVO GERAL 3

2.2 OBJETIVOS ESPECÍFICOS 3

3 REVISÃO DA LITERATURA

3.1 Nitrogênio na natureza $\quad 4$

3.2 Problemas associados ao lançamento do nitrogênio presente em águas 6

$\begin{array}{lll}3.3 & \text { Necessidade de tratamento face à legislação } & 7\end{array}$

3.4 Remoção do nitrogênio presente em águas residuárias: $\quad 10$

3.4.1 Processos físico-químicos aplicados para remoção do nitrogênio presente nas águas residuárias

3.4.2 Remoção biológica do nitrogênio presente nos despejos domésticos e industriais

3.4.3 Cálculos do consumo de substrato para desnitrificação biológica 15

3.4.4 Remoção biológica do nitrogênio presente nos despejos via nitrito 16

3.5 Acúmulo de nitrito em sistemas biológicos de tratamento de águas residuárias 18

3.6 Processos alternativos para remoção do nitrogênio de águas residuárias 22

3.6.1 Processo SHARON (Single Rector High Activity Ammonia Removal Over Nitrite) 22

3.6.2 Processo ANAMMOX (Anaerobic Ammonium Oxidation) 24

3.6.3 Associação SHARON-ANAMMOX 25

3.6.4 Nitrificação e Desnitrificação Simultâneas (SND) 27

$\begin{array}{llr}3.7 & \text { FENOL } & 29\end{array}$

3.7.1 Ocorrência e utilização do fenol 29

3.7.2 Problemas à saúde dos seres humanos associados à exposição ao fenol 30

3.7.3 Necessidade de tratamento face à legislação 31 
3.7.4 Alternativas para remoção do fenol presente em despejos

3.7.5 Formação de nitrofenóis 35

3.8 Sistema de lodos ativados operados em bateladas seqüenciais 37

3.8.1 Controle e monitoramento das etapas do ciclo de tratamento 40

4 MATERIAL E MÉTODOS 45

4.1 Água residuária sintética 46

$\begin{array}{lll}4.2 & \text { Inoculo } & 48\end{array}$

$\begin{array}{lll}4.3 & \text { Aparato experimental } & 48\end{array}$

4.3.1 Fase 01 - Testes exploratórios em escala de bancada 48

4.3.2 FASE 02 - Ciclos de tratamento conduzidos no reator piloto operado em 50 bateladas seqüenciais

4.4 Procedimentos operacionais de rotina 52

4.5 Operação do sistema e condução da pesquisa 53

4.5.1 Fase 01: Testes exploratórios para observação do acúmulo de nitrito 53

4.5.2 Fase 02: Pesquisa da remoção de nitrogênio amoniacal via nitrito utilizando 55 fenol como fonte de carbono

4.6 Seqüência de cálculo para realização dos balanços de massa 61

4.6.1 Início da etapa aerada do ciclo 61

$\begin{array}{lll}\text { 4.6.2 Final da etapa arada do ciclo } & 61\end{array}$

4.6.3 Início da etapa anóxica do ciclo 61

4.6.4 Durante a etapa anóxica do ciclo 62

4.6.5 Cálculo das eficiências 62

4.6.6 Cálculo das taxas específicas de nitrificação, desnitrificação e "desnitritação" 62

4.6.7 Relação Fenol removido / NOt removido durante a etapa anóxica 63

5 APRESENTAÇÃO E DISCUSSÃO DOS RESULTADOS 64

5.1 Fase 01: Testes exploratórios 64 
5.1.1 Etapa 01: Temperatura $=35^{\circ} \mathrm{C}$; $\mathrm{pH}=7,0$

5.1.2 Etapa 02 - Temperatura $\cong 30^{\circ} \mathrm{C}$; ; aeração intermitente; $\mathrm{pH} \cong 7,0$

5.1.3 Etapa 03 - Investigação do acúmulo de nitrito através da manipulação do pH 71

5.2 Fase 02: Pesquisa da remoção de nitrogênio amoniacal, via nitrito, utilizando 78 fenol como fonte de carbono

5.2.1 Etapa 01 - Concentração afluente de nitrogênio amoniacal $\cong 200,0 \mathrm{mg}$ N/L $\quad 78$

5.2.2 Etapa 02-Concentração afluente de nitrogênio amoniacal $\cong 300,0 \mathrm{mg} \mathrm{N} / \mathrm{L} \quad 96$

5.2.3 Etapa 03 - Concentração afluente de nitrogênio amoniacal $\cong 500,0$ mg NL 110

$\begin{array}{lll}5.3 & \text { Balanço de alcalinidade } & 120\end{array}$

5.3.1 Consumo de alcalinidade durante a etapa de nitritação 120

5.3.2 Recuperação de alcalinidade durante a desnitritação 121

5.4 Relação D.Q.O/N obtida durante a desnitritação 122

5.5 Investigação da formação de nitrofenóis através do contato entre fenol e nitrito no conteúdo do reator piloto

125

5.6 Investigação da aplicação do etanol como fonte de carbono alternativa ao fenol para desnitritação

6 CONCLUSÕES

7 SUGESTÕES PARA FUTURAS PESQUISAS 132

REFERÊNCIAS BIBLIOGRÁFICAS 133

$\begin{array}{ll}\text { ANEXOS } & 148\end{array}$

ANEXO A - Fotos do sistema de lodos ativados em escala piloto operado 148 durante a presente pesquisa

ANEXO B - Concentrações de $\mathrm{N}-\mathrm{NH}_{3}$, fenol, $\mathrm{N}^{-\mathrm{NO}_{2}}{ }^{-}, \mathrm{N}^{-\mathrm{NO}_{3}}{ }^{-}$. $\mathrm{NH}_{3}$ e $\mathrm{HNO}_{2}$ no conteúdo do reator piloto ao longo dos ciclos de tratamento.

ANEXO B1 - Etapa 01 - Concentração no afluente em torno de 200 mg N/L

ANEXO B2 - Etapa 02 - Concentração no afluente em torno de 300 mg N/L 153

ANEXO B3 - Etapa 03 - Concentração no afluente em torno de 500 mg N/L 155 
ANEXO C - Análise qualitativa de compostos fenólicos utilizando cromatografia gasosa acoplada a espectrômetro de massa.

ANEXO C1 - Amostra retirada do conteúdo do reator com 24 horas anóxicas

ANEXO C2 - Amostra retirada do conteúdo do reator com 36 horas anóxicas

158

ANEXO D - Cálculos

159

ANEXO D1 - Concentração no afluente em torno de 200 mg N/L

ANEXO D2 - Concentração no afluente em torno de 300 mg N/L 


\section{LISTA DE FIGURAS}

Figura 01 - Ciclo do Nitrogênio na Biosfera............................................................. 05

Figura 02 - Variação do número de oxidação do nitrogênio...................................... 12

Figura 03 - Curvas das velocidades máximas específicas de crescimento em função da temperatura para Nitrossomonas e Nitrobacter.

Figura 04 - Perfis temporais pH e ORP e OD de um sistema operado em bateladas seqüenciais para remoção de matéria orgânica e nitrogênio

Figura 05 - Perfil temporal do pH de um sistema operado em bateladas seqüenciais para remoção de matéria orgânica e nitrogênio.

Figura 06 - Perfil temporal do ORP de um sistema operado em bateladas seqüenciais para remoção de matéria orgânica e nitrogênio.

Figura 07 - Perfil temporal da concentração de O.D. de um sistema operado em bateladas seqüenciais para remoção de matéria orgânica e nitrogênio.......

Figura 08 - Esquema de funcionamento do sistema piloto de lodos ativados instalado no C.T.H.

Figura 09 - Desenho esquemático do aparato experimental, utilizado na primeira fase da pesquisa (testes exploratórios em escala de bancada).

Figura 10 - Desenho esquemático do aparato experimental, utilizado durante a segunda fase da pesquisa.

Figura 11 - Seqüência cronológica das etapas do ciclo de tratamento.

Figura 12 - Perfis temporais das concentrações de $\mathrm{N}_{-} \mathrm{NO}_{2}{ }^{-}$ao longo da etapa 01 (Testes em bancada com temperatura $=35^{\circ} \mathrm{C}$ ).

Figura 13 - Perfis temporais das concentrações de $\mathrm{N}_{-} \mathrm{NO}_{3}{ }^{-}$ao longo da etapa 01 (Testes em bancada com temperatura $=35^{\circ} \mathrm{C}$ ).

Figura 14 - Perfis temporais das concentrações de $\mathrm{N}_{-} \mathrm{NO}_{2}{ }^{-}$ao longo da etapa 02 de testes exploratórios (15' aerados e 15' sem aeração).

Figura 15 - Perfis temporais das concentrações de $\mathrm{N}_{-} \mathrm{NO}_{3}{ }^{-}$ao longo da etapa 02 de testes exploratórios (15' aerados e 15' sem aeração).

Figura 16 - Perfis temporais das concentrações de $\mathrm{N}_{-} \mathrm{NO}_{2}{ }^{-}$e ao longo da etapa 02 de testes exploratórios (30' aerados e 15' sem aeração).

Figura 17 - Perfis temporais das concentrações de $\mathrm{N}_{-} \mathrm{NO}_{3}{ }^{-}$e ao longo da etapa 02 de testes exploratórios (30' aerados e 15' sem aeração). 
Figura 18 - Perfis temporais das concentrações de $\mathrm{N}_{-} \mathrm{NO}_{2}{ }^{-}$ao longo da etapa 02 de testes exploratórios (45' aerados e 15' sem aeração)..

Figura 19 - Perfis temporais das concentrações de $\mathrm{N}_{-} \mathrm{NO}_{3}{ }^{-}$ao longo da etapa 02 de testes exploratórios (45' aerados e 15' sem aeração).

Figura 20 - Perfis temporais das concentrações de $\mathrm{N}-\mathrm{NO}_{2}{ }^{-}$ao longo da etapa 03 de testes exploratórios $-\mathrm{T} \cong 30^{\circ} \mathrm{C}, \mathrm{pH} \cong 7,50$.

Figura 21 - Perfis temporais das concentrações de $\mathrm{N}_{-\mathrm{NO}_{3}}{ }^{-}$ao longo da etapa 03 de testes exploratórios $-\mathrm{T} \cong 30^{\circ} \mathrm{C}, \mathrm{pH} \cong 7,50$.

Figura 22 - Perfis temporais das concentrações de $\mathrm{N}_{-} \mathrm{NO}_{2}{ }^{-}$ao longo da etapa 03 de testes exploratórios $-\mathrm{T} \cong 30^{\circ} \mathrm{C}, \mathrm{pH} \cong 7,80$.

Figura 23 - Perfis temporais das concentrações de $\mathrm{N}_{-} \mathrm{NO}_{3}{ }^{-}$ao longo da etapa 03 de testes exploratórios $-\mathrm{T} \cong 30^{\circ} \mathrm{C}, \mathrm{pH} \cong 7,80$.

Figura 24 - Perfis temporais das concentrações de $\mathrm{N}_{-\mathrm{NO}_{2}}{ }^{-}$ao longo da etapa 03 de testes exploratórios $-\mathrm{T} \cong 30^{\circ} \mathrm{C}, \mathrm{pH} \cong 8,00$.

Figura 25 - Perfis temporais das concentrações de $\mathrm{N}_{-} \mathrm{NO}_{3}{ }^{-}$ao longo da etapa 03 de testes exploratórios $-\mathrm{T} \cong 30^{\circ} \mathrm{C}, \mathrm{pH} \cong 8,00$.

Figura 26 - Perfis temporais das concentrações de $\mathrm{N}-\mathrm{NO}_{2}{ }^{-}$; $\mathrm{N}-\mathrm{NO}_{3}{ }^{-}$; fenol; $\mathrm{N}^{-\mathrm{NH}_{3}}$ no conteúdo do reator piloto - Ciclo de partida - Etapa 01.

Figura 27 - Perfis temporais de $\mathrm{pH}$ e oxigênio dissolvido no conteúdo do reator piloto- Ciclo de Partida - Etapa 01.

Figura 28 - Perfis temporais das concentrações de $\mathrm{N}^{-\mathrm{NO}_{2}}{ }_{2}^{-}$N-NO${ }_{3}^{-}$; fenol; $\mathrm{N}_{-} \mathrm{NH}_{3}$ no conteúdo do reator piloto - Ciclo 02 - Etapa 01.

Figura 29 - Perfis temporais de $\mathrm{pH}$ e oxigênio dissolvido no conteúdo do reator piloto - Ciclo 02 - Etapa 01.

Figura 30 - Perfis temporais das concentrações de $\mathrm{N}-\mathrm{NO}_{2}{ }^{-} ; \mathrm{N}-\mathrm{NO}_{3}{ }^{-}$; fenol; $\mathrm{N}-\mathrm{NH}_{3}$ no conteúdo do reator piloto - Ciclo 03- Etapa 01.

Figura 31 - Perfis temporais de $\mathrm{pH}$ e oxigênio dissolvido no conteúdo do reator piloto - Ciclo 03 - Etapa 01.

Figura 32 - Perfis temporais das concentrações de $\mathrm{N}-\mathrm{NO}_{2}{ }^{-}$; $\mathrm{N}-\mathrm{NO}_{3}{ }^{-}$; fenol; $\mathrm{N}_{-} \mathrm{NH}_{3}$ no conteúdo do reator piloto - Ciclo 04 - Etapa 01.

Figura 33 - Perfis temporais de $\mathrm{pH}$ e oxigênio dissolvido no conteúdo do reator piloto - Ciclo 04 - Etapa 01

Figura 34 - Perfis temporais das concentrações de $\mathrm{N}-\mathrm{NO}_{2}{ }^{-} ; \mathrm{N}_{-} \mathrm{NO}_{3}{ }^{-}$; fenol; $\mathrm{N}-\mathrm{NH}_{3}$ no conteúdo do reator piloto - Ciclo 05 - Etapa 01. 
Figura 35 - Perfis temporais de $\mathrm{pH}$ e oxigênio dissolvido no conteúdo do reator piloto - Ciclo 05 - Etapa 01.

Figura 36 - Perfis temporais das concentrações de $\mathrm{N}-\mathrm{NO}_{2}{ }^{-}$; $\mathrm{N}-\mathrm{NO}_{3}{ }^{-}$; fenol; $\mathrm{N}^{-\mathrm{NH}_{3}}$ no conteúdo do reator piloto - Ciclo 06- Etapa 01

Figura 37 - Perfis temporais de $\mathrm{pH}$ e oxigênio dissolvido no conteúdo do reator piloto - Ciclo 06 - Etapa 01.

Figura 38 - Perfis temporais das concentrações de $\mathrm{N}-\mathrm{NO}_{2}{ }^{-} ; \mathrm{N}-\mathrm{NO}_{3}{ }^{-}$; fenol; $\mathrm{N}^{-\mathrm{NH}_{3}}$ no conteúdo do reator piloto - Ciclo 07- Etapa 01.

Figura 39 - Perfis temporais de $\mathrm{pH}$ e oxigênio dissolvido no conteúdo do reator piloto - Ciclo 07 - Etapa 01

Figura 40 - Perfis temporais das concentrações de $\mathrm{N}-\mathrm{NO}_{2}{ }^{-} ; \mathrm{N}-\mathrm{NO}_{3}{ }^{-}$; fenol; $\mathrm{N}-\mathrm{NH}_{3}$ no conteúdo do reator piloto, calculadas como a média dos valores obtidos entre os ciclos 08 e 12

Figura 41 - Perfis temporais das médias dos valores de pH e oxigênio dissolvido, no conteúdo do reator piloto, monitorados entre os ciclos 08 e 12

Figura 42 - Perfis temporais das concentrações de $\mathrm{N}^{-\mathrm{NO}_{2}}{ }^{-}$; $\mathrm{N}-\mathrm{NO}_{3}{ }^{-}$; fenol; $\mathrm{N}-\mathrm{NH}_{3}$ no conteúdo do reator piloto - Ciclo 01 - Etapa 02.

Figura 43 - Perfis temporais de pH e O D. no conteúdo do reator piloto - Ciclo 01 Etapa 02.

Figura 44 - Perfil temporal de ORP no conteúdo do reator piloto - Ciclo 01 - Etapa 02

Figura 45 - Perfis temporais das concentrações de $\mathrm{N}^{-\mathrm{NO}_{2}}{ }^{-}$; $\mathrm{N}-\mathrm{NO}_{3}{ }^{-}$; fenol; $\mathrm{N}^{-\mathrm{NH}_{3}}$ no conteúdo do reator piloto - Ciclo 02 - Etapa 02

Figura 46 - Perfis temporais de pH e O D. no conteúdo do reator piloto - Ciclo 02 Etapa 02.

Figura 47 - Perfil temporal de ORP no conteúdo do reator piloto - Ciclo 02 - Etapa 02

Figura 48 - Perfis temporais das concentrações de $\mathrm{N}-\mathrm{NO}_{2}{ }^{-}$; N-NO ${ }_{3}{ }^{-}$; fenol; $\mathrm{N}^{-\mathrm{NH}_{3}}$ no conteúdo do reator piloto - Ciclo 03 - Etapa 02.

Figura 49 - Perfis temporais de pH e O D. no conteúdo do reator piloto - Ciclo 03 Etapa 02.

Figura 50 - Perfil temporal de ORP no conteúdo do reator piloto - Ciclo 03 - Etapa 02 
Figura 51 - Perfis temporais das concentrações de $\mathrm{N}-\mathrm{NO}_{2}{ }^{-} ; \mathrm{N}-\mathrm{NO}_{3}{ }^{-}$; fenol; $\mathrm{N}_{-} \mathrm{NH}_{3}$ no conteúdo do reator piloto - Ciclo 04 - Etapa 02.

Figura 52 - Perfis temporais de pH e O D. no conteúdo do reator piloto - Ciclo 04 Etapa 02.

Figura 53 - Perfil temporal de ORP no conteúdo do reator piloto - Ciclo 04 - Etapa 02.

Figura 54 - Perfis temporais das concentrações de $\mathrm{N}^{-\mathrm{NO}_{2}}{ }^{-} ; \mathrm{N}-\mathrm{NO}_{3}{ }^{-}$; fenol; $\mathrm{N}^{-\mathrm{NH}_{3}}$ no conteúdo do reator piloto - Ciclo 05 - Etapa 02.

Figura 55 - Perfis temporais de pH e O D. no conteúdo do reator piloto - Ciclo 05 Etapa 02.

Figura 56 - Perfil temporal de ORP no conteúdo do reator piloto - Ciclo 05 - Etapa 02.

Figura 57 - Perfis temporais das concentrações de $\mathrm{N}_{-\mathrm{NO}_{2}}^{-} ; \mathrm{N}^{-} \mathrm{NO}_{3}{ }^{-}$; fenol; $\mathrm{N}-\mathrm{NH}_{3}$ no conteúdo do reator piloto - Ciclo 01- Etapa 03.

Figura 58 - Perfis temporais de pH e oxigênio dissolvido no conteúdo do reator piloto - Ciclo 01 - Etapa 03

Figura 59 - Perfil temporal de ORP no conteúdo do reator piloto - Ciclo 01 - Etapa 03.

Figura 60 - Perfis temporais das concentrações de $\mathrm{N}_{-\mathrm{NO}_{2}}{ }^{-}$; N-NO ${ }_{3}{ }^{-}$; fenol; $\mathrm{N}-\mathrm{NH}_{3}$ no conteúdo do reator piloto - Ciclo 02 - Etapa 03.

Figura 61 - Perfis temporais das concentrações de $\mathrm{N}_{-\mathrm{NO}_{2}}{ }^{-}$; N-NO ${ }_{3}{ }^{-}$; fenol; $\mathrm{N}_{-} \mathrm{NH}_{3}$ no conteúdo do reator piloto - Ciclo 03 - Etapa 03.

Figura 62 - Perfis temporais de $\mathrm{pH}$ e oxigênio dissolvido no conteúdo do reator piloto - Ciclo 02 - Etapa 03

Figura 63 - Perfil Temporal de ORP no conteúdo do reator piloto - Ciclo 02 - Etapa 03

Figura 64 - Perfis temporais de $\mathrm{pH}$ e oxigênio dissolvido no conteúdo do reator piloto - Ciclo 03 - Etapa 03

Figura 65 - Perfil temporal de ORP no conteúdo do reator piloto - Ciclo 03 - Etapa 03.

Figura 66 - Dissociação do fenol em meio aquoso.

Figura 67 - Perfis das concentrações de $\mathrm{N}_{-} \mathrm{NO}_{2}{ }^{-}$e $\mathrm{N}-\mathrm{NO}_{3}{ }^{-}$, calculadas como a média de três testes anóxicos utilizando etanol como fonte de carbono para desnitritação. 
Figura 68 - Perfis dos valores médios de $\mathrm{pH}$ e Redox de três testes anóxicos utilizando etanol como fonte de carbono para desnitritação..................... 128 


\section{LISTA DE TABELAS}

Tabela 01 - Padrões de qualidade das formas de nitrogênio para cursos d'água............

Tabela 02 - Padrões para formas de nitrogênio em cursos d'água doce classe 2 para o estado de São Paulo.

Tabela 03 Processos físico-químicos para remoção de nitrogênio de águas residuárias.

Tabela 04 - Reações da desnitrificação biológica utilizando diferentes substratos........

Tabela 05 - Reações da desnitrificação utilizando compostos inorgânicos.

Tabela 06 - Condições operacionais e parâmetros para o acúmulo do $\mathrm{N}-\mathrm{NO}_{2}{ }^{-}$obtidos em outras pesquisas

Tabela 07 - Padrões de qualidade para compostos fenólicos em cursos d'água doce, classe 2 .

Tabela 08 - Condições operacionais e resultados de algumas pesquisas visando a biodegradação do fenol sob condições anaeróbias e anóxicas.

Tabela 09 - Exemplos de despejos industriais ricos em fenol e $\mathrm{N}-\mathrm{NH}_{3}$

Tabela 10 - Diferentes etapas do ciclo de tratamento em reatores operados em batelada

Tabela 11 - Dosagem de produtos químicos utilizados no preparo da água residuária sintética.

Tabela 12 - Composição da solução de micronutrientes essenciais.

Tabela 13 - Preparo do despejo sintético utilizado na fase de testes exploratórios.......

Tabela 14 - Métodos analíticos para primeira fase da pesquisa.

Tabela 15 - Concentração de nitrogênio amoniacal nas etapas da segunda fase da pesquisa.

Tabela 16 - Condições operacionais ao longo da segunda fase da pesquisa

Tabela 17 - Seqüência de amostragem e métodos analíticos durante a segunda fase da pesquisa.

Tabela 18 - Concentrações de $\mathrm{N}_{-} \mathrm{NO}_{2}{ }^{-}$e $\mathrm{N}^{-N_{3}}{ }^{-}$ao longo de 12 horas aeróbias (Fase 01 - Etapa 01).

Tabela 19 - Concentrações de $\mathrm{N}^{-\mathrm{NO}_{2}}{ }^{-}$e $\mathrm{N}-\mathrm{NO}_{3}{ }^{-}$ao longo de 12 horas aeróbias; Fase 01 Etapa 02 - (15' aeróbios e 15' sem aeração, ao longo de doze horas)... 
Tabela 20 - Concentrações de $\mathrm{N}^{-\mathrm{NO}_{2}}{ }^{-}$e $\mathrm{N}-\mathrm{NO}_{3}{ }^{-}$ao longo de 12 horas aeróbias; Fase 01 Etapa 02 - (30' aeróbios e 15' sem aeração, ao longo de doze horas)....................

Tabela 21 - Concentrações de N-NO2- e N-NO3- ao longo de 12 horas aeróbias; Fase 01 Etapa 02 - (45' aeróbios e 15' sem aeração, ao longo de doze horas).

Tabela 22 - Concentrações de $\mathrm{N}-\mathrm{NO}_{2}{ }^{-}$e $\mathrm{N}-\mathrm{NO}_{3}{ }^{-}$ao longo de 12 horas aeróbias (Fase 01 - Etapa 02) - pH na faixa entre 7,5 e 8,0 $\left(\mathrm{T}=30^{\circ} \mathrm{C}\right)$.

Tabela 23 - Resumo das condições operacionais e resultados médios da fase de testes exploratórios em escala de bancada.

Tabela 24 - Resumo dos resultados da etapa 01 (nitrogênio amoniacal afluente = $200 \mathrm{mg}$ N/L) - Fase 02

Tabela 25 - Resumo dos resultados da etapa $02\left(\mathrm{~N}-\mathrm{NH}_{3}\right.$ afluente $\left.=300 \mathrm{mg} \mathrm{N} / \mathrm{L}\right)-$ Fase 02.

Tabela 26 - Consumo de $\mathrm{CaCO}_{3}$ durante a etapa aeróbia.

Tabela 27 - Dados para realização dos cálculos da relação D.Q.O./N teórica

Tabela 28 - Resultados das análises de compostos fenólicos. 


\section{LISTA DE ABREVIATURAS E SIGLAS}

$\mathrm{A} / \mathrm{M}$

ANAMMOX

APHA

AWWA

B.T.X.

CANON

CETESB

CONAMA

C.T.H

DBO

DQO

EDTA

ETA

$\mathrm{h}$

IARC

$\mathrm{kg}$

$\mathrm{kJ}$

$\mathrm{L}$

mg

$\mathrm{mL}$

$\mu \mathrm{g}$

$\mu \mathrm{m}$

NAT

O.D.

OLAND

ORP

$\mathrm{pH}$

p.p.b. relação Alimento/Microrganismo

Anaerobic Ammonium Oxidation

American Public Health Association

American Water Works Association

Benzeno, Tolueno e Xileno

Completely autotrophic nitrogen removal over nitrite

Companhia de Tecnologia de Saneamento Ambiental

Conselho Nacional do Meio Ambiente

Centro Tecnológico de Hidráulica

Demanda Bioquímica de Oxigênio

Demanda Química de Oxigênio

Ácido Tetra-acético Etilenodiamina

Estação de Tratamento de Água

horas

International Agency for Cancer Research

kilograma

kiloJoule

litros

miligrama

mililitro

micrograma

micrômetro

Nitrogênio Amoniacal Total

Oxigênio Dissolvido

Oxygen-limited autotrophic nitrification denitrification

Potencial de oxi-redução

Potencial Hidrogeniônico

partes por bilhão 
SBR

SHARON

S.M.A.

S.N.D.

SS

SST

SSV

THM's

Tx.

$\mathrm{T}$

UFC

UASB

USP

USEPA

UV

WEF
Sequencing Batch Reactor

Single Rector High Activity Ammonia Removal Over Nitrite

Secretaria de Meio Ambiente

Simultaneous Nitrification and Denitrification

Sólidos em Suspensão

Sólidos em Suspensão Totais

Sólidos em Suspensão Voláteis

Trihalometanos

Taxa

Temperatura

Unidade Formadora de Colônia

Upflow Anaerobic Sludge Bioreactor

Universidade de São Paulo

United States Environmental Protect Agency

Ultra Violeta

Water Environment Federation 


\section{LISTA DE SÍMBOLOS}

$\begin{array}{ll}{ }^{\circ} \mathrm{C} & \text { graus Celsius } \\ \mathrm{C} / \mathrm{N} & \text { relação carbono/nitrogênio } \\ \mathrm{DQO} / \mathrm{N} & \text { relação DQO/nitrogênio } \\ \mathrm{e}^{-} & \text {elétron livre } \\ \mathrm{f}_{\mathrm{Cv}} & \text { fração da D.Q.O. utilizada pelos microrganismos para o anabolismo } \\ \mathrm{Ka} & \text { constante de ionização da amônia na condição de equilíbrio } \\ \mathrm{Kb} & \text { constante de ionização do nitrito na condição de equilíbrio } \\ \mathrm{Kw} & \text { constante de ionização da água } \\ \mathrm{Ko} & \text { constante de saturação em termos de oxigênio } \\ \mu_{\mathrm{máx}} & \text { velocidade máxima específica de crescimento } \\ \mu & \text { velocidade específica de crescimento } \\ \mathrm{N} & \text { refere-se ao símbolo do elemento nitrogênio } \\ \mathrm{N}-\mathrm{NOx} & \text { nitrito + nitrato } \\ \mathrm{Y} & \text { coeficiente de síntese celular }\end{array}$




\section{INTRODUÇÃO:}

O nitrogênio é um elemento essencial presente na constituição das células dos seres vivos e em muitos outros compostos. Porém, quando descartado no meio ambiente em quantidades excessivas causa desequilíbrios, com importantes implicações econômicas e ambientais.

Diante desses problemas, as nações têm adotado medidas restritivas para o lançamento das diferentes formas de nitrogênio presentes nos despejos, trazendo à comunidade técnica e científica o desafio de desenvolver tecnologias para reduzir a concentração desse elemento nas águas residuárias antes do descarte no meio ambiente.

Apesar da comprovada eficiência na remoção de formas nitrogenadas de alguns processos físico-químicos, sua utilização requer mão de obra especializada, além da adição de produtos químicos. Os sistemas biológicos para remoção de compostos nitrogenados apresentam como vantagem, além da ausência de produtos químicos prejudiciais ao meio ambiente, menores custos de implantação e operação, embora o impacto financeiro da adequada disposição final da fase sólida (lodo biológico gerado no processo) necessite de uma avaliação criteriosa.

O tratamento biológico para remoção de nitrogênio é tradicionalmente conduzido em duas etapas: na primeira (nitrificação), bactérias autotróficas oxidam o nitrogênio amoniacal a nitrito e nitrato, respectivamente, em meio ambiente com disponibilidade de oxigênio livre $\left(\mathrm{O}_{2}\right)$; na segunda (desnitrificação), bactérias heterotróficas reduzem as formas oxidadas do nitrogênio a nitrogênio gasoso $\left(\mathrm{N}_{2}\right)$ utilizando uma fonte de carbono em ambientes caracterizados pela ausência de $\mathrm{O}_{2}$.

Recentemente, os pesquisadores e técnicos têm buscado a aplicação de rotas biológicas alternativas para remoção do nitrogênio de águas residuárias. Essas novas rotas utilizam o nitrito como forma oxidada predominante do nitrogênio amoniacal na etapa aeróbia do processo, o que resulta em economia significativa no dimensionamento dos sistemas de 
aeração, já que a demanda por oxigênio para nitrificação fica reduzida; e ainda diminui a necessidade de energia para redução do nitrito pelas bactérias heterotróficas, possibilitando a utilização desse processo de tratamento para águas residuárias com baixa relação carbono/nitrogênio $(\mathrm{C} / \mathrm{N})$ sem a necessidade de adição de alguma fonte externa de carbono para desnitrificação, o que também reduz os custos operacionais do processo.

Algumas águas residuárias industriais possuem na sua constituição concentrações elevadas de nitrogênio amoniacal e compostos fenólicos, notadamente fenol, a exemplo dos despejos das indústrias química; petroquímica; de resinas; siderúrgica, dentre outras. A aplicação do tratamento biológico para remoção associada do nitrogênio amoniacal e fenol, utilizando esse composto como única fonte de carbono na etapa anóxica é objeto de estudo do Departamento de Engenharia Hidráulica e Sanitária da Escola Politécnica da Universidade de São Paulo desde 2000.

A presente pesquisa propôs a investigação das condições de remoção pela via simplificada (nitritação) do nitrogênio amoniacal e do fenol, presentes em água residuária sintética, utilizando o próprio fenol como fonte de carbono para desnitritação. Tal estratégia de tratamento busca associar a economia da ausência de fonte externa de carbono na etapa anóxica do processo, com aquela oriunda da menor necessidade de fornecimento de oxigênio na etapa de acúmulo de nitrito. 


\section{OBJETIVOS:}

\subsection{OBJETIVO GERAL:}

O objetivo da presente pesquisa foi avaliar a remoção biológica do nitrogênio pela via simplificada (nitritação) utilizando fenol como fonte de carbono na etapa anóxica (desnitritação) operando um sistema de lodos ativados com biomassa em suspensão, em bateladas seqüenciais, alimentado com água residuária sintética constituída predominantemente por nitrogênio amoniacal e fenol.

\subsection{OBJETIVOS ESPECÍFICOS:}

Os objetivos específicos da pesquisa foram:

- Avaliar a influência dos valores de $\mathrm{pH}$, temperatura e concentração de oxigênio dissolvido para predominância do nitrito ao final da etapa aeróbia.

- Determinar as concentrações de amônia livre e ácido nitroso não ionizado para o acúmulo de $\mathrm{N}_{-} \mathrm{NO}_{2}^{-}$na massa líquida do reator.

- Avaliar a utilização do fenol como fonte de carbono para os microrganismos na etapa anóxica dos ciclos de tratamento.

- Obter os parâmetros de projeto para nitritação e desnitritação para a água residuária sintética utilizada na presente pesquisa

- Avaliar a formação de compostos nitrogenados (nitrofenóis) potencialmente tóxicos, durante os ciclos de tratamento. 


\section{REVISÃO DA LITERATURA:}

\subsection{NITROGÊNIO NA NATUREZA:}

Associadas às fontes de carbono, energia e oxigênio, todos os organismos vivos necessitam de uma fonte de nitrogênio para a biossíntese dos aminoácidos, bases púricas e pirímidicas, que são unidades fundamentais nitrogenadas constituintes das proteínas e dos ácidos nucléicos. A diferenciação ocorre na forma química do nitrogênio utilizada pelos organismos vivos. (MADIGAN; MARTINKO; PARKER, 1997).

O nitrogênio molecular $\left(\mathrm{N}_{2}\right)$, presente na atmosfera e dissolvido no oceano, representa a grande maioria do nitrogênio existente na Terra. Esse nitrogênio torna-se reativo e biologicamente viável para plantas e algas somente através: do processo de fixação biológica; reações químicas desencadeadas por descargas elétricas na atmosfera e atividade vulcânica. A geração de $\mathrm{N}_{2}$ também pode ocorrer artificialmente através da produção industrial de fertilizantes ou na queima de combustíveis fósseis. (HOWARTH, 2004).

Fontes naturais que contribuem para a ocorrência de nitrogênio no meio líquido são: precipitação atmosférica, poeira e a fixação biológica realizada pelas cianobactérias ou pelas algas verdes. Esses organismos são autotróficos, ou seja, fixam o nitrogênio e realizam fotossíntese, retirando do gás carbônico do ar $\left(\mathrm{CO}_{2}\right)$ todo carbono que necessitam para suas atividades metabólicas. Algumas outras espécies de bactérias fixadoras de nitrogênio vivem no solo simbioticamente em raízes de algumas leguminosas (MADIGAN; MARTINKO; PARKER, 1997; VAN BENTHUM, 1998).

A etapa seguinte do ciclo do $\mathrm{N}_{2}$ na biosfera é realizada por microrganismos (bactérias nitrificantes, fungos e actinomicetos) que o oxidam a nitrito $\left(\mathrm{NO}_{2}^{-}\right)$e posteriormente a nitrato $\left(\mathrm{NO}_{3}{ }^{-}\right)$em ambientes com disponibilidade de $\mathrm{O}_{2}$. 
Fechando o ciclo, microrganismos facultativos heterotróficos, para obtenção da energia necessária às suas atividades metabólicas, realizam a redução do nitrogênio oxidado $\left(\mathrm{NO}_{2}^{-}\right.$, $\mathrm{NO}_{3}{ }^{-}$) a $\mathrm{N}_{2}$ gasoso, em ambientes caracterizados pela ausência de $\mathrm{O}_{2}$, também conhecidos como anóxicos, utilizando uma fonte de carbono como fornecedora de elétrons.

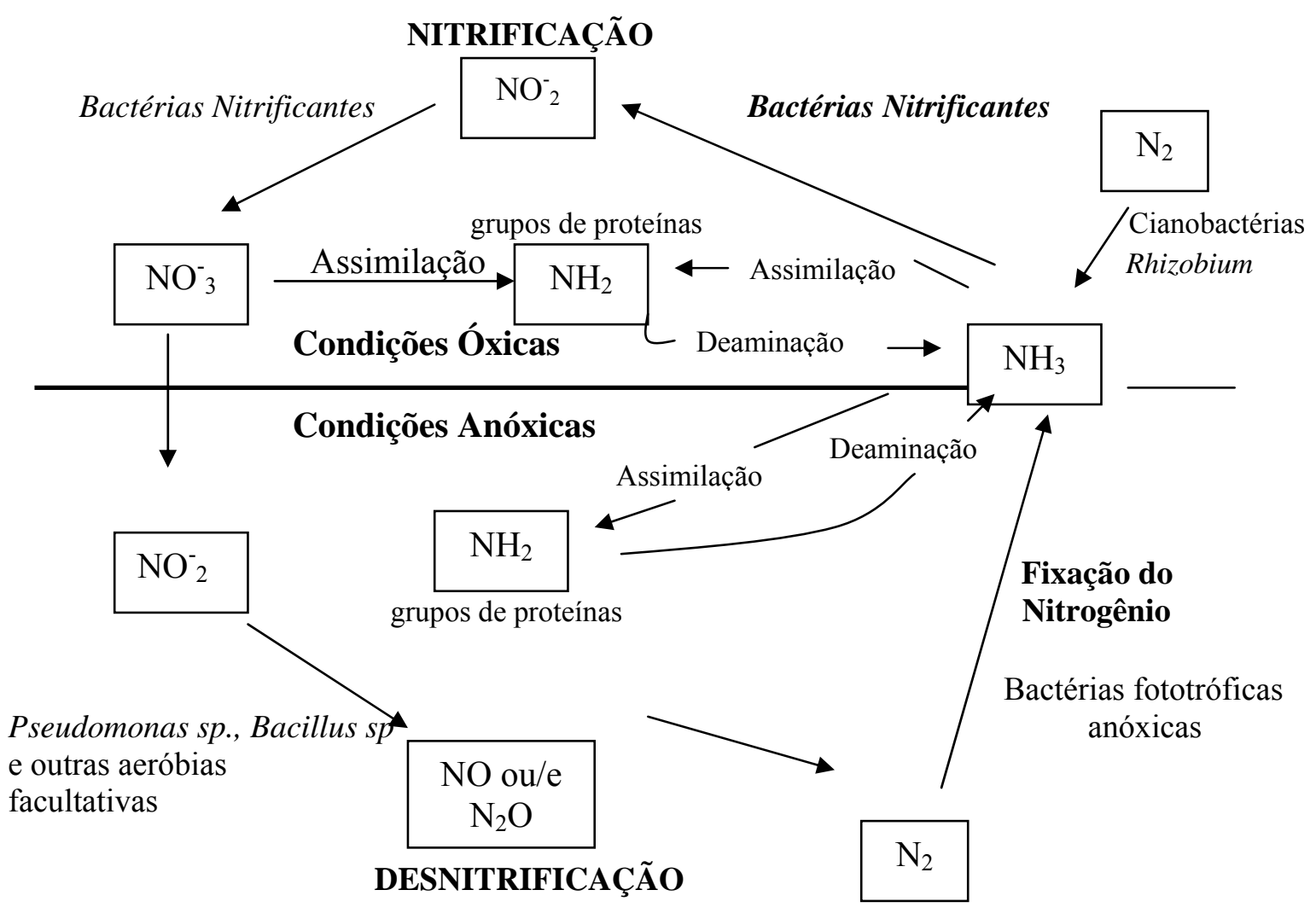

Figura 01: Ciclo do Nitrogênio na Biosfera.

Fonte: adaptado de MADIGAN; MARTINKO; PARKER, 1997.

As atividades humanas têm alterado significativamente o ciclo do nitrogênio na Terra, com efeitos deletérios pronunciados, tanto sobre a saúde dos seres humanos, quanto sobre o equilíbrio ecológico dos ecossistemas naturais. As ações antrópicas, atualmente, contribuem com cerca de 30 a $45 \%$ de todo nitrogênio fixado na Terra, por todos os processos, nos continentes e oceanos. (HOWARTH, 2004).

Merecem destaque os lançamentos, no meio líquido, dos compostos nitrogenados oriundos das mais diversas atividades antrópicas: esgotos domésticos; algumas águas residuárias industriais; escoamento de águas de irrigação de diversas culturas agrícolas fertilizadas artificialmente com produtos ricos em amônia; o líquido oriundo da degradação do lixo 
urbano (chorume); águas residuárias resultantes da decomposição dos dejetos da criação de animais em escala industrial. (RANDALL, 2004).

\subsection{Problemas Associados ao Lançamento do Nitrogênio Presente em Águas RESIDUÁRIAS:}

Inicialmente, o trabalho de técnicos e cientistas ligados ao tratamento de águas residuárias estava focado na redução da carga orgânica presente nos despejos. Com o melhor elucidamento da dinâmica dos ecossistemas, principalmente os aquáticos, que são os receptores comuns do lançamento de despejos, percebeu-se que apenas a remoção da matéria orgânica carbonácea não era suficiente para manter o equilíbrio nesses ambientes; era preciso minimizar a concentração dos macronutrientes, notadamente nitrogênio e fósforo, essenciais para o crescimento de algas e outros organismos aquáticos (RANDALL; BARNARD; STENSEL, 1995).

O lançamento indiscriminado de compostos nitrogenados ${ }^{1}$ presentes em águas residuárias potencialmente pode causar os seguintes prejuízos (RANDALL; BARNARD; STENSEL, 1995; VAN BENTHUM, 1998; HOWARTH, 2004):

- Toxicidade à vida aquática, pois a amônia livre $\left(\mathrm{NH}_{3}\right)$ impede as trocas gasosas nas guelras dos peixes.

- Consumo do oxigênio do meio aquático no processo de oxidação da amônia (nitrificação).

- Aumenta a demanda pelo desinfetante nas ETA's que utilizam cloro na desinfecção da água, uma vez que o cloro reage com o íon amônio $\left(\mathrm{NH}_{4}{ }^{+}\right)$formando cloraminas. Essas são desinfetantes menos eficazes que o ácido hipocloroso.

- Causam um grave problema de saúde pública, a Metahemoglobinemia, popularmente conhecida como "doença dos bêbes azuis", que resulta na morte prematura dos recém

\footnotetext{
${ }^{1}$ inclui o nitrogênio orgânico (proteínas, aminoácidos e uréia), íon amônio $\left(\mathrm{NH}_{4}^{+}\right)$, amônia livre $\left(\mathrm{NH}_{3}{ }^{+}\right)$, nitrito e nitrato.
} 
nascidos. Essa doença está associada à redução do nitrato a nitrito, que por sua vez oxida o ferro II a ferro III nas moléculas de hemoglobina, incapacitando a troca de oxigênio e matando por asfixia.

- Algumas pesquisas epidemiológicas sugerem que a ingestão de elevadas concentrações de nitrato pode favorecer o desenvolvimento de câncer no aparelho digestivo, aborto e outros problemas de saúde como distúrbios no sistema neurológico.

- Prejudicam o reúso da água, principalmente para fins industriais.

A poluição por nitrogênio está diretamente relacionada à acidificação dos solos, eutrofização em ecossistemas marinhos próximos à costa e perda da biodiversidade em vários ecossistemas aquáticos e terrestres. (HOWARTH, 2004).

\subsection{NECESSIDADE DE TRATAMENTO FACE À LEGISLAÇÃO:}

Diante dos problemas ambientais e dos problemas relacionados à saúde pública, os órgãos ambientais regulamentam o lançamento de despejos contendo nitrogênio, nas suas diversas formas.

O Conselho Nacional do Meio Ambiente (CONAMA), por meio da Resolução n 357 de 17 de março de 2005, que dispõe sobre a classificação dos corpos de água e dá diretrizes ambientais para o seu enquadramento, bem como estabelece as condições e padrões de lançamento de efluentes, determina como limite para o lançamento de nitrogênio amoniacal total, concentração inferior a $20,0 \mathrm{mg}$ N/L. A determinação deste valor, como limite de lançamento, está associada à toxicidade conferida pela amônia aos organismos aquáticos, uma vez que, considerando o $\mathrm{pH}$ neutro para os corpos receptores e a temperatura de $25^{\circ} \mathrm{C}$. têm-se na condição de equilíbrio:

$\mathrm{NH}_{3}+\mathrm{H}_{2} \mathrm{O} \leftrightarrow \mathrm{NH}_{4}^{+}+\mathrm{OH}^{-}\left(\mathrm{Kb}=1,75 \times 10^{-5}\right)$, donde: 
$\mathrm{Kb}=\left[\mathrm{NH}_{4}^{+}\right] .\left[\mathrm{OH}^{-}\right]$

$\left[\mathrm{NH}_{3}\right] \cdot\left[\mathrm{H}_{2} \mathrm{O}\right]$

Para $\mathrm{N}-\mathrm{NH}_{3}=20,0 \mathrm{mg} / \mathrm{L}$, a concentração molar é: $\left[\mathrm{NH}_{3}\right]=\left(20 / 14 \times 10^{3}\right)=1,428 \times 10^{-3}$ molar.

$\left[\mathrm{OH}^{-}\right]$para $\mathrm{pH}=7,0$ é igual a $1,0 \times 10^{-7}$ e $\left[\mathrm{H}_{2} \mathrm{O}\right]=1,0$; daí, efetuando os cálculos têm-se:

$\mathrm{NH}_{4}^{+}(\mathrm{mg} / \mathrm{L})\left(25^{\circ} \mathrm{C}\right.$., e $\left.\mathrm{pH}=7,0\right) \cong 4,5 \mathrm{mg} / \mathrm{L}$, tal valor já é tóxico para os peixes. (PIVELI e KATO, 2006).

Apesar desse valor, deve-se observar que a Resolução 357 do CONAMA ressalva a obrigatoriedade da realização de testes ecotoxicológicos e permite aos órgãos ambientais estaduais adotarem valores mais restritivos que o preconizado, quando comprovados efeitos tóxicos agudos em organismos aquáticos ou inviabilizar o abastecimento das populações; assim como, permite a adoção de valores mais elevados que o estabelecido, associando testes ecotoxicológicos, toxicológicos e estudos de dispersão no corpo receptor, desde que não prejudique os usos previstos para o corpo d'água.

O lançamento de efluentes em um determinado corpo receptor deve observar, também, os padrões referentes à classe de enquadramento do curso d'água em questão. A Resolução CONAMA 357, no art. $32, \S 1^{\circ}$, estabelece que o lançamento de efluentes deve atender simultaneamente às condições e padrões de lançamento de efluentes e não ocasionar a ultrapassagem das condições e padrões de qualidade da água, estabelecidos para as respectivas classes, nas condições das vazões de referência. $\mathrm{O}$ art. 42 estabelece que, enquanto não aprovados os respectivos enquadramentos, as águas doces serão consideradas classe 2 , as salinas e salobras classe 1, exceto se as condições de qualidade atuais forem melhores, o que determinará a aplicação da classe mais rigorosa correspondente. Os padrões estabelecidos para cursos d'água, tratando-se das formas de nitrogênio, estão mostrados na tabela 01. 
Tabela 01 - Padrões de qualidade das formas de nitrogênio para cursos d'água:

\begin{tabular}{|cccc|}
\hline \hline Parâmetro & $\begin{array}{c}\text { Águas Salinas } \\
\text { Classe 1 }\end{array}$ & $\begin{array}{c}\text { Águas Salobras } \\
\text { Classe 1 }\end{array}$ & Águas doces Classe 2 \\
\hline \hline Nitrato & $0,40 \mathrm{mg} / \mathrm{L} \mathrm{N}$ & $0,40 \mathrm{mg} / \mathrm{L} \mathrm{N}$ & $10,0 \mathrm{mg} / \mathrm{L} \mathrm{N}$ \\
\hline Nitrito & $0,07 \mathrm{mg} / \mathrm{L} \mathrm{N}$ & $0,07 \mathrm{mg} / \mathrm{L} \mathrm{N}$ & $1,0 \mathrm{mg} / \mathrm{L} \mathrm{N}$ \\
\hline Nitrogênio & & & $3,7 \mathrm{mg} / \mathrm{L} \mathrm{N}$, para pH $<7,5$ \\
amoniacal & $0,40 \mathrm{mg} / \mathrm{L} \mathrm{N}$ & $0,40 \mathrm{mg} / \mathrm{L} \mathrm{N}$ & $\begin{array}{c}2,0 \mathrm{mg} / \mathrm{L} \mathrm{N}, \text { para } 7,5<\mathrm{pH}<8,0 \\
\text { total }\end{array}$ \\
& & $\begin{array}{c}1,0 \mathrm{mg} / \mathrm{L} \mathrm{N}, \text { para } 8,0<\mathrm{pH}<8,5 \\
0,5 \mathrm{mg} / \mathrm{L} \mathrm{N}, \text { para } \mathrm{pH}>8,5\end{array}$ \\
\hline \hline
\end{tabular}

Fonte: Adaptado da Resolução CONAMA 357 de 17 de março de 2005.

Para águas doces de classes 1 e 2, quando o nitrogênio for fator limitante para eutrofização, o órgão ambiental competente poderá, sob condições estabelecidas, adotar como valor limite para lançamento do nitrogênio total (após oxidação) 1,27 mg N/L para ambientes lênticos e 2,18 mg N/L para ambientes lóticos, na vazão de referência. Os valores máximos admissíveis dos parâmetros relativos às formas químicas de nitrogênio e fósforo, nas condições de vazão de referência, poderão ser alterados em decorrência de condições naturais, ou quando estudos ambientais específicos, que considerem também a poluição difusa, comprovem que esses novos limites não acarretarão prejuízos para os usos previstos no enquadramento do corpo de água.

No estado de São Paulo, o Decreto ${ }^{\circ}$ 8.468, de 8 de setembro de 1976, que regulamenta a Lei n 997, de 31 de maio de 1976, que Dispõe sobre a Prevenção e o Controle da Poluição, traz no art. 18, a definição dos padrões de emissão para efluentes industriais lançados, direta ou indiretamente, nas coleções de água. Além de obedecerem aos limites deste artigo, os efluentes não poderão conferir ao corpo receptor características em desacordo com o enquadramento do mesmo, na respectiva classe proposta. A tabela 02 mostra os padrões de qualidade para nitrogênio da água doce, classe 2, para o estado de São Paulo. 
Tabela 02 - Padrões para formas de nitrogênio em cursos d'água doce classe 2 para o estado de São Paulo:

\begin{tabular}{|cc|}
\hline \hline Parâmetro & Águas doces Classe 2 \\
\hline \hline Nitrato & $10,0 \mathrm{mg} / \mathrm{L} \mathrm{N}$ \\
\hline Nitrito & $1,0 \mathrm{mg} / \mathrm{L} \mathrm{N}$ \\
\hline Amônia & $0,5 \mathrm{mg} / \mathrm{L} \mathrm{N}$ \\
\hline \hline
\end{tabular}

Fonte: Adaptado do Decreto 8.468 de 8 de setembro de 1976, Legislação Ambiental do Estado de São Paulo.

Ainda no estado de São Paulo, a Secretaria de Estado do Meio Ambiente publicou a Resolução SMA-3 de 22 de fevereiro de 2000, que implementou o controle ecotoxicológico de efluentes líquidos. Portanto, além de atender ao decreto 8.468, em especial aqueles parâmetros regulamentados pelo artigo 18, as eventuais interações entre as substâncias presentes no efluente não podem causar, ou potencialmente causar, efeitos tóxicos aos organismos aquáticos no corpo receptor.

\subsection{REMoÇÃo do Nitrogênio Presente EM ÁGUAS RESIDUÁRIAS:}

\subsubsection{PROCESSOS FÍSICO-QUÍMICOS APLICADOS PARA REMOÇÃO DO NITROGÊNIO PRESENTE NAS ÁGUAS RESIDUÁRIAS:}

Alguns processos físico-químicos são aplicados principalmente em despejos industriais altamente concentrados em nitrogênio amoniacal para reduzir as concentrações desse composto antes da entrada do efluente em sistemas biológicos de tratamento (METCALF E EDDY INC., 2003). A tabela 03 apresenta os principais processos físico-químicos aplicados para remoção ou redução da concentração de nitrogênio presente em algumas águas residuárias.

Tabela 03 - Processos físico-químicos para remoção de nitrogênio de águas residuárias:

\begin{tabular}{|l|l|}
\hline \multicolumn{1}{|c|}{ Composto nitrogenado } & \multicolumn{1}{c|}{ Processo aplicado } \\
\hline Amônia $\left(\mathrm{NH}_{4}^{+}\right)$ & Oxidação com cloro (cloração ao breakpoint) \\
\hline Amônia livre $\left(\mathrm{NH}_{3}\right)$ & Air stripping \\
\hline Amônia $\left(\mathrm{NH}_{4}^{+}\right)$e nitrato $\left(\mathrm{NO}_{3}{ }^{-}\right)$ & Troca iônica \\
\hline
\end{tabular}

Fonte: Adaptado de METCALF E EDDY INC., 2003. 


\subsubsection{REMOÇÃO BIOLÓGICA DO NITROGÊNIO PRESENTE NOS DESPEJOS DOMÉSTICOS E INDUSTRIAIS:}

Os processos biológicos para remoção de nitrogênio envolvem a reprodução, sob condições controladas, daqueles processos que ocorrem naturalmente na biosfera (Figura 01).

A alternativa mais aplicada para remoção biológica de nitrogênio pode ser descrita como um processo em duas etapas. A primeira é a oxidação da amônia a nitrato em ambiente aeróbio (nitrificação) e a segunda é a utilização do nitrato, formado na primeira etapa, como aceptor de elétrons para respiração biológica, promovendo a redução desse íon a nitrogênio molecular (desnitrificação) (VAN HAANDEL e MARAIS, 1999).

A nitrificação envolve dois grupos de bactérias autotróficas filogeneticamente relacionados: as bactérias que oxidam amônia (predominantemente Nitrosomonas sp e Nitrosospira $s p$ ) e as bactérias que oxidam nitrito (predominantemente Nitrobacter sp e Nitrospira $s p$ ). Quase todas bactérias nitrificantes são obrigatoriamente quimolito-autotróficas, ou seja, obtêm todo carbono necessário às suas funções vitais a partir do $\mathrm{CO}_{2}$ (BLACKALL, 2000; DAIMS, 2000; PHILIPS; LAANBROEK; VERSTRAETE, 2002).

O primeiro passo da nitrificação é a oxidação da amônia até nitrito através da formação da hidroxilamina $\left(\mathrm{NH}_{2} \mathrm{OH}\right)$ como composto intermediário. A reação de formação da hidroxilamina (reação 01) é endotérmica. Após essa etapa, ocorre a conversão da hidroxilamina a nitrito (reação 02) usando oxigênio como aceptor final de elétrons e gerando energia.

$$
\begin{aligned}
& \mathrm{NH}_{3}+\mathrm{O}_{2}+2 \mathrm{H}^{+}+2 \mathrm{e}^{-} \rightarrow \mathrm{NH}_{2} \mathrm{OH}+\mathrm{H}_{2} \mathrm{O} \\
& \mathrm{NH}_{2} \mathrm{OH}+\mathrm{H}_{2} \mathrm{O} \rightarrow \mathrm{NO}_{2}^{-}+5 \mathrm{H}^{+}+4 \mathrm{e}^{-} \\
& \underline{0.5 \mathrm{O}_{2}}+2 \mathrm{H}^{+} \rightarrow 2 \mathrm{e}^{-}+\mathrm{H}_{2} \\
& \mathrm{NH}_{3}+1.5 \mathrm{O}_{2} \rightarrow \mathrm{NO}_{2}^{-}+\mathrm{H}^{+}+\mathrm{H}_{2} \mathrm{O} \quad\left(\Delta \mathrm{G}=-275 \mathrm{~kJ} \mathrm{molN}^{-1}\right)
\end{aligned}
$$

Desse ponto, o nitrito formado é oxidado a nitrato pelas bactérias oxidantes de nitrito. A reação global da nitrificação e a geração de energia está apresentada na reação 06. 
$\mathrm{NO}_{2}^{-}+\mathrm{H}_{2} \mathrm{O} \rightarrow \mathrm{NO}_{3}^{-}+2 \mathrm{H}^{+}+2 \mathrm{e}^{-}$

$\underline{0.5 \mathrm{O}_{2}}+2 \mathrm{H}^{ \pm}+2 \mathrm{e}^{-} \rightarrow \mathrm{H}_{2} \underline{\mathrm{O}}$

$\mathrm{NO}_{2}^{-}+0.5 \mathrm{O}_{2} \rightarrow \mathrm{NO}_{3}^{-}-\left(\Delta \mathrm{G}=75 \mathrm{~kJ} \mathrm{~mol}^{-1} \mathrm{~N}\right)$

$\mathrm{NH}_{3}+2 \mathrm{O}_{2} \rightarrow \mathrm{NO}_{3}^{-}+\mathrm{H}^{+}+\mathrm{H}_{2} \mathrm{O} \quad\left(\Delta \mathrm{G}=350 \mathrm{~kJ} \mathrm{~mol}^{-1} \mathrm{~N}\right)$

A fixação do $\mathrm{CO}_{2}$ consome cerca de $80 \%$ da energia gerada pelas bactérias que oxidam amônia, e para cada átomo de carbono fixado, as bactérias nitrificantes precisam oxidar 35 moléculas de $\mathrm{NH}_{3}$ ou 100 moléculas de nitrito, portanto o coeficiente de síntese celular dos microorganismos nitrificantes é baixo. Além disso, a taxa de crescimento é lenta comparada aos microrganismos heterotróficos (PHILIPS; LAANBROEK; VERSTRAETE, 2002).

A figura 02 mostra a variação do número de oxidação do nitrogênio nos processos de nitrificação e desnitrificação:

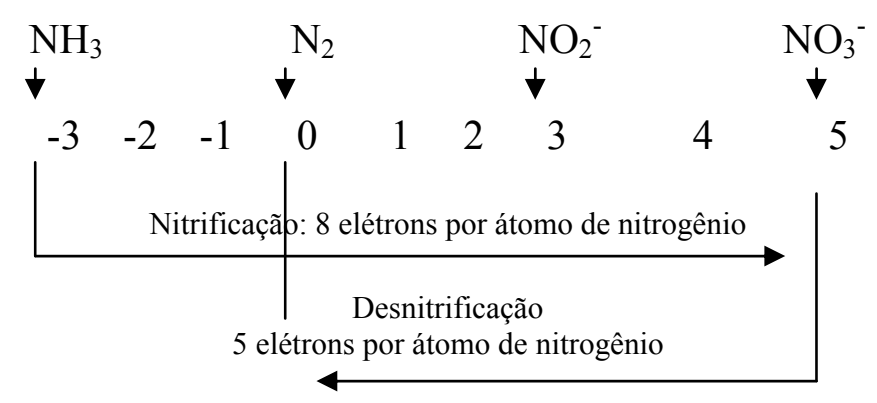

Figura 02: Variação do número de oxidação do nitrogênio.

Fonte: adaptado de VAN HAANDEL E MARAIS, 1999.

Considerando as reações (01 a 06), a quantidade de oxigênio requerida no processo pode ser calculada:

Consumo de $\mathrm{O}_{2}$ para nitrificação de $1 \mathrm{~mol}$ de $\mathrm{N}-\mathrm{NH}_{3}=64 / 14=4,57 \mathrm{mg} \mathrm{O}_{2} / \mathrm{mg} \mathrm{N}$.

Deve-se considerar o fato que o processo de oxidação biológica do íon amônio produz efeito sobre a alcalinidade da água residuária, estequiometricamente, nota-se que 2 moles de $\mathrm{H}^{+}$são produzidos por mol de nitrato formado. Sabendo-se que a produção de $1 \mathrm{~mol} \mathrm{de} \mathrm{H}^{+}$é equivalente ao consumo de $1 \mathrm{~mol}$ de alcalinidade ou $50 \mathrm{~g} \mathrm{CaCO}_{3}$, têm-se na nitrificação:

Variação de alcalinidade $=-100 / 14=-7,14 \mathrm{mg} \mathrm{CaCO}_{3} / \mathrm{mg} \mathrm{N}$.

A segunda etapa do processo de remoção biológica do nitrogênio é conhecida como

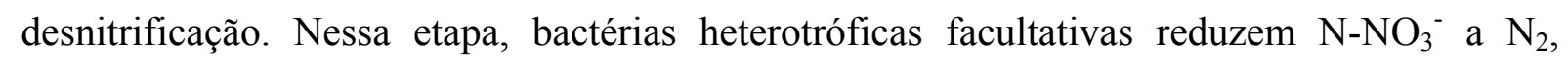


utilizando uma fonte orgânica de carbono. A tabela 04 mostra as reações de desnitrificação biológica utilizando diferentes fontes de carbono. (VAN HAANDEL E MARAIS, 1999).

Tabela 04 - Reações da desnitrificação biológica utilizando diferentes substratos:

\begin{tabular}{|ll|}
\hline \multicolumn{1}{|c|}{ Fonte de Carbono } & \multicolumn{1}{c|}{ Reação } \\
\hline \hline Metanol & $5 \mathrm{CH}_{3} \mathrm{OH}+6 \mathrm{NO}_{3}^{-} \rightarrow 3 \mathrm{~N}_{2}+5 \mathrm{CO}_{2}+7 \mathrm{H}_{2} \mathrm{O}+6 \mathrm{OH}^{-}$ \\
\hline Ácido Acético: & $5 \mathrm{CH}_{3} \mathrm{COOH}+8 \mathrm{NO}_{3}{ }^{-} \rightarrow 4 \mathrm{~N}_{2}+10 \mathrm{CO}_{2}+6 \mathrm{H}_{2} \mathrm{O}+8 \mathrm{OH}^{-}$ \\
\hline Esgoto Bruto: & $\mathrm{C}_{10} \mathrm{H}_{19} \mathrm{O}_{3} \mathrm{~N}+10 \mathrm{NO}_{3}{ }^{-} \rightarrow 5 \mathrm{~N}_{2}+10 \mathrm{CO}_{2}+3 \mathrm{H}_{2} \mathrm{O}+\mathrm{NH}_{3}+10 \mathrm{OH}^{-}$ \\
\hline Glicose & $5 \mathrm{C}_{6} \mathrm{H}_{12} \mathrm{O}_{6}+24 \mathrm{NO}_{3}^{-}+24 \mathrm{H}^{+} \rightarrow 12 \mathrm{~N}_{2}+30 \mathrm{CO}_{2}+42 \mathrm{H}_{2} \mathrm{O}$ \\
\hline \hline
\end{tabular}

Fonte: adaptado de Metcalf and Eddy Inc., 2003

A redução de cada óxido de nitrogênio é catalisada por uma enzima específica, geralmente referida como óxido de nitrogênio $\left(\mathrm{NO}_{3}^{-}, \mathrm{NO}_{2}^{-}, \mathrm{NO}\right.$ ou $\mathrm{N}_{2} \mathrm{O}$ redutase $\left.{ }^{2}\right)$. Em cada etapa do processo de redução, as formas oxidadas de nitrogênio servem como aceptoras de elétrons na respiração, acompanhada da oxidação de compostos orgânicos como doadores de elétrons para geração de energia e nova matéria celular (PHILIPS; LAANBROEK; VERSTRAETE, 2002).

No processo de desnitrificação, o nitrato (número de oxidação $=+5$ ) é reduzido para $\mathrm{N}_{2}$ (número de oxidação $=0$ ), o que representa a transferência de 5 elétrons por átomo de $\mathrm{N}$. Portanto, dos oito elétrons liberados durante a oxidação do $\mathrm{N}_{-\mathrm{NH}_{3}}$ a $\mathrm{NO}_{3}{ }^{-}$, cinco são recuperados na redução. Assim, observa-se que uma fração igual a 5/8 do oxigênio necessário para nitrificação pode ser recuperada durante a desnitrificação. Ou seja:

$$
(5 / 8) \times 4,57 \mathrm{mg} \mathrm{O}_{2} \cdot \mathrm{mg} \mathrm{N}^{-1}=2,86 \mathrm{mg} \mathrm{O}_{2} \cdot \mathrm{mg} \mathrm{N}^{-1}
$$

Conclui-se que para remoção de nitrogênio de uma água residuária, utilizando processo biológico de nitrificação/desnitrificação, o consumo líquido de oxigênio é:

$$
4,57-2,86=1,71 \mathrm{mg} \mathrm{O}_{2} \cdot \mathrm{mg} \mathrm{N}^{-1}
$$

Esse fato traz importantes repercussões para o dimensionamento de um sistema de tratamento de águas residuárias sob o ponto de vista econômico. Estima-se que o consumo de oxigênio para nitrificação seja em torno de 33 por cento do consumo total. Observando as relações

\footnotetext{
${ }^{2}$ Nitrito redutase; Nitrato redutase, etc...
} 
anteriores, constata-se que um sistema projetado para nitrificação e desnitrificação consumiria $5 / 8 * 33 \% \cong 20$ por cento a menos que um sistema somente com nitrificação. Como o consumo de oxigênio é o fator principal dos custos operacionais em estações de tratamento, a redução obtida é bastante significativa (VAN HAANDEL E MARAIS, 1999; METCALF e EDDY INC., 2003).

As reações de desnitrificação, independente da fonte de carbono, apontam a recuperação de 1 mol de alcalinidade por mol de nitrato reduzido. Conclui-se que o processo de nitrificação/desnitrificação apresenta um consumo de alcalinidade de $3,57 \mathrm{mg} \mathrm{CaCO}_{3} \cdot \mathrm{mg} \mathrm{N}^{-1}$; diferente de sistemas apenas nitrificantes, nos quais o consumo de alcalinidade é de 7,14 mg $\mathrm{CaCO}_{3} \cdot \mathrm{mg} \mathrm{N}^{-1}$. Esse desempenho também implica em conseqüências econômicas, uma vez que reduz a necessidade de adição de alcalinizante, com a finalidade de manter o pH do sistema na faixa ótima para o desenvolvimento dos microrganismos (VAN HAANDEL E MARAIS, 1999).

Outras bactérias podem utilizar compostos inorgânicos como fornecedores de elétrons para desnitrificação (Tabela 05), por exemplo: enxofre ou hidrogênio (BALMELLE; et al., 1992; FURUMAI; TAGUI; FUJITA, 1996; VERSTRAETE; PHILLIPS, 1998; JETTEN et al., 1999).

Tabela 05 - Reações da desnitrificação utilizando compostos inorgânicos:

\begin{tabular}{|ll|}
\hline \multicolumn{1}{|c|}{ Composto Inorgânico } & \multicolumn{1}{c|}{ Reação } \\
\hline Hidrogênio & $2 \mathrm{NO}_{3}{ }^{-}+5 \mathrm{H}_{2}+2 \mathrm{H}^{+} \rightarrow \mathrm{N}_{2}+6 \mathrm{H}_{2} \mathrm{O}$ \\
\hline Enxofre & $8 \mathrm{NO}_{3}^{-}+5 \mathrm{HS}^{-}+3 \mathrm{H}^{+} \rightarrow 4 \mathrm{~N}_{2}+5 \mathrm{SO}_{2}{ }^{-}+4 \mathrm{H}_{2} \mathrm{O}$ \\
\hline
\end{tabular}

Fonte: adaptado de PHILIPS; LAANBROECK e VERSTRAETE, 2002.

Nos sistemas de tratamento de águas residuárias, principalmente naqueles que possuem digestores anaeróbios do lodo biológico, pode ocorrer um processo diferente da desnitrificação, caracterizado pela formação do íon amônio $\left(\mathrm{NH}_{4}{ }^{+}\right)$ao invés do $\mathrm{N}_{2}$ como produto final. Esse processo, conhecido como redução desassimilatória do nitrato a íon 
amônio, é realizado por bactérias fermentativas, por exemplo: Aeromonas sp, Vibrio spp, Clostridium sp (VERSTRAETE E PHILLIPS, 1998) A reação é a seguinte:

Redução Desassimilatória do Nitrato a Ìon Amônio:

$$
\mathrm{NO}_{3}{ }^{-}+4 \mathrm{H}_{2}+2 \mathrm{H}^{+} \rightarrow \mathrm{NH}_{4}{ }^{+}+3 \mathrm{H}_{2} \mathrm{O}
$$

Bactérias fermentativas do nitrato competem diretamente com as bactérias desnitrificantes. $\mathrm{O}$ processo de redução desassimilatória do nitrato aceita oito elétrons contra somente cinco do processo de desnitrificação. Então, a redução desassimilatória é favorecida em ambientes nos quais a presença do aceptor de elétrons é limitada em relação ao doador de elétrons, ou seja, concentrações baixas de nitrito ou nitrato (PHILIPS; LAANBROEK; VERSTRAETE, 2002). Semelhante à redução desassimilatória do nitrato a íon amônio, também ocorre uma redução assimilatória do nitrato a íon amônio. Apesar desses processos serem similares, as enzimas e a função são bastante diferentes. Na redução assimilatória do nitrato, o íon amônio resultante é incorporado dentro do material celular como nitrogênio orgânico sendo utilizado como fonte suplementar nutricional para os microrganismos (SORENSEN, $1978^{3}$ apud PHILIPS; LAANBROEK; VERSTRAETE, 2002).

\subsubsection{CÁlCULOS DO CONSUMO DE SUBSTRATO PARA DESNITRIFICAÇÃO BIOLÓGICA:}

A desnitrificação corresponde à redução do nitrogênio oxidado $\left(\mathrm{NO}_{2}^{-}\right.$e $\left.\mathrm{NO}_{3}^{-}\right)$a nitrogênio gasoso $\left(\mathrm{N}_{2}\right)$. A maioria dos microrganismos desnitrificantes são heterotróficos facultativos, e normalmente abundantes (Pseudomonas sp, Micrococcus sp e outros) (VON SPERLING, 2002).

Microrganismos heterotróficos, para obtenção de energia (catabolismo) e síntese de material celular (anabolismo), utilizam compostos orgânicos como fornecedores de elétrons em

\footnotetext{
${ }^{3}$ SØRENSEN J (1978) Capacity for denitrification and reduction of nitrate to ammonia in a coastal marine sediment. Appl. Environ.Microb. 35(2): 301-305.
} 
reações de oxi-redução. Baseados em princípios termodinâmicos, estima-se, aproximadamente, a proporção da energia presente nas moléculas dos compostos orgânicos que é transformada em biomassa (microrganismos) em sistemas de tratamento de águas residuárias. Essa proporção, denominada de coeficiente de síntese celular (Y), é expressa como gramas de sólidos em suspensão voláteis por gramas de substrato (D.Q.O.) metabolizado (g SSV/g D.Q.O.). O valor (Y = 0,45 mg SSV/mg D.Q.O consumida) usualmente adotado, advém da média de diversas observações experimentais. O valor consagrado para fração da D.Q.O utilizada pelos microrganismos para o anabolismo $\left(f_{\mathrm{cv}}=1,48 \mathrm{mg}\right.$ D.Q.O / mg SSV) foi obtido por Marais e Ekama (1976) através de extensa investigação experimental. (VAN HAANDEL e MARAIS, 1999).

Com esses valores, podem-se obter as frações da D.Q.O utilizadas pelos microrganismos heterotróficos em seus processos metabólicos. $\mathrm{f}_{\mathrm{cv}} \mathrm{x} \quad \mathrm{Y}=1,48$ x $0,45=0,67$, conseqüentemente, $(1-0,67)=0,33$, donde conclui-se que $2 / 3$ da D.Q.O. consumida nos sistemas de tratamento de efluentes é sintetizada, enquanto $1 / 3$ é oxidada, consumindo oxigênio na proporção de $0,33 \mathrm{~g} \mathrm{O}_{2}$ utilizado / g D.Q.O. consumida. (VAN HAANDEL e MARAIS, 1999).

Respeitando a relação: $1 \mathrm{mg} \mathrm{N}^{-\mathrm{NO}_{3^{-}}} \cong 2,86 \mathrm{mg} \mathrm{O} \mathrm{O}_{2}$ então, teoricamente, espera-se um consumo de substrato durante a desnitrificação igual a D.Q.O. ${ }_{\text {consumida }}=\mathrm{mg} \mathrm{N}-\mathrm{NO}_{3}{ }^{-}$reduzido $\mathrm{x}$ $2,86 / 0,33 \cong 8,6 \mathrm{mg}$ D.Q.O / $\mathrm{mg} \mathrm{N}-\mathrm{NO}_{3}{ }^{-}$removido.

\subsubsection{REMOÇÃo BIOLÓGICA DO NITROGÊNIO PRESENTE NOS DESPEJOS VIA NITRITO:}

Inicialmente considerado um efeito indesejado, pela toxicidade em ambientes aquáticos e pelo aumento da demanda por cloro nos processos de desinfecção de águas de abastecimento, o acúmulo de nitrito e sua posterior redução a nitrogênio gasoso passaram a despertar interesse 
dos pesquisadores, principalmente pela possibilidade de economia no dimensionamento de sistemas de areação em estações de tratamento de águas residuárias. (TURK E MAVINIC, 1989).

Tal interesse justifica-se, uma vez que a produção de nitrito é uma condição intermediária sempre presente em sistemas projetados para nitrificação. Essa alternativa é usualmente denominada de nitritação; via simplificada ou via curta para remoção de nitrogênio de águas residuárias. (POLLICE et al., 2002; FUX E SIEGRIST, 2004).

Observando as reações 01 e 02, bem como a variação dos números de oxidação do nitrogênio no processo de nitrificação (Figura 02), constata-se que a oxidação de nitrogênio até nitrito, e sua posterior redução a nitrogênio molecular permite a economia de $25 \%$ do oxigênio requerido, $((1,5 \times 32) / 14)=3,43 \mathrm{mg} \mathrm{O}_{2} \cdot \mathrm{mg} \mathrm{N}^{-1}$. Além disso, o nitrito (número de oxidação +3) durante o processo de desnitrificação é reduzido a nitrogênio molecular (número de oxidação 0). Assim dos 6 elétrons transferidos durante a etapa de oxidação da amônia até nitrito, três são recuperados no processo de desnitrificação. Ou seja:

$$
\text { (3/6) x } 3,43 \mathrm{mg} \mathrm{O}_{2} \cdot \mathrm{mg} \mathrm{N}^{-1}=1,71 \mathrm{mg} \mathrm{O}_{2} \cdot \mathrm{mg} \mathrm{N}^{-1} \text {. }
$$

Então o consumo de D.Q.O. teórico para desnitritação é:

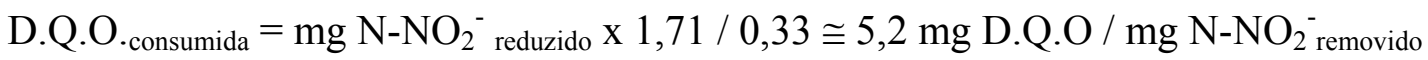

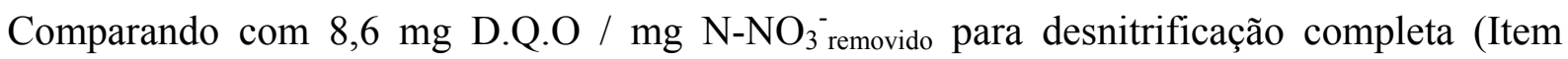
3.4.3), demonstra-se que a economia teórica de fonte de carbono para remoção de nitrogênio amoniacal pela via simplificada é igual a : $(8,6-5,2) / 8,6 \cong 40 \%$.

Trabalhos anteriores apontam como vantagens da remoção de nitrogênio de águas residuárias pela via simplificada: uma taxa de desnitrificação 63\% superior; uma produção de biomassa durante a etapa anóxica menor e aparentemente nenhum efeito tóxico resultante do acúmulo do nitrito. Porém, aparentemente, a taxa de acúmulo de nitrito não pode ser mantida 
indefinidamente (TURK E MAVINIC, 1989; POLLICE et al., 2002; FUX E SIEGRIST, 2004; YUN et al., 2004; ZDRADEK, 2005).

O processo de remoção do nitrogênio amoniacal pela via simplificada (nitritação e desnitritação) não somente diminui o consumo de oxigênio para oxidação do nitrogênio amoniacal como também reduz a demanda por carbono orgânico para redução do nitrogênio amoniacal oxidado. Portanto, é especialmente recomendado para o tratamento de águas residuárias que apresentam baixa relação carbono/nitrogênio $(\mathrm{C} / \mathrm{N})$, a exemplo do efluente de digestores anaeróbios, líquidos percolados de aterros sanitários, efluentes de reatores anaeróbios tratando esgoto doméstico e algumas águas residuárias industriais (CHUNG e BAE, 2002; CHOI et al., 2004; FUX E SIEGRIST, 2004; AKERMAN, 2005; MOSQUERACORRAL et al., 2005).

\subsection{ACÚMULO DE NITRITO EM SISTEMAS BIOLÓGICOS DE TRATAMENTO DE ÁGUAS RESIDUÁRIAS:}

O acúmulo de nitrito em ambientes aquáticos, quase sempre, resulta de alterações na cinética de crescimento das bactérias envolvidas no processo de nitrificação. O desequilíbrio pode ocorrer pelo aumento da taxa de oxidação da amônia, preterindo a taxa de oxidação do nitrito. (PHILIPS; LAANBROEK; VERSTRAETE, 2002).

Esse desequilíbrio pode ser induzido pela manipulação de alguns parâmetros, sendo que os mais usuais são: a concentração de amônia afluente; idade do lodo; potencial hidrogeniônico $(\mathrm{pH})$, temperatura; concentração de oxigênio dissolvido e presença de substâncias tóxicas (GARRIDO et. al., 1996; GÓRSKA; CICHO e MIKSCH, 1997; YOO et al., 1999; JOO et. al., 2000; GRUNDITZ e DALHAMAR, 2001; BAE et al., 2002; RUIZ; JEISON e CHAMY, 2003; LI et al., 2004; LAI et al., 2004; DANIEL, 2005; ZDRADEK, 2005). 
Outros parâmetros tais como: razão D.Q.O/N, concentração de hidroxilamina livre, tipo de operação do sistema de tratamento (contínuo ou bateladas seqüenciais), contato entre a biomassa e a água residuária, tipo de cultivo da biomassa (imobilizada ou em suspensão), concentração de carbono inorgânico, capacidade de neutralização, também podem influenciar para o acúmulo de nitrito (YANG e ALLEMAN, 1992; PHILIPS; LAANBROEK; VERSTRAETE, 2002; JENICEK et al., 2004; NOOPHAN; FIGUEROA; MUNAKATAMARR, 2004; GEE e KIM, 2004; AKERMAN, 2005; MOSQUERA-CORRAL et al., 2005). Anthonisen et al. (1976) postularam que o acúmulo de nitrito poderia estar relacionado a concentrações de amônia livre (reação 08) e de ácido nitroso $\left(\mathrm{HNO}_{2}\right)$ livre; e certas concentrações poderiam ser inibitórias a todo processo de nitrificação.

$$
\mathrm{NH}_{4}{ }^{+}+\mathrm{OH}^{-} \leftrightarrow \mathrm{NH}_{3}+\mathrm{H}_{2} \mathrm{O}(08)
$$

Os pesquisadores coletaram dados da literatura, realizaram experimentos em escala de bancada e corroboraram seus resultados com outros estudos independentes, concluindo que:

- As concentrações de amônia livre que inibem as bactérias oxidantes de amônia são maiores que as inibidoras para os microrganismos que oxidam nitrito. A faixa de inibição das oxidantes de amônia foi de 10 a $150 \mathrm{mg} \mathrm{NH} / \mathrm{L}$ de, enquanto a inibição das oxidantes de nitrito ocorreu na faixa de 0,1 a $10 \mathrm{mg} \mathrm{NH} / \mathrm{L}$.

- Inibição de todo processo de nitrificação organismos ocorreu a concentrações de $\mathrm{HNO}_{2}$ entre 0,22 e $2,8 \mathrm{mg} \mathrm{HNO}_{2} / \mathrm{L}$.

- As concentrações inibitórias da amônia livre e de ácido nitroso livre para nitrificação foram afetadas pela aclimatação dos microrganismos, temperatura e número da atividade dos organismos nitrificantes.

Anthonisen et al. (1976) propuseram equações (09 e 10) relacionando as concentrações de amônia livre e ácido nitroso livre com o pH do meio aquoso. 
Amônia livre $\left(\mathrm{mg} \mathrm{NH}_{3} / \mathrm{L}\right)=\underline{17} \times \underline{\mathrm{NAT} \times 10^{\mathrm{pH}}}$

$$
14 \mathrm{Ka} / \mathrm{Kw}+10^{\mathrm{pH}}
$$

NAT $=$ Nitrogênio amoniacal total (íon amônio + amônia livre) $(\mathrm{mg} / \mathrm{L})$

$\mathrm{K}_{\mathrm{a}}=10^{-9,24} \quad\left(\right.$ Constante de ionização da amônia no equilíbrio a $20^{\circ} \mathrm{C}$ )

$\mathrm{K}_{\mathrm{w}}=0,69 \times 10^{-14} \quad\left(\right.$ Constante de ionização da água a $\left.20^{\circ} \mathrm{C}\right)$

$\mathrm{K}_{\mathrm{a}} / \mathrm{K}_{\mathrm{w}}=\mathrm{e}^{(6,344 /(273+\mathrm{T}))}$

$\mathrm{T}=$ Temperatura $\mathrm{em}{ }^{\circ} \mathrm{C}$

$$
\text { Ácido Nitroso Livre }(\mathrm{mg} \mathrm{HNO} 2 / \mathrm{L})=\frac{46}{14} \times \frac{\mathrm{N}^{-N_{2}}}{\mathrm{~K}_{\mathrm{b}}}=\frac{(\mathrm{mg} / \mathrm{L})}{10^{\mathrm{pH}}}
$$

$\mathrm{K}_{\mathrm{b}}=\mathrm{e}^{(-2300 / 273+\mathrm{T})}$,

$\mathrm{K}_{\mathrm{b}}=($ constante de ionização do nitrito no equilíbrio)

Phillips, Laanbroek e Verstraete (2002) ressaltaram que a concentração do íon-amônio $\left(\mathrm{NH}_{4}{ }^{+}\right)$ pode causar o acúmulo de nitrito, mas o efeito da amônia livre $\left(\mathrm{NH}_{3}\right)$ era aparentemente mais pronunciado. A amônia livre é uma inibidora competitiva da atividade da enzima nitritooxidoredutase, a qual está localizada na membrana celular das bactérias oxidantes de nitrito.

Outro importante parâmetro para o alcance de elevadas eficiências de remoção do nitrogênio amoniacal de águas residuárias, via nitrito, é a concentração de oxigênio dissolvido (O.D.). Alguns pesquisadores investigaram a influência desse parâmetro, e em certas pesquisas manipularam apenas a concentração de $\mathrm{O}$. D. para obter acúmulo de $\mathrm{N}_{-} \mathrm{NO}_{2}{ }^{-}$e concluíram que deficiência de oxigênio influência, de maneira mais significativa, a atividade das bactérias que oxidam nitrito do que aquelas que oxidam amônia (GARRIDO et al., 1996; JOO et al., 2000; RUIZ; JEISON e CHAMY, 2003; LAI et al., 2004).

Anthonisen et al. (1976) durante a condução das suas pesquisas observaram que alterações de temperatura também influenciavam de maneira significativa o equilíbrio entre $\mathrm{NH}_{3} / \mathrm{NH}_{4}{ }^{+}$e $\mathrm{HNO}_{2} / \mathrm{NO}_{2}^{-}$(equações 08 e 09). Acréscimos na temperatura causam acréscimos na concentração da amônia livre, possibilitando acúmulo de $\mathrm{N}^{-\mathrm{NO}_{2}}{ }^{-}$. A concentração de $\mathrm{NH}_{3}$ a 
$30^{\circ} \mathrm{C}$. é cerca de duas vezes maior que a $20^{\circ} \mathrm{C}$., para o mesmo $\mathrm{pH}$ e mesma concentração de nitrogênio amoniacal total.

Além de influenciar o equilíbrio entre as espécies químicas, a relação entre as taxas de crescimento dos microrganismos nitrificantes muda com a temperatura (Figura 03). Para Phillips, Laanbroek e Verstraete (2002) a temperatura ótima para nitritação é maior que para nitratação, mas a temperaturas superiores a $25^{\circ} \mathrm{C}$ a taxa máxima de crescimento específico das Nitrobacter sp é inferior da taxa máxima de crescimento das Nitrossomonas sp, possibilitando o acúmulo de $\mathrm{N}-\mathrm{NO}_{2}$.

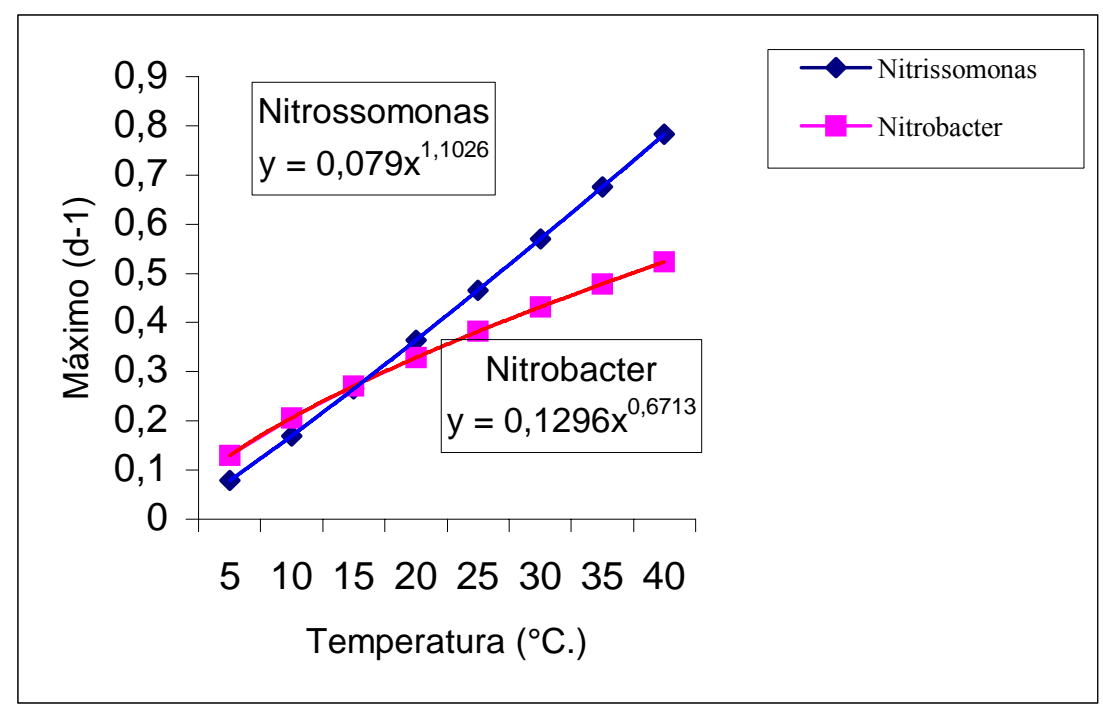

Figura 03: Curvas das velocidades máximas específicas de crescimento em função da temperatura para Nitrossomonas sp $e$ Nitrobacter sp.

Fonte: Adaptado de VERSTRAETE E PHILIPS, 1998

A tabela 06 relaciona alguns trabalhos visando o acúmulo de nitrito em sistemas de tratamento de águas residuárias, os parâmetros e condições operacionais manipuladas pelos pesquisadores e os principais resultados obtidos.

Tabela 06 - Condições operacionais e parâmetros para o acúmulo do ${\mathrm{N}-\mathrm{NO}_{2}}^{-}$obtidos em outras pesquisas:

\begin{tabular}{|c|c|c|c|c|c|c|}
\hline $\begin{array}{l}\mathrm{N}^{-\mathrm{NH}_{4}}{ }^{+} \\
(\mathrm{mg} \mathrm{N} / \mathrm{l})\end{array}$ & $\begin{array}{c}\mathrm{NH}_{3} \\
(\mathrm{mg} \mathrm{N} / \mathrm{l})\end{array}$ & pH & $\begin{array}{c}\mathbf{T} \\
\left({ }^{\circ} \mathbf{C} .\right)\end{array}$ & Efeito Observado & Regime & Referência \\
\hline -- & 0,02 & $<7$ & 20 & $\begin{array}{c}\text { Baixas concentrações de } \\
\text { nitrito }\end{array}$ & L.A.contínuo & $\begin{array}{l}\text { Prakasam e } \\
\text { Loehr (1972) }\end{array}$ \\
\hline-- & $0.08-0.82$ & -- & -- & $\begin{array}{c}\text { Baixas concentrações de } \\
\text { nitrito }\end{array}$ & - & $\begin{array}{l}\text { Anthonsisen et } \\
\text { al. (1976) }\end{array}$ \\
\hline 490 & 13 & 8 & -- & $\begin{array}{l}100 \% \text { de inibição da } \\
\text { oxidação do nitrito }\end{array}$ & -- & $\begin{array}{c}\text { Verstraete et al } \\
\text { (1977) }\end{array}$ \\
\hline
\end{tabular}


Tabela 06 - Condições operacionais e parâmetros para o acúmulo do $\mathrm{N}^{-\mathrm{NO}_{2}}{ }^{-}$obtidos em outras pesquisas:

continuação

\begin{tabular}{|c|c|c|c|c|c|c|}
\hline 40 & 15 & 9 & -- & acúmulo de nitrito transiente & L.A. batelada & $\begin{array}{c}\text { Sauter e } \\
\text { Alleman (1980) }\end{array}$ \\
\hline-- & $5-20$ & -- & 20 & acúmulo de nitrito estável & $\begin{array}{l}\text { biomassa não } \\
\text { aclimatada }\end{array}$ & $\begin{array}{c}\text { Turk e Mavinic } \\
\text { (1989) }\end{array}$ \\
\hline-- & -- & 7 & 25 & acúmulo de nitrito estável & $\begin{array}{l}\text { L.A. batelada } \\
0.5 \mathrm{mg} \mathrm{O}_{2} / \mathrm{L}\end{array}$ & $\begin{array}{c}\text { Hanaki et al. } \\
\text { (1990) }\end{array}$ \\
\hline 100 & 6,6 & 8 & 25 & $\begin{array}{c}100 \% \text { de } \mathrm{N}-\mathrm{NH}_{3} \text { como N- } \\
\mathrm{NO}_{2}^{-}\end{array}$ & $\begin{array}{l}\text { L.A. contínuo } \\
2.5 \mathrm{mg} \mathrm{O}_{2} / \mathrm{L}\end{array}$ & $\begin{array}{l}\text { Balmelle et al. } \\
\text { (1992) }\end{array}$ \\
\hline-- & 0.5 & 7 & 18 & $\begin{array}{c}\text { Baixas concentrações de } \\
\text { nitrito }\end{array}$ & -- & $\begin{array}{l}\text { Mulder et al. } \\
(1995)\end{array}$ \\
\hline 35 & 8,9 & 7 & 15 & $50 \%$ de $\mathrm{N}-\mathrm{NH}_{3}$ como $\mathrm{N}-\mathrm{NO}_{2}$ & -- & $\begin{array}{l}\text { Mauret et al. } \\
\quad(1996)\end{array}$ \\
\hline 500 & $1-6$ & 8 & -- & $\begin{array}{c}100 \% \text { de } \mathrm{N}-\mathrm{NH}_{3} \text { como N- } \\
\mathrm{NO}_{2}^{-}\end{array}$ & L.A. contínuo & $\begin{array}{c}\text { Górska et al. } \\
\text { (1997) }\end{array}$ \\
\hline$\cong 30$ & 0,35 & -- & 25 & $70 \%$ de N-NH$H_{3}$ como $\mathrm{N}^{-\mathrm{NO}_{2}}{ }^{-}$ & L.A. batelada & $\begin{array}{l}\text { Rhee, Lee e Lee } \\
\text { (1997) }\end{array}$ \\
\hline $50-300$ & -- & 7 & 25 & acúmulo estável de nitrito & F.B.F.A. & $\begin{array}{c}\text { Joo et al. } \\
(2000)\end{array}$ \\
\hline 50 & $>4,0$ & $8-9$ & 30 & $77 \%$ de $\mathrm{N}-\mathrm{NH}_{3}$ como $\mathrm{N}^{-\mathrm{NO}_{2}}{ }^{-}$ & $\begin{array}{l}\text { L.A. batelada } \\
1.5 \mathrm{mg} \mathrm{O}_{2} / \mathrm{L} \\
\end{array}$ & $\begin{array}{l}\text { Bae et al. } \\
(2002)\end{array}$ \\
\hline $300-750$ & $1-3$ & 7,5 & -- & $\begin{array}{c}100 \% \text { de } \mathrm{N}-\mathrm{NH}_{3} \text { como N- } \\
\mathrm{NO}_{2}^{-}\end{array}$ & $\begin{array}{l}\text { biomassa } \\
\text { imobilizada }\end{array}$ & $\begin{array}{l}\text { Kim et al. } \\
(2003)\end{array}$ \\
\hline 610 & -- & $6,1-9,0$ & -- & $65 \%$ de $\mathrm{N}-\mathrm{NH}_{3}$ como $\mathrm{N}-\mathrm{NO}_{2}^{-}$ & $\begin{array}{l}\text { L.A.contínuo } \\
0.7 \mathrm{mg} \mathrm{O}_{2} / \mathrm{L}\end{array}$ & $\begin{array}{l}\text { Ruiz et al. } \\
\text { (2003) }\end{array}$ \\
\hline $80-200$ & -- & $8-9,5$ & 23 & $98 \%$ de $\mathrm{N}-\mathrm{NH}_{3}$ como $\mathrm{N}-\mathrm{NO}_{2}^{-}$ & batelada & $\begin{array}{l}\text { Li et al. } \\
(2004)\end{array}$ \\
\hline 1.250 & -- & 8,5 & -- & $\begin{array}{c}100 \% \text { de } \mathrm{N}-\mathrm{NH}_{3} \text { como N- } \\
\mathrm{NO}_{2}^{-}\end{array}$ & $\begin{array}{l}\text { L.A. batelada } \\
4.0 \mathrm{mg} \mathrm{O}_{2} / \mathrm{L}\end{array}$ & $\begin{array}{l}\text { Jenicek et al. } \\
(2004)\end{array}$ \\
\hline 1.200 & -- & 7,5 & 25 & $\begin{array}{c}100 \% \text { de } \mathrm{N}-\mathrm{NH}_{3} \text { como N- } \\
\mathrm{NO}_{2}^{-}\end{array}$ & $\begin{array}{l}\text { L.A. batelada } \\
2,0 \mathrm{mg} \mathrm{O}_{2} / \mathrm{L}\end{array}$ & $\begin{array}{l}\text { Akerman } \\
(2005)\end{array}$ \\
\hline
\end{tabular}

L.A. - Lodos ativados

F.B.F.A - Filtro biológico de fluxo ascendente

\subsection{PROCESSOS ALTERNATIVOS PARA REMOÇÃO DO NITROGÊNIO DE ÁGUAS RESIDUÁRIAS:}

\subsubsection{Processo SHARON (Single Rector High Activity Ammonia Removal Over Nitrite):}

Este processo aplica o conceito da diferença das velocidades específicas de crescimento das bactérias que oxidam amônia e as que oxidam nitrito, associado a um tempo de detenção celular (idade do lodo) baixo e $\mathrm{pH} \cong 7,0$. Essa associação permite o descarte, do sistema de tratamento, das bactérias que oxidam nitrito, uma vez que, a velocidade de crescimento dessas 
é menor quando submetidas à faixa de temperatura usualmente empregada no processo SHARON.

Para favorecer o crescimento das bactérias que oxidam amônia, o conteúdo do reator é mantido a elevadas temperaturas, pois, teoricamente, a velocidade específica de crescimento das bactérias que oxidam nitrito é menor acima dos $35^{\circ} \mathrm{C}$ (Figura 03). Assim, a idade do lodo deve ser escolhida baseada na idade mínima para manutenção dos organismos que oxidam amônia e descarte daqueles que oxidam nitrito.

Mulder e Van Kempen (1997) apontaram como principais vantagens do processo SHARON o baixo investimento de implantação, operação e manutenção, uma vez que se utiliza apenas um reator e os custos com aeração são reduzidos. Porém, salientam que o sistema em escala real apresenta dificuldades para manutenção da temperatura em faixas tão elevadas, principalmente em países de clima temperado.

Mulder et al. (2001) relataram os resultados obtidos do primeiro sistema de tratamento, construído em escala real, para remoção de nitrogênio amoniacal de liquido oriundo do desaguamento de lodo biológico em uma estação de tratamento de esgotos domésticos na Holanda (Rotterdam Sluisjjesdijk). Os pesquisadores determinaram concentrações de amônia, no afluente, superiores a $1.000 \mathrm{mg} \mathrm{N}-\mathrm{NH}_{3} / \mathrm{L}$ e eficiências de conversão a $\mathrm{N}_{-} \mathrm{NO}_{2}{ }^{-}$próximas a 90\%. Ressaltaram que a geração de calor, através do processo de conversão biológica, ajudou a manter a temperatura na faixa ótima, entre 30 e $40^{\circ} \mathrm{C}$.

Mósquera-Corral et al. (2005) operaram um reator SHARON em escala de bancada para estudar a influência da carga orgânica e da presença de sais inorgânicos no processo de acúmulo de $\mathrm{N}_{-} \mathrm{NO}_{2}{ }^{-}$. Obtiveram como condição operacional ótima para o acúmulo de nitrito: temperatura de $35^{\circ} \mathrm{C}$., tempo de residência hidráulico de 1 dia, $\mathrm{pH}$ igual a 7,1 e concentração de oxigênio dissolvido acima de $2,0 \mathrm{mg} \mathrm{O}_{2} / 1$. 
Van Kempen et al. (2005) avaliaram o desempenho do processo SHARON implantado nas estações de tratamento de esgotos domésticos das cidades de Rotterdam-Dokhaven e Utrecht, através da análise de dados gerados ao longo de muitos anos de operação. Esses pesquisadores ressaltaram que o processo SHARON é indicado para melhoria da eficiência na remoção de nitrogênio em três situações:

1. estações com limitações na capacidade do sistema de aeração;

2. sistemas de lodos ativados com limitada capacidade de desnitrificação;

3. situações em que a nitrificação é limitada pela idade do lodo.

A implantação do processo SHARON, na avaliação desses pesquisadores, levou ao decréscimo de 50\% na concentração de amônia no efluente da estação Rotterdam-Dokhaven e elevou a eficiência de remoção de nitrogênio total para valores superiores a 75\% na estação de Utrecht.

\subsubsection{Processo AnAmmox (Anaerobic Ammonium Oxidation):}

Mulder et al. (1995) observaram a diminuição das concentrações de $\mathrm{N}-\mathrm{NH}_{3}$ em um reator de leito fluidizado, utilizado para digestão de resíduos de uma indústria de fermento biológico na Holanda. Esse fenômeno despertou a atenção dos pesquisadores para a possibilidade da ocorrência de um processo de oxidação anaeróbia da amônia. Tal processo decorre com a utilização do nitrito como aceptor de elétrons e recebeu a denominação de ANAMMOX (Anaerobic Ammonium Oxidation).

A reação que governa o processo é:

$$
\mathrm{NO}_{2}^{-}+\mathrm{NH}_{4}^{+} \rightarrow \mathrm{N}_{2}+2 \mathrm{H}_{2} \mathrm{O}
$$

Jetten et al. (1999) observaram uma taxa máxima específica de oxidação de 55 n.mol $\mathrm{NH}_{4}{ }^{+} / \min$ (mg proteína) nesse processo, o que conduz a uma taxa de crescimento dos 
microrganismos muito baixa (cerca de $0,003 \mathrm{~h}^{-1}$ ). Esse valor resulta em um tempo estimado para duplicação da população de 11 dias. A implicação é uma partida muito lenta do sistema, porém a vantagem é justamente a baixíssima produção de lodo, além disso, como o processo é autotrófico não necessita de fonte externa de carbono para remoção do nitrogênio amoniacal em uma posterior etapa de desnitrificação. A equação estequiométrica da produção celular para o processo ANAMMOX é:

$1 \mathrm{NH}_{4}{ }^{+}+1,32 \mathrm{NO}_{2}^{-}+0,066 \mathrm{HCO}_{3}^{-}+0,13 \mathrm{H}^{+} \rightarrow 1,02 \mathrm{~N}_{2}+0,26 \mathrm{NO}_{3}{ }^{-}+0,066 \mathrm{CH}_{2} \mathrm{O}_{0,5} \mathrm{~N}_{0,15}+2,03 \mathrm{H}_{2} \mathrm{O}$

Fux e Siegrist (2004) observaram que o termo ANAMMOX deve ser exclusivamente utilizado para remoção autotrófica de nitrogênio pelos microrganismos da ordem dos Planctinomicetos, ainda que certas bactérias do gênero Nitrossomonas sp possam remover amônia em meio anaeróbio. Esses pesquisadores ressaltam que a remoção autotrófica de nitrogênio conduzida em um único reator aerado foi observada em diversos experimentos em diferentes centros de pesquisas, e devido à falta de caracterização dos microrganismos responsáveis pelo processo, o mesmo foi denominado de Aerobic/ anoxic deammonification na Universidade de Hanover na Alemanha; "Oland" (Oxygen-limited autotrophic nitrification denitrification) na Universidade Ghent na Bélgica; e "Canon" (Completely autotrophic nitrogen removal over nitrite) na Universidade de Tecnologia de Delft na Holanda; mas a caracterização molecular tem revelado que a deficiência de nitrogênio, em todos os casos, deve-se a microrganismos pertencentes à ordem dos Planctinomicetos.

\subsubsection{ASSOCIAÇÃO SHARON-ANAMMOX:}

A característica da necessidade do nitrito como aceptor de elétrons para remoção anaeróbia da amônia, intrínseca ao processo ANAMMOX, tem aguçado pesquisas aplicando dois reatores em série. O primeiro operado como um reator $S H A R O N$, visando o acúmulo de $\mathrm{N}^{-\mathrm{NO}_{2}}{ }^{-}$, e o 
efluente desse reator conduzido a um reator $A N A M M O X$ para remoção do nitrogênio amoniacal.

Helmer et al (2001) afirmaram que qualquer utilização do processo ANAMMOX para tratamento de águas residuárias precisa de uma etapa preliminar, na qual cerca de $50 \%$ da amônia disponível para os microrganismos precisa ser oxidada a $\mathrm{N}-\mathrm{NO}_{2}{ }^{-}$.

Fux e Siegrist (2004) compararam a opção SHARON-ANAMMOX com a remoção de nitrogênio pela via tradicional (nitrificação/desnitrificação) e ressaltaram que a caracterização da água residuária é importante na comparação dos custos, uma vez que a capacidade de tamponamento determinará a necessidade de construção de tanques e sistemas de dosagem de alcalinizante. Os pesquisadores também apontaram que não se deve subestimar a taxa de consumo de oxigênio em nenhuma das duas opções, mostrando que uma taxa específica de produção de nitrito de $2,0 \mathrm{~kg} \mathrm{~N}-\mathrm{NO}_{2}-\mathrm{m}^{3}$.dia requer sob condições operacionais uma taxa de fornecimento de $\mathrm{O}_{2}$ de aproximadamente $7,0 \mathrm{~kg} \mathrm{O} / \mathrm{m}^{3}$.dia.

Wyffels et al. (2004) operaram um sistema em dois estágios (acúmulo de nitrito seguido de ANAMMOX) e obtiveram uma eficiência de remoção do $\mathrm{N}^{-\mathrm{NH}_{3}}$ no processo combinado de $82 \%$, sendo a taxa de remoção de nitrogênio igual a $0,55 \mathrm{~kg} \mathrm{~N} . \mathrm{m}^{3} /$ dia, sem adição de nenhuma fonte de carbono.

Third et al (2005) conduziram experimentos em escala de bancada, buscando identificar os parâmetros importantes para o controle do processo SHARON-ANAMMOX. Segundo esses pesquisadores, os parâmetros essenciais foram: concentração de $\mathrm{N}^{-\mathrm{NO}_{2}}{ }^{-}$afluente ao reator ANAMMOX, concentração de O.D. $<1,0 \mathrm{mg} \mathrm{O}_{2} / \mathrm{L}$ no conteúdo do reator SHARON e a temperatura, mantida na massa líquida do reator $S H A R O N$ na faixa $\operatorname{dos} 30^{\circ} \mathrm{C}$.

Volcke et al. (2005) confirmaram o crescente interesse pela combinação SHARON ANAMMOX, mas ressaltaram que quando a razão nitrito:amônia no afluente ao reator ANAMMOX desvia da ideal (1:1) o processo perde eficiência; além disso os pesquisadores 
alertaram que o acúmulo de $\mathrm{N}_{-} \mathrm{NO}_{2}{ }^{-}$no conteúdo do reator $A N A M M O X$, pode conduzir o tratamento ao colapso.

Hwang et al. (2005) aplicaram a combinação SHARON-ANAMMOX em escala laboratorial ao efluente líquido da digestão anaeróbia de resíduos da criação de porcos. O consumo de alcalinidade no reator SHARON foi de $8,5 \mathrm{~g} \mathrm{CaCO}_{3} / \mathrm{g} \mathrm{N}^{-\mathrm{NH}_{4}}{ }^{+}$convertida, enquanto no reator ANAMMOX a taxa de específica de remoção de nitrogênio foi de $0,44 \mathrm{~kg}$ de $\mathrm{N}$ solúvel / $\mathrm{kg}$ SSV.dia.

\subsubsection{NITRIFICAÇ̃̃O E DESNITRIFICAÇ̃̃O SIMULTÂNEA (S.N.D.):}

Lesley e Kuenen (1984) encontraram evidências da utilização simultânea do oxigênio e do nitrato como aceptor de elétrons durante a respiração pelo organismo Thiosphaera pantotropha,. Enzimas características da desnitrificação foram encontradas, mesmo em organismos não expostos ao $\mathrm{NO}_{3}^{-}$.

Lloyd, Boddy e Davies (1987) provaram, com auxílio de técnicas de espectrofotometria de massa, a ocorrência da desnitrificação, realizada por diferentes bactérias, em escala laboratorial, mesmo quando a concentração de oxigênio dissolvido aproximou-se dos valores de saturação.

Muench, Lant e Keller (1996) operaram, em bateladas seqüenciais, dois reatores em escala de bancada, alimentados com esgoto doméstico e notaram a ocorrência da desnitrificação durante a etapa aerada do ciclo. Os autores apontaram predominantemente o $\mathrm{N}^{-\mathrm{NO}_{2}}{ }^{-}$como forma oxidada do nitrogênio amoniacal, e que o prolongamento da etapa aeróbia, além daquele tempo necessário a degradação da matéria orgânica, reduz a "desnitrificação aeróbia". Pochana et al. (1999) realizaram experimentos em escala de bancada para compreender as condições e processos que governam a ocorrência da S.N.D. e concluíram que a fonte de 
carbono e a concentração de oxigênio dissolvido eram os mais importantes parâmetros do processo.

Yoo et al. (1999) ressaltam que a S.N.D., quando acompanhada da inibição da etapa de oxidação do nitrito, agrega as vantagens inerentes aos processos de remoção do nitrogênio amoniacal pela via simplificada (menor consumo de $\mathrm{O}_{2}$ e menor ou ausência da necessidade de fonte externa de carbono para desnitrificação).

Puznava, Payraudeau e Thornberg (2001) operaram um filtro biológico aerado, em escala piloto, tratando água residuária sintética com concentração de $\mathrm{N}_{-} \mathrm{NH}_{4}{ }^{+}$variando de 30 a 80 mg N/L. A concentração de O.D. na massa líquida variou de 0,5 a $3,0 \mathrm{mg} \mathrm{O}_{2} / \mathrm{L}$. Os pesquisadores aplicaram o conceito da nitrificação e desnitrificação simultâneas, sem adição de fonte externa de carbono, e alcançaram eficiências de 60 a 70\% de remoção de nitrogênio total.

Wang et al. (2005) monitoraram a S.N.D. em um bioreator com membranas em escala de bancada e alcançaram eficiência de remoção de $\mathrm{N}^{-\mathrm{NH}_{4}}{ }^{+}$superiores a $90 \%$. As condições operacionais ótimas foram: concentração de oxigênio dissolvido de $1,0 \mathrm{mg} \mathrm{O}_{2} / \mathrm{L}$; pH igual a 7,2; razão $\mathrm{C} / \mathrm{N}$ no afluente igual a 30 e temperatura da água na membrana mantida em $24^{\circ} \mathrm{C}$. 


\subsection{FENOL:}

\subsubsection{OCORRÊNCIA E UTILIZAÇÃO DO FENOL:}

Compostos fenólicos podem ser produzidos naturalmente ou através de processos antropogênicos. Podem ser encontrados em alguns alimentos, dejetos humanos ou animais e decomposição da matéria orgânica; já como composto sintético, o fenol foi isolado do piche do carvão em 1834 e denominado ácido carbólico. Esta era a única fonte artificial desse composto até o final da primeira guerra mundial, quando se passou a produzir fenol a partir da sulfonatação do benzeno e hidrólise do sulfonato. Deriva, também, da extração de combustíveis fósseis, processos produtivos de indústrias petroquímicas e farmacêuticas e unidades de destilação do carvão nas siderúrgicas (ECKENFELDER,1997; USEPA, 2005).

A forma mais difundida de utilização do fenol é como intermediário na produção de algumas resinas fenólicas, as quais apresentam baixo custo além de grande versatilidade, podendo ser usadas em diversos segmentos industriais, tais como: indústrias de adesivos; construção; automotivos e madeira compensada. Encontra aplicação como desinfetante e anestésico em fórmulas medicinais de antibióticos e loções anti-sépticas, e também, como inibidor do desenvolvimento de alguns fungos e bactérias (ECKENFELDER, 1997). A United States Environmental Protection Agency (U.S.E.P.A) o considera um poluente orgânico prioritário desde 1976 (USEPA, 2006). 


\subsubsection{PROBLEMAS À SAÚDE DOS SERES HUMANOS ASSOCIADOS À EXPOSIÇ̃̃o AO FENOL:}

Alem Sobrinho; Garcia Júnior e Rodenas (1983) ressaltaram que concentrações tão pequenas quanto $2,0 \mu \mathrm{g} \mathrm{C}_{6} \mathrm{H}_{5} \mathrm{OH} / \mathrm{L}$ são suficientes para causar problemas de sabor e odor em águas de abastecimento tratadas com cloro, devido à formação de clorofenóis.

Segundo a U.S.E.P.A. (2005), uma grande variedade de estudos epidemiológicos tem avaliado a carcinogênese do fenol, mas esses estudos não são conclusivos, principalmente quanto à dose relativa associada ao desenvolvimento do câncer em seres humanos. Pesquisas com animais que respiraram ar com elevadas concentrações desse composto permitiram a observação de irritação dos pulmões, tremor muscular e perda de coordenação motora. Exposição prolongada por diversas semanas causou paralisia e severas insuficiências cardíaca, hepática, renal e pulmonar, e em alguns casos, morte (USEPA, 2005).

Seres humanos que tiveram a pele exposta ao fenol apresentaram problemas pulmonares, diarréia, urina escura e anemia hemolítica. Ratos de laboratório que sofreram, durante semanas consecutivas, aplicação direta de fenol sobre a pele desenvolveram leucemia. Segundo a International Agency for Research on Câncer (IARC) (2004), o fenol enquadra-se no grupo 03 de substâncias e misturas classificadas como não carcinogênicas a humanos. Lançamento de águas residuárias contendo elevadas concentrações de fenóis diretamente no meio ambiente, traz graves conseqüências, não só pela toxicidade conferida aos organismos aquáticos, como também pelo desequilíbrio gerado pela demanda de oxigênio requerida na degradação desse poluente.

Alguns despejos de origem industrial, notadamente os da indústria siderúrgica, apresentam, normalmente, concentrações de fenóis elevadas, por volta de $1.000 \mathrm{mg} \mathrm{C}_{6} \mathrm{H}_{5} \mathrm{OH} / \mathrm{L}$ e, diante dos problemas apresentados, o lançamento deve obedecer a padrões de emissão, preconizados 
na legislação ambiental em vigor, nas diferentes esferas de governo (Federal, Estadual e Municipal).

\subsubsection{NECESSIDADE DE TRATAMENTO FACE À LEGISLAÇÃO:}

Os limites para lançamento de efluentes estabelecidos pela Resolução CONAMA 357 relacionados aos compostos fenólicos são estabelecidos como fenóis totais (substâncias que reagem com 4-aminoantipirina) e não podem ser superiores a $0,5 \mathrm{mg} \mathrm{C}_{6} \mathrm{H}_{5} \mathrm{OH} / \mathrm{L}$. A mesma Resolução ainda prevê no art. 35 que: "o órgão ambiental competente poderá, quando a vazão do corpo de água estiver abaixo da vazão de referência, estabelecer restrições e medidas adicionais, de caráter excepcional e temporário, aos lançamentos de efluentes que possam, dentre outras conseqüências":

I - acarretar efeitos tóxicos agudos em organismos aquáticos; ou

II - inviabilizar o abastecimento das populações.

Como a maioria dos rios brasileiros está enquadrada na classe 2, é importante observar os limites estabelecidos para os padrões de qualidade da água dessa classe (Tabela 07).

Tabela 07 - Padrões de qualidade para compostos fenólicos em cursos d'água doce, classe 2:

\begin{tabular}{|lc|}
\hline \hline \multicolumn{1}{|c|}{ Parâmetro } & Limite Classe 2 \\
\hline \hline 2-CloroFenol & $0,1 \mu \mathrm{g} / \mathrm{L}$ \\
\hline 2,4-DicloroFenol & $0,3 \mu \mathrm{g} / \mathrm{L}$ \\
\hline Fenóis totais (substâncias que reagem com 4-aminoantipirina) & $0,003 \mathrm{mg} / \mathrm{L} \mathrm{C} \mathrm{H}_{5} \mathrm{OH}$ \\
\hline Pentaclorofenol & $0,009 \mathrm{mg} / \mathrm{L}$ \\
\hline 2,4,6 Triclorofenol & $0,01 \mathrm{mg} / \mathrm{L}$ \\
\hline \hline
\end{tabular}

Fonte: adaptado da Resolução CONAMA 357, 2005.

No estado de São Paulo, o Decreto n 8.468, de 8 de setembro de 1976, que regulamenta a Lei $n^{\circ}$ 997, de 31 de maio de 1976, e dispõe sobre a prevenção e o controle da poluição, traz no art. 18, a definição dos padrões de emissão para efluentes industriais lançados, direta ou indiretamente, nas coleções de água, e com relação ao lançamento do fenol é igual à legislação federal, limitando a concentração em menor que $0,5 \mathrm{mg} \mathrm{C}_{6} \mathrm{H}_{5} \mathrm{OH} / \mathrm{L}$. Para padrões 
de qualidade de cursos d'água classe 2, a legislação paulista é mais restritiva que a federal, sendo que o padrão de qualidade para fenol é de 0,001 mg $\mathrm{C}_{6} \mathrm{H}_{5} \mathrm{OH} / \mathrm{L}$.

A legislação ambiental do estado de São Paulo estipula, através do artigo 19-A do decreto 15.245/80, o lançamento dos efluentes na rede coletora de esgotos. Para despejos contendo fenol, a concentração desse poluente não pode exceder 5,0 mg $\mathrm{C}_{6} \mathrm{H}_{5} \mathrm{OH} / \mathrm{L}$.

Alguns despejos industriais (indústria siderúrgica, petroquímica, resinas, química) apresentam concentração de fenol muito acima dos valores permitidos para lançamento pela legislação, e faz-se necessário o tratamento desses despejos antes do lançamento, tanto em corpos d'água, quanto na rede coletora de esgotos.

\subsubsection{ALTERNATIVAS PARA REMOÇÃO DO FENOL PRESENTE EM DESPEJOS:}

A remoção de compostos fenólicos dos despejos, gerados nos diversos processos industriais, pode ser alcançada por processos físico-químicos ou através de processos biológicos de tratamento.

Alguns processos físico-químicos consagrados são: adsorção em carvão ativado, extração com solvente e oxidação química (ECKENFELDER, 1997). Estes são, em geral, mais dispendiosos que o tratamento biológico, pois utilizam produtos químicos caros, além de requisitarem mão-de-obra e equipamentos especializados. A adsorção em carvão ativado e a extração com solvente são processos que apenas transferem o contaminante de uma fase para outra, requisitando um tratamento posterior. Portanto, processos biológicos são preferíveis, já que conduzem a uma completa mineralização dos fenóis. (SARFARAZ et al. 2004).

Para despejos industriais contendo elevadas concentrações de compostos fenólicos, além de concentrações expressivas de substâncias recalcitrantes, a exemplo de águas residuárias da unidade de destilação do carvão em indústrias siderúrgicas, a associação de um pré-tratamento 
físico-químico seguido de tratamento biológico é, geralmente, aplicada (KOSTENBAIDER; FLECKSTEINER， 1969; YANG; HUMPHREY， 1975; GANCZARCZYK， 1979; GREENFIELD; NEUFELD, 1981; TABAK et al., 1981; JONES et al., 1983; STOVER e KINCANNON, 1983; YIBO et al., 1991; YI et al., 1994; MORITA et al., 1997; LEE et al. 2001).

A principal via de biodegradação do fenol é baseada na hidroxilação, transformando-o em catecol e posterior fissão do anel aromático. O rompimento do anel aromático pode dar-se em duas posições: orto ou meta. A maioria dos microrganismos degradadores de fenol realizam a clivagem do anel na posição orto, confirmando pela medição da atividade enzimática em tanques de aeração construídos em escala laboratorial (KUMARAN e PARUCHURI, 1997; KIBRET, SOMITSCH e ROBRA, 2000).

Outras rotas bioquímicas podem ser utilizadas para oxidação desses compostos, uma das quais a anaeróbia. (HEALY, JR. e YOUNG, 1979; DWYER et al, 1983; SUIDAN et al., 1988). O fenol é inicialmente convertido a benzoato e posteriormente se formam ácidos carboxílicos, a estrutura anelar é clivada formando heptanoato. O heptanoato é degradado, tanto através de $\beta$ oxidação, originando valerato, propionato e acetato, ou diretamente formando propionato e butirato; que posteriormente podem ser oxidados a acetato (KOBAYASHI et al. 1989 apud FANG et al., $1996^{4}$ ). O tratamento biológico de águas residuárias fenólicas pela via aeróbia sempre recebeu considerável atenção; após 1990, este cenário está sofrendo alteração, uma vez que os pesquisadores têm dedicado maior atenção aos processos anaeróbios (VEERESH, KUMAR e MEHROTRA, 2005).

A tabela 08 mostra um resumo de algumas pesquisas visando à remoção biológica de fenol utilizando diferentes rotas bioquímicas e condições operacionais variadas.

\footnotetext{
${ }^{4}$ KOBAYASHI, T. et al. Methanogenic degradation of phenol and benzoate in acclimated sludges. Water Science and Technology, Londres, v. 21, p. 55-65, 1989.
} 
Tabela 08 - Condições operacionais e resultados de algumas pesquisas visando a biodegradação do fenol sob condições anaeróbias e anóxicas:

\begin{tabular}{|c|c|c|c|c|}
\hline Reator biológico & $\begin{array}{l}\text { Fenol afluente } \\
\left(\mathrm{mgC}_{6} \mathrm{H}_{5} \mathrm{OH} / \mathrm{L}\right)\end{array}$ & $\mathrm{T}\left({ }^{\circ} \mathrm{C}\right)$ & $\begin{array}{c}\text { Eficiência } \\
\text { de } \\
\text { remoção }\end{array}$ & Fonte \\
\hline $\begin{array}{l}\text { UASB com recirculação do efluente, em } \\
\text { escala de bancada }\end{array}$ & 1.400 & 37 & $90 \%$ & $\begin{array}{c}\text { Chang et al. } \\
(1995)\end{array}$ \\
\hline $\begin{array}{l}\text { UASB com recirculação do efluente, em } \\
\text { escala de bancada }\end{array}$ & 1.260 & 37 & $97 \%$ & Fang et al. (1996) \\
\hline $\begin{array}{l}\text { UASB com recirculação do efluente, em } \\
\text { escala de bancada }\end{array}$ & 2.000 & $34-35$ & $99 \%$ & $\begin{array}{c}\text { Lay e Cheng } \\
(1998)\end{array}$ \\
\hline $\begin{array}{l}\text { UASB com recirculação do efluente e } \\
\text { adição de glicose, em escala de bancada }\end{array}$ & 1.260 & 37 & $98 \%$ & Tay et al. (2001) \\
\hline $\begin{array}{l}\text { Lodos ativados operado em bateladas } \\
\text { com aeração intermitente, em escala de } \\
\text { bancada }\end{array}$ & 1.000 & 25 & $99 \%$ & $\begin{array}{l}\text { Yamagishi et al. } \\
\text { (2001) }\end{array}$ \\
\hline $\begin{array}{l}\text { UASB sem recirculação do efluente, em } \\
\text { escala de bancada }\end{array}$ & 1.176 & 30 & $87 \%$ & Mehrotra (2003) \\
\hline Lodos ativados em escala piloto & 1.000 & -- & $99 \%$ & Dombroski (2003) \\
\hline $\begin{array}{l}\text { UASB com recirculação do efluente, em } \\
\text { escala de bancada }\end{array}$ & 1.260 & 26,5 & $98 \%$ & Fang et al. (2004) \\
\hline $\begin{array}{c}\text { Remoção anóxica operando um reator em } \\
\text { bateladas com biomassa imobilizada, em } \\
\text { escala de bancada }\end{array}$ & 1050 & 30 & $80 \%$ & $\begin{array}{l}\text { Sarfaraz et al. } \\
\quad(2004)\end{array}$ \\
\hline $\begin{array}{l}\text { Filtro anaeróbio de leito granular } \\
\text { expandido, em escala de bancada }\end{array}$ & 400 a 1.200 & $15-18$ & $>60 \%$ & $\begin{array}{c}\text { Collins et al. } \\
(2005)\end{array}$ \\
\hline $\begin{array}{l}\text { Remoção anóxica realizando testes em } \\
\text { escala de bancada }\end{array}$ & 360 & 20 & $40 \%$ & $\begin{array}{l}\text { Eiroa et al. } \\
\quad(2005)\end{array}$ \\
\hline $\begin{array}{l}\text { UASB anóxico em escala de bancada, } \\
\text { operado com alimentação contínua e } \\
\text { recirculação do efluente }\end{array}$ & 1.010 & 23 & $90 \%$ & $\begin{array}{l}\text { Eiroa et al. } \\
\quad(2005)\end{array}$ \\
\hline
\end{tabular}

Algumas águas residuárias industriais possuem na sua constituição concentrações elevadas de nitrogênio amoniacal e compostos fenólicos, notadamente fenol, a exemplo dos despejos das indústrias química e petroquímica; de resinas; siderúrgica, dentre outras. A tabela 10 mostra alguns despejos ricos em fenol e $\mathrm{N}_{-} \mathrm{NH}_{3}$. Entretanto, estudos da remoção de fenol em ambientes anóxicos são escassos.

Tabela 09 - Exemplos de despejos industriais ricos em fenol e N-NH $\mathrm{H}_{3}$ :

\begin{tabular}{|c|c|c|}
\hline Atividade Industrial & Fenol (mg C $\left.6 \mathrm{H}_{5} \mathrm{OH}\right)$ & $\begin{array}{c}\text { Nitrogênio } \\
\left(\mathrm{mg} \mathrm{N}-\mathrm{NH}_{3} / \mathrm{L}\right)\end{array}$ \\
\hline Siderurgia (unidade de destilação do carvão) & $350-910$ & $1.300-7.300$ \\
\hline Refinarias de Petróleo & 154 & 120 \\
\hline Resinas para preservação da madeira & 1.790 & 384 \\
\hline Petroquímica & $2.000-25.000$ & $4.630-10.500$ \\
\hline
\end{tabular}

Fonte: adaptado de (BRAILE e CAVALCANTI, 1993). 
A seguir apresenta-se a reação da desnitrificação completa usando fenol como fonte de carbono (THOMAS et al., 2002; SARFARAZ et al., 2004)

$$
28 \mathrm{NO}_{3}^{-}+5 \mathrm{C}_{6} \mathrm{H}_{5} \mathrm{OH} \leftrightarrows 14 \mathrm{~N}_{2}+30 \mathrm{CO}_{2}+28 \mathrm{OH}^{-}+\mathrm{H}_{2} \mathrm{O}(
$$

Segundo a estequiometria, a quantidade de fenol requerida para completa desnitrificação de 1 mol de nitrato a 1 mol de nitrogênio gasoso é 0,179 mol, ou expressando em massa, para a redução de $1 \mathrm{~g}$ de $\mathrm{NO}_{3}{ }^{-}$são necessárias $0,27 \mathrm{~g}$ de fenol.

A reação da desnitritação utilizando fenol como fonte de carbono é:

$$
25 \mathrm{NO}_{2}^{-}+3 \mathrm{C}_{6} \mathrm{H}_{5} \mathrm{OH} \rightarrow 12,5 \mathrm{~N}_{2}+18 \mathrm{CO}_{2}+16 \mathrm{OH}^{-}+\mathrm{H}_{2} \mathrm{O}(15)
$$

Realizando os cálculos acima se percebe que a redução de 1 mol de nitrito requer 0,12 mol.de fenol; em massa essa relação é: $1,0 \mathrm{~g}$ de $\mathrm{NO}_{2}{ }^{-} / 0,245 \mathrm{~g}$ de fenol.

\subsubsection{FORMAÇÃO DE NiTROFENÓIS:}

Fenóis sofrem um grande número de reações de substituição eletrofílica devido à alta reatividade do anel aromático. O mecanismo usual envolve ácido sulfúrico e ácido nítrico para geração do íon nitronium $\left(\mathrm{NO}_{2}{ }^{+}\right)$, conforme a seguinte seqüência de reações (TURNEY e WRIGHT, 1959; MORRISON e BOYD, 1992).

$$
\begin{gathered}
\mathrm{HNO}_{3}+\mathrm{H}_{2} \mathrm{SO}_{4} \rightarrow \mathrm{H}_{3} \mathrm{O}^{+}+2 \mathrm{HSO}_{4}^{-}+\mathrm{NO}_{2}^{+} \text {(16) } \\
\mathrm{NO}_{2}^{+}+\mathrm{C}_{6} \mathrm{H}_{6} \rightarrow \mathrm{C}_{6} \mathrm{H}_{6} \mathrm{NO}_{2}
\end{gathered}
$$

Ácido nítrico é um conhecido agente "nitratante" para fenol, principalmente em elevadas concentrações; o fenol é convertido em 2,4,6 - Trinitrofenol; 2 ou 4 - nitrofenol. Submetido a baixas temperaturas $\left(7-8^{\circ} \mathrm{C}\right.$.), ácido nitroso converte fenol em nitrosofenol, da mesma maneira, se obtêm mononitrofenóis usando ácido nítrico concentrado, esses são processos consagrados na indústria química (MORRISON e BOYD, 1992; PATNAIK e KHOURY, 2004). A reação do fenol com ácido nitroso e ácido nítrico em solução aquosa de ácido 
sulfúrico $\left(19-45 \% \mathrm{H}_{2} \mathrm{SO}_{4}\right)$ a $25^{\circ} \mathrm{C}$ resulta na formação de $p$ - nitrofenol através de um processo de nitrosação-oxidação. (AL-OBAIDI e MOODIE, 1985).

Nitrito em contato com fenol pode induzir a formação de nitrofenóis através de um processo foto-induzido (radiação ultra-violeta); porém, recentemente, observou-se a formação de 2 e 4 -nitrofenol apenas pelo contato entre nitrito e fenol sem a foto-indução. A reação ocorreu à temperatura ambiente, em ampla faixa de $\mathrm{pH}(2$ a 10$)$ e na presença ou ausência de luz. (VIONE et al., 2002; PATNAIK e KHOURY, 2004).

Estudos têm demonstrado a possibilidade de aplicação de tratamento biológico para remoção de nitrofenóis, tanto em águas residuárias, quanto no solo. Alguns microrganismos (Nocardioides sp., Pseudomonas putida, Arthrobacter sp.; Bacillus sphaericus e Moraxella sp.) são capazes de degradar esses compostos sob variadas condições abióticas (ZEYER e KEARNEY, 1984; KIKUGAWA E KATO, 1988; CHO et al., 1998; LI et al., 1998; KADIYALA et al., 1998; KULKARNI e CHAUDHARI, 2006). 


\subsection{SISTEMAS DE LODOS ATIVADOS OPERADOS EM BATELADAS SEQUENCIAIS:}

Os britânicos Ardern e Lockeet (1914) foram os primeiros a observar as vantagens de reter uma biomassa adaptada dentro de um tanque de tratamento de águas residuárias. Trabalhando com frascos de volume entre 2 - 3 litros, eles mostraram que o tempo de aeração necessário para atingir a nitrificação era reduzido de 5 semanas para 9 horas, quando o lodo que restava após a decantação do líquido tratado era mantido nos frascos. (ARORA et al., 1985). Portanto os primeiros sistemas de lodos ativados eram constituídos de apenas um tanque no qual, ao longo do tempo, em períodos pré-determinados, ocorria o processo de depuração da água residuária. A seqüência operacional é, geralmente, composta das seguintes etapas: enchimento; reações; sedimentação; descarte do efluente tratado e repouso. (VAN HAANDEL E MARAIS, 1999).

A partir de 1980 a tecnologia de operação em batelada tornou-se mais aplicada, uma vez que se passou a conhecer melhor o sistema, se desenvolveram vertedores flutuantes mais confiáveis e o emprego do processo de automação foi mais difundido. Recentemente, tem se aprimorado o processo para obtenção da remoção biológica de nutrientes, notadamente nitrogênio e fósforo. (VON SPERLING, 2002)

As principais vantagens associadas ao modo de operação em bateladas seqüenciais estão listadas a seguir: (ARORA et al., 1985; VAN HAANDEL E MARAIS, 1999; VON SPERLING, 2002).

- o tanque, operado em batelada, serve como tanque de equalização e assim o sistema é mais resistente a cargas de choque e variações da vazão afluente sem apresentar problemas para o processo como um todo; 
- durante os primeiros anos de vida útil da planta de tratamento, nos quais a vazão afluente é significativamente menor, a instalação de sensores de nível permite a utilização de apenas uma fração do volume do taque;

- não requer bombas para recirculação do lodo biológico;

- $\quad$ simplicidade operacional e boa sedimentabilidade do lodo biológico;

- desenvolvimento de microrganismos Filamentosos pode ser controlado através de manobras operacionais durante a etapa de enchimento.

Porém a capacidade de aeração em sistemas em batelada é maior que aquela instalada em sistemas com unidades separadas, uma vez que o consumo de oxigênio para estabilização dos poluentes é o mesmo e o tempo destinado ao fornecimento de ar no sistema em batelada é menor. Portanto deve-se levar em consideração o custo de instalação dos aeradores e o consumo de energia na comparação com um sistema operando convencionalmente. (VAN HAANDEL E MARAIS, 1999). 
Tabela 10 - Diferentes etapas do ciclo de tratamento em reatores operados em batelada:

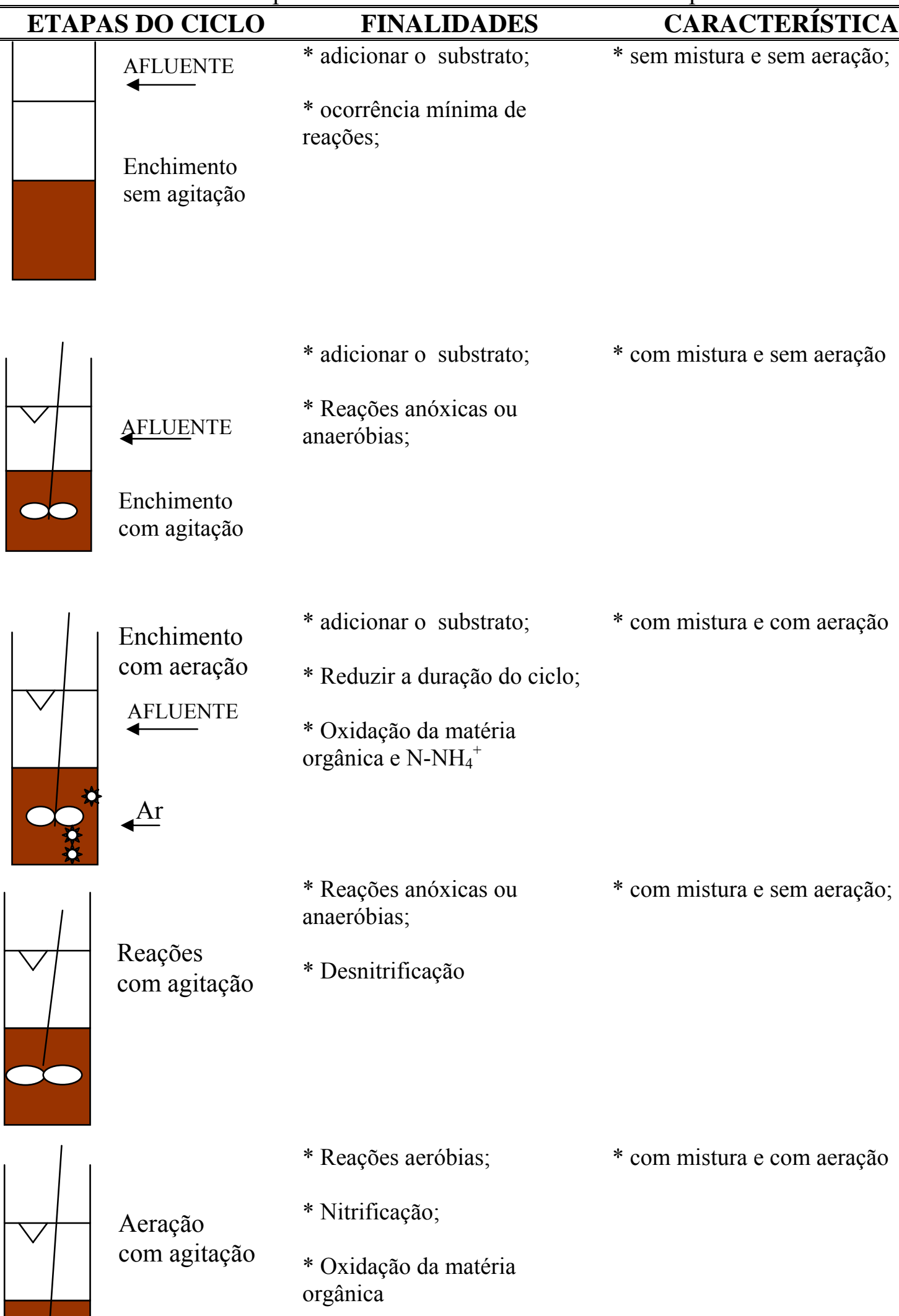


Tabela 10 - Diferentes etapas do ciclo de tratamento em reatores operados em batelada continuação

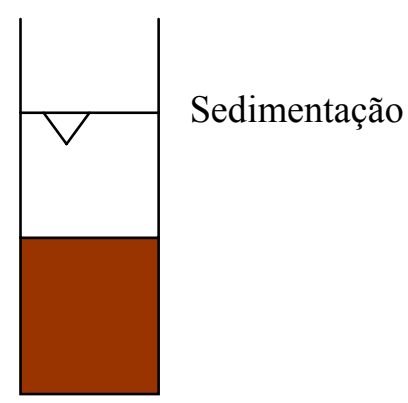

* Separação de fases (Sólido - * sem mistura e sem aeração líquido)

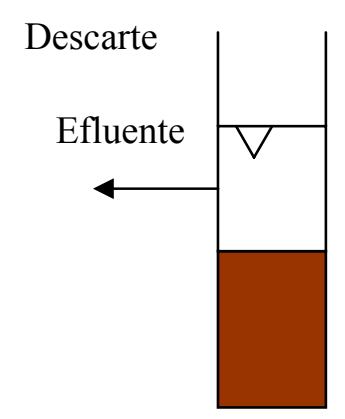

* Remoção do efluente final * * sem mistura e sem aeração tratado

* Descarte do excesso de lodo; * sem mistura e sem aeração

Repouso

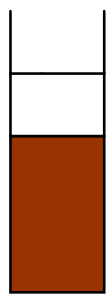

* Ajustes operacionais para o

início de um novo ciclo

Fonte: adaptado de ARIMA (2005).

\subsubsection{CONTROLE E MONITORAMENTO DAS ETAPAS DO CICLO DE TRATAMENTO:}

A operação de um sistema de lodos ativados em batelada caracteriza-se pela adaptabilidade à automação. Como as etapas do tratamento são definidas em intervalos de tempo, essa automação pode ser controlada por microprocessadores que definirão, por exemplo, o tempo de entrada do afluente no sistema; o tempo destinado à aeração; a abertura e fechamento das válvulas de descarte etc. Dessa maneira, a redução dos custos com mão-de-obra é significativa ao longo da vida útil da planta de tratamento. (KAMIYAMA, 1988). 
O controle em tempo real, sobre a duração dos períodos destinados às reações biológicas, é necessário devido às variações na composição da água residuária no início de cada batelada. A principal dificuldade na aplicação desse controle é a falta de informações em tempo real, uma vez que, as análises de laboratório não são adequadas para esse tipo de monitoramento. Assim, busca-se a utilização de parâmetros indiretos como: pH; concentração de oxigênio dissolvido na massa líquida e potencial de oxi-redução no conteúdo do reator (ORP). (PLISSON-SAUNE et al., 1996; SUESCUN et al., 2001; CASTELLÓ et al., 2002; CECIL, 2003; CHEN et al., 2004; LI et al., 2004; ARIMA, 2005).

O desenvolvimento de sensores de monitoramento on line mais robustos e que exigem baixa manutenção, ficando imersos nos tanques de processo, associados à aplicação de lógica de programação Fuzzy é bastante promissora para o controle e alcance de excelentes eficiências no tratamento de águas residuárias em sistemas operados em bateladas. (WANG et al., 2004; PENG et al., 2005; ARIMA, 2005).

As figuras 04, 05, 06 e 07 apresentam os perfis de monitoramento de $\mathrm{pH}$, potencial de oxiredução e oxigênio dissolvido e alguns pontos identificados como o início e final das diferentes etapas dos ciclos de tratamento de esgotos domésticos em reatores de lodos ativados operados em bateladas seqüenciais.

O comportamento da curva de $\mathrm{pH}$ nas figuras 04 (entre os pontos B e BB) e 05 (entre os pontos Ap e Bp) segundo os pesquisadores, definiriam o "vale da amônia"; indicando a ocorrência da nitrificação. Esse comportamento, associado ao desenvolvimento de pesquisas na área de inteligência artificial, é promissor para automação de sistema de lodos ativados operados em bateladas seqüenciais, otimizando o tempo destinado a cada reação do ciclo de tratamento. Aparentemente o perfil de ORP é mais apropriado para o controle das reações durante a fase anóxica dos ciclos de tratamento, valores negativos de ORP foram associados 
com a extinção do $\mathrm{N}_{-\mathrm{NO}_{3}}{ }^{-}$no conteúdo do reator e início da fermentação anaeróbia. (CASTELLÓ et al., 2002; CECIL, 2003; PENG et al., 2005; ARIMA, 2005).

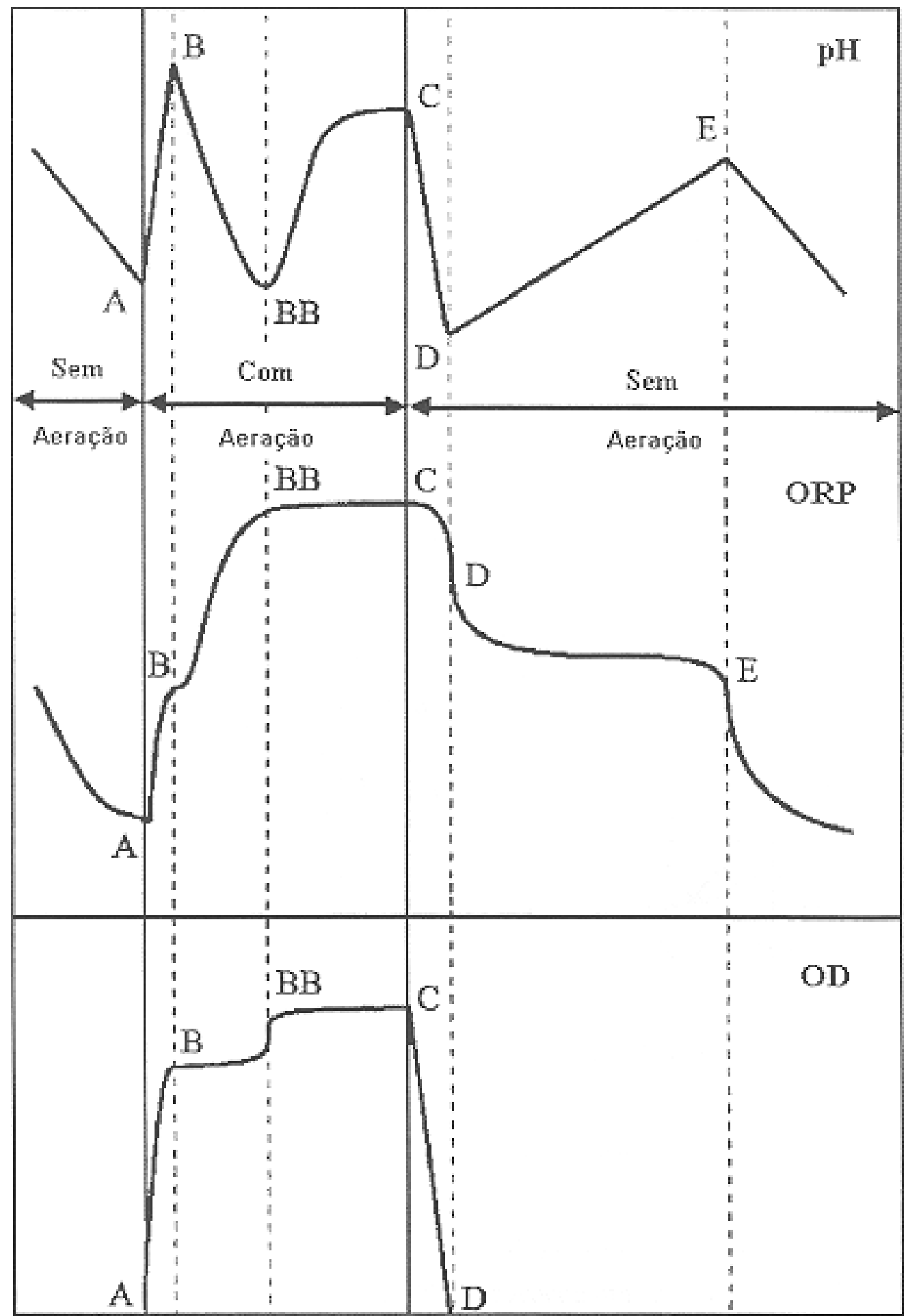

Figura 04: Perfis temporais pH e ORP e OD de um sistema operado em bateladas seqüenciais para remoção de matéria orgânica e nitrogênio.

Fonte: Cybis (1992) 
Petancial hidrogenisnito

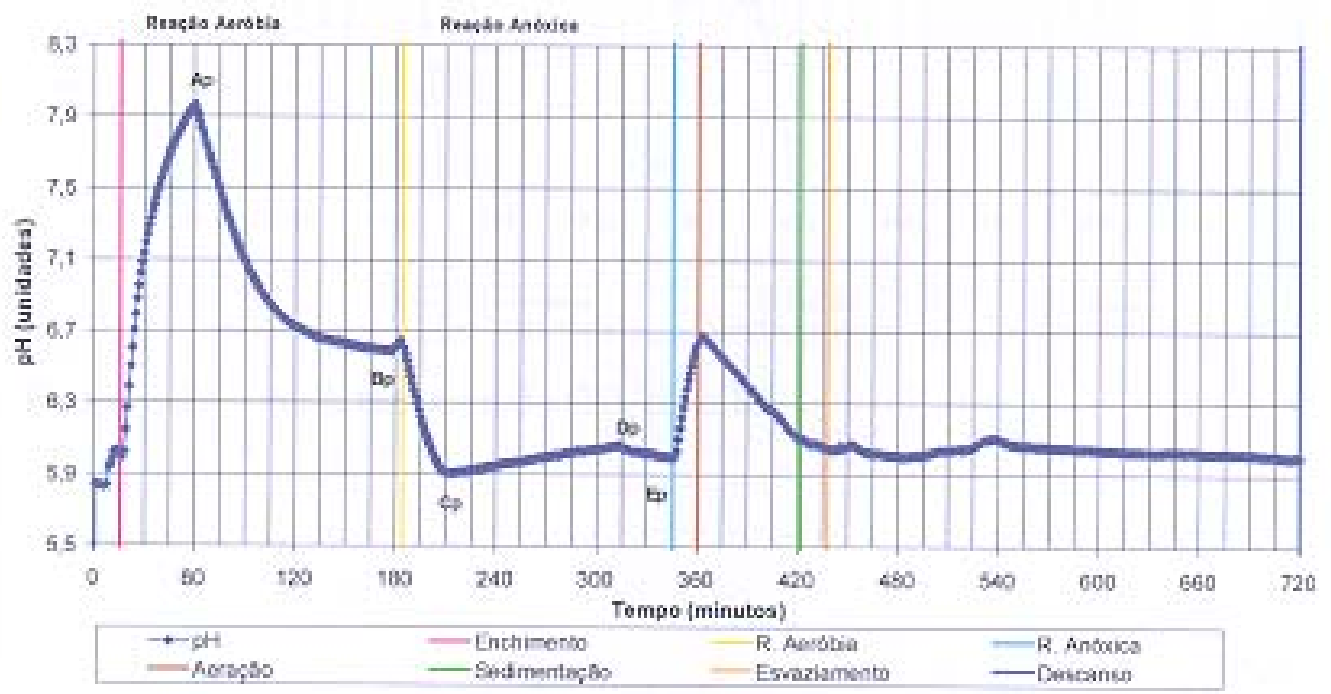

Figura 05: Perfil temporal do $\mathrm{pH}$ de um sistema operado em bateladas seqüenciais para remoção de matéria orgânica e nitrogênio.

Fonte : Arima (2005).

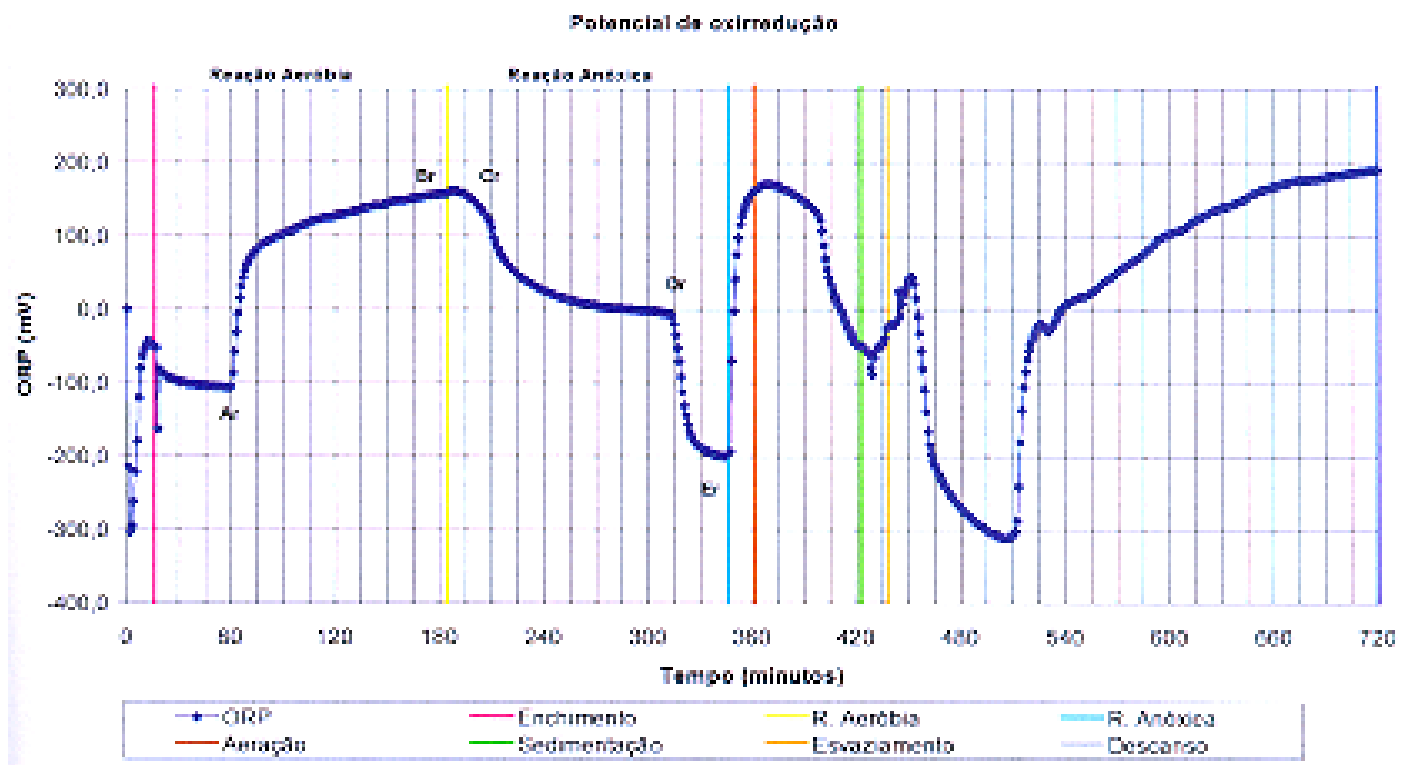

Figura 06: Perfil temporal do ORP de um sistema operado em bateladas seqüenciais para remoção de matéria orgânica e nitrogênio.

Fonte : Arima (2005). 


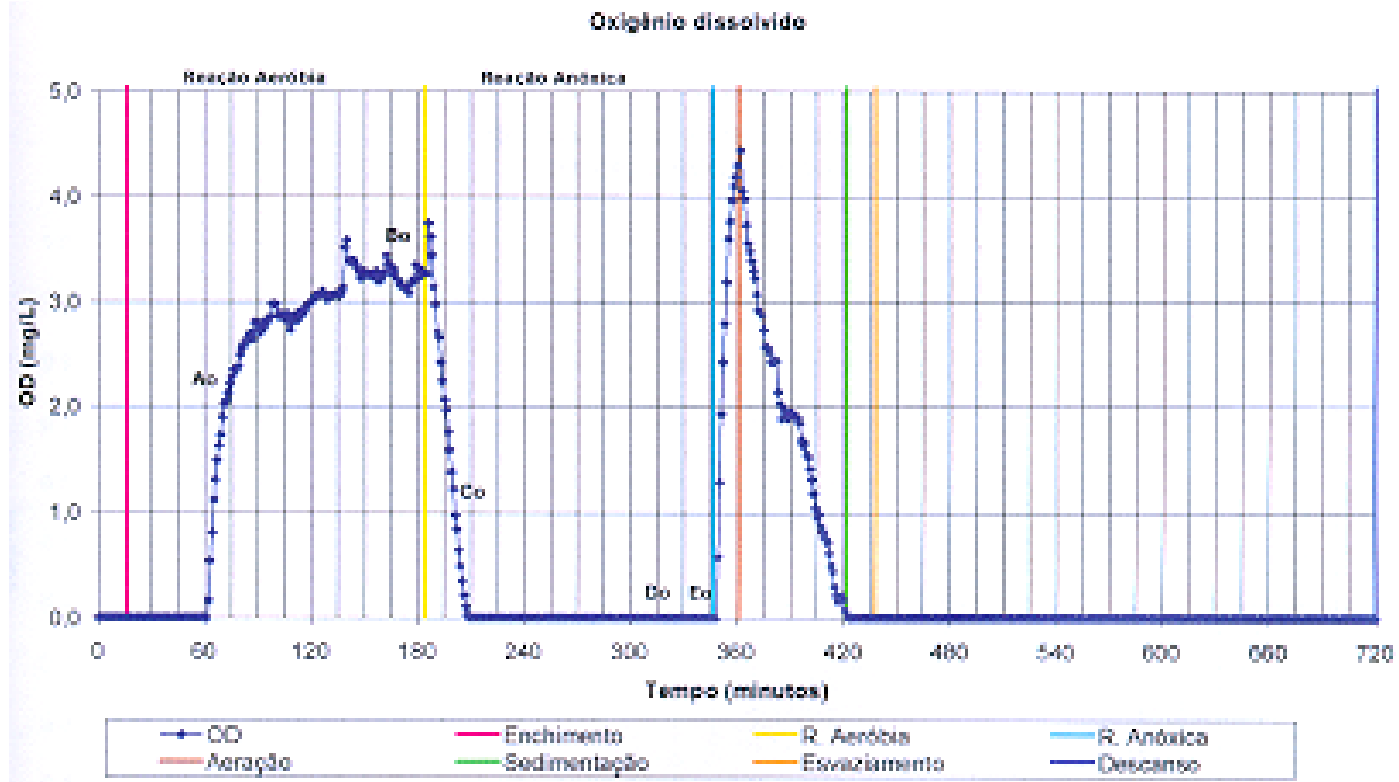

Figura 07: Perfil temporal da concentração de oxigênio dissolvido de um sistema operado em bateladas seqüenciais para remoção de matéria orgânica e nitrogênio.

Fonte : Arima (2005). 


\section{MATERIAL E MÉTODOS:}

A pesquisa para avaliação da remoção biológica do nitrogênio pela via simplificada (nitritação) utilizando fenol como fonte de carbono na etapa anóxica (desnitritação), foi conduzida em duas fases distintas.

A meta da primeira fase foi identificar quais condições operacionais e parâmetros eram importantes para a obtenção da predominância do nitrito na massa líquida do reator, ao final de um determinado período aeróbio. Essa fase foi dividida em três etapas: durante a primeira investigou-se a influência da temperatura para o acúmulo de $\mathrm{N}_{-} \mathrm{NO}_{2}^{-}$; na segunda etapa buscou-se a predominância do nitrito através da limitação do fornecimento de oxigênio e, por

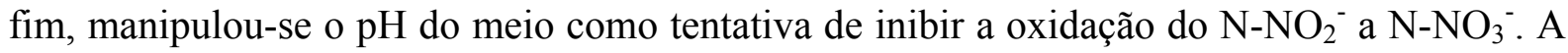
investigação foi conduzida em um béquer inoculado com 1,5 litro de lodo biológico e alimentado com 0,5 litro de um despejo líquido sintético contendo nitrogênio amoniacal ( $\cong 150 \mathrm{mg} \mathrm{N} / \mathrm{L}$ ) e sem fenol. Ao término dos testes descartava-se todo conteúdo do béquer.

A partir dos resultados da primeira fase, partiu-se para operação de um sistema de lodos ativados em bateladas seqüenciais com volume útil de 20 litros, alimentado com uma água residuária sintética com fenol $\left(1.000 \mathrm{mg} \mathrm{C}_{6} \mathrm{H}_{5} \mathrm{OH} / \mathrm{L}\right)$ e nitrogênio amoniacal. Essa fase foi conduzida em três etapas distintas que se caracterizaram pelo aumento gradual da concentração de nitrogênio amoniacal no afluente (200; 300 e $500 \mathrm{mg}$ N/L) e, conseqüentemente, da carga de nitrogênio amoniacal afluente ao sistema piloto de tratamento. A duração das etapas do ciclo de tratamento (enchimento, anóxica, aerada, repouso e descarte) no interior do reator também foi ajustada durante a pesquisa, como condição para o alcance da eficiência do processo de tratamento. Monitorou-se o comportamento do $\mathrm{pH}$ e do potencial de oxi-redução no conteúdo do reator, ao longo das diferentes etapas dos ciclos de tratamento. 


\section{1 ÁGUA RESIDUÁRIA SINTÉTICA:}

Uma água residuária similar à utilizada na segunda fase da presente pesquisa, simulando despejo da unidade de destilação do carvão da indústria siderúrgica (coqueria), já fora objeto de estudos do Departamento de Engenharia Hidráulica e Sanitária da Escola Politécnica da Universidade de São Paulo. Inicialmente, Da Costa (1999) estudou a tratabilidade desse despejo em um sistema de lodos ativados; posteriormente, Aun (2001) e Dombroski (2003) avaliaram a remoção do nitrogênio amoniacal, presente nos despejos, utilizando o próprio fenol como fonte de carbono para desnitrificação.

A água residuária sintética utilizada na condução da segunda fase da presente pesquisa (Tabela 11) difere da anteriormente citada pela ausência dos compostos: Benzeno (50 mg/L), Tolueno (30 mg/L), Xileno (50 mg/L), Naftaleno (30 mg/L) e Ferrocianeto de potássio (133 mg/L). A retirada desses compostos orgânicos aromáticos da composição da água residuária sintética, deriva das conclusões obtidas nas pesquisas anteriores (AUN, 2001; DOMBROSKI, 2003), que nas concentrações utilizadas esses compostos orgânicos não interferem no processo de nitrificação e desnitrificação; quanto ao ferrocianeto de potássio, utilizado como fonte de íons cianeto, a indústria siderúrgica, atualmente, o elimina em etapa físico-química anterior ao tratamento biológico.

Tabela 11 - Dosagem de produtos químicos utilizados no preparo da água residuária sintética.

\begin{tabular}{|lc|}
\hline Produtos químicos & Dosagem (mg/L) \\
\hline \hline Fenol & 1.000 \\
\hline Cloreto de amônio & Fase 01: 764 \\
& Fase 02: 1.146 \\
& Fase 03: 1.911 \\
\hline Sulfato de manganês & 53 \\
\hline Cloreto de cálcio & 53 \\
\hline Sulfato de magnésio & 330 \\
\hline Sulfato ferroso & 69 \\
\hline Fosfato de potássio bibásico & 200 \\
\hline
\end{tabular}


Além dos produtos químicos apresentados na tabela 11, foi acrescentada uma solução de micronutrientes na proporção de $1 \mathrm{~mL}$ para cada litro de água residuária sintética. Esses micronutrientes são importantes na complementação dos requerimentos nutricionais das células dos microrganismos e desempenham importante papel sobre a atuação de diversas enzimas (CAMPOS, 1999). Esta solução era preparada com a adição das quantidades dos produtos químicos (Tabela 12) em $100 \mathrm{~mL}$. de água desionizada. Após a utilização a solução era estocada sob temperatura de $4^{\circ} \mathrm{C}$. por prazo máximo de cinco dias.

Tabela 12 - Composição da solução de micronutrientes essenciais:

\begin{tabular}{|cc|}
\hline \hline Produto Químico & Concentração (mg/L) \\
\hline \hline $\mathrm{FeSO}_{4}$ & 2.728 \\
\hline $\mathrm{EDTA}$ & 50.000 \\
\hline$\left(\mathrm{NH}_{4}\right)_{6} \mathrm{Mo}_{7} \mathrm{O}_{24}$ & 1.036 \\
\hline $\mathrm{MnCl}_{2}$ & 3.220 \\
\hline $\mathrm{ZnSO}_{4}$ & 12.354 \\
\hline $\mathrm{CaCl}_{2}$ & 5.540 \\
\hline $\mathrm{CoCl}_{2}$ & 880 \\
\hline $\mathrm{CuSO}_{4}$ & 1.004 \\
\hline
\end{tabular}

Fonte: CAMPOS, (1999).

O preparo da água residuária sintética para cada ciclo de tratamento consistia das seguintes etapas:

1. Dosagem dos produtos químicos de acordo com a tabela 11;

2. Dissolução dos reagentes em 5,0 (cinco) litros de água destilada com auxílio de um agitador magnético;

3. Acréscimo da solução de micronutrientes $(1 \mathrm{~mL} / \mathrm{L})$;

4. A água residuária sintética preparada era mantida sob agitação até o final do seu lançamento no reator piloto. 


\subsection{INÓCULO:}

O inóculo foi proveniente do tanque anóxico do sistema piloto de lodos ativados, instalado no Centro Tecnológico de Hidráulica da USP (CTH) em operação desde setembro de 2004. Este sistema trata um despejo sintético com altas concentrações de fenol (1.000 mg $\left.\mathrm{C}_{6} \mathrm{H}_{5} \mathrm{OH} / \mathrm{L}\right)$ e nitrogênio amoniacal (500 mg N/L), promovendo a oxidação total do nitrogênio amoniacal (remoção via nitrato), utilizando fenol como fonte de carbono para desnitrificação em um reator pré-anóxico.

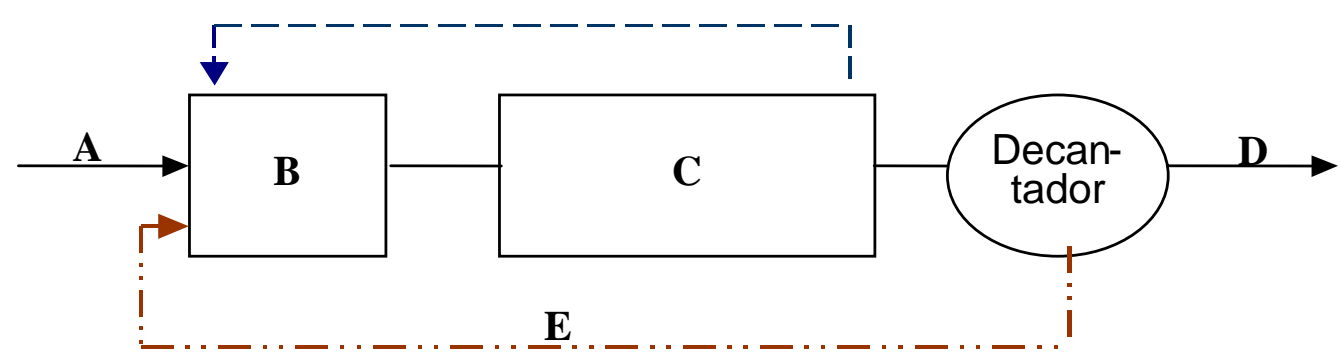
A - Afluente
B - Reator Anóxico
C - Reator Aeróbio
D - Saída do efluente tratado
E - Reciclo de Lodo

Figura 08: Esquema de funcionamento do sistema piloto de lodos ativados instalado no C.T.H.

\subsection{APARATO EXPERIMENTAL:}

\subsubsection{FASE 01 - TESTES EXPLORATÓRIOS EM ESCALA DE BANCADA:}

A figura 09 apresenta um desenho esquemático do aparato experimental da primeira fase da presente pesquisa, conduzida em um béquer com volume de 2,0 litros. 


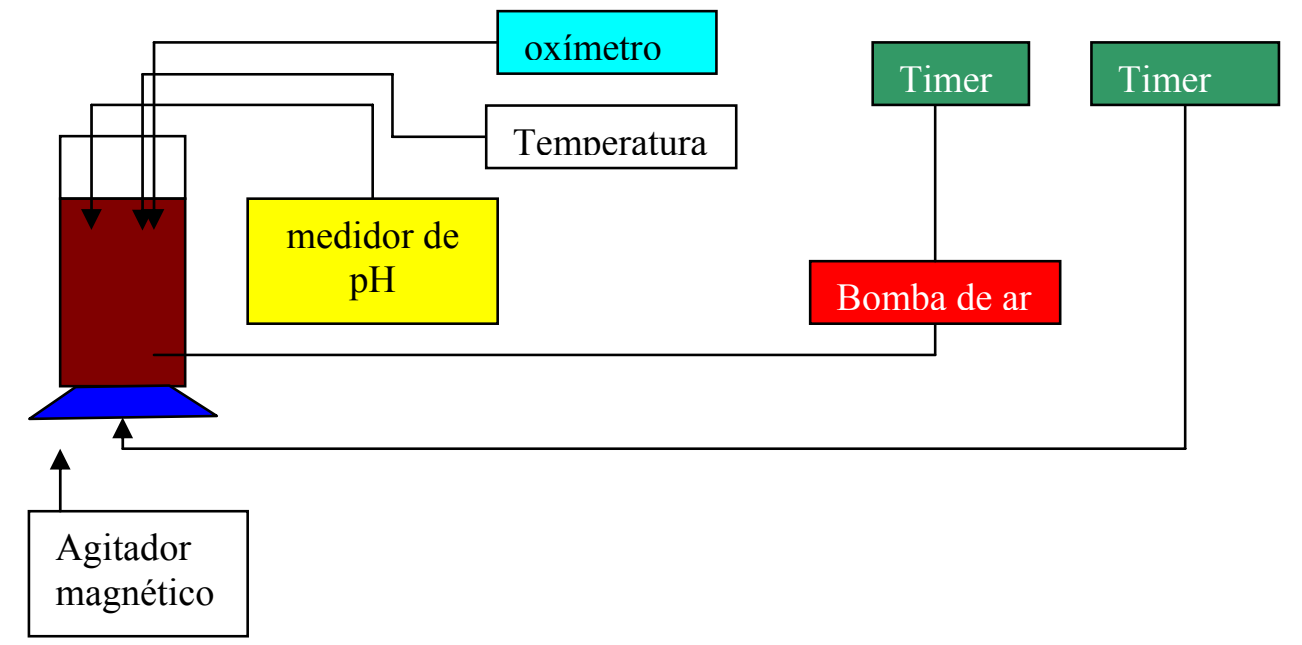

Figura 09: Desenho esquemático do aparato experimental, utilizado na primeira fase da pesquisa (testes exploratórios em escala de bancada).

Para montagem do experimento utilizaram-se os seguintes materiais e equipamentos:

- Becker de vidro com volume de 2,0 litros.

- $\quad$ Agitador magnético.

- Medidor portátil de oxigênio dissolvido (Marca YSI, modelo 55S), com um sensor de membrana, permitindo a leitura da concentração de oxigênio dissolvido no conteúdo do reator, durante todo tempo de duração do experimento.

- controladores programáveis (timers) para permitir a definição dos tempos das diferentes fases do ciclo de tratamento (enchimento, aeração, decantação e descarte).

- Medidor de pH de bancada, marca ORION, modelo 720A, associado a um eletrodo potenciométrico combinado, encapsulado com vidro, permanentemente imerso no conteúdo do reator.

- Aquecedor de imersão com termostato, adquirido de acordo com o volume da massa líquida.

- Bomba de ar similar à utilizada em aquários domésticos. 


\subsubsection{FASE 02 - CiCLOS DE TRATAMENTO CONDUZIDOS NO REATOR PILOTO OPERADO EM BATELADAS SEQUENCIAIS:}

A figura 10 apresenta um desenho esquemático do aparato experimental utilizado durante a segunda fase da presente pesquisa, conduzida em um reator com volume útil de 20 litros, alimentado com água residuária sintética composta predominantemente por fenol e nitrogênio amoniacal.

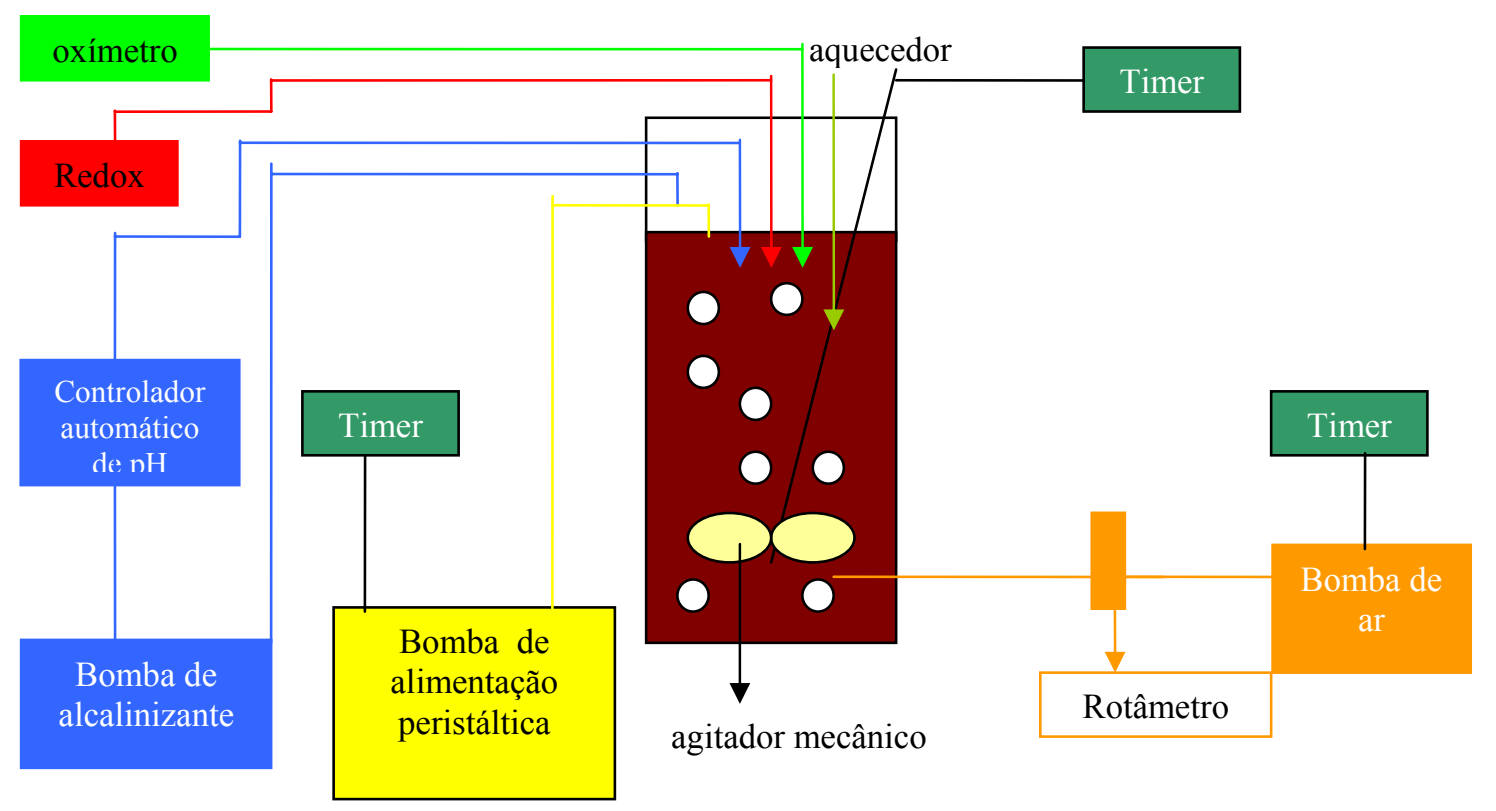

Figura 10: Desenho esquemático do aparato experimental, utilizado durante a segunda fase da pesquisa.

Para montagem do experimento utilizaram-se os seguintes materiais e equipamentos:

- Reator construído em acrílico, com as seguintes dimensões internas: 25 x 25 x $40 \mathrm{~cm}$.

- Agitador mecânico para homogeneização da massa líquida.

- Bomba peristáltica multicanal, marca Ismatec, para dosagem do afluente.

- Bomba da marca Millipore com saída de ar acoplada a um rotâmetro.

- controladores programáveis (timers) para permitir a definição dos tempos do ciclo de tratamento (enchimento, anóxico, aeração, decantação e descarte). 
- Aquecedor de imersão com termostato, adquirido de acordo com o volume da massa líquida.

- Controlador automático de $\mathrm{pH}$, marca Prominent, modelo D1C, associado a sensor (modelo Prominent PHEP 112 - SE) composto por um eletrodo potenciométrico combinado a um eletrodo de referência, encapsulados com vidro, permanentemente mergulhado no conteúdo do reator. A programação desse equipamento permitiu a comunicação com uma bomba dosadora de solução alcalinizante (Hidróxido de sódio), mantendo o pH na etapa aeróbia dos ciclos na faixa desejada. Durante a fase anóxica, esse equipamento realizava a leitura do valor de $\mathrm{pH}$ no conteúdo do reator, mas não adicionava a solução de hidróxido de sódio.

- Bomba dosadora de solução alcalinizante, marca Prominent, vazão máxima de 2,1 litros/hora.

- Medidor portátil de oxigênio dissolvido (Marca YSI, modelo 55S), com um sensor de membrana, permitindo a leitura da concentração de oxigênio dissolvido no conteúdo do reator, durante todo tempo de duração do experimento.

- Medidor de potencial Redox de bancada, marca ORION, modelo 720A, associado a um eletrodo combinado de baixa necessidade de manutenção e compensação automática de temperatura (ORION 91-79), com fio de platina, usando $\mathrm{Ag} / \mathrm{AgCl}$ como elemento de referência, permanentemente mergulhado no conteúdo do reator. (Esse equipamento foi instalado a partir da etapa que a concentração de nitrogênio amoniacal afluente era igual $300 \mathrm{mg} \mathrm{N} / \mathrm{L})$. 


\subsection{PRocedimentos DE ROTINA:}

As operações rotineiras no sistema envolveram as seguintes atividades ao longo do ciclo de tratamento:

- Limpeza e calibração do sensor de pH utilizando padrões físico-químicos, em conformidade com o Standard Methods (APHA; AWWA; WEF, 1998).

- Limpeza e calibração do sensor para leitura do sinal de ORP utilizando a solução de limpeza e calibração (ORION 967961) fornecida pelo fabricante.

- Limpeza e calibração do medidor de oxigênio dissolvido seguindo a rotina recomendada pelo fabricante, observando a durabilidade e necessidade de substituição da membrana a cada 30 dias. Essa rotina permitiu uma maior precisão das leituras efetuadas.

- Preparo da água residuária sintética (item 4.1) e leitura do pH do afluente.

- Preparo da solução alcalinizante de hidróxido de sódio.

- Aferição da vazão afluente; 


\subsection{OPERAÇÃO DO SISTEMA E CONDUÇÃO DA PESQUISA:}

\subsubsection{FASE 01: TESTES EXPLORATÓRIOS PARA OBSERVAÇÃO DO ACÚMULO DE NITRITO:}

Essa fase buscou identificar as condições que permitissem obter a predominância do nitrito como forma oxidada do nitrogênio amoniacal; para tanto foram monitorados os seguintes fatores abióticos: $\mathrm{pH}$, concentração de oxigênio dissolvido no conteúdo do béquer e temperatura da massa líquida. Durante essa fase não foi acrescentado fenol à água residuária sintética.

Essa fase da pesquisa foi conduzida em um béquer com volume de 2,0 litros, dos quais 1,5 litros foram preenchidos com lodo biológico oriundo do tanque anóxico do sistema apresentado na figura 08 e alimentado com 0,5 litro de água residuária sintética, preparada de acordo com as dosagens apresentadas na tabela 13.

Tabela 13 - Preparo do despejo sintético utilizado na fase de testes exploratórios:

\begin{tabular}{|lc|}
\hline \hline Produtos químicos & Dosagem (mg/L) \\
\hline Cloreto de Amônia & 592 \\
\hline Sulfato de Manganês & 53 \\
\hline Cloreto de Cálcio & 53 \\
\hline Sulfato de Magnésio & 330 \\
\hline Sulfato ferroso & 69 \\
\hline Fosfato de Potássio bibásico & 200 \\
\hline \hline
\end{tabular}

Após a alimentação, ligava-se a bomba para promoção da aeração durante 12 horas; após esse período desligava-se a aeração e agitação. Ao término do teste descartava-se todo conteúdo do béquer, independente da concentração final de nitrogênio amoniacal.

Os testes foram divididos em três etapas:

- Primeira Etapa: investigação da influência da temperatura como parâmetro de controle para o acúmulo de nitrito; não houve limitação do fornecimento de oxigênio e o pH foi mantido na faixa neutra $(\mathrm{pH}=7,0)$ pela adição manual de solução alcalinizante de $\mathrm{NaOH}$; 
- Segunda Etapa: investigação da possibilidade de utilização da aeração intermitente como maneira de limitar o fornecimento de oxigênio ao sistema. A intermitência era alcançada com auxílio de um temporizador programável em intervalos de quinze minutos que interrompia o fornecimento de energia à bomba de aeração em intervalos de tempo préprogramados. A temperatura da massa líquida do reator, ao longo dessa fase investigativa, esteve próxima a $30^{\circ} \mathrm{C}$.

- Terceira Etapa: o pH era mantido em valores pré-estabelecidos utilizando para tanto a adição de uma solução alcalinizante $(\mathrm{NaOH})$. A temperatura foi mantida próxima a $30^{\circ} \mathrm{C}$ e não havia limitação do fornecimento de oxigênio.

A duração de cada uma das etapas foi aproximadamente 10 dias, sendo que os testes eram realizados duas vezes por semana. As análises das formas oxidadas de nitrogênio eram efetuadas a cada duas horas; a concentração de nitrogênio amoniacal, no início e no final do teste. A determinação de sólidos em suspensão do conteúdo do reator era realizada uma vez por dia com coleta no início do teste. Os procedimentos experimentais foram conduzidos de acordo com Standard Methods (APHA; AWWA; WEF,1998) e estão descriminados na tabela 14.

Tabela 14 - Métodos analíticos para primeira fase da pesquisa:

\begin{tabular}{|ll|}
\hline \multicolumn{1}{|c|}{ Parâmetro } & \multicolumn{1}{c|}{ Método Analítico } \\
\hline \hline Nitrogênio Amoniacal $^{2}$ & Titulométrico precedido de destilação \\
\hline Nitrito $^{1,2}$ & Colorimétrico \\
\hline Nitrato $^{1,2}$ & $\begin{array}{l}\text { Eletrométrico utilizando eletrodo de íon } \\
\text { específico. }\end{array}$ \\
\hline Sólidos em suspensão & Gravimétrico \\
\hline pH & Eletrométrico \\
\hline Oxigênio Dissolvido & Eletrodo de membrana \\
\hline Temperatura & Termômetro de Mercúrio \\
\hline \hline
\end{tabular}

1 - Imediatamente após a coleta, as amostras foram filtradas em membrana de diâmetro de poro $=0,45$ $\mu \mathrm{m}$;

2 - Imediatamente após a coleta foi acrescentada solução de 2,4,6 Triclorometil Piridina

As concentrações de amônia livre e de ácido nitroso não ionizado foram calculadas baseadas nas equações propostas por Anthonisen et al. (1976): 


$$
\text { Amônia livre }(\operatorname{mg~NH} / \mathrm{L})=\frac{17}{14} \times \frac{\mathrm{NAT} \times 10^{\mathrm{pH}}}{\mathrm{Ka} / \mathrm{Kw}+10^{\mathrm{pH}}}
$$

NAT $=$ Nitrogênio amoniacal total $(\mathrm{mg} \mathrm{N} / \mathrm{L})$

$\mathrm{K}_{\mathrm{a}}=10^{-9,24} \quad$ (Constante de ionização da amônia na condição equilíbrio a $20^{\circ} \mathrm{C}$ )

$\mathrm{K}_{\mathrm{W}}=0,69 \times 10^{-14} \quad\left(\right.$ Constante de ionização da água a $\left.20^{\circ} \mathrm{C}\right)$

$\mathrm{K}_{\mathrm{a}} / \mathrm{K}_{\mathrm{w}}=\mathrm{e}^{(6344 /(273+\mathrm{T})}$

$\mathrm{T}=$ Temperatura $\mathrm{em}^{\circ} \mathrm{C}$

$$
\text { Ácido Nitroso Livre }\left(\mathrm{mg} \mathrm{HNO}_{2} / \mathrm{L}\right)=\frac{46}{14} \times \frac{\left(\mathrm{mg} \mathrm{N}^{-N O}\right.}{\mathrm{K}_{\mathrm{b}} \times 10}=\frac{/ \mathrm{L})}{\mathrm{pH}}
$$

$\mathrm{K}_{\mathrm{b}}=\mathrm{e}^{(-2300 / 273+\mathrm{T})}$

$\mathrm{K}_{\mathrm{b}} \quad$ (constante de ionização do nitrito na condição de equilíbrio)

\subsubsection{FASE 02: PESQUISA DA REMOÇÃO DE NITROGÊNIO AMONIACAL VIA NITRITO UTILIZANDO} FENOL COMO FONTE DE CARBONO:

A pesquisa das características da nitritação e desnitritação, utilizando fenol $(1.000 \mathrm{mg}$ $\mathrm{C}_{6} \mathrm{H}_{5} \mathrm{OH} / \mathrm{L}$ em todas as fases da pesquisa) como fonte de carbono na etapa anóxica, foi conduzida em três etapas distintas que se caracterizaram pelo aumento gradual da concentração de nitrogênio amoniacal no afluente e, conseqüentemente, da carga de nitrogênio amoniacal afluente ao sistema de tratamento, constituído de um reator operado em bateladas seqüenciais com volume útil de 20 litros. A tabela 15 apresenta as concentrações de nitrogênio amoniacal em cada etapa dessa fase da pesquisa.

Tabela 15 - Concentração de nitrogênio amoniacal nas etapas da segunda fase da pesquisa:

\begin{tabular}{|cc|}
\hline \hline ETAPA DA PESQUISA & NITROGÊNIO AMONIACAL \\
\hline \hline 01 & $200 \mathrm{mg} \mathrm{N} / \mathrm{L}$ \\
\hline 02 & $300 \mathrm{mg} \mathrm{N} / \mathrm{L}$ \\
\hline 03 & $500 \mathrm{mg} \mathrm{N} / \mathrm{L}$ \\
\hline
\end{tabular}

A duração das etapas do ciclo de tratamento (enchimento, anóxica, aerada, repouso e descarte) no interior do reator também foi ajustada durante a pesquisa, e não pré-estabelecida. 
A duração dessas etapas é condição para alcance da eficiência do tratamento e remoção dos poluentes. A etapa anóxica era realizada com alimentação e reação concomitante (adição gradual de afluente), podendo prolongar-se a reação anóxica além do tempo destinado à alimentação; esse procedimento visava evitar a ocorrência de cargas de choque de fenol sobre a biomassa. A tabela 16 mostra as condições operacionais utilizadas ao longo da segunda fase da presente pesquisa. 
Tabela 16 - Condições operacionais ao longo da segunda fase da pesquisa:

\begin{tabular}{|c|c|c|c|c|c|c|c|}
\hline \multicolumn{8}{|c|}{ PARÂMETROS } \\
\hline & $\begin{array}{c}\text { Carga de N-NH } \\
\left(\mathrm{g} \mathrm{N}-\mathrm{NH}_{3} / \mathrm{dia}\right)\end{array}$ & $\begin{array}{c}\text { Carga de FENOL } \\
\left(\mathrm{g} \mathrm{C}_{6} \mathrm{H}_{5} \mathrm{OH} / \mathrm{dia}\right)\end{array}$ & $\begin{array}{c}\mathrm{Q} \\
(\mathrm{ml} / \mathrm{min})\end{array}$ & $\begin{array}{l}\text { Temp. } \\
\left({ }^{\circ} \mathrm{C}\right)\end{array}$ & $\begin{array}{c}\mathrm{pH} \\
\text { (etapa aeróbia) }\end{array}$ & $\begin{array}{c}\text { Etapa Aeróbia } \\
\text { (Horas) }\end{array}$ & $\begin{array}{c}\text { Etapa Anóxica } \\
\text { (Horas) }\end{array}$ \\
\hline \multicolumn{8}{|l|}{ Etapa 01} \\
\hline Ciclo 01 & 0,5 & 2,3 & 2,6 & 32 & 8,3 & 15 & 18 \\
\hline Ciclo 02 & 0,5 & 2,3 & 2,5 & 32,5 & 8,3 & 15 & 18 \\
\hline Ciclo 03 & 1,0 & 4,7 & 8,0 & 32 & 8,3 & 15 & 10 \\
\hline Ciclo 04 & 0,9 & 5,0 & 8,3 & 32 & 8,3 & 15 & 10 \\
\hline Ciclo 05 & 1,0 & 4,8 & 8,1 & 33 & 8,3 & 10 & 10 \\
\hline Ciclo 06 & 1,0 & 4,8 & 16,0 & 33 & 8,3 & 10 & 10 \\
\hline Ciclo 07 & 1,0 & 5,0 & 16,0 & 32 & 8,3 & 10 & 10 \\
\hline Ciclo 08 & 1,0 & 4,7 & 8,0 & 33 & 8,3 & 10 & 10 \\
\hline Ciclo 09 & 1,0 & 4,9 & 8,1 & 32 & 8,3 & 10 & 10 \\
\hline Ciclo 10 & 1,0 & 4,7 & 8,0 & 33 & 8,3 & 10 & 10 \\
\hline Ciclo 11 & 1,0 & 4,9 & 8,0 & 33 & 8,3 & 10 & 10 \\
\hline Ciclo 12 & 0,9 & 4,8 & 8,0 & 33 & 8,3 & 10 & 10 \\
\hline \multicolumn{8}{|l|}{ Etapa 02} \\
\hline Ciclo 01 & 1,4 & 4,7 & 5,4 & 25 & 8,3 & 15 & 15 \\
\hline Ciclo 02 & 1,3 & 4,4 & 5,0 & 25 & 8,3 & 15 & 24 \\
\hline Ciclo 03 & 1,4 & 4,9 & 5,0 & 24 & 8,3 & 17 & 22 \\
\hline Ciclo 04 & 1,4 & 4,5 & 5,0 & 24 & 8,3 & 15 & 24 \\
\hline Ciclo 05 & 1,3 & 4,5 & 5,0 & 23,5 & 8,2 & 15 & 24 \\
\hline \multicolumn{8}{|l|}{ Etapa 03} \\
\hline Ciclo 01 & 2,3 & 4,6 & 5,6 & 25 & 7,8 & 24 & 24 \\
\hline Ciclo 02 & 2,6 & 5,0 & 3,5 & 25 & 8,3 & 24 & 24 \\
\hline Ciclo 03 & 2,5 & 5,1 & 3,5 & 25 & 8,3 & 24 & 24 \\
\hline
\end{tabular}


seqüência cronológica das etapas do ciclo de tratamento foi: lançamento gradual de 5,0 litros de despejo sintético, com agitação e sem aeração - reator anóxico com agitação (etapa facultativa) - aeração com agitação - sedimentação sem agitação e sem aeração - descarte de 5,0 litros do sobrenadante através de sifonamento. A figura 11 apresenta cronologicamente as etapas do ciclo.

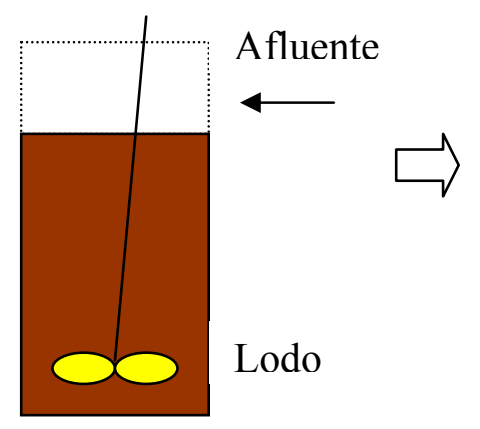

Enchimento com agitação

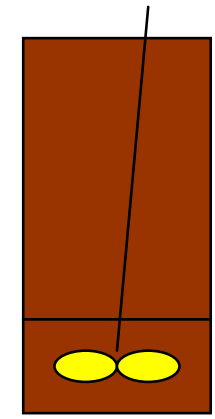

Anóxico

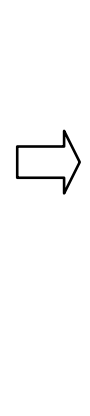

Figura 11: Seqüência cronológica das etapas do ciclo de tratamento.

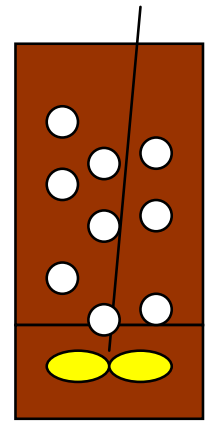

Aeração

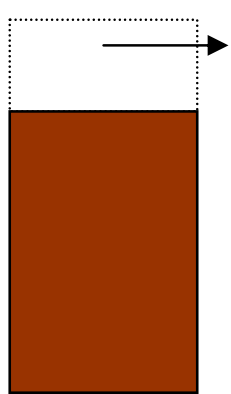

Sedimentação e descarte

A ausência de sólidos em suspensão no afluente (água residuária sintética) definiu os volumes utilizados: 5,0 (cinco) litros de afluente e 15,0 (quinze) litros de lodo biológico em todas etapas da pesquisa; pelo mesmo motivo, o único descarte de lodo realizado era aquele oriundo da realização das análises de laboratório. Investigações anteriores (AUN, 2001) apontaram a necessidade da manutenção de uma concentração de sólidos em suspensão voláteis no conteúdo do reator de tal forma que a relação fenol/SSV fosse inferior a 0,1 dia $^{-1}$ para evitar a inibição da desnitrificação.

Analisando a figura 11, constata-se que o volume descartado (5,0 litros) apresenta uma concentração de nitrogênio oxidado elevada, uma vez que o descarte é realizado após o período aerado do ciclo. Portanto esse efluente necessitaria de um tratamento para redução dessa quantidade de nitrogênio ( 25\%). Realizaram-se, então, alguns testes exploratórios com etanol como fonte de carbono para desnitritação. 
As concentrações de amônia livre e de ácido nitroso livre foram calculadas baseadas nas equações propostas por Anthonisen et al. (1976).

Foram realizadas análises exploratórias investigando a possibilidade de formação de nitrofenóis a partir do contato entre o fenol e nitrito na massa líquida do reator piloto. Esses dois ensaios foram realizados com 1 litro de amostra retirada da massa líquida do reator piloto, decorridas 24 e 36 horas anóxicas, durante a etapa da pesquisa cuja concentração de nitrogênio amoniacal no afluente era de $500 \mathrm{mg}$ N/L. As amostras eram imediatamente filtradas em membrana de diâmetro de poro $0,45 \mu \mathrm{m}$ e preservadas de acordo com (APHA, AWWA, WEF, 1998), para envio ao laboratório.

A extração dos compostos fenólicos da matriz aquosa foi realizada através do método USEPA SW-846 3510C. Para a extração foi utilizado 1 litro de amostra; colocada em funil de separação de 2 litros; acidificada até $\mathrm{pH} \cong 2$. Após a acidificação foi adicionada à amostra quantidade conhecida de compostos surrogate ${ }^{5}$ e o solvente de extração $(60 \mathrm{~mL}$ de diclorometano). Após agitação vigorosa durante cerca de dois minutos e breve repouso, o extrato (fase inferior) foi filtrado em funil contendo lã de vidro e sulfato de sódio. Àquela fase aquosa que permaneceu no funil, foi adicionado $60 \mathrm{~mL}$ de diclorometano e repetiu-se a operação de extração. O extrato obtido foi então concentrado em equipamento KudernaDanish em banho-maria a $70^{\circ} \mathrm{C}$, até volume final de $1 \mathrm{~mL}$.

A análise de fenóis foi realizada de acordo com o método USEPA SW-846 8270D, por GC/MS (Cromatógrafo gasoso acoplado a espectrômetro de massas). O instrumento foi da Hewlett Packard: (Cromatógrafo a gás = 5890 - Séries II) e Espectrômetro de Massas = 5972 com Coluna $=$ DB-5MS.

5 compostos que não são encontrados na natureza, e que servem para monitorar a porcentagem de recuperação obtida durante o processo de extração, nesse caso: 2-Fluorofenol e Fenol-d5. 
A tabela 17 apresenta a seqüência de amostragem e os métodos analíticos de acordo com o Standard Methods (APHA; AWWA; WEF, 1998) aplicados durante a segunda fase da pesquisa.

Tabela 17 - Seqüência de amostragem e métodos analíticos durante a segunda fase da pesquisa:

\begin{tabular}{|c|c|c|c|}
\hline PARÂMETROS & FREQÜÊNCIA & ETAPA & MÉTODOS \\
\hline Compostos Fenólicos & a cada 3 horas & Anóxica e aerada & $\begin{array}{l}\text { Fotométrico direto } \\
\text { precedido de destilação }\end{array}$ \\
\hline D.Q.O. & a cada 3 horas & Anóxica & Refluxo aberto \\
\hline Nitrogênio Amoniacal $^{2}$ & a cada 3 horas & Aerada & $\begin{array}{l}\text { Titulométrico precedido } \\
\text { de destilação }\end{array}$ \\
\hline Nitrito $^{1,2}$ & a cada 3 horas & Anóxica e aerada & Colorimétrico \\
\hline Nitrato ${ }^{1,2}$ & a cada 3 horas & Anóxica e aerada & $\begin{array}{l}\text { Eletrométrico utilizando } \\
\text { eletrodo de íon } \\
\text { específico. }\end{array}$ \\
\hline Nitrofenóis $^{3}$ & Amostras pontuais & Anóxica & $\begin{array}{l}\text { Cromatografia gasosa } \\
\text { associada a } \\
\text { espectrometro de massa }\end{array}$ \\
\hline Alcalinidade & $\begin{array}{c}\text { início e final das } \\
\text { etapas }\end{array}$ & Anóxica e aerada & $\begin{array}{l}\text { Titulação } \\
\text { potenciométrica }\end{array}$ \\
\hline \begin{tabular}{|l|} 
Sólidos em Suspensão \\
Totais (SST) \\
\end{tabular} & diária & início do ciclo & Gravimétrico \\
\hline \begin{tabular}{|l|} 
Sólidos em Suspensão \\
Voláteis (SSV)
\end{tabular} & diária & início do ciclo & Gravimétrico \\
\hline Temperatura & permanente & ----- & $\begin{array}{l}\text { Termômetro de } \\
\text { Mercúrio }\end{array}$ \\
\hline $\mathrm{pH}$ & permanente & ---- & Eletrométrico \\
\hline Potencial Redox & permanente & ---- & Eletrométrico \\
\hline Oxigênio Dissolvido & permanente & ---- & Eletrodo de membrana \\
\hline
\end{tabular}

1 - Imediatamente após a coleta as amostras foram filtradas em membrana de diâmetro de poro $=0,45$ $\mu \mathrm{m}$;

2 - Imediatamente após a coleta foi acrescentada solução de Piridina (composto inibidor da nitrificação);

3 - método USEPA SW-846 8270D utilizando cromatógrafo à Gás 5890 Series II acoplado a Espectrômetro de Massas 5972 - Coluna = DB-5MS. 


\subsection{SEQÜÊNCIA DE CÁlCULO PARA REALIZAÇÃO DOS BALANÇOS DE MASSA:}

Carga de Namoniacal $\left(\mathrm{kg}\right.$ Namoniacal/dia) $=$ Concentração $\mathrm{N}$ amoniacal ${ }_{\text {afluente }} \mathrm{x} \mathrm{Q}_{\text {alimentação }}$ Carga de fenol $\left(\mathrm{kg}\right.$ fenol/dia) $=$ Concentração fenol ${ }_{\text {afluente }} \times \mathrm{Q}_{\text {alimentação }}$ $\mathrm{T}$ - tempo

\subsubsection{INÍ́CIO DA ETAPA AERADA DO CiClO:}

Massa de Namoniacal $=$ Concentração Namoniacal ${ }_{\text {massa liquida }} \mathrm{x}$ Volume da Massa Líquida Massa de $\mathrm{N}-\mathrm{NO}_{2}{ }^{-}=$Concentração $\mathrm{N}^{-\mathrm{NO}_{2}}{ }^{-}$massa líquida $\mathrm{x}$ Volume da Massa Líquida Massa de $\mathrm{N}^{-\mathrm{NO}_{3}}{ }^{-}(\mathrm{mg})=$ Concentração $\mathrm{N}^{-\mathrm{NO}_{3}}{ }^{-}$massa líquida $\mathrm{x}$ Volume da Massa Líquida

\subsubsection{FinAl DA ETAPA AERADA Do Ciclo:}

Massa de Namoniacal $=$ Concentração Namoniacal massa líquida $\mathrm{x}$ (Volume da Massa Líquida - Volume retirado para análises)

Massa de $\mathrm{N}-\mathrm{NO}_{2}{ }^{-}=$Concentração $\mathrm{N}-\mathrm{NO}_{2}{ }^{-}$massa líquida $\mathrm{x}$ (Volume da Massa Líquida - Volume retirado para análises)

Massa de $\mathrm{N}^{-\mathrm{NO}_{3}}{ }^{-}=$Concentração $\mathrm{N}^{-N_{3}}{ }_{3}^{-}$massa líquida $\mathrm{x}$ (Volume da Massa Líquida - Volume retirado para análises)

\subsubsection{INÍCIO DA ETAPA ANÓXICA DO CiClO:}

Massa de $\mathrm{N}-\mathrm{NO}_{2}{ }^{-}=$Massa de N-NO${ }_{2}^{-}$(Final da Etapa Aeróbia) $-($Volume descartado x Concentração $\mathrm{N}-\mathrm{NO}_{2}{ }^{-}$massa líquida )

Massa de $\mathrm{N}^{-\mathrm{NO}_{3}}{ }^{-}(\mathrm{mg})=$ Massa de $\mathrm{N}^{-N_{3}}{ }_{3}^{-}$(Final da Etapa Aeróbia) - (Volume descartado $\mathrm{x}$ Concentração $\mathrm{N}_{-} \mathrm{NO}_{3}^{-}$massa líquida $)$

Volume descartado $=5,0$ litros 


\subsubsection{DURANTE A ETAPA ANÓXICA DO CiClO: (A CADA 3 HORAS)}

Massa de fenol Aplicada a cada 3 horas $=Q_{\text {alimentaça }}$ x 3 horas x Concentração fenol afluente

Massa de fenol ao final de 3 horas $=$ Concentração fenol massa líquida $\times[(15+(\mathrm{Q}$ alimentação $\times 3$ horas $)$ Volume retirado para análises)].

Massa de fenol Utilizada em 3 horas = Massa de fenol Aplicada a cada 3 horas - Massa de fenol ao final de 3 horas

\subsubsection{CÁlCULO DAS EFICIÊNCIAS:}

Remoção de Namoniacal (\%) = Massa de Namoniacal aplicada - Massa de Namoniacal ao final do ciclo x 100 Massa de $\mathrm{N}-\mathrm{NH}_{3}$ aplicada

Remoção de fenol $(\%)=($ Massa de fenol aplicada - Massa de fenol utilizada $) \times 100$ Massa de fenol aplicada

\subsubsection{CÁlculos DAS TAXAS ESPECÍFICAS DE NITRIFICAÇÃO, DESNITRIFICAÇÃO E DESNITRITAÇÃO:}

Taxa de Nitrificação $(\mathrm{kg}$ Namoniacal $/ \mathrm{kg}$ SSV.dia $)=\left(\right.$ Massa de Namoniacal removida $\left./ \mathrm{T}_{1}\right) \times 24$

$\mathrm{T}_{1}=$ Tempo de duração da etapa aeróbia

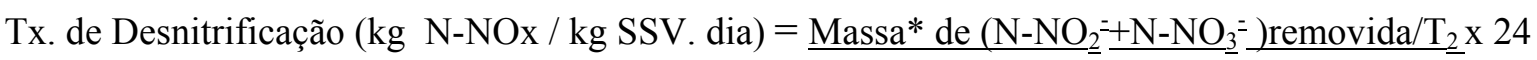

Massa de $\mathrm{SSV}_{\text {massa liquida }}$

Taxa de Desnitritação $=\underline{\text { Massa de N-NO }} 2=$

Massa de SSV massa líquida

$\mathrm{T}_{2}=$ Tempo de duração da etapa anóxica

* Massa de $\mathrm{N}_{-} \mathrm{NO}_{2}{ }^{-}+\mathrm{N}_{-} \mathrm{NO}_{3}{ }^{-}$ao final da etapa anóxica do ciclo de tratamento. 
4.6.7 RELAÇÃo FENOL REMOVIDo/NOX REMOVIDo DURANTE A ETAPA ANÓXICA:

Fenol removido $/ \mathrm{N}-\mathrm{NOx}$ removido $(\mathrm{kg}$ Fenol $/ \mathrm{kg}$ N-NOx $)=\quad$ Massa de fenol removida Massa de $\left(\mathrm{N}-\mathrm{NO}_{2}^{-}+\mathrm{N}-\mathrm{NO}_{3}^{-}\right)$removida $\mathrm{N}-\mathrm{NOx}=\left(\mathrm{N}-\mathrm{NO}_{2}^{-}+\mathrm{N}^{-} \mathrm{NO}_{3}^{-}\right)$ 


\section{APRESENTAÇÃO E DISCUSSÃO DOS RESULTADOS:}

\subsection{FASE 01: TESTES EXPLORATÓRIOS:}

\subsubsection{ETAPA $01-$ TEMPERATURA $\cong 35^{\circ} \mathrm{C}$; $\mathrm{PH} \cong 7,0$.}

A temperatura influencia diretamente a velocidade específica de crescimento dos microrganismos. Durante essa etapa investigou-se a possibilidade da manutenção da temperatura em um valor que, segundo a literatura, (TURK e MAVINIC, 1989; GRUNDITZ e DALHAMMAR ,2001; PHILIPS; LAANBROEK e VERSTRAETE, 2002); favoreceria a

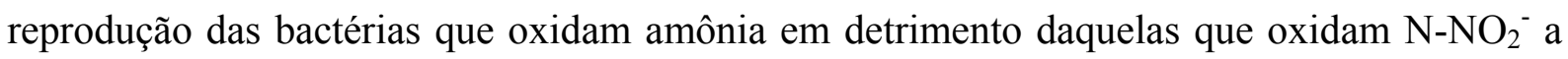
$\mathrm{N}-\mathrm{NO}_{3}{ }^{-}$

$\mathrm{O}$ ajuste de um termostato acoplado a um aquecedor permitiu conservar a temperatura na massa líquida próxima a $35^{\circ} \mathrm{C}$. $\mathrm{O} \mathrm{pH}$ foi mantido na faixa neutra $(\mathrm{pH} \cong 7,0)$ pela adição manual de uma solução de hidróxido de sódio e não houve restrição do fornecimento de $\mathrm{O}_{2}$ ao conteúdo do reator.

A tabela 18 mostra os valores das concentrações de $\mathrm{N}^{-\mathrm{NO}_{2}}{ }^{-}$e $\mathrm{N}-\mathrm{NO}_{3}{ }^{-}$ao longo das 12 horas aeróbias.

Tabela 18 - Concentrações de $\mathrm{N}_{-} \mathrm{NO}_{2}{ }^{-}$e $\mathrm{N}_{-\mathrm{NO}_{3}}{ }^{-}$ao longo de 12 horas aeróbias (Fase 01 Etapa 01)

\begin{tabular}{|l|c|c|c|c|c|c|c|}
\hline & \multicolumn{7}{|c|}{ Horas Aeróbias } \\
\hline & 0 & 2 & 4 & 6 & 8 & 10 & 12 \\
\hline $\mathrm{N}_{-} \mathrm{NO}_{2}{ }^{-}$ & $0,0 \pm 0,1$ & $0,9 \pm 0,5$ & $0,2 \pm 0,2$ & $0,1 \pm 0,1$ & $0,1 \pm 0,1$ & $0,1 \pm 0,1$ & $0,1 \pm 0,2$ \\
\hline $\mathrm{N}_{-} \mathrm{NO}_{3}{ }^{-}$ & $0,0 \pm 0,0$ & $0,5 \pm 0,4$ & $2,0 \pm 1,0$ & $3,8 \pm 1,4$ & $5,8 \pm 1,8$ & $7,5 \pm 2,3$ & $9,4 \pm 2,9$ \\
\hline
\end{tabular}

As figuras 12 e 13 apresentam a distribuição das concentrações de $\mathrm{N}^{-\mathrm{NO}_{2}}{ }^{-}$e $\mathrm{N}^{-\mathrm{NO}_{3}}{ }^{-}$obtidas nos 14 testes realizados com duração de 12 horas aeróbias, deve-se salientar que esse intervalo de tempo não era suficiente para oxidação de todo nitrogênio amoniacal. 


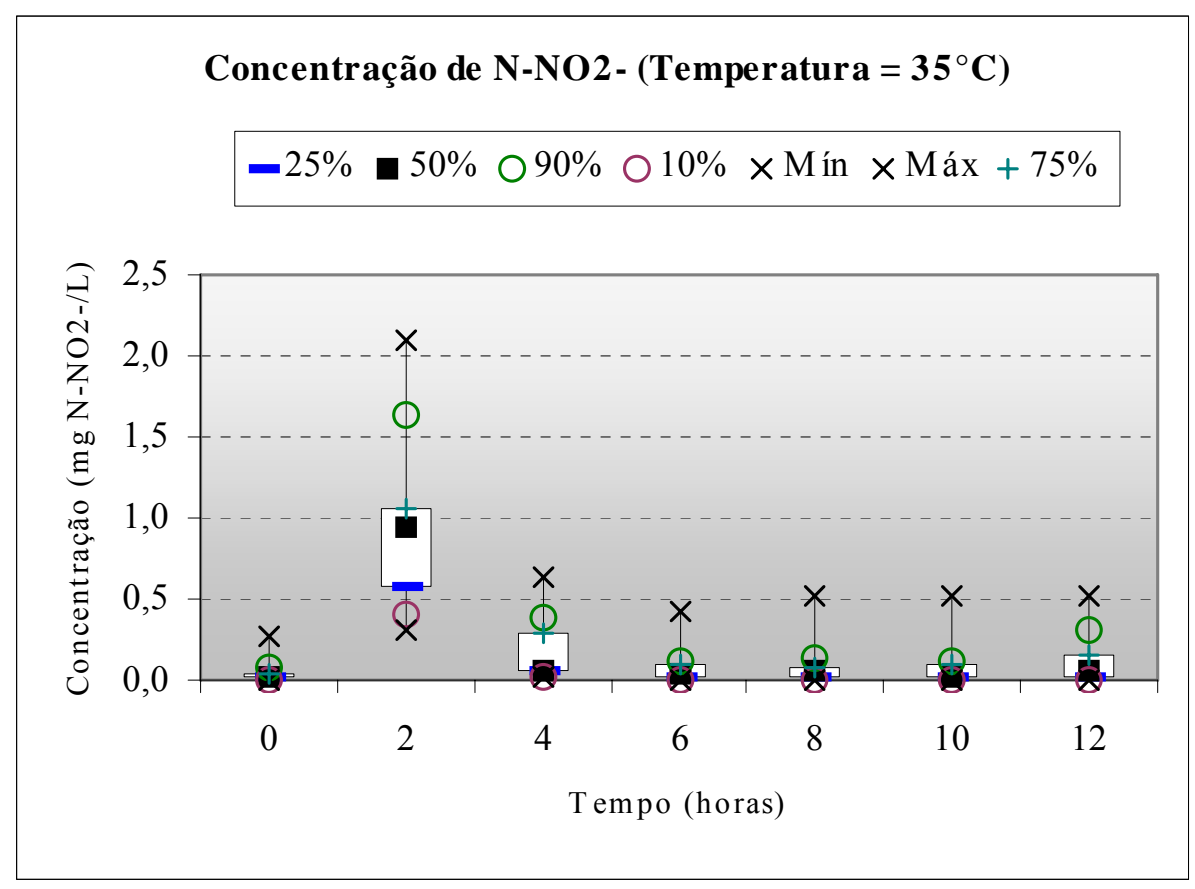

Figura 12: Perfis temporais das concentrações de $\mathrm{N}_{-} \mathrm{NO}_{2}^{-}$, no conteúdo do reator, obtidas ao longo da fase de testes exploratórios (14 testes) - Etapa 01 . ( $\mathrm{T} \cong 35^{\circ} \mathrm{C}$ e $\left.\mathrm{pH} \cong 7,0\right)$.

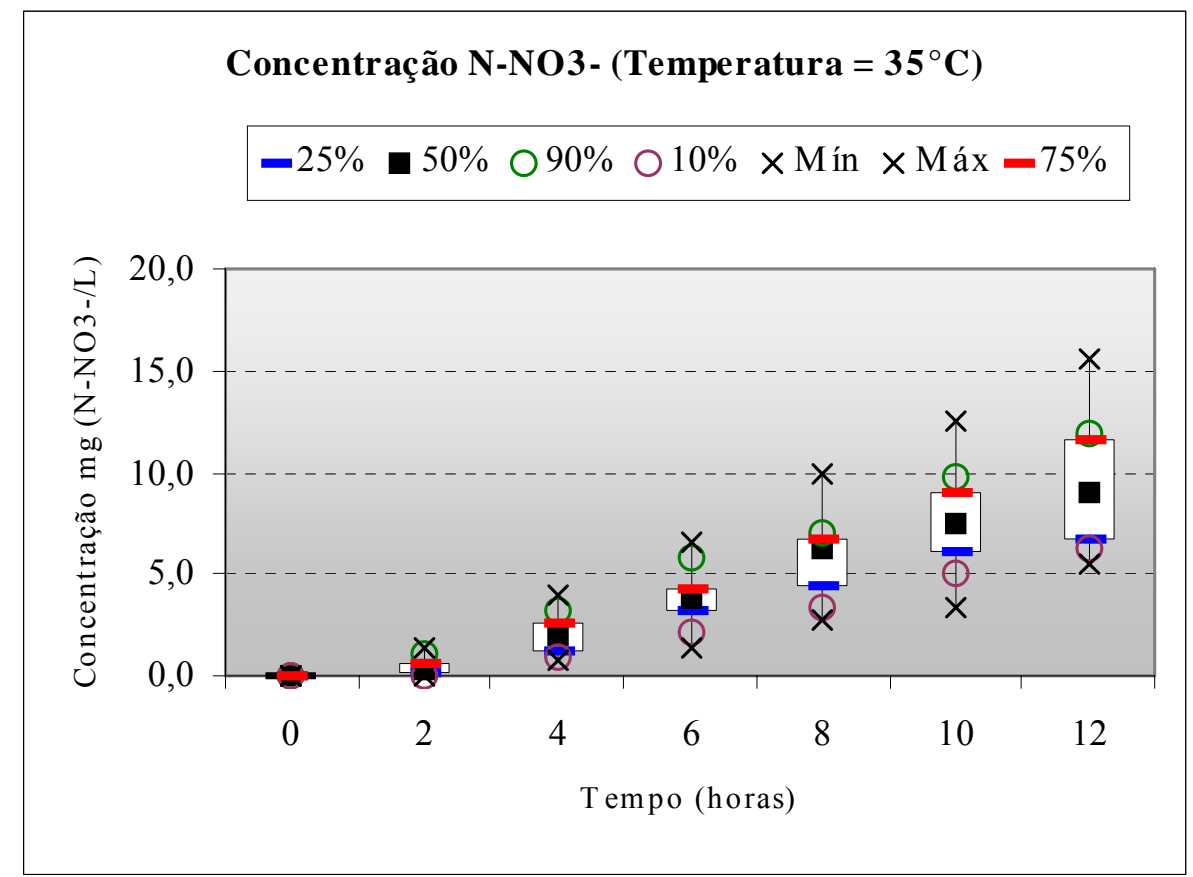

Figura 13: Perfis temporais das concentrações de $\mathrm{N}_{-} \mathrm{NO}_{3}{ }^{-}$, no conteúdo do reator, obtidas ao longo da fase de testes exploratórios (14 testes) - Etapa 01 . ( $\mathrm{T} \cong 35^{\circ} \mathrm{C}$ e $\left.\mathrm{pH} \cong 7,0\right)$. 
As figuras 12 e 13 apontam que apenas a manutenção da temperatura em valores considerados pela literatura como inibidores da atividade das bactérias que oxidam nitrito, não foi eficiente para promover o acúmulo de $\mathrm{N}_{-} \mathrm{NO}_{2}{ }^{-}$no conteúdo do reator.

A relação $\mathrm{N}^{-\mathrm{NO}_{2}}{ }^{-} /\left(\mathrm{N}_{-} \mathrm{NO}_{2}{ }^{-}+\mathrm{N}^{-\mathrm{NO}_{3}}{ }^{-}\right)$, calculada como a média dos 14 valores obtidos, foi igual a $1 \%$, enquanto a relação $\mathrm{N}_{-} \mathrm{NO}_{3}{ }^{-} /\left(\mathrm{N}_{-} \mathrm{NO}_{2}{ }^{-}+\mathrm{N}^{-} \mathrm{NO}_{3}{ }^{-}\right)$igual a $99 \%$; expressando assim a predominância do nitrato ao final dos ciclos aerados.

O valor médio das eficiências de remoção de nitrogênio amoniacal foi de 59\%, tal fato está associado à duração do ciclo aerado (12 horas).

O procedimento operacional, descartando todo conteúdo do béquer ao final do teste, pode ter contribuído para o insucesso dessa estratégia, uma vez que o inóculo era proveniente de um sistema de lodos ativados com nitrificação total. A manutenção de baixas idades do lodo associado a elevadas temperaturas (processo SHARON) em longo prazo poderia ter promovido o acúmulo de nitrito; "lavando" do sistema as bactérias que oxidam nitrito; entretanto tal estratégia foi descartada, função da característica da água residuária, pois essa sendo sintética, não possui sólidos em suspensão na sua composição e portanto a adoção de baixas idades do lodo poderia descartar do sistema de tratamento outros grupos de microrganismos, inclusive aqueles que oxidam amônia.

\subsubsection{ETAPA $02-$ TEMPERATURA $\cong 30^{\circ} \mathrm{C}$; AERAÇÃO INTERMITENTE; $\mathrm{PH} \cong 7,0$ :}

Essa etapa buscou investigar a possibilidade de acúmulo de nitrito com controle do fornecimento de ar ao conteúdo do reator. A estratégia baseia-se na limitação da transferência de oxigênio para dentro do floco biológico, o que, teoricamente, favoreceria as bactérias que oxidam amônia em detrimento daquelas que oxidam $\mathrm{N}_{-} \mathrm{NO}_{2}{ }^{-}$a $\mathrm{N}-\mathrm{NO}_{3}{ }^{-}$. 
Para o desenvolvimento dessa etapa instalou-se um timer programável em intervalos de tempo múltiplos de 15 minutos. As figuras 14 e 15 apresentam a distribuição das concentrações de N-NO${ }_{2}{ }^{-}$e $\mathrm{N}^{-\mathrm{NO}_{3}}{ }_{3}^{-}$dos 6 testes realizados com a programação de 15 minutos aerados e 15 sem aeração, ao longo de 12 horas.

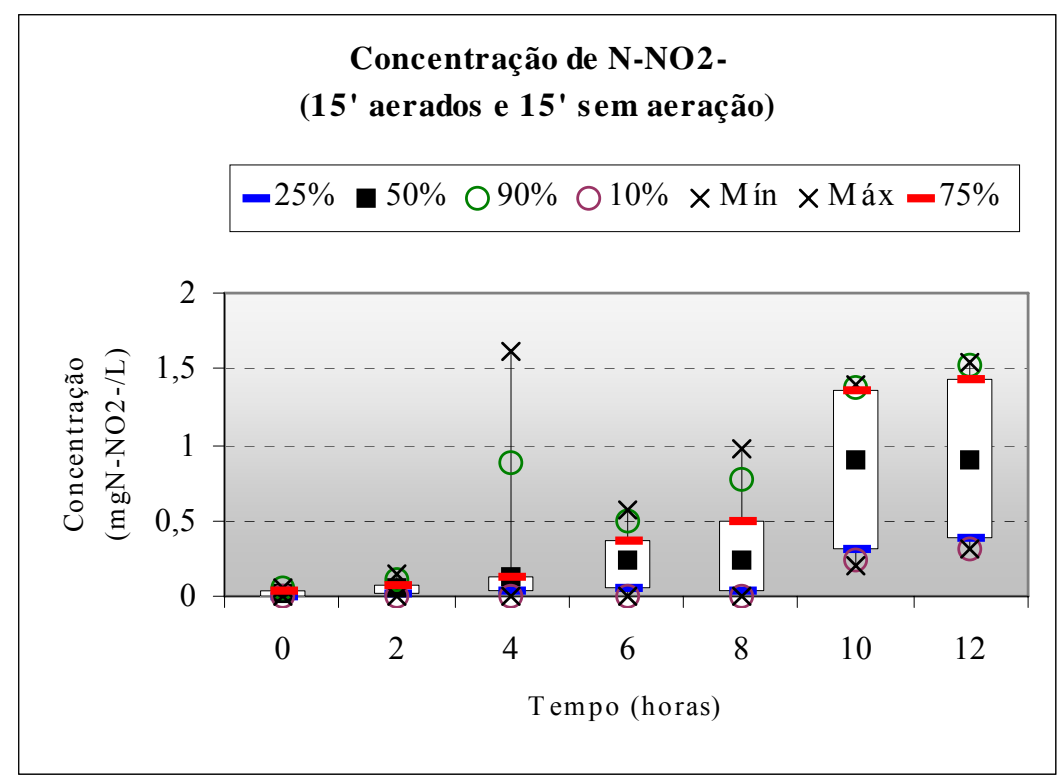

Figura 14: Perfis temporais das concentrações de $\mathrm{N}^{-\mathrm{NO}_{2}}{ }^{-}$, no conteúdo do reator, obtidas ao longo de 6 testes exploratórios - Etapa 02 (15' aerados e 15' sem aeração); $\mathrm{T} \cong 30^{\circ} \mathrm{C}$ e $\mathrm{pH} \cong 7,0$.

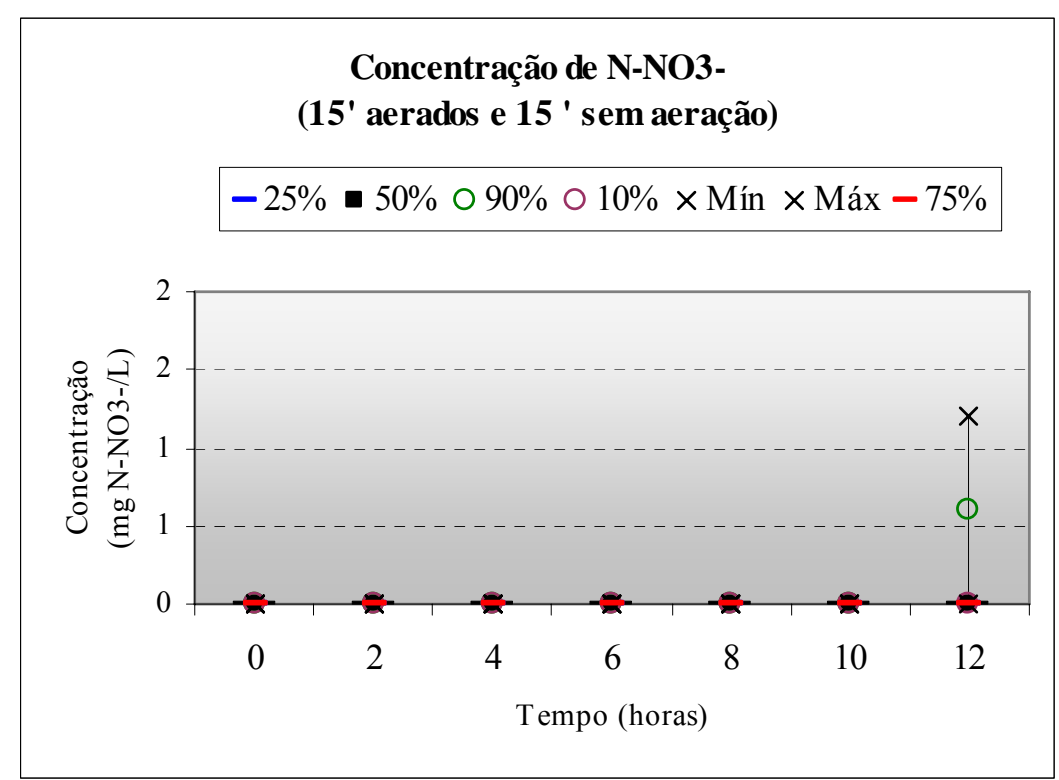

Figura 15: Perfis temporais das concentrações de $\mathrm{N}^{-\mathrm{NO}_{3}}{ }^{-}$, no conteúdo do reator, obtidas ao longo de 6 testes exploratórios - Etapa 02 (15' aerados e 15' sem aeração); $\mathrm{T} \cong 30^{\circ} \mathrm{C}$ e $\mathrm{pH} \cong 7,0$. 
A tabela 19 mostra as médias dos valores de $\mathrm{N}^{-\mathrm{NO}_{2}}{ }^{-}$e $\mathrm{N}_{-\mathrm{NO}_{3}}{ }^{-}$obtidos ao longo dos seis testes com programação de $15^{\prime}$ aeróbios e $15^{\prime}$ sem aeração, ao longo de doze horas.

Tabela 19 - Concentrações de $\mathrm{N}^{-\mathrm{NO}_{2}}{ }^{-}$e $\mathrm{N}_{-} \mathrm{NO}_{3}{ }^{-}$ao longo de 12 horas aeróbias; Fase 01 Etapa 02 - (15' aeróbios e $15^{\prime}$ sem aeração, ao longo de doze horas).

\begin{tabular}{|l|c|c|c|c|c|c|c|}
\hline & \multicolumn{7}{|c|}{ Horas Aeróbias } \\
\hline & 0 & 2 & 4 & 6 & 8 & 10 & 12 \\
\hline $\mathrm{N}_{-} \mathrm{NO}_{2}{ }^{-}$ & $0,0 \pm 0,0$ & $0,1 \pm 0,1$ & $0,3 \pm 0,6$ & $0,2 \pm 0,2$ & $0,3 \pm 0,4$ & $0,8 \pm 0,6$ & $0,9 \pm 0,6$ \\
\hline $\mathrm{N}_{-} \mathrm{NO}_{3}^{-}$ & $0,0 \pm 0,0$ & $0,0 \pm 0,0$ & $0,0 \pm 0,0$ & $0,0 \pm 0,0$ & $0,0 \pm 0,0$ & $0,0 \pm 0,0$ & $0,2 \pm 0,5$ \\
\hline
\end{tabular}

Os cálculos de balanço de massa revelaram que com a estratégia adotada não era possível alcançar eficiências satisfatórias de oxidação de $\mathrm{N}^{-\mathrm{NH}_{3}}$. Programando 15 ' aerados seguidas de $15^{\prime}$ sem aeração, ao longo das doze horas, a eficiência média de remoção de $\mathrm{N}^{-\mathrm{NH}_{3}}$ foi de apenas $16 \%$.

Diante dos resultados obtidos, programou-se 30 minutos aerados e 15 minutos sem aeração. Realizando 4 testes, alcançou-se eficiência média de remoção de nitrogênio amoniacal de $36 \%$, porém não se obteve predominância do $\mathrm{N}^{-\mathrm{NO}_{2}}{ }^{-}$, uma vez que a relação $\mathrm{N}-\mathrm{NO}_{3}{ }^{-} /\left(\mathrm{N}_{-}-\mathrm{NO}_{2}{ }^{-}\right.$ $+\mathrm{N}_{-} \mathrm{NO}_{3}{ }^{-}$) alcançou 70\%. A tabela 20 mostra as médias dos valores de $\mathrm{N}^{-\mathrm{NO}_{2}}{ }^{-}$e $\mathrm{N}_{-\mathrm{NO}_{3}}^{-}$ obtidos ao longo dos quatro testes com programação de 30' aeróbios e 15' sem aeração, ao longo de doze horas, e as figuras 16 e 17 apresentam a distribuição temporal dessas concentrações.

Tabela 20 - Concentrações de $\mathrm{N}^{-\mathrm{NO}_{2}}{ }^{-}$e $\mathrm{N}^{-\mathrm{NO}_{3}}{ }^{-}$ao longo de 12 horas aeróbias; Fase 01 Etapa 02 - (30' aeróbios e 15' sem aeração, ao longo de doze horas).

\begin{tabular}{|l|c|c|c|c|c|c|c|}
\hline & \multicolumn{7}{|c|}{ Horas Aeróbias } \\
\hline & 0 & 2 & 4 & 6 & 8 & 10 & 12 \\
\hline $\mathrm{N}_{-}-\mathrm{NO}_{2}{ }^{-}$ & $0,0 \pm 0,0$ & $0,1 \pm 0,0$ & $0,4 \pm 0,1$ & $0,7 \pm 0,1$ & $1,0 \pm 0,1$ & $1,2 \pm 0,2$ & $1,9 \pm 0,3$ \\
\hline $\mathrm{N}_{-} \mathrm{NO}_{3}{ }^{-}$ & $0,0 \pm 0,0$ & $0,6 \pm 0,2$ & $1,8 \pm 0,7$ & $2,3 \pm 1,2$ & $1,1 \pm 0,4$ & $3,5 \pm 1,7$ & $4,5 \pm 1,8$ \\
\hline
\end{tabular}




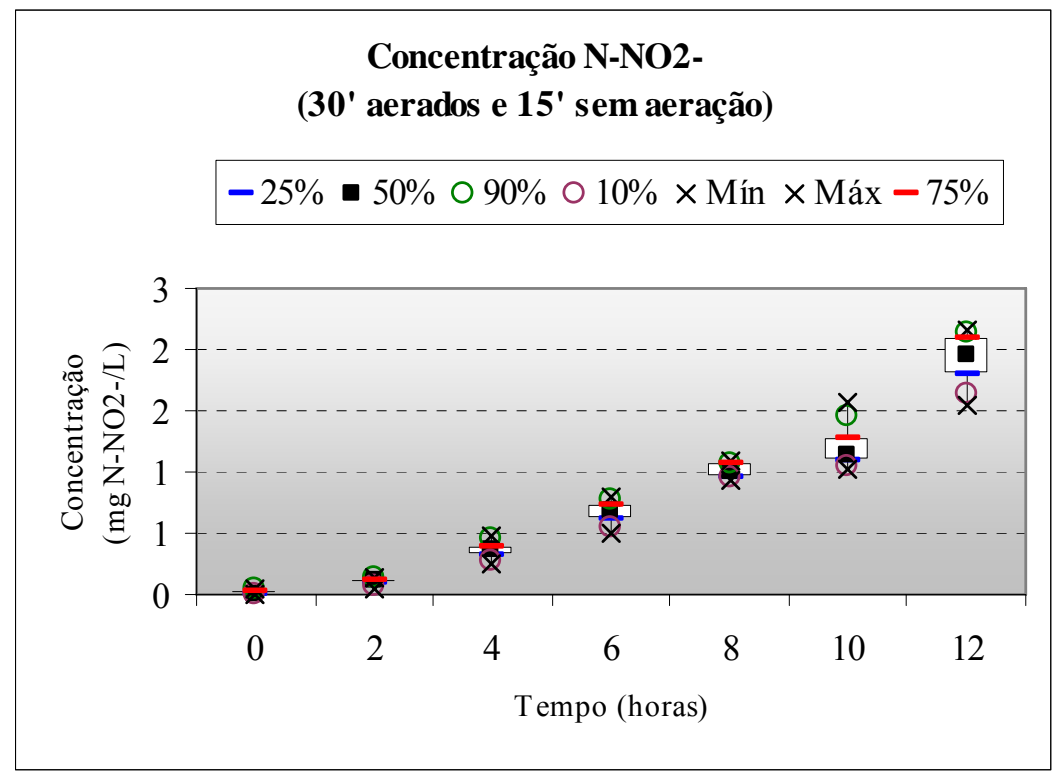

Figura 16: Perfis temporais das concentrações de $\mathrm{N}^{-\mathrm{NO}_{2}}{ }^{-}$, no conteúdo do reator, obtidas ao longo de 4 testes exploratórios - Etapa 02 (30' aerados e 15' sem aeração); $\mathrm{T} \cong 30,5^{\circ} \mathrm{C}$ e $\mathrm{pH} \cong 7,0$.

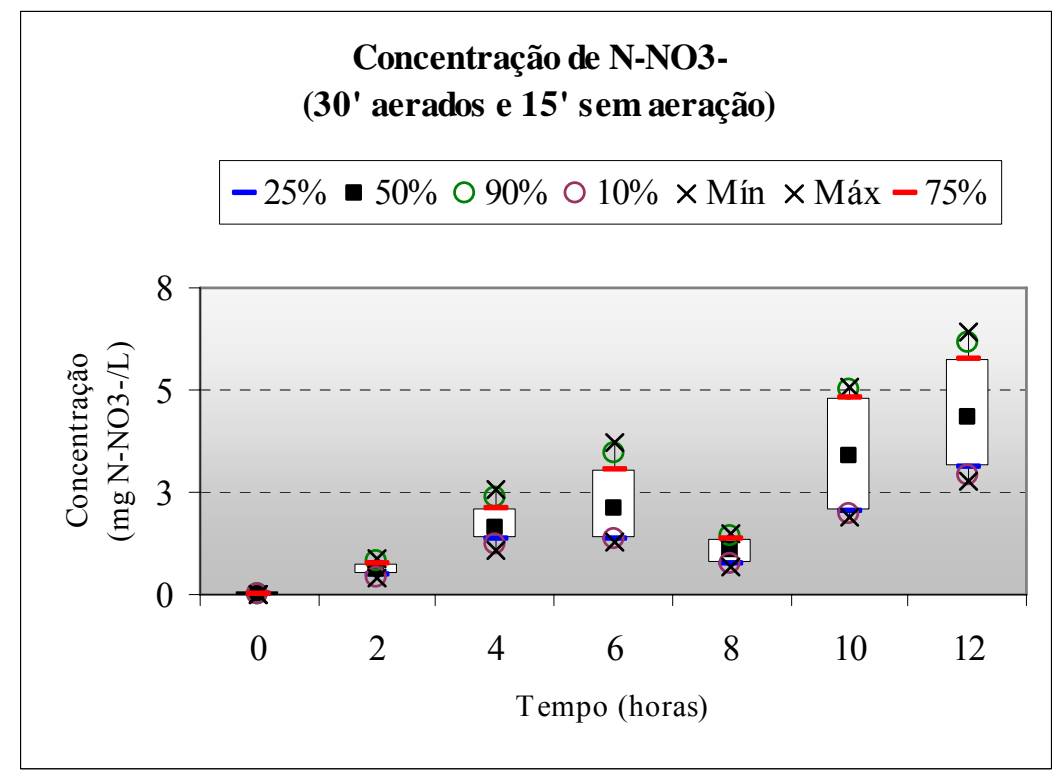

Figura 17: Perfis temporais das concentrações de $\mathrm{N}^{-\mathrm{NO}_{3}}{ }^{-}$, no conteúdo do reator, obtidas ao longo de 4 testes exploratórios - Etapa 02 (30' aerados e 15' sem aeração); $\mathrm{T} \cong 30,5^{\circ} \mathrm{C}$ e $\mathrm{pH} \cong 7,0$.

Finalmente, com 45 minutos aerados e 15 sem aeração realizaram-se 6 testes; totalizando 16 testes com a estratégia de intermitência do fornecimento de ar. Essa última estratégia permitiu a obtenção de eficiência média de remoção de $\mathrm{N}^{-\mathrm{NH}_{3}}$ igual a $68 \%$, entretanto, como 
evidenciam as figuras 18 e 19 e os resultados da tabela 21 , não foi possível obter a predominância do nitrito ao final dos testes.

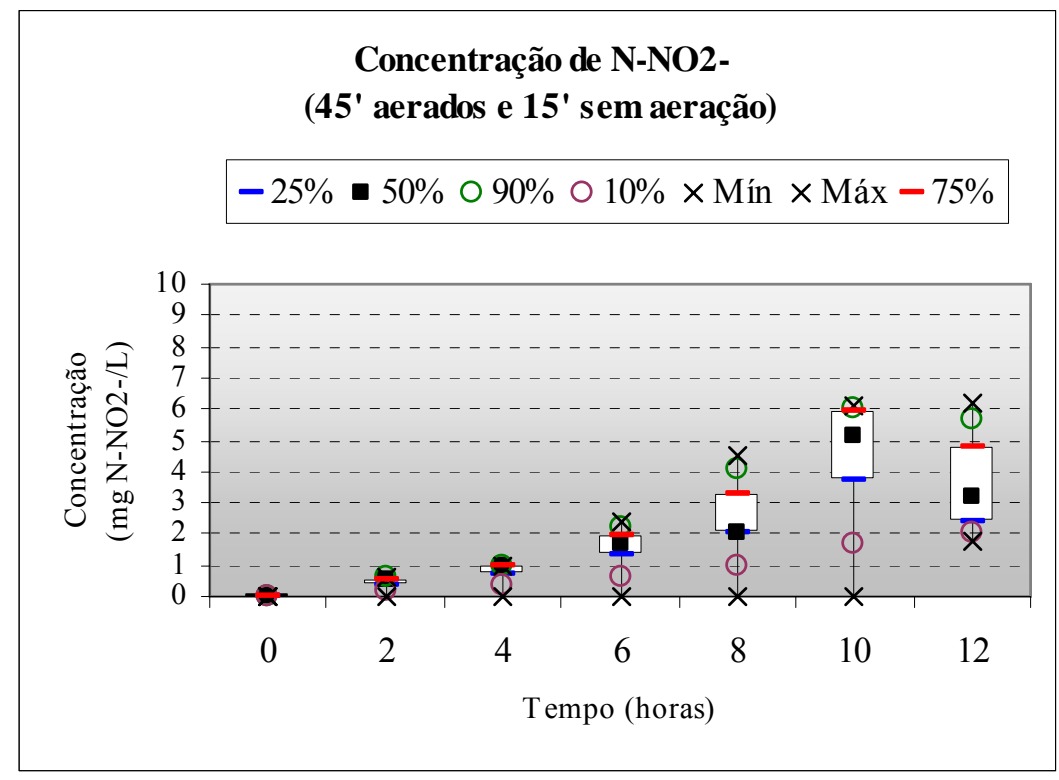

Figura 18: Perfis temporais das concentrações de $\mathrm{N}^{-\mathrm{NO}_{2}}{ }^{-}$, no conteúdo do reator, obtidas ao longo de 6 testes exploratórios - Etapa 02 (45' aerados e 15' sem aeração); $\mathrm{T} \cong 30^{\circ} \mathrm{C}$ e $\mathrm{pH} \cong 7,0$.

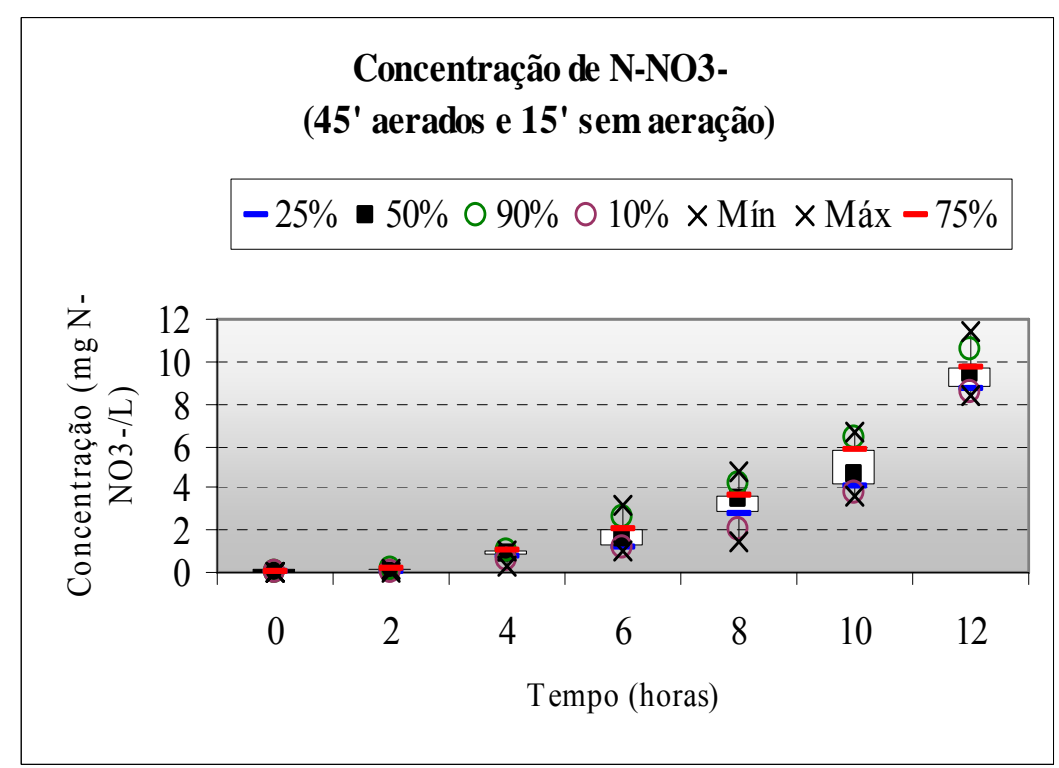

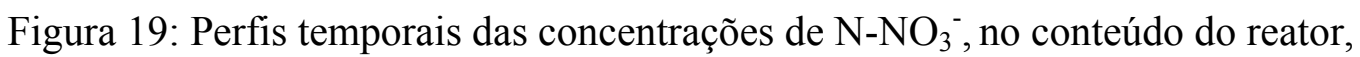
obtidas ao longo de 6 testes exploratórios - Etapa 02 (45' aerados e 15' sem aeração); $\mathrm{T} \cong 30^{\circ} \mathrm{C}$ e $\mathrm{pH} \cong 7,0$. 
Tabela 21 - Concentrações de $\mathrm{N}^{-\mathrm{NO}_{2}}{ }^{-}$e $\mathrm{N}_{-} \mathrm{NO}_{3}{ }^{-}$ao longo de 12 horas aeróbias; Fase 01 Etapa $02-$ (45' aeróbios e $15^{\prime}$ sem aeração, ao longo de doze horas).

\begin{tabular}{|l|c|c|c|c|c|c|c|}
\hline & \multicolumn{7}{|c|}{ Horas Aeróbias } \\
\hline & 0 & 2 & 4 & 6 & 8 & 10 & 12 \\
\hline $\mathrm{N}_{-} \mathrm{NO}_{2}{ }^{-}$ & $0,0 \pm 0,0$ & $0,4 \pm 0,2$ & $0,7 \pm 0,4$ & $1,5 \pm 0,8$ & $2,4 \pm 1,6$ & $4,3 \pm 2,3$ & $3,6 \pm 1,7$ \\
\hline $\mathrm{N}^{-} \mathrm{NO}_{3}{ }^{-}$ & $0,0 \pm 0,0$ & $0,1 \pm 0,1$ & $0,8 \pm 0,3$ & $1,7 \pm 0,8$ & $3,2 \pm 1,1$ & $4,9 \pm 1,2$ & $9,5 \pm 1,1$ \\
\hline
\end{tabular}

Essa etapa revelou que as estratégias adotadas, limitando o fornecimento de ar através da aeração intermitente, conduz a redução da eficiência de remoção do nitrogênio amoniacal, além de não evidenciar a predominância do nitrito no conteúdo do reator.

\subsubsection{ETAPA 03 - INVESTIGAÇÃO DO ACÚMULO DE NITRITO ATRAVÉS DA MANIPULAÇÃO DO $\mathrm{pH}$ :}

A incapacidade para promover a inibição das bactérias que oxidam nitrito levou a investigação do efeito de outro parâmetro considerado limitante da atividade desses microrganismos.

Mantendo o $\mathrm{pH}$ em valores pré-determinados estudou-se qual a forma oxidada de nitrogênio amoniacal que prevalecia no conteúdo do reator. Foram realizados 15 testes, dos quais: 4 mantendo $\mathrm{pH}$ próximo a 7,5; 6 testes com o valor do $\mathrm{pH}$ controlado em torno de 7,8; e, finalmente 5 testes com $\mathrm{pH}$ próximo de 8,0. Durante essa etapa, a temperatura foi mantida em torno de $30^{\circ} \mathrm{C}$ e não houve limitação do fornecimento de oxigênio As figuras $20,21,22,23$, 24 e 25 apresentam a distribuição temporal das concentrações de $\mathrm{N}_{-} \mathrm{NO}_{2}{ }^{-}$e $\mathrm{N}_{-} \mathrm{NO}_{3}{ }^{-}$ao longo das doze horas com fornecimento de oxigênio. A tabela 22 mostra os resultados para os três valores de $\mathrm{pH}$. 
Tabela 22 - Concentrações de $\mathrm{N}_{-} \mathrm{NO}_{2}{ }^{-}$e $\mathrm{N}^{-\mathrm{NO}_{3}}{ }^{-}$ao longo de 12 horas aeróbias (Fase 01 Etapa 02$)-\mathrm{pH}$ na faixa entre 7,5 e $8,0\left(\mathrm{~T}=30^{\circ} \mathrm{C}\right)$.

\begin{tabular}{|c|c|c|c|c|c|c|c|}
\hline \multicolumn{8}{|c|}{$\mathrm{pH}=7,5$} \\
\hline \multicolumn{8}{|c|}{ Horas Aeróbias } \\
\hline & 0 & 2 & 4 & 6 & 8 & 10 & 12 \\
\hline $\mathrm{N}^{-\mathrm{NO}_{2}}{ }^{-}$ & $0,0 \pm 0,0$ & $0,3 \pm 0,4$ & $0,6 \pm 0,7$ & $0,5 \pm 0,3$ & $0,8 \pm 0,5$ & $1,4 \pm 0,9$ & $1,5 \pm 1,4$ \\
\hline $\mathrm{N}^{-\mathrm{NO}_{3}}{ }^{-}$ & $0,0 \pm 0,0$ & $0,5 \pm 0,5$ & $2,0 \pm 1,2$ & $3,4 \pm 2,3$ & $6,3 \pm 2,4$ & $8,0 \pm 1,9$ & $8,9 \pm 2,0$ \\
\hline \multicolumn{8}{|c|}{$\mathrm{pH}=7,8$} \\
\hline \multicolumn{8}{|c|}{ Horas Aeróbias } \\
\hline & 0 & 2 & 4 & 6 & 8 & 10 & 12 \\
\hline $\mathrm{N}^{-\mathrm{NO}_{2}}{ }^{-}$ & $0,0 \pm 0,1$ & $0,3 \pm 0,4$ & $1,2 \pm 1,0$ & $1,1 \pm 1,6$ & $2,2 \pm 2,2$ & $4,6 \pm 3,6$ & $5,8 \pm 4,6$ \\
\hline $\mathrm{N}^{-\mathrm{NO}_{3}}{ }^{-}$ & $0,0 \pm 0,0$ & $0,1 \pm 0,2$ & $0,5 \pm 0,3$ & $1,2 \pm 1,0$ & $2,2 \pm 1,3$ & $4,2 \pm 1,9$ & $6,3 \pm 2,9$ \\
\hline \multicolumn{8}{|c|}{$\mathrm{pH}=\mathbf{8 , 0}$} \\
\hline \multicolumn{8}{|c|}{ Horas Aeróbias } \\
\hline & 0 & 2 & 4 & 6 & 8 & 10 & 12 \\
\hline $\mathrm{N}^{-\mathrm{NO}_{2}}{ }^{-}$ & $0,1 \pm 0,1$ & $1,5 \pm 0,4$ & $3,9 \pm 1,4$ & $6,0 \pm 1,7$ & $8,1 \pm 1,0$ & $9,4 \pm 1,4$ & $11,6 \pm 1,6$ \\
\hline $\mathrm{N}^{-\mathrm{NO}_{3}}{ }^{-}$ & $0,0 \pm 0,0$ & $0,1 \pm 0,2$ & $0,6 \pm 0,8$ & $0,5 \pm 0,5$ & $0,6 \pm 0,4$ & $0,8 \pm 0,6$ & $1,3 \pm 0,8$ \\
\hline
\end{tabular}

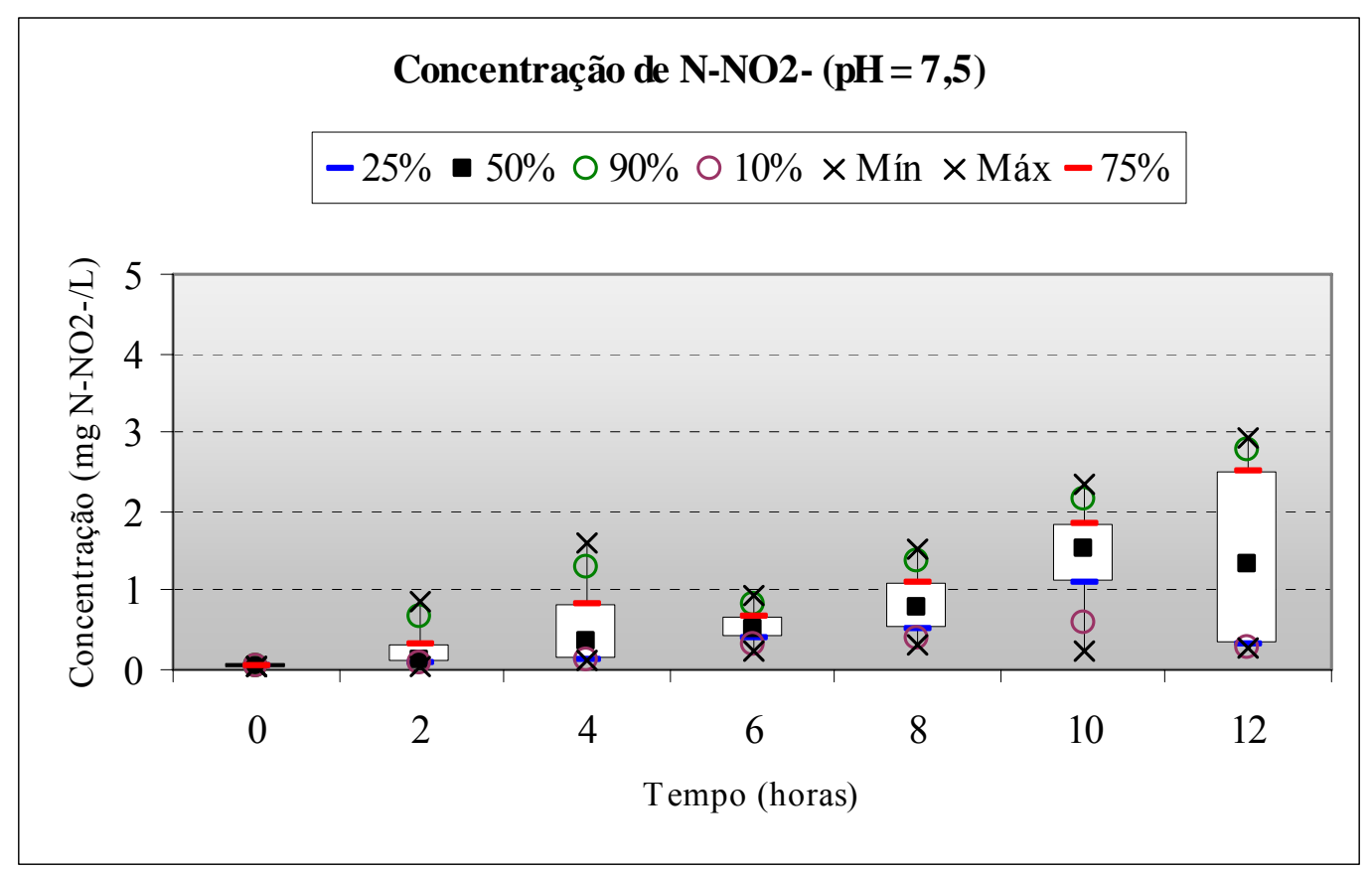

Figura 20: Perfis temporais das concentrações de $\mathrm{N}_{-\mathrm{NO}_{2}}{ }^{-}$, no conteúdo do reator, obtidas ao longo de 4 testes exploratórios - Etapa $02 ; \mathrm{T} \cong 30^{\circ} \mathrm{C}$ e $\mathrm{pH} \cong 7,5$. 


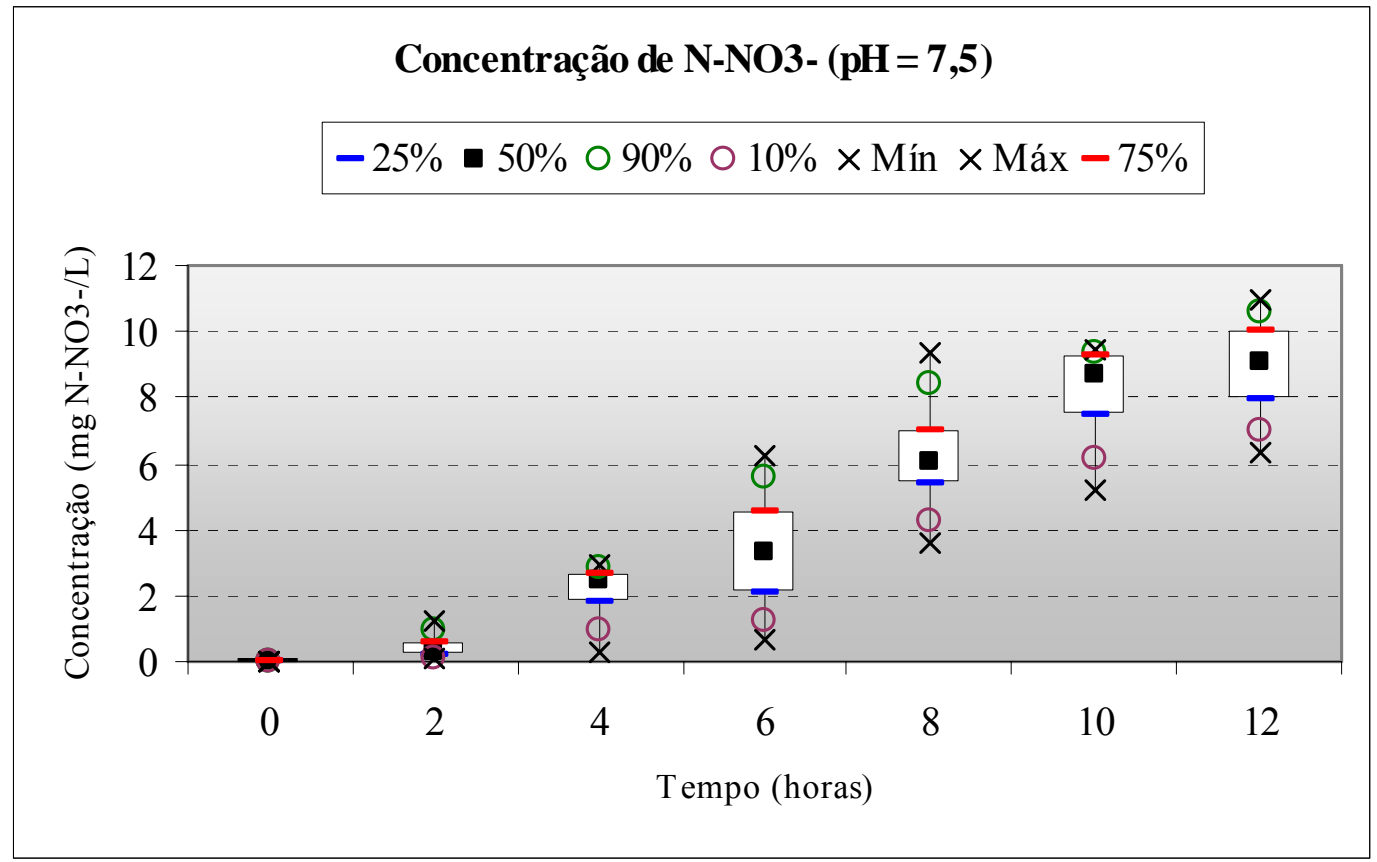

Figura 21: Perfis temporais das concentrações de $\mathrm{N}_{-} \mathrm{NO}_{3}{ }^{-}$, no conteúdo do reator, obtidas ao longo de 4 testes exploratórios - Etapa $02 ; \mathrm{T} \cong 30^{\circ} \mathrm{C}$ e $\mathrm{pH} \cong 7,5$.

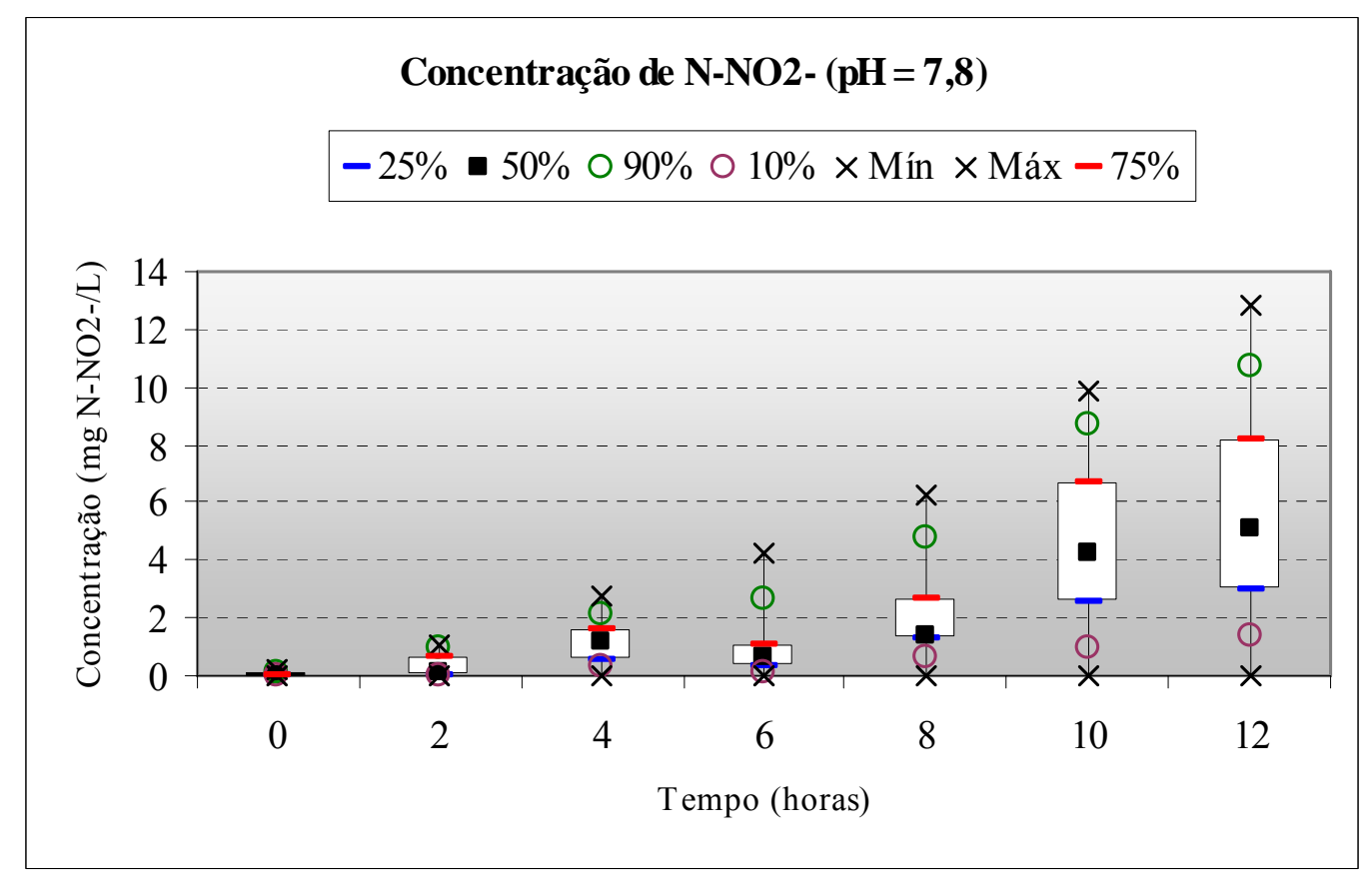

Figura 22: Perfis temporais das concentrações de $\mathrm{N}^{-\mathrm{NO}_{2}}{ }^{-}$, no conteúdo do reator, obtidas ao longo de 6 testes exploratórios - Etapa $02 ; \mathrm{T} \cong 30^{\circ} \mathrm{C}$ e $\mathrm{pH} \cong 7,8$. 


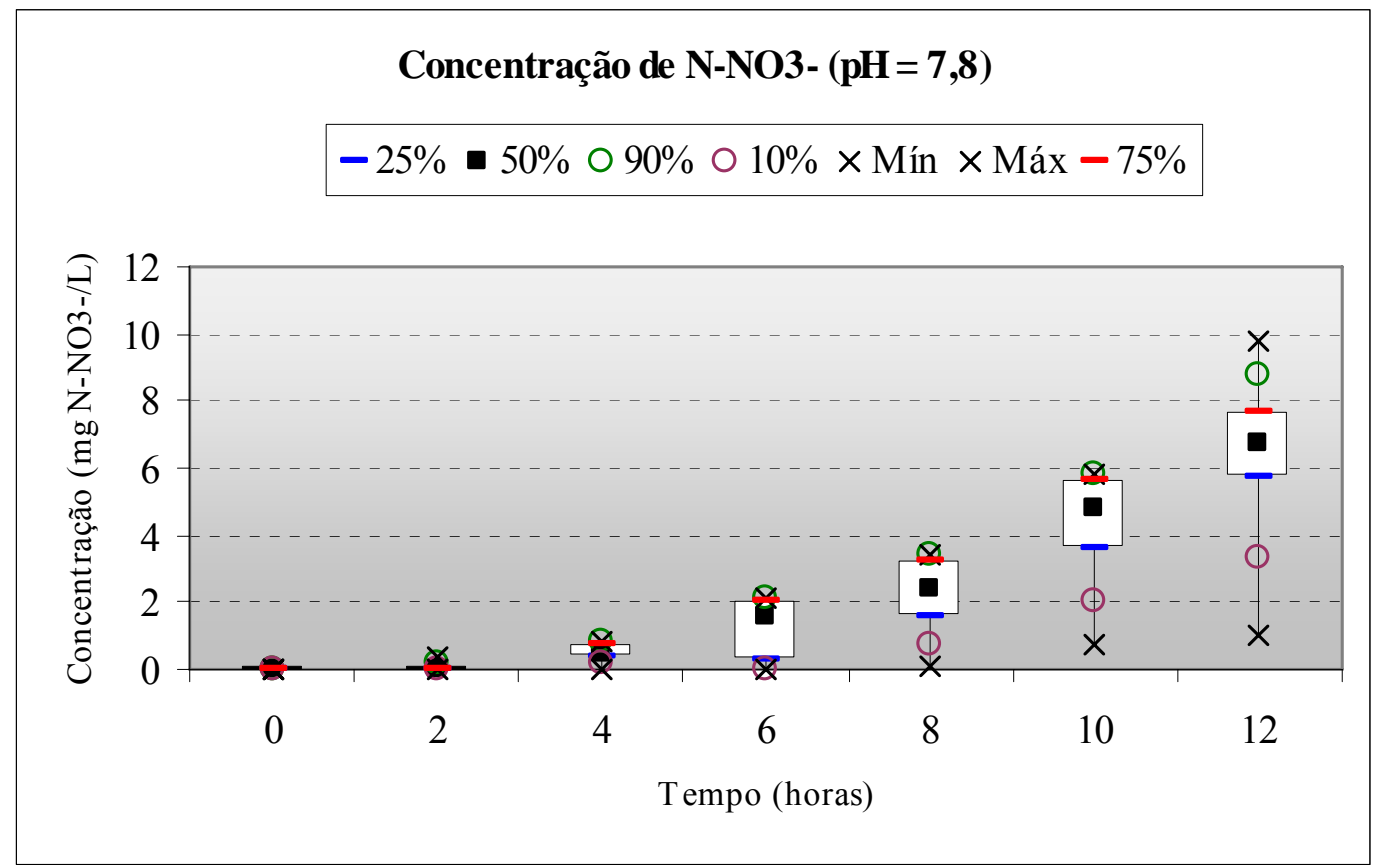

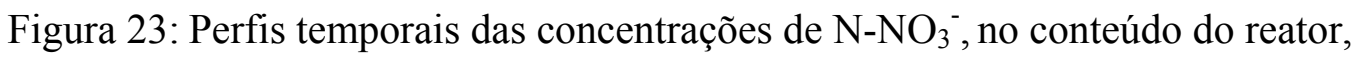
obtidas ao longo de 6 testes exploratórios - Etapa $02 ; \mathrm{T} \cong 30^{\circ} \mathrm{C}$ e $\mathrm{pH} \cong 7,8$.

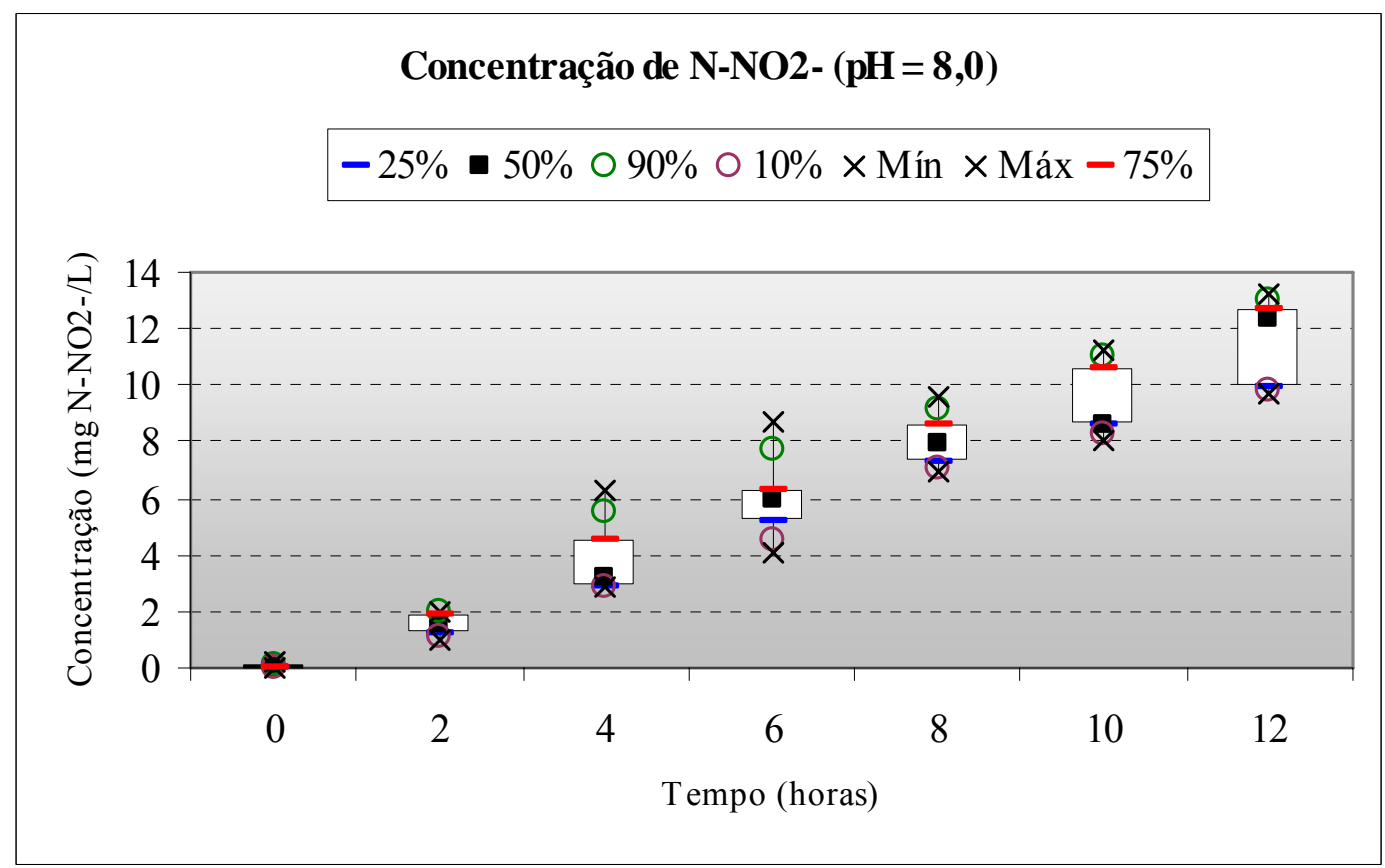

Figura 24: Perfis temporais das concentrações de $\mathrm{N}^{-\mathrm{NO}_{2}}{ }^{-}$, no conteúdo do reator, obtidas ao longo de 6 testes exploratórios - Etapa $02 ; \mathrm{T} \cong 30^{\circ} \mathrm{C}$ e $\mathrm{pH} \cong 8,0$. 


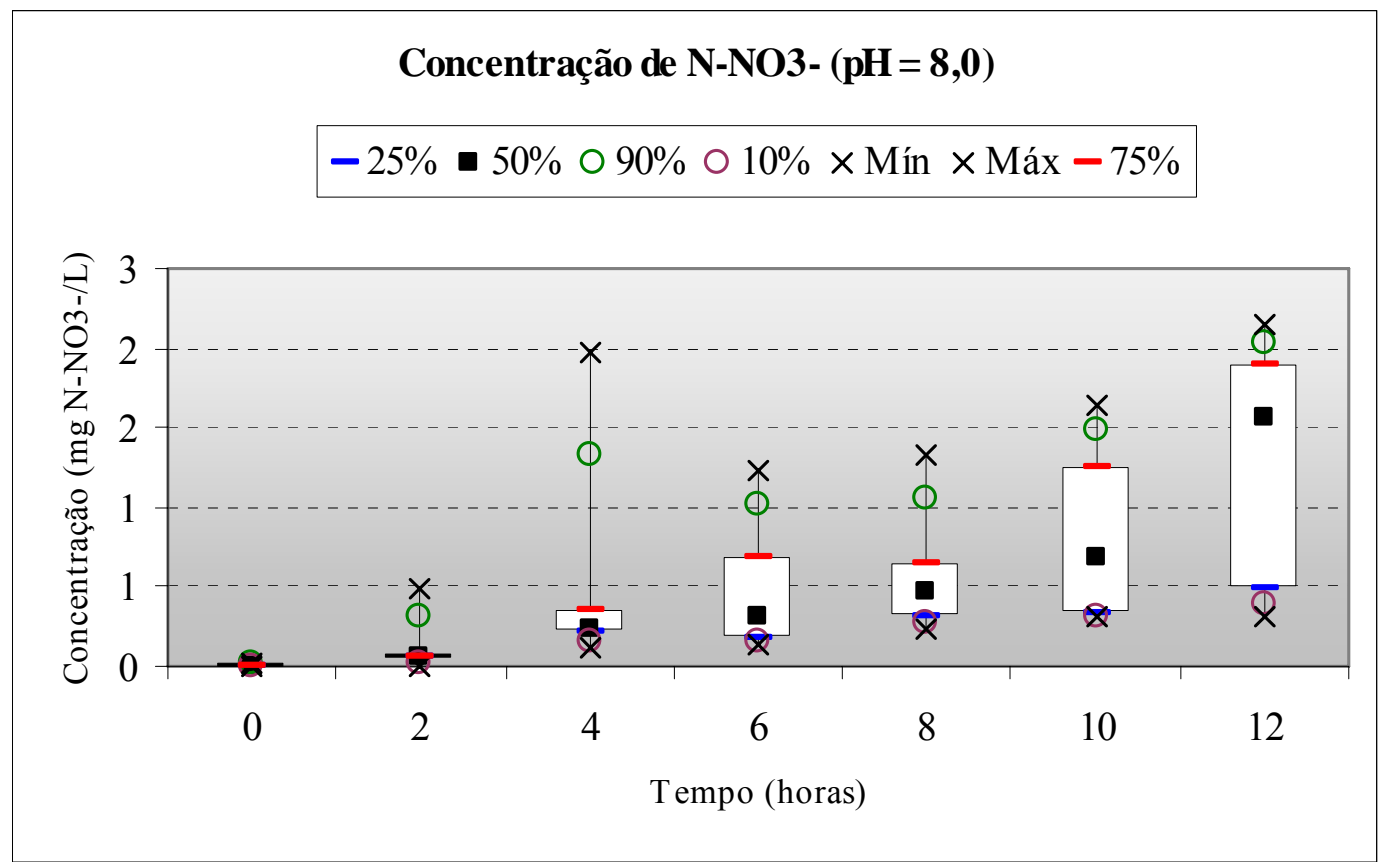

Figura 25: Perfis temporais das concentrações de $\mathrm{N}_{-} \mathrm{NO}_{3}{ }^{-}$, no conteúdo do reator, obtidas ao longo de 6 testes exploratórios - Etapa $02 ; \mathrm{T} \cong 30^{\circ} \mathrm{C}$ e $\mathrm{pH} \cong 8,0$.

A manipulação do pH e o deslocamento do equilíbrio entre íon amônio e amônia livre a favor da manutenção de concentrações de $\mathrm{NH}_{3}$ no conteúdo do reator na faixa de 0,38 a $1,95 \mathrm{mg}$ $\mathrm{NH}_{3} / \mathrm{L}$, apontaram a possibilidade de acúmulo de $\mathrm{N}^{-\mathrm{NO}_{2}}{ }^{-}$na massa líquida. Anthonisen et al. (1976) observaram a inibição da atividade das bactérias que oxidam nitrito quando a concentração de $\mathrm{NH}_{3}$ na massa líquida encontrava-se na faixa de 0,1 a 1,0 mg NH$/ \mathrm{L}$.

Apesar do acúmulo de $\mathrm{N}_{-} \mathrm{NO}_{2}^{-}$nos testes realizados com $\mathrm{pH}=7,8$, resultados mais expressivos foram encontrados quando o $\mathrm{pH}=8,0$. Durante estes testes, a concentração de amônia livre variou de 1,0 até $1,95 \mathrm{mg} \mathrm{NH} / \mathrm{L}$. Os cálculos da concentração de ácido nitroso não ionizado $\left(\mathrm{HNO}_{2}\right)$ foram realizados, uma vez que aqueles pesquisadores observaram inibição dos microrganismos nitrificantes quando a concentração de $\mathrm{HNO}_{2}$ variou na faixa de 0,28 a 2,8 $\mathrm{mg} \mathrm{HNO}_{2} / \mathrm{L}$; portanto valores superiores aos encontrados nos testes exploratórios $\left(<0,001 \mathrm{mg} \mathrm{HNO}_{2} / \mathrm{L}\right)$.

A realização destes testes exploratórios revelou a necessidade da manutenção do $\mathrm{pH}$ em valores mais elevados que aqueles usualmente encontrados nas plantas de tratamento 
biológico de águas residuárias para o alcance do acúmulo sustentado de nitrito. A temperatura e a concentração de oxigênio dissolvido, quando manipulados isoladamente, ou apresentaram resultados inexpressivos de remoção de $\mathrm{N}_{-} \mathrm{NH}_{3}$, ou não foram eficientes para o acúmulo de N$\mathrm{NO}_{2}{ }^{-}$. A tabela 23 mostra um resumo das condições operacionais e resultados médios obtidos ao longo da fase de testes exploratórios.

Com as informações levantadas na fase de testes exploratórios, partiu-se para segunda fase da pesquisa, buscando a remoção de nitrogênio amoniacal, via nitrito, utilizando fenol como fonte de carbono. 
Tabela 23 - Resumo das condições operacionais e resultados médios da fase de testes exploratórios em escala de bancada.

\begin{tabular}{|c|c|c|c|c|c|c|c|}
\hline & $\begin{array}{l}\mathbf{n}^{\circ} \text { de } \\
\text { ciclos }\end{array}$ & pH & Temp. & $\begin{array}{c}\text { Fornecimento de } \\
\text { O.D. }\end{array}$ & $\begin{array}{l}\text { Remoção } \\
\text { de N-NH }\end{array}$ & $\mathrm{N}-\mathrm{NO}_{2}^{-}+\mathrm{N} \mathrm{NO}_{2}^{-}-\mathrm{NO}_{3}^{-}$ & $\frac{\mathrm{N}-\mathrm{NO}_{3}^{-}}{\mathrm{N}-\mathrm{NO}_{2}^{-}+\mathrm{N}-\mathrm{NO}_{3}^{-}}$ \\
\hline Etapa $01^{*}$ & 14 & 7,0 & $35^{\circ} \mathrm{C}$ & sem limitação & $59 \%$ & $1 \%$ & $99 \%$ \\
\hline Etapa $02 *$ & 06 & 7,0 & $30^{\circ} \mathrm{C}$ & $\begin{array}{c}15^{\prime} \text { aerados e } \\
15^{\prime} \text { sem aeração }\end{array}$ & $16 \%$ & $82 \%$ & $18 \%$ \\
\hline Etapa $02 *$ & 04 & 7,0 & $30,5^{\circ} \mathrm{C}$ & $\begin{array}{c}30^{\prime} \text { aerados e } \\
15^{\prime} \text { sem aeração }\end{array}$ & $36 \%$ & $30 \%$ & $70 \%$ \\
\hline Etapa $02 *$ & 06 & 7,0 & $30^{\circ} \mathrm{C}$ & $\begin{array}{c}45^{\prime} \text { aerados e } \\
15^{\prime} \text { sem aeração }\end{array}$ & $68 \%$ & $28 \%$ & $72 \%$ \\
\hline Etapa $03 *$ & 04 & 7,5 & $30^{\circ} \mathrm{C}$ & sem limitação & $69 \%$ & $9 \%$ & $91 \%$ \\
\hline Etapa $03 *$ & 06 & 7,8 & $30^{\circ} \mathrm{C}$ & sem limitação & $55 \%$ & $48 \%$ & $52 \%$ \\
\hline Etapa 03* & 05 & 8,0 & $30^{\circ} \mathrm{C}$ & sem limitação & $55 \%$ & $90 \%$ & $10 \%$ \\
\hline
\end{tabular}


5.2 FASE 02: PESQUiSA DA REMOÇÃO DE NITROGÊNIO AMONIACAL, VIA NITRITO, UTILIZANDO FENOL COMO FONTE DE CARBONO:

\subsubsection{ETAPA 01 - CONCENTRAÇÃO AFLUENTE DE NITROGÊNIO AMONIACAL $\cong 200 \mathrm{mg}$ N/L:}

Essa etapa da pesquisa foi conduzida em um reator piloto com volume útil de 20 litros, operado em bateladas seqüenciais (Item 4.5.2). Para partida do sistema prepararam-se dois litros de água residuária sintética sem fenol, os demais componentes foram àqueles apresentados no Item 4.5.1. Após o final da etapa aeróbia, foram preparados mais três litros de água residuária sintética com fenol (1.000 mg $\left.\mathrm{C}_{6} \mathrm{H}_{5} \mathrm{OH} / \mathrm{L}\right)$, adicionados ao sistema de forma gradual em uma etapa anóxica, não houve descarte entre o final da etapa aeróbia e o início da etapa anóxica A duração dessas etapas e os perfis de distribuição das concentrações estão apresentados na figura 26.

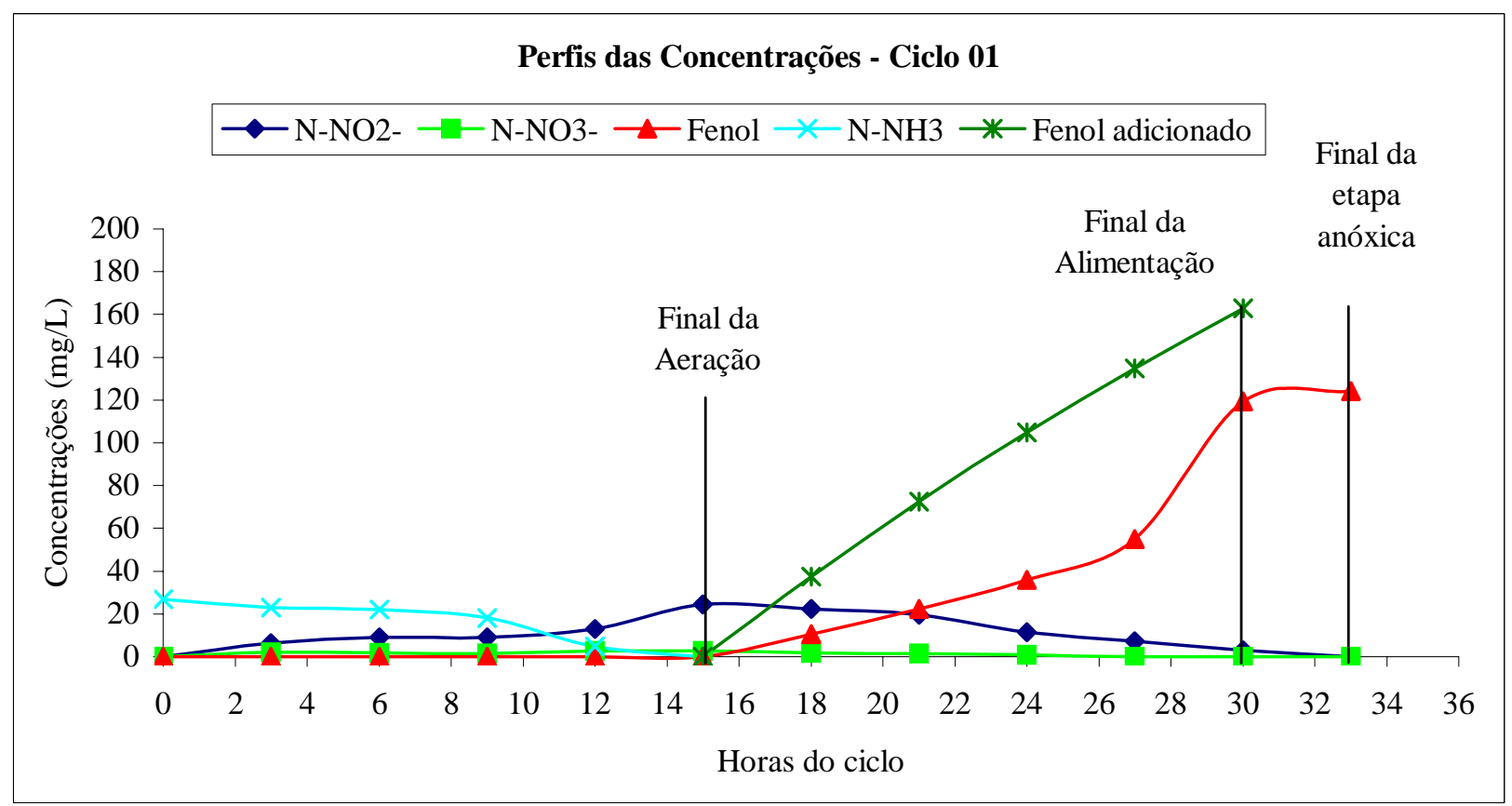

Figura 26: Perfis temporais das concentrações de $\mathrm{N}_{-} \mathrm{NO}_{2}{ }^{-}$; $\mathrm{N}^{-\mathrm{NO}_{3}}{ }_{3}$; fenol; $\mathrm{N}^{-\mathrm{NH}_{3}}$ no conteúdo do reator piloto - Ciclo de partida $\left(\mathrm{pH}\right.$ na etapa aeróbia $\cong 8,3$; $\left.\mathrm{T} \cong 32^{\circ} \mathrm{C}\right)$ - Etapa 01 .

Apesar das 15 horas de duração da etapa aeróbia no ciclo de partida, ao final de 12 horas a concentração de nitrogênio amoniacal era de 4,8 mg N-NH$/ 2$. Ao final dessa etapa o nitrito predominou como forma oxidada do nitrogênio, uma vez que a relação $\mathrm{N}_{-} \mathrm{NO}_{2}^{-} /\left(\mathrm{N}_{-} \mathrm{NO}_{2}^{-}{ }^{-}\right.$ 


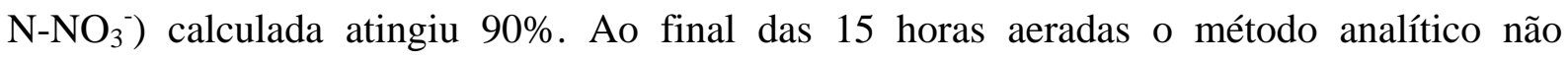
detectou $\mathrm{N}-\mathrm{NH}_{3}$ e a taxa de nitritação específica foi igual a $0,01 \mathrm{~kg} \mathrm{~N}-\mathrm{NH}_{3} / \mathrm{kg} \mathrm{SSV}$.dia. A concentração de SSV no início desse ciclo de remoção foi de 3.420 mg SSV/L e a carga aplicada ao sistema foi de $0,5 \mathrm{~g} \mathrm{~N}-\mathrm{NH}_{3} /$ dia.

$\mathrm{O} \mathrm{pH}$, ao longo da etapa aeróbia do ciclo, foi mantido próximo a 8,3, o que possibilitou a existência de uma concentração de amônia livre na faixa entre 4,0 e 0,8 mg $\mathrm{NH}_{3} / \mathrm{L}$. Esses valores são considerados inibitórios aos microrganismos que oxidam $\mathrm{N}^{-\mathrm{NO}_{2}}{ }^{-}$a $\mathrm{N}_{-} \mathrm{NO}_{3}{ }^{-}$. (ANTHONISEN et al., 1976). A temperatura variou entre 32 e $33^{\circ} \mathrm{C}$. A figura 27 mostra os perfis dos parâmetros pH e oxigênio dissolvido ao longo desse ciclo de tratamento.

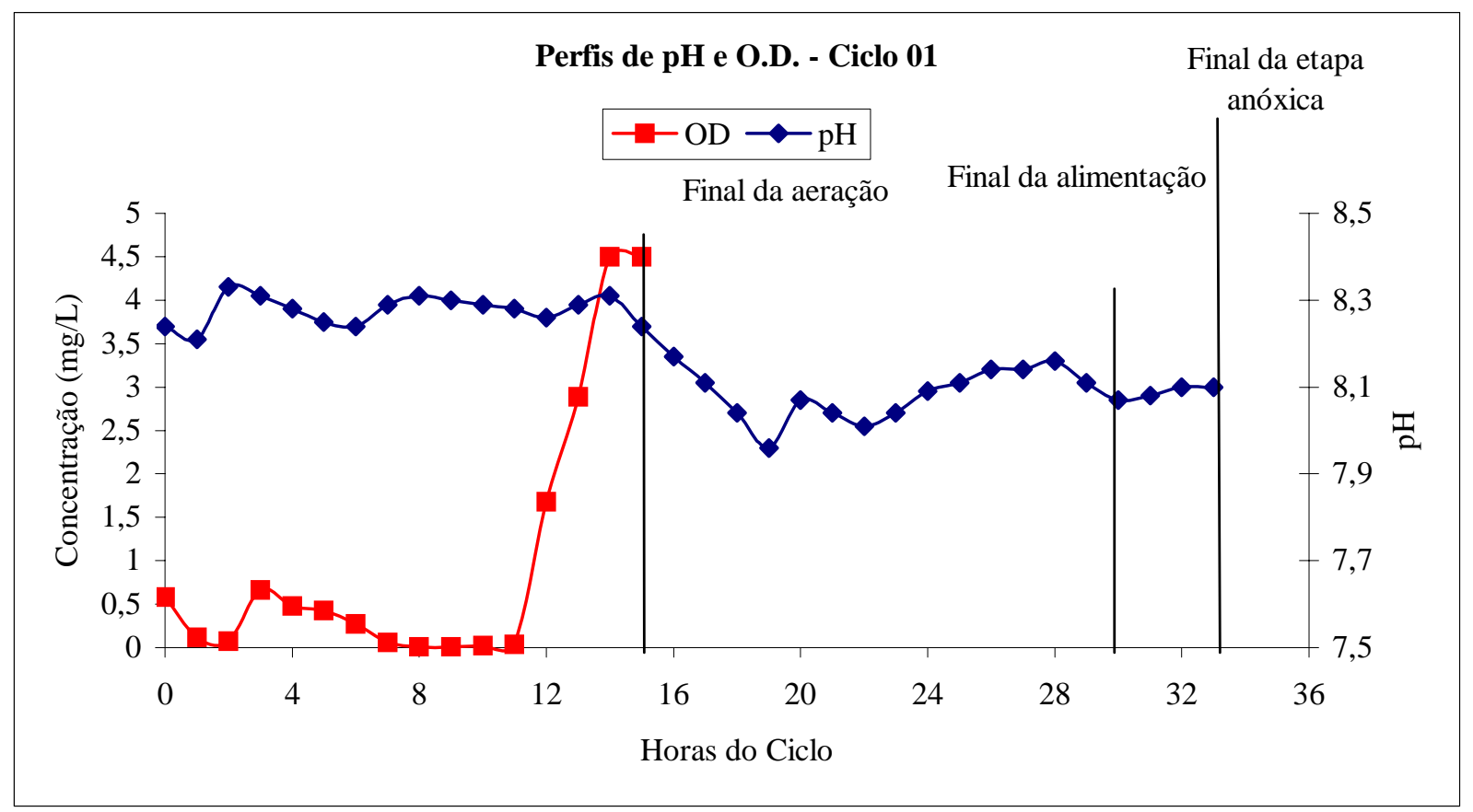

Figura 27: Perfis temporais de pH e oxigênio dissolvido no conteúdo do reator piloto- Ciclo de Partida - Etapa 01

Observando as figuras 26 e 27 constata-se que o final da disponibilidade de nitrogênio amoniacal (próximo a 15 horas da etapa aeróbia do ciclo de tratamento) é acompanhado por uma elevação na concentração de O. D. no meio líquido.

A etapa anóxica durou 18 horas, das quais 15 horas foram com adição gradual de água residuária. Ao final dessa etapa a eficiência de remoção de fenol foi de $28 \%$ para uma carga de 2,3 g $\mathrm{C}_{6} \mathrm{H}_{5} \mathrm{OH} /$ dia, alcançando-se 99\% na remoção do nitrogênio oxidado. A relação 
alimento/microrganismo (A/M) foi de 0,07 kg fenol / kg SSV.dia. A taxa de desnitritação específica igual a 0,01 $\mathrm{kg} \mathrm{N}-\mathrm{NO}_{2}{ }^{-} / \mathrm{kg}$ SSV.dia. Ao final da etapa de sedimentação do ciclo de partida descartou-se 5,0 litros do sobrenadante do conteúdo do reator piloto.

Para realização do ciclo 02 de tratamento a carga aplicada foi de aproximadamente 0,5 g N$\mathrm{NH}_{3}$ /dia e 2,3 $\mathrm{g} \mathrm{C}_{6} \mathrm{H}_{5} \mathrm{OH} /$ dia. As figuras 28 e 29 apresentam a duração das etapas do ciclo 02 e os perfis de distribuição das concentrações das espécies químicas e parâmetros abióticos no conteúdo do reator (pH e O. D.).

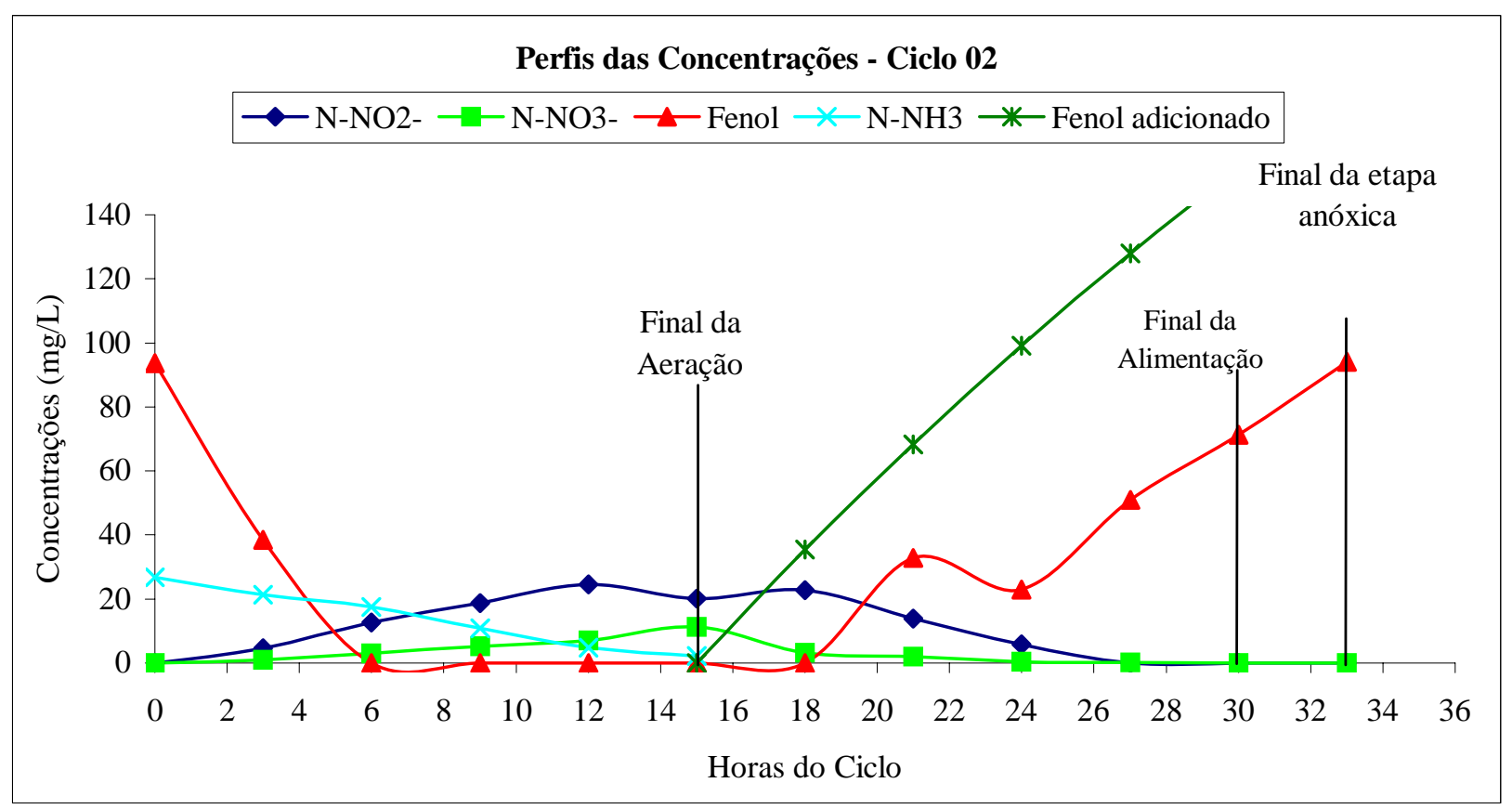

Figura 28: Perfis temporais das concentrações de $\mathrm{N}-\mathrm{NO}_{2}{ }^{-} ; \mathrm{N}-\mathrm{NO}_{3}{ }^{-}$; fenol; $\mathrm{N}-\mathrm{NH}_{3}$ no conteúdo do reator piloto - Ciclo 02. ( $\mathrm{pH}$ na etapa aeróbia $\cong 8,3 ; \mathrm{T} \cong 32^{\circ} \mathrm{C}$ ) - Etapa 01 . 


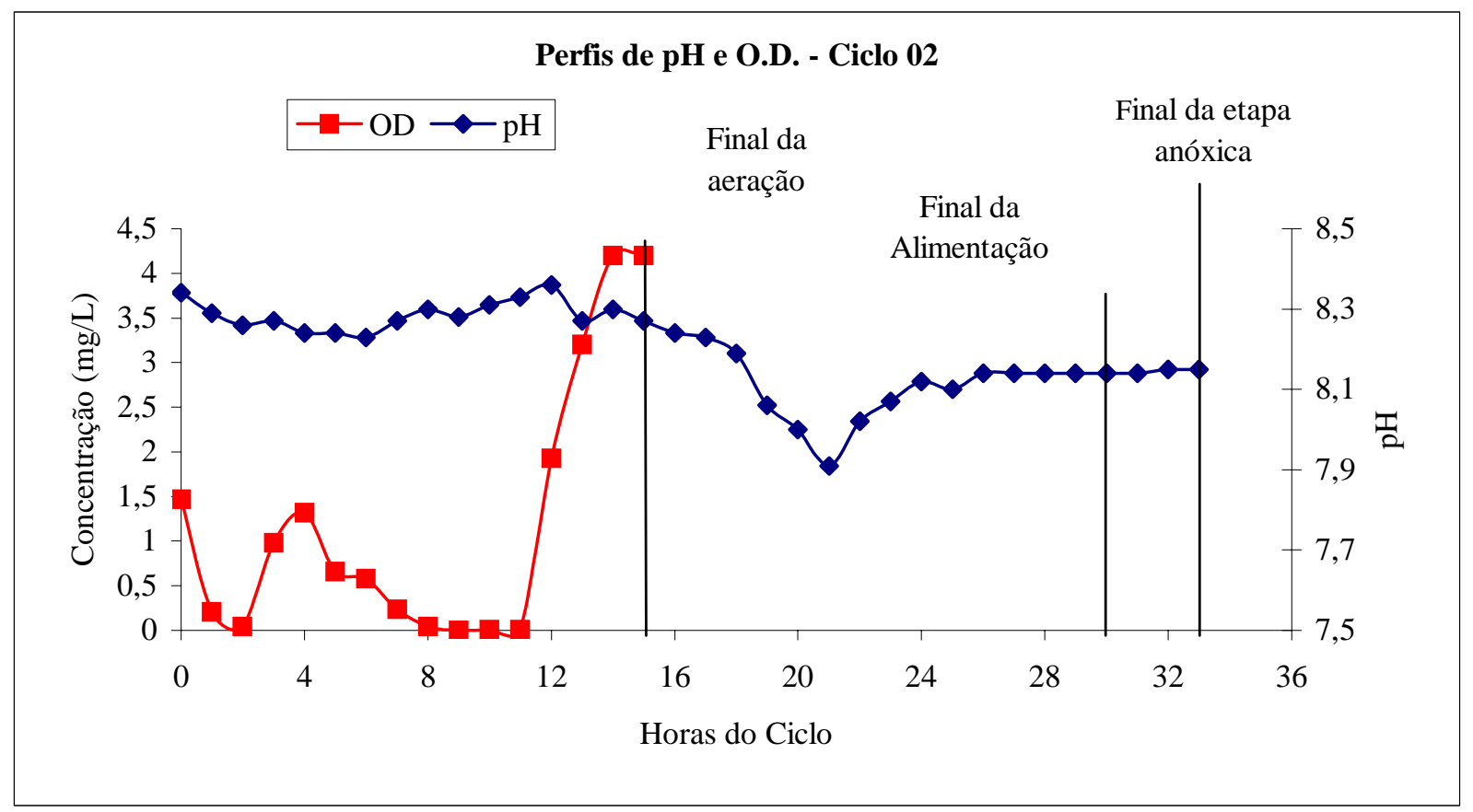

Figura 29: Perfis temporais de $\mathrm{pH}$ e oxigênio dissolvido no conteúdo do reator piloto - Ciclo 02 - Etapa 01.

A taxa de nitritação específica, calculada para o ciclo 02, foi igual a 0,01 $\mathrm{kg} \mathrm{N}-\mathrm{NH}_{3} / \mathrm{kg}$ SSV.dia. A concentração de SSV foi de $3.280 \mathrm{mg}$ SSV/L. Apesar da boa eficiência de

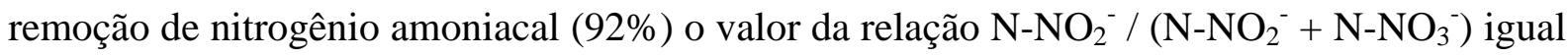
a 64 \% evidencia a ocorrência, no conteúdo do reator, da oxidação de parte da concentração de $\mathrm{N}-\mathrm{NO}_{2}{ }^{-}$a N-NO${ }_{3}^{-}$. A concentração de amônia livre variou na faixa de 4,4 a $0,4 \mathrm{mg} \mathrm{NH}_{3} / \mathrm{L}$, portanto dentro daquela faixa considerada inibitória (ANTHONISEN et al, 1976). Porém, algumas pesquisas (TURK e MAVINIC, 1989; BALMELLE et al., 1992; BAE et al., 2002) advertem para possibilidade de aclimatação dos microrganismos que oxidam nitrito às concentrações de amônia não ionizada. Outro fator que pode ter favorecido a oxidação do N$\mathrm{NO}_{2}{ }^{-}$a $\mathrm{N}^{-\mathrm{NO}_{3}}{ }^{-}$é a extensão da etapa aeróbia, ou seja, a disponibilidade de oxigênio além daquela necessária apenas à oxidação do nitrogênio amoniacal a $\mathrm{N}-\mathrm{NO}_{2}{ }^{-}$.

Assim como no ciclo 01, a etapa anóxica do ciclo 02 teve duração de 18 horas, das quais 15 horas foram com adição gradual de água residuária. Obteve-se, para remoção de fenol e nitrogênio oxidado (N-NOx) eficiências de 40\% e 99\%, respectivamente, durante essa fase do 
ciclo de remoção. A relação alimento microrganismo foi de 0,08 kg fenol / kg SSV.dia e a

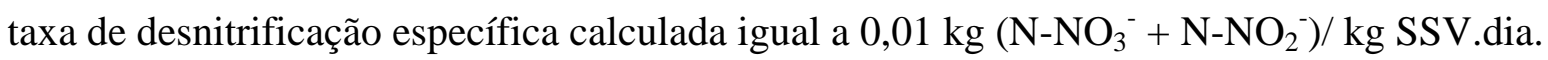
Para realização do ciclo 03 a carga de nitrogênio amoniacal foi aproximadamente igual a 1,0 g $\mathrm{N}-\mathrm{NH}_{3}$ /dia e 4,7 g $\mathrm{C}_{6} \mathrm{H}_{5} \mathrm{OH} /$ dia. A concentração de SSV nesse ciclo foi de $3.510 \mathrm{mg}$ SSV/L; a temperatura variou na faixa de 31 a $32^{\circ} \mathrm{C}$. e o $\mathrm{pH}$ durante a etapa aeróbia foi mantido próximo a 8,3.

Ao final de 15 horas do ciclo de tratamento, com fornecimento de oxigênio, atingiu-se eficiência de remoção de nitrogênio amoniacal de 95\%. A relação $\mathrm{N}-\mathrm{NO}_{2}{ }^{-} /\left(\mathrm{N}^{-\mathrm{NO}_{2}}{ }^{-}+\mathrm{N}-\mathrm{NO}_{3}{ }^{-}\right)$ foi igual a 87\%, ainda que a concentração de nitrato, no conteúdo do reator, tenha sido igual a 8,2 mg $\mathrm{N}-\mathrm{NO}_{3}{ }^{-} / \mathrm{L}$ ao final da etapa aeróbia. A concentração de amônia não ionizada, que variou dentro da faixa de 8,1 a $0,4 \mathrm{mg} \mathrm{NH}_{3} / \mathrm{L}$, não inibiu completamente a atividade dos microrganismos que oxidam nitrito. A taxa de nitritação específica foi de 0,02 kg N-NH$/ \mathrm{kg}$ SSV.dia.

A etapa anóxica do ciclo 03 teve duração de 10 horas e foi operada com alimentação e reação concomitantes, interrompendo-se a etapa anóxica ao final do lançamento do despejo. A taxa de aplicação volumétrica foi de $0,03 \mathrm{~kg} \mathrm{C}_{6} \mathrm{H}_{5} \mathrm{OH} / \mathrm{m}^{3}$.hora e a relação A/M igual a $0,07 \mathrm{~kg}$ fenol / kg SSV.dia. Ao final da fase anóxica, alcançaram-se eficiências de remoção de fenol e nitrogênio amoniacal oxidado iguais a 42 e 95\%, respectivamente; a taxa de desnitritação específica foi igual a $0,03 \mathrm{~kg} \mathrm{~N}-\mathrm{NO}_{2}{ }^{-} / \mathrm{kg}$ SSV.dia e a relação fenol removido $/ \mathrm{N}-\mathrm{NO}_{\mathrm{x}}$ removido foi igual a 2,2 kg fenol removido $/ \mathrm{kg} \mathrm{N}-\mathrm{NO} x_{\text {removido. }}$

As figuras 30 e 31 mostram os perfis temporais das concentrações das espécies químicas no conteúdo do reator e dos parâmetros monitorados durante o ciclo 03. 


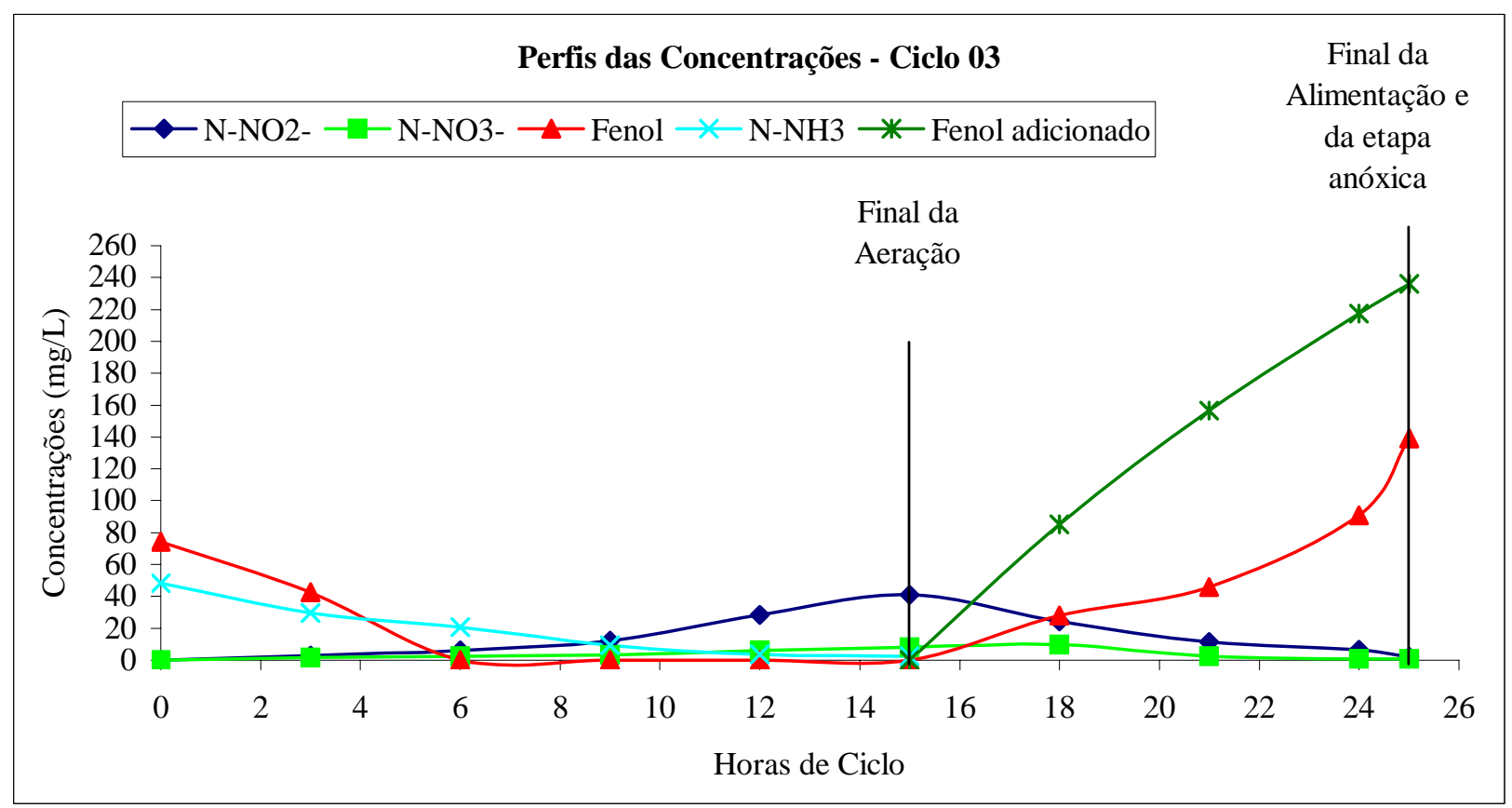

Figura 30: Perfis temporais das concentrações de $\mathrm{N}-\mathrm{NO}_{2}{ }^{-} ; \mathrm{N}-\mathrm{NO}_{3}{ }^{-}$; fenol; $\mathrm{N}-\mathrm{NH}_{3}$ no conteúdo do reator piloto - Ciclo 03. ( $\mathrm{pH}$ na etapa aeróbia $\cong 8,3 ; \mathrm{T} \cong 32^{\circ} \mathrm{C}$ ) - Etapa 01 .

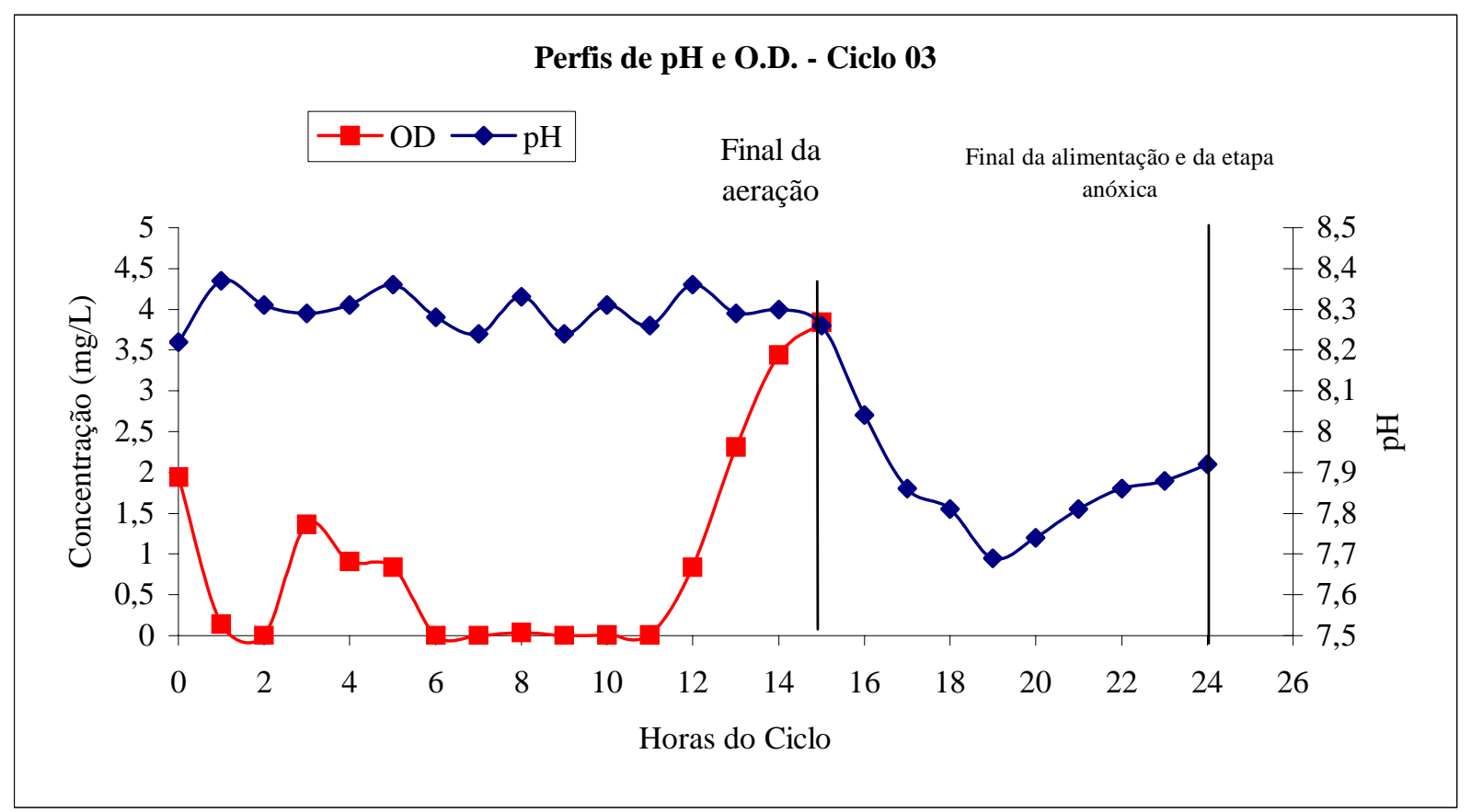

Figura 31: Perfis temporais de pH e oxigênio dissolvido no conteúdo do reator piloto - Ciclo 03 - Etapa 01.

A concentração de SSV diminuiu significativamente entre os ciclos 03 e 04 . Na análise realizada no início do ciclo 03 obteve-se concentração de SSV igual a 3.510 mg SSV/L; já no início do quarto ciclo a concentração de SSV obtida foi de 2.608 mg SSV/L. Possivelmente 
esse fato está associado à adaptação da biomassa, uma vez que a concentração de SSV no sobrenadante descartado entre os ciclos 03 e 04 foi igual a 7,0 mg SSV/L.

Para realização do ciclo 04 os tempos destinados às diferentes reações no conteúdo do reator piloto não foram alterados, sendo que a etapa aerada durou 15 horas e a etapa anóxica 10 horas, interrompendo-se a etapa anóxica ao final da alimentação. As cargas, de nitrogênio amoniacal e fenol, afluentes a esse ciclo de tratamento foram iguais a 0,9 $\mathrm{g} \mathrm{N}-\mathrm{NH}_{3} /$ dia e 5,0 g $\mathrm{C}_{6} \mathrm{H}_{5} \mathrm{OH} /$ dia.

As figuras 32 e 33 apresentam os perfis de distribuição das concentrações e parâmetros abióticos (pH e O. D.) no conteúdo do reator piloto ao longo do ciclo 04.

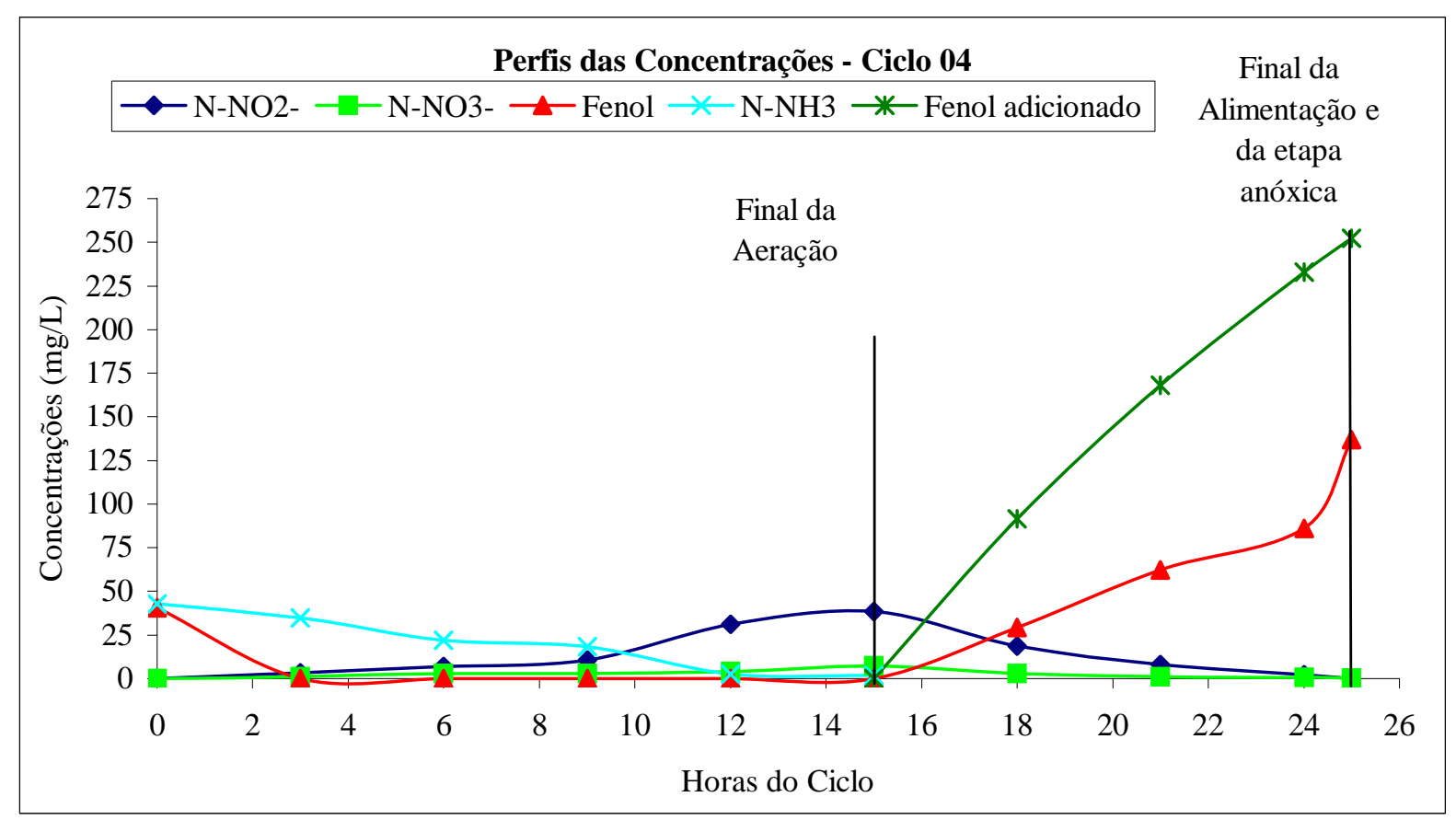

Figura 32: Perfis temporais das concentrações de $\mathrm{N}-\mathrm{NO}_{2}{ }^{-} ; \mathrm{N}-\mathrm{NO}_{3}{ }^{-}$; fenol; $\mathrm{N}-\mathrm{NH}_{3}$ no conteúdo do reator piloto - Ciclo 04. (pH na etapa aeróbia $\left.\cong 8,3 ; \mathrm{T} \cong 31,5^{\circ} \mathrm{C}\right)$ - Etapa 01 . 


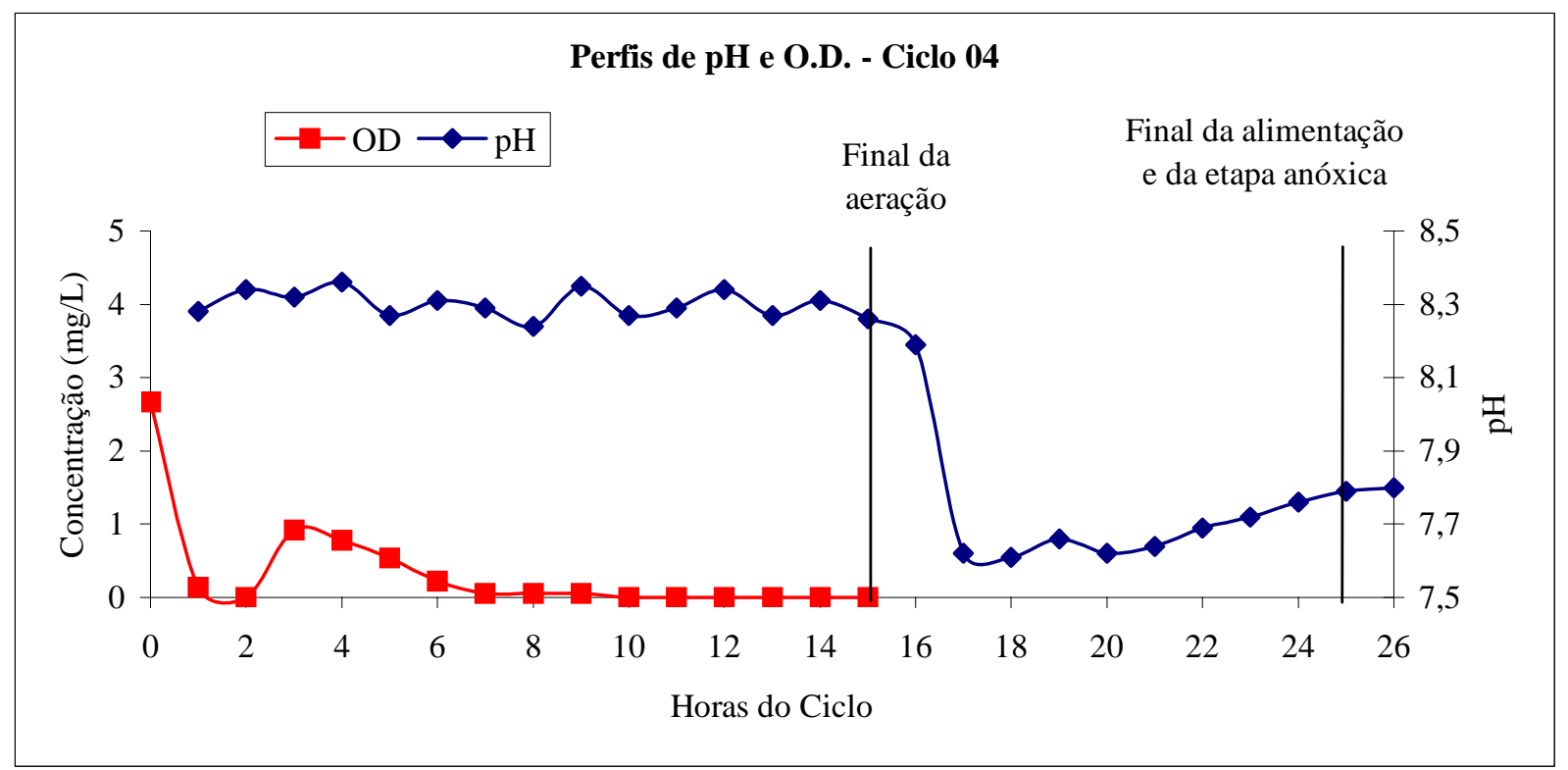

Figura 33: Perfis temporais de $\mathrm{pH}$ e oxigênio dissolvido no conteúdo do reator piloto - Ciclo 04 - Etapa 01.

Mesmo com a significativa redução da concentração de SSV obteve-se uma boa eficiência de remoção de $\mathrm{N}-\mathrm{NH}_{3}$ (96\%) sendo que a taxa de nitritação específica calculada apresentou valor

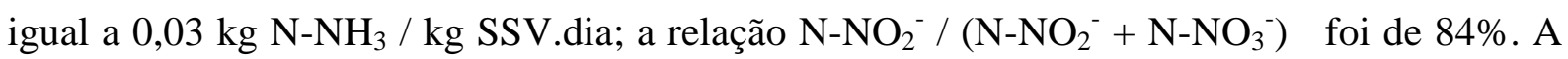
concentração de amônia livre, durante a etapa aeróbia do ciclo de tratamento, variou entre a 7,1 e $0,3 \mathrm{mg} \mathrm{NH} / \mathrm{L}$.

A etapa anóxica foi marcada por um desempenho similar àquele do ciclo 03 , mesmo com a relação A/M (0,13 kg fenol / kg SSV.dia) superior àquela (0,10 kg fenol / kg SSV.dia) obtida como inibitória aos microrganismos heterotróficos degradadores de fenol (AUN, 2001). A eficiência de remoção de fenol atingiu $46 \%$ e de nitrogênio oxidado, 99\%; a taxa de desnitritação específica foi igual a 0,04 $\mathrm{kg} \mathrm{N}-\mathrm{NO}_{2}{ }^{-} / \mathrm{kg}$ SSV.dia especifica. A relação fenol removido $/ \mathrm{N}-\mathrm{NOx}$ removido, calculada para o ciclo 04 , foi de $2,6 \mathrm{~kg}$ fenol removido $/ \mathrm{kg} \mathrm{N}-\mathrm{NOx}$ removido. Para realização do quinto ciclo de tratamento ajustou-se o rotâmetro, associado a bomba de aeração, de tal maneira que a concentração de O D. lida no conteúdo do reator fosse próxima a 1,0 mg $\mathrm{O}_{2} / \mathrm{L}$ durante a fase aeróbia. Nos ciclos anteriores, notava-se que devido à atividade dos microrganismos durante a fase aeróbia do ciclo de tratamento, a leitura da concentração 
de O.D. apontava resultados nulos (Figuras 27, 29, 31 e 33). Reduziu-se a duração da etapa aeróbia do ciclo para 10 horas, mantendo a temperatura na faixa de 32 a $33^{\circ} \mathrm{C}$ e valor de $\mathrm{pH}$ próximo a 8,3.

Para uma carga aplicada, no ciclo 05, de 1,0 g N-NH 3 /dia, a eficiência de remoção atingiu 89\% (concentração ao final da etapa aeróbia aproximadamente igual a $4 \mathrm{mg} \mathrm{N}-\mathrm{NH}_{3} / \mathrm{L}$ ).

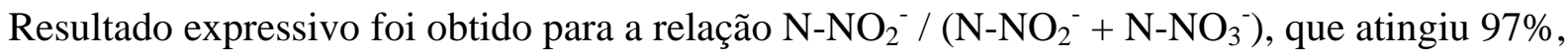
maior valor desde o início da operação do sistema piloto. A taxa de nitritação específica, calculada, foi igual a $0,03 \mathrm{~kg} \mathrm{~N}-\mathrm{NH}_{3}$ / kg SSV.dia para uma concentração de SSV, no início do ciclo de tratamento, de $2.808 \mathrm{mg} \mathrm{SSV/L}$.

As figuras 34 e 35 apresentam os perfis temporais das concentrações das espécies químicas e dos parâmetros monitorados, no conteúdo do reator, durante o ciclo 05.

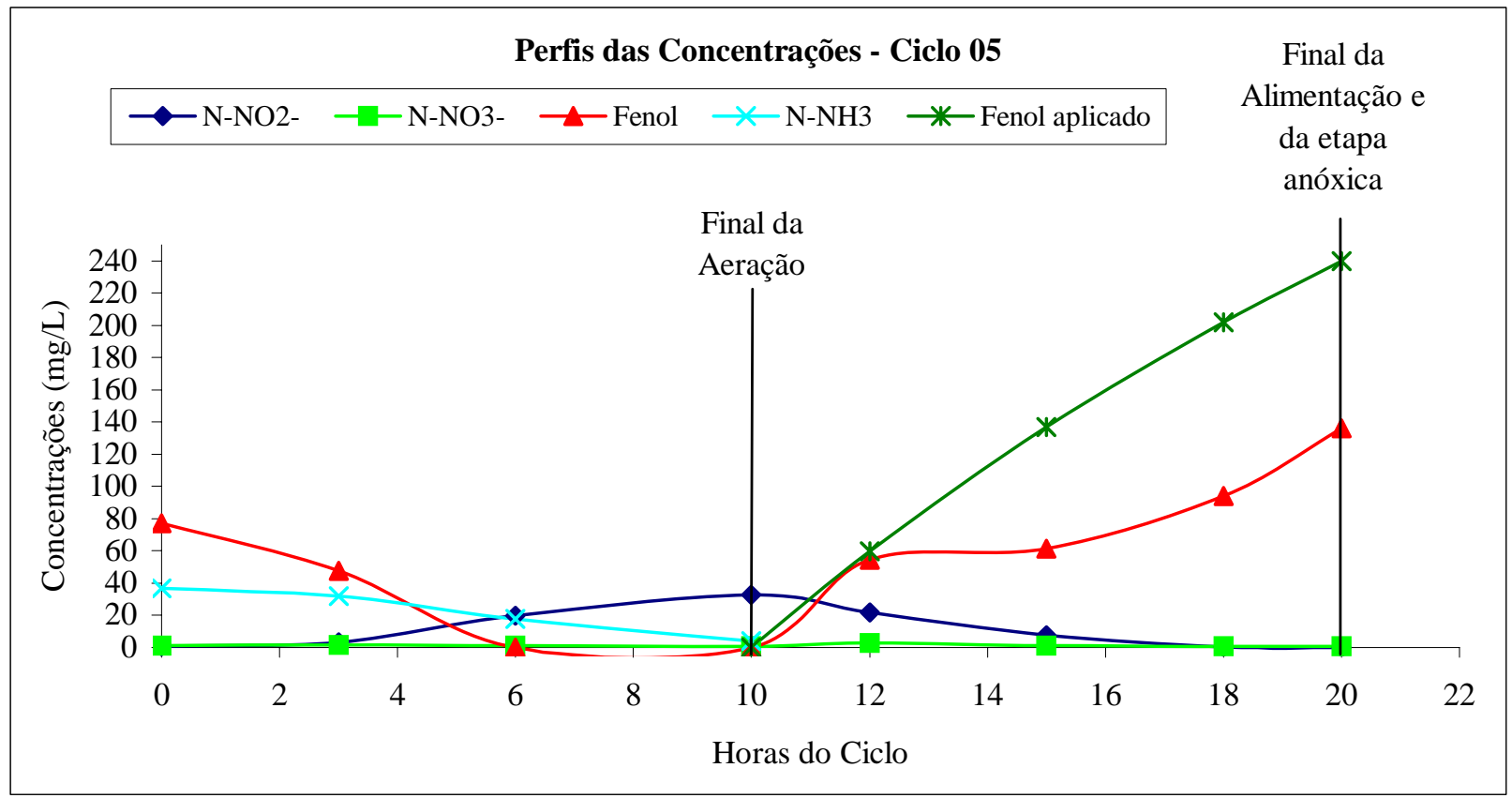

Figura 34: Perfis temporais das concentrações de $\mathrm{N}^{-\mathrm{NO}_{2}}{ }^{-} ; \mathrm{N}-\mathrm{NO}_{3}{ }^{-}$; fenol; $\mathrm{N}-\mathrm{NH}_{3}$ no conteúdo do reator piloto - Ciclo 05 ( $\mathrm{pH}$ na etapa aeróbia $\cong 8,3 ; \mathrm{T} \cong 33^{\circ} \mathrm{C}$ ) - Etapa 01 . 


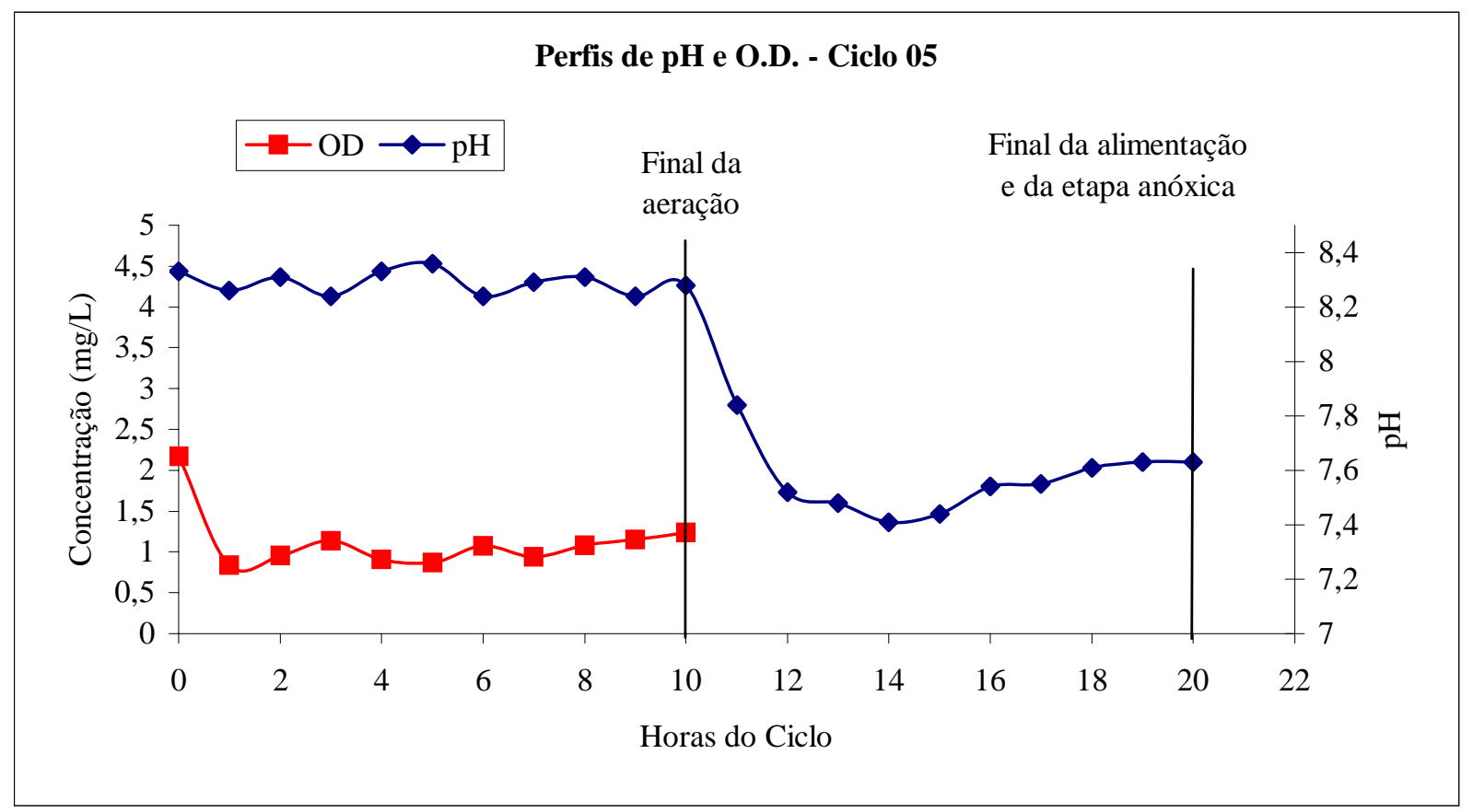

Figura 35: Perfis temporais de pH e oxigênio dissolvido no conteúdo do reator piloto - Ciclo 05 - Etapa 01.

Garrido et al. (1996) observaram acúmulo estável de nitrito quando a relação entre as concentrações de oxigênio dissolvido e amônia livre na massa líquida era menor que 10 mg $\mathrm{O}_{2} / \mathrm{mg} \mathrm{NH}_{3}$; como durante a realização do quinto ciclo foi possível observar a leitura da concentração de O.D. (mantida próxima a 1,0 mg $\mathrm{O}_{2} / \mathrm{L}$ ), calculou-se a relação O.D/ $\mathrm{NH}_{3}$ constatando-se que a mesma variou entre $\left(0,4\right.$ e 2,2 $\left.\mathrm{mg} \mathrm{O}_{2} / \mathrm{mg} \mathrm{NH}_{3} \cdot \mathrm{L}^{-1}\right)$, além disso a concentração de amônia livre também esteve naquela faixa considerada inibitória aos organismos que oxidam nitrito (6,1 a 0,5 $\left.\mathrm{mg} \mathrm{NH}_{3} / \mathrm{L}\right)$. O excelente resultado, acima de 95\%, obtido para relação $\mathrm{N}-\mathrm{NO}_{2}{ }^{-} /\left(\mathrm{N}^{-} \mathrm{NO}_{2}{ }^{-}+\mathrm{N}^{-\mathrm{NO}_{3}}{ }^{-}\right)$aponta a necessidade de otimização do tempo de fornecimento de oxigênio à biomassa, de tal maneira que se disponibilize $\mathrm{O}_{2}$ apenas para oxidação do nitrogênio a nitrito; um tempo de aeração excessivo parece favorecer a oxidação do nitrito, acumulado no conteúdo do reator, a nitrato.

A duração da etapa anóxica durante o ciclo 05 de tratamento foi de 10 horas, ao final dessas, as eficiências de remoção de fenol (carga afluente de 4,8 g $\mathrm{C}_{6} \mathrm{H}_{5} \mathrm{OH} /$ dia) e nitrogênio amoniacal oxidado foram iguais a 49 e 97\%, respectivamente; a taxa de desnitritação 
específica igual a 0,03 $\mathrm{kg} \mathrm{N}-\mathrm{NO}_{2}^{-} / \mathrm{kg}$ SSV.dia. A relação A/M foi igual a 0,13 $\mathrm{kg}$ fenol $/ \mathrm{kg}$ SSV.dia, obtendo-se uma relação de 3,4 kg fenol removido/ kg N-NOx removido.

Durante a operação dos ciclos 06 e 07 investigou-se o aumento da taxa de aplicação volumétrica para 0,07 $\mathrm{kg} \mathrm{C}_{6} \mathrm{H}_{5} \mathrm{OH} / \mathrm{m}^{3}$.hora. A etapa aeróbia do ciclo durou 10 horas mantendo uma concentração de O D., no conteúdo do reator, próxima a 1,0 mg $\mathrm{O}_{2} / \mathrm{L}$. Durante a realização dos ciclos 06 e 07 a temperatura na massa líquida do reator piloto variou na faixa de 32 a $33^{\circ} \mathrm{C}$. e o valor do $\mathrm{pH}$ na etapa aeróbia foi controlado próximo a 8,3.

Durante o ciclo 06, para uma carga de $1,0 \mathrm{~g} \mathrm{~N}-\mathrm{NH}_{3} /$ dia, a eficiência de remoção foi de 95\%, com uma relação $\mathrm{N}-\mathrm{NO}_{2}^{-} /\left(\mathrm{N}_{-} \mathrm{NO}_{2}^{-}+\mathrm{N}^{-} \mathrm{NO}_{3}{ }^{-}\right)$igual a $91 \%$. O ciclo 07 , para uma carga afluente de 1,0 g N-NH$/$ dia, apresentou eficiência de remoção desse composto de 95\%, e a relação $\mathrm{N}-\mathrm{NO}_{2}^{-} /\left(\mathrm{N}_{-} \mathrm{NO}_{2}^{-}+\mathrm{N}-\mathrm{NO}_{3}{ }^{-}\right)$igual a $97 \%$. A taxa de nitritação específica em ambos os ciclos (06 e 07) foi igual a 0,03 kg N-NH$/$ kg SSV.dia.

A etapa anóxica foi marcada pela inibição do processo de desnitritação. A eficiência de remoção de fenol foi de $33 \%$ no ciclo 06 e de $26 \%$ no ciclo 07 , portanto aquém dos valores encontrados nos ciclos anteriores. Além disso a remoção de nitrogênio amoniacal oxidado foi de 53\% no ciclo 06 (concentração ao final da fase anóxica $=18,0 \mathrm{mg} \mathrm{N}-\mathrm{NO}_{2}{ }^{-} / \mathrm{L}$ ) e de apenas

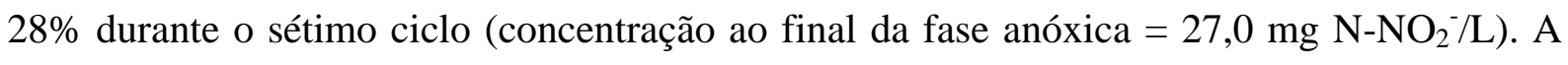
opção por taxas de aplicação volumétricas elevadas $\left(0,07 \mathrm{~kg} \mathrm{C}_{6} \mathrm{H}_{5} \mathrm{OH} / \mathrm{m}^{3}\right.$.hora) provavelmente, causou inibição aos microrganismos heterotróficos degradadores de fenol. Eiroa et al. (2005) operaram um reator continuamente alimentado com fenol, em escala de bancada, e constataram que taxas de aplicação volumétricas próximas a 0,023 kg $\mathrm{C}_{6} \mathrm{H}_{5} \mathrm{OH}$ / $\mathrm{m}^{3}$.hora, já inibiam a redução biológica do nitrato a $\mathrm{N}_{2}$. Porém, esses pesquisadores associaram a inibição à toxicidade conferida pelo fenol à biomassa e não às taxas de aplicação volumétricas. 
A concentração de SSV durante o ciclo 06 foi de 3.040 mg SSV/L e no ciclo 07 de 2.945 mg SSV/L. A relação A/M para os ciclos 06 e 07 foi igual a 0,06 kg fenol / kg SSV.dia, portanto abaixo do valor considerado inibitório (AUN, 2001). Dombroski (2003) também observou inibição do processo de desnitrificação com relações A/M inferiores a 0,10 kg fenol / kg SSV.dia. A inibição, observada, corrobora a necessidade de uma adição gradual de fenol ao longo da etapa anóxica do ciclo.

As figuras 36, 37, 38 e 39 apresentam os perfis temporais das concentrações das espécies químicas e dos parâmetros abióticos monitorados ao longo dos ciclos 06 e 07.

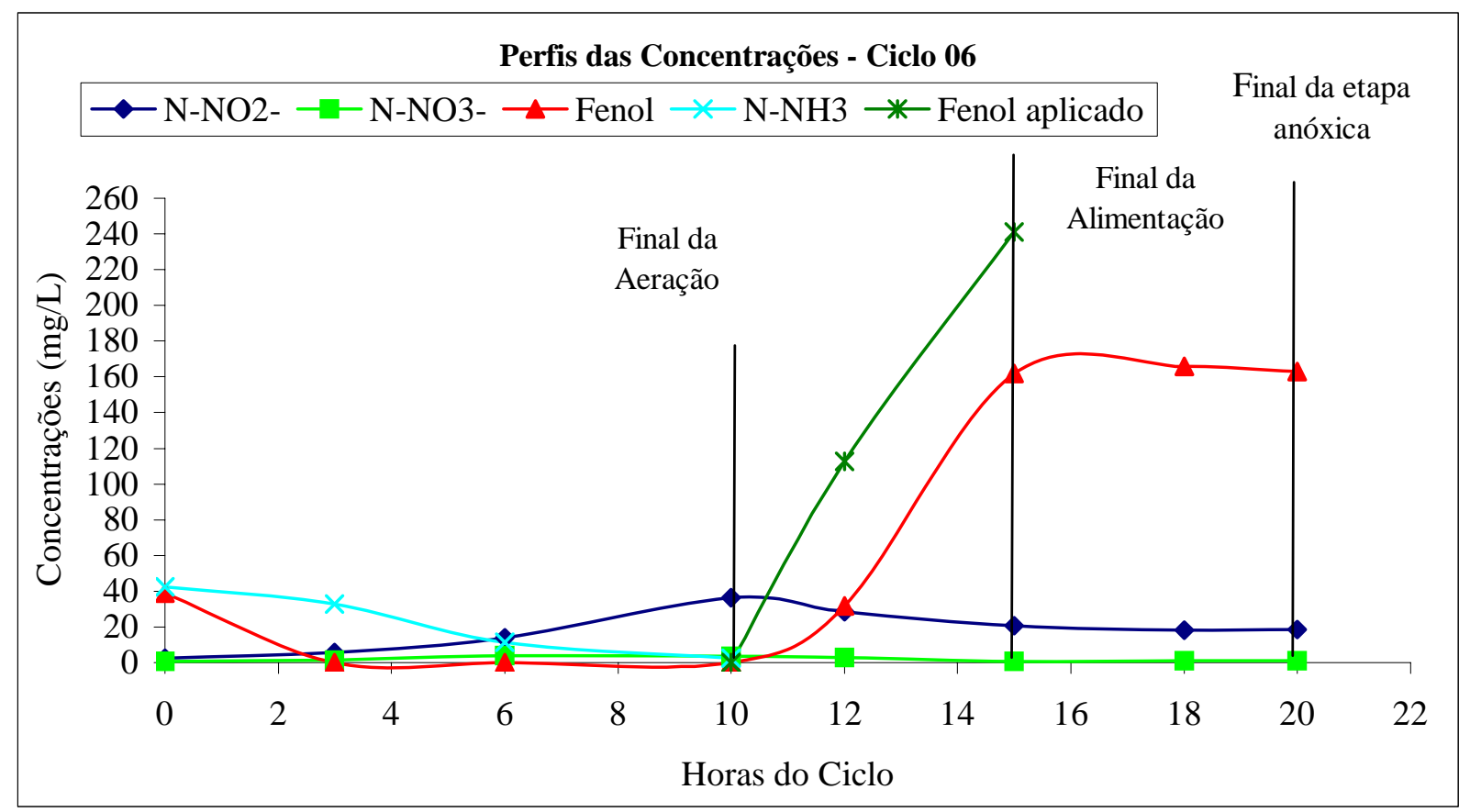

Figura 36: Perfis temporais das concentrações de $\mathrm{N}_{-} \mathrm{NO}_{2}{ }^{-} ; \mathrm{N}_{-} \mathrm{NO}_{3}{ }^{-}$; fenol; $\mathrm{N}_{-} \mathrm{NH}_{3}$ no conteúdo do reator piloto - Ciclo 06. ( $\mathrm{pH}$ na etapa aeróbia $\cong 8,3 ; \mathrm{T} \cong 33^{\circ} \mathrm{C}$ ) - Etapa 01 . 


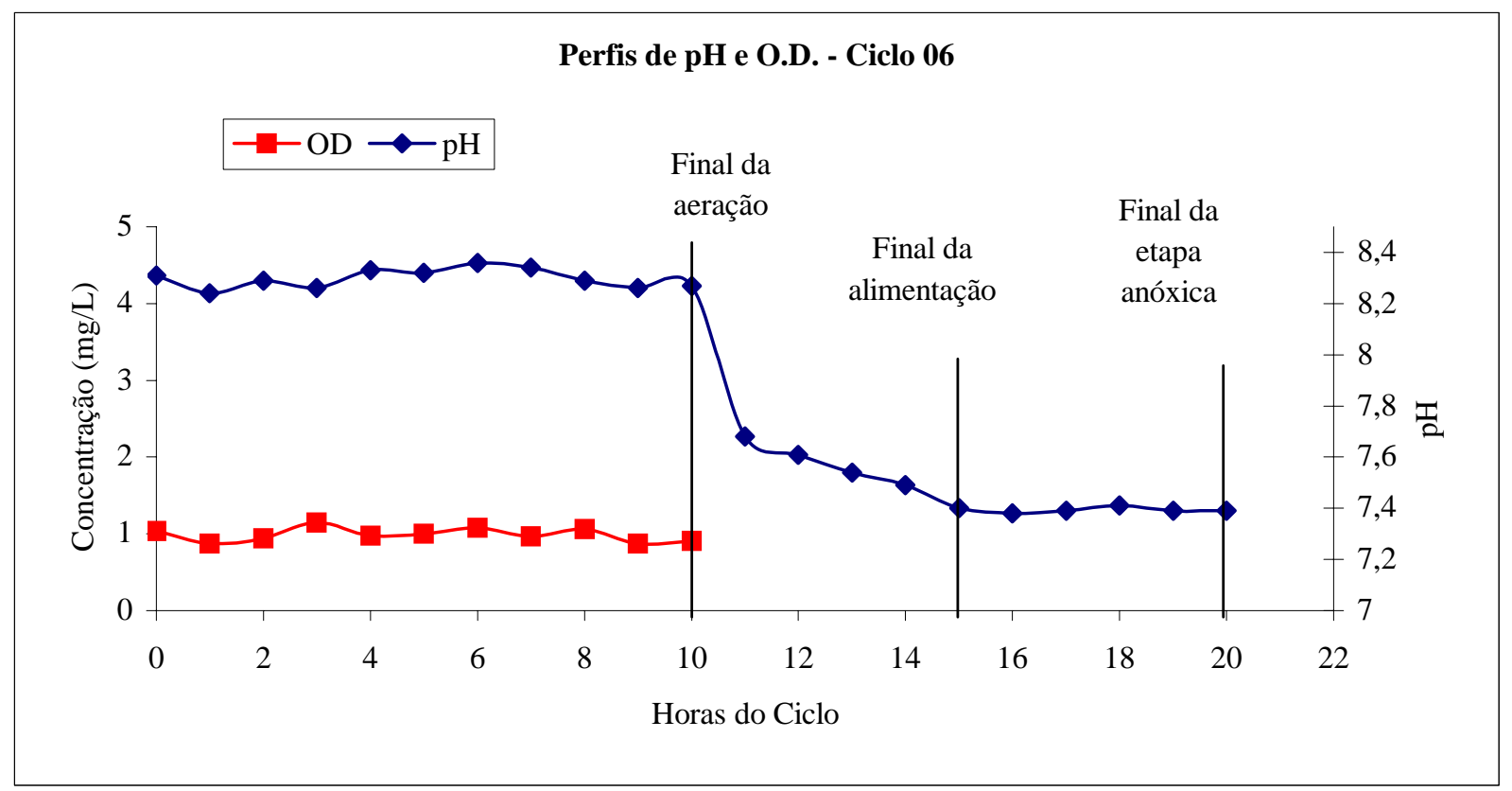

Figura 37: Perfis temporais de pH e oxigênio dissolvido no conteúdo do reator piloto - Ciclo 06 - Etapa 01.

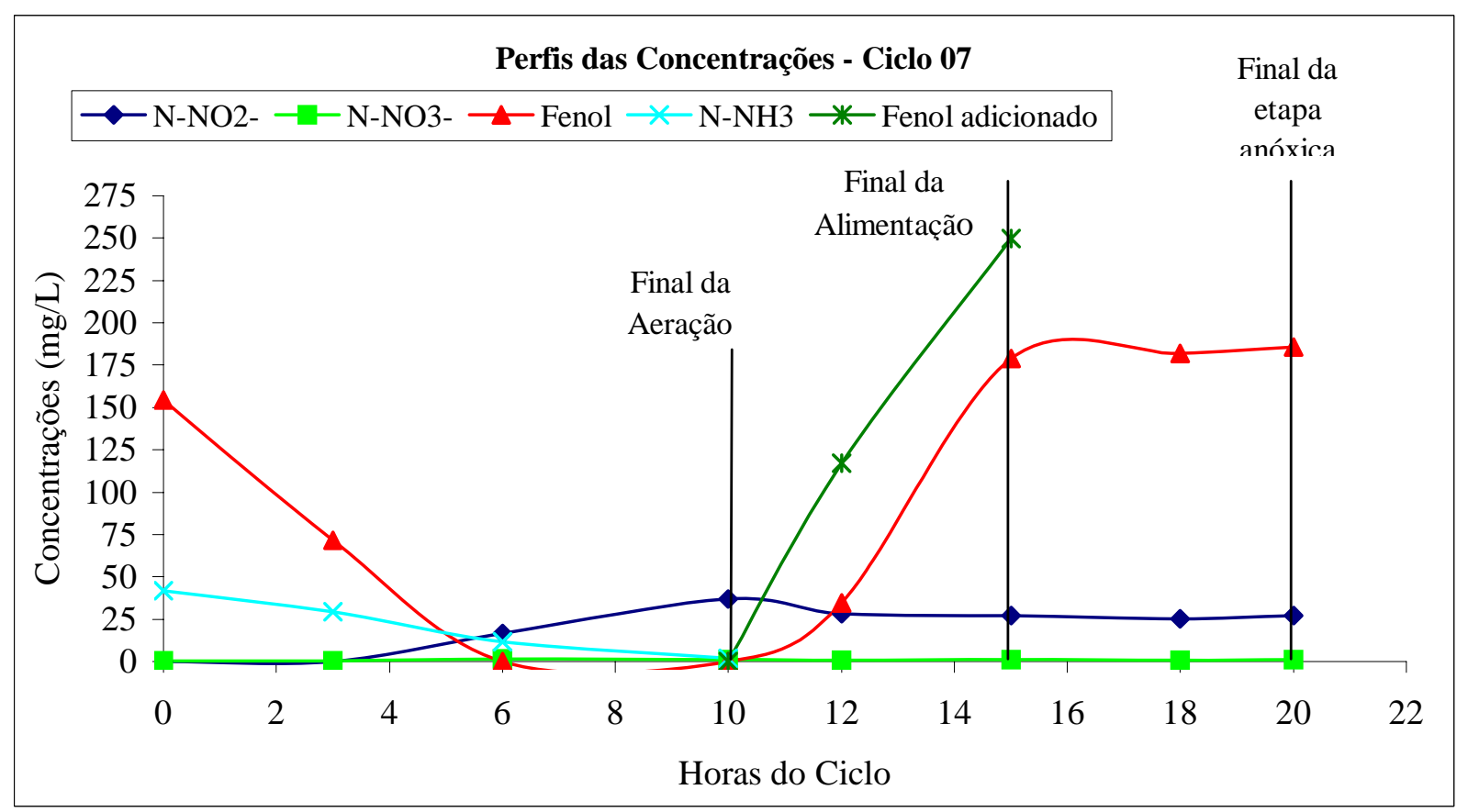

Figura 38: Perfis temporais das concentrações de $\mathrm{N}_{-} \mathrm{NO}_{2}{ }^{-}$; $\mathrm{N}-\mathrm{NO}_{3}{ }^{-}$; fenol; $\mathrm{N}-\mathrm{NH}_{3}$ no conteúdo do reator piloto - Ciclo 07 ( $\mathrm{pH}$ na etapa aeróbia $\cong 8,3$; $\mathrm{T} \cong 32,2^{\circ} \mathrm{C}$.) - Etapa 01 . 


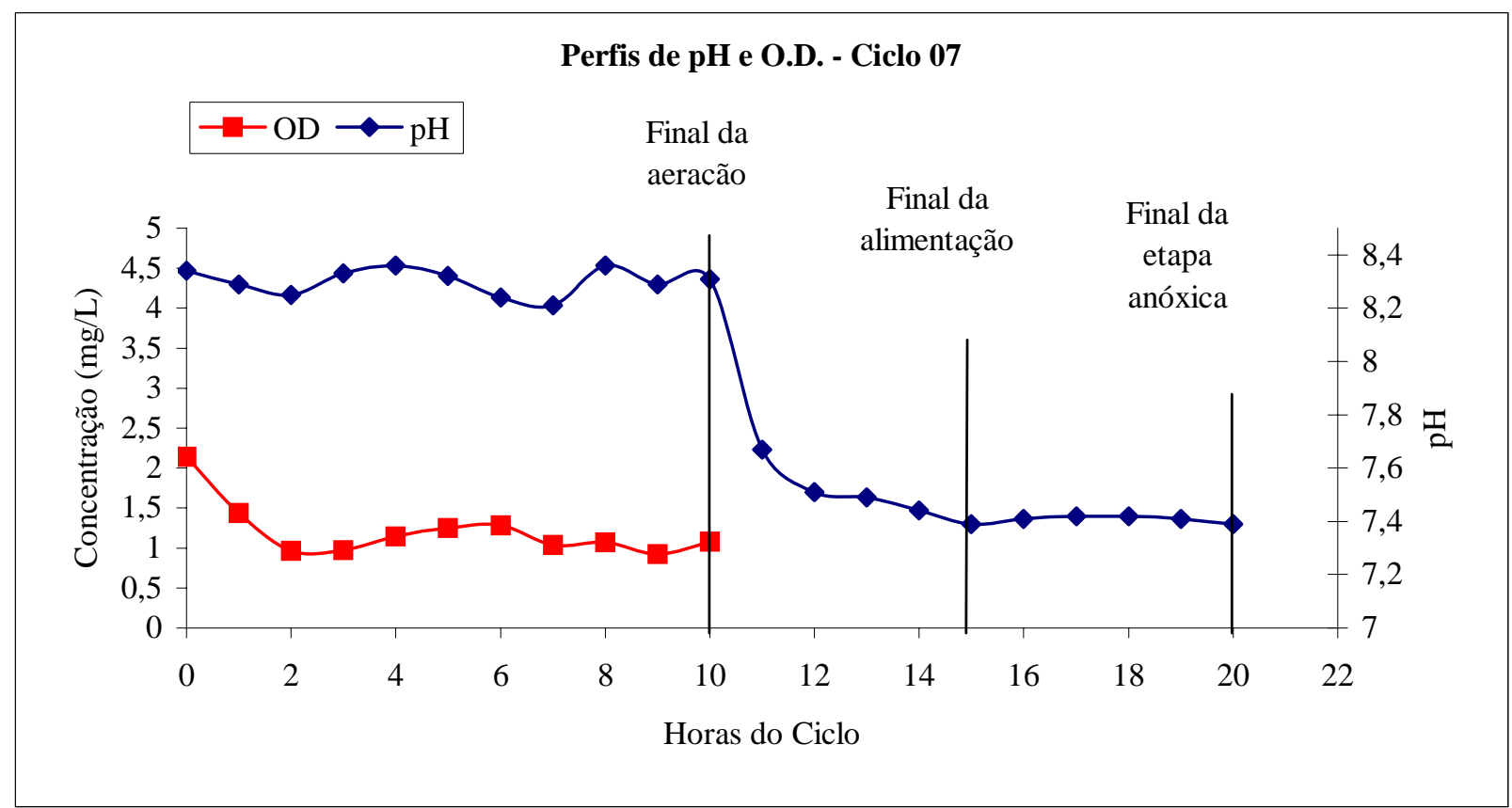

Figura 39: Perfis temporais de pH e oxigênio dissolvido no conteúdo do reator piloto - Ciclo 07 - Etapa 01.

A inibição da desnitritação, observada nos ciclos 06 e 07, induziu ao retorno da operação com adição gradual de água residuária fenólica ao longo da etapa anóxica, respeitando a taxa de aplicação volumétrica igual a 0,03 $\mathrm{kg} \mathrm{C}_{6} \mathrm{H}_{5} \mathrm{OH} / \mathrm{m}^{3}$. hora. Os ciclos: 08, 09, 10, 11 e 12, a exemplo do ciclo 05, foram realizados com duração de 10 horas da etapa aeróbia com

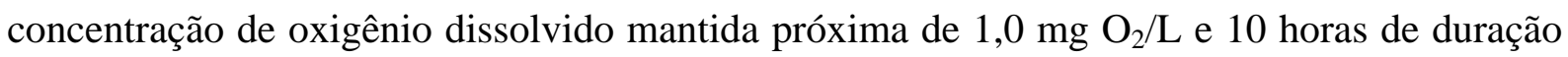
da etapa anóxica coincidindo com o período destinado à alimentação (alimentação e reação concomitantes, interrompendo-se a etapa anóxica ao final da adição da água residuária sintética). Ao longo desses ciclos de remoção, a temperatura no conteúdo do reator variou entre 32 e $33^{\circ} \mathrm{C}$.

A adição gradual de fenol permitiu a recuperação da eficiência da remoção do nitrogênio amoniacal oxidado não ocorrendo desequilíbrios semelhantes àqueles observados nos ciclos 06 e 07 . No ciclo 08 a eficiência de remoção de nitrogênio amoniacal oxidado foi de 97\% e a de fenol igual a 51\%, evidenciando a recuperação do sistema. 
A concentração de SSV entre os ciclos 08 e 12 variou entre 2.175 e 2.485 mg SSV/L; as eficiências de remoção de $\mathrm{N}-\mathrm{NH}_{3}$ foram sempre superiores a de 93\%, apresentando valores da relação $\mathrm{N}-\mathrm{NO}_{2}^{-} /\left(\mathrm{N}_{-} \mathrm{NO}_{2}^{-}+\mathrm{N}^{-} \mathrm{NO}_{3}^{-}\right)$maiores que 0,95 em todos os ciclos, evidenciando, portanto, a predominância do nitrito como forma oxidada do nitrogênio amoniacal ao longo desses ciclos. A taxa de nitritação calculada variou na entre 0,03 e 0,05 kg N-NH$/$ kg SSV.dia.

Os resultados dos ciclos 08 ao 12 (tabela 24), para a etapa anóxica, apresentaram remoção de fenol entre 37\% e 42\% e nitrogênio amoniacal oxidado entre 97\% e 100 \%; a taxa de desnitritação específica variou de 0,03 a $0,05 \mathrm{~kg} \mathrm{~N}-\mathrm{NO}_{2}^{-} / \mathrm{kg}$ SSV.dia. A relação fenol

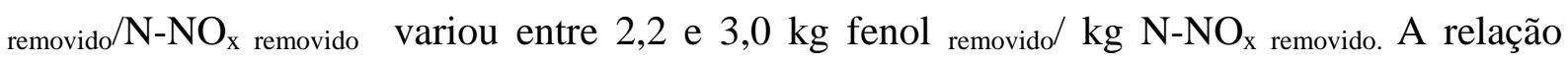
alimento/microrganismo (A/M) variou entre 0,09 e 0,11 kg fenol / kg SSV .dia.

As figuras 40 e 41 apresentam os perfis das concentrações das espécies químicas e dos parâmetros abióticos com as condições operacionais dos ciclos 08 ao 12 . Uma vez que a duração das diferentes etapas do ciclo de tratamento não sofreu alteração entre os ciclos 08 e 12, utilizou-se a média calculada das concentrações das espécies químicas para geração das figuras 40 e 41. 


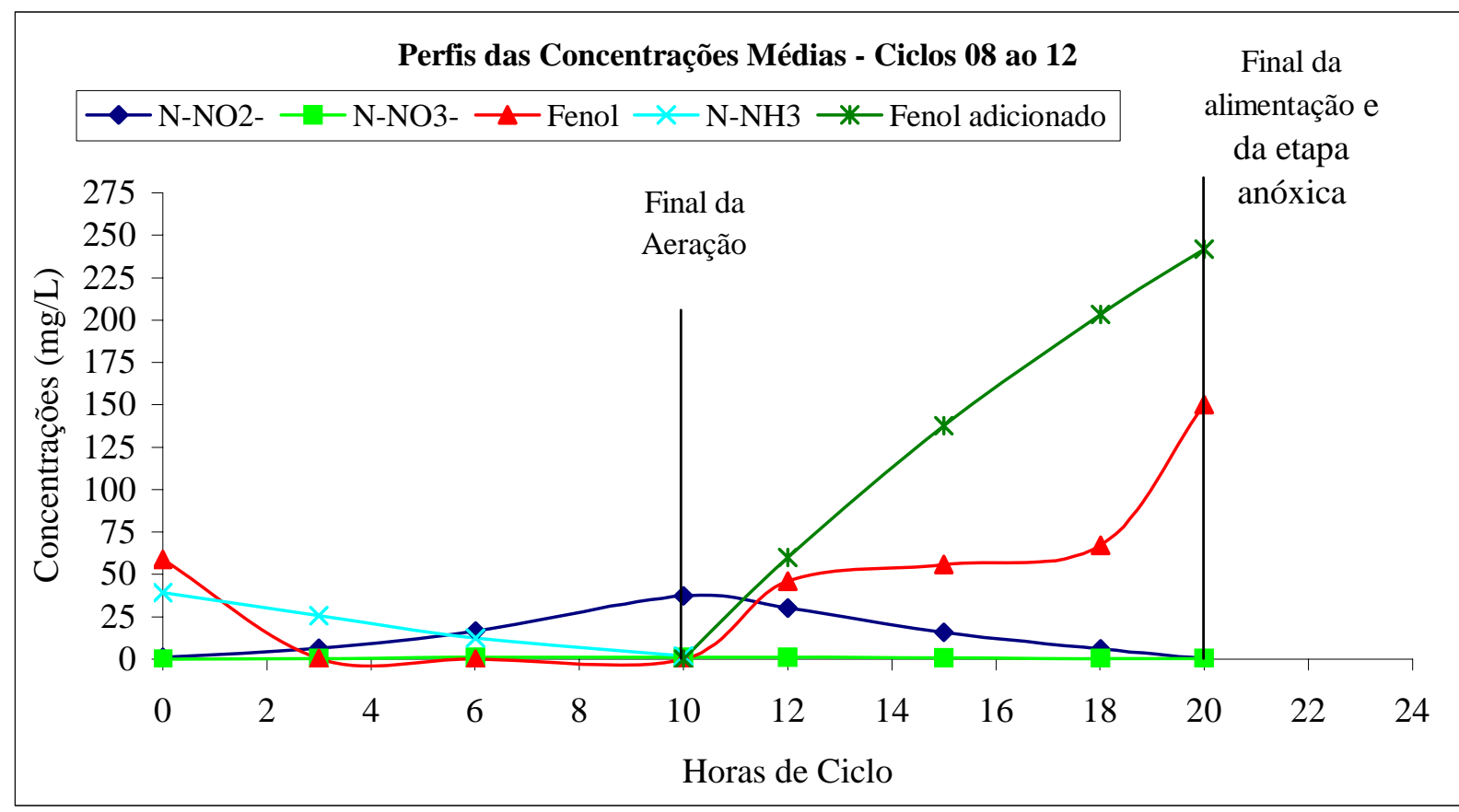

Figura 40: Perfis temporais das concentrações de $\mathrm{N}-\mathrm{NO}_{2}{ }^{-}$; $\mathrm{N}-\mathrm{NO}_{3}{ }^{-}$; fenol; $\mathrm{N}-\mathrm{NH}_{3}$ no conteúdo do reator piloto, calculadas como a média dos valores obtidos entre os ciclos 08 e 12 ( $\mathrm{pH}$ na etapa aeróbia $\cong 8,3 ; \mathrm{T} \cong 33^{\circ} \mathrm{C}$.).

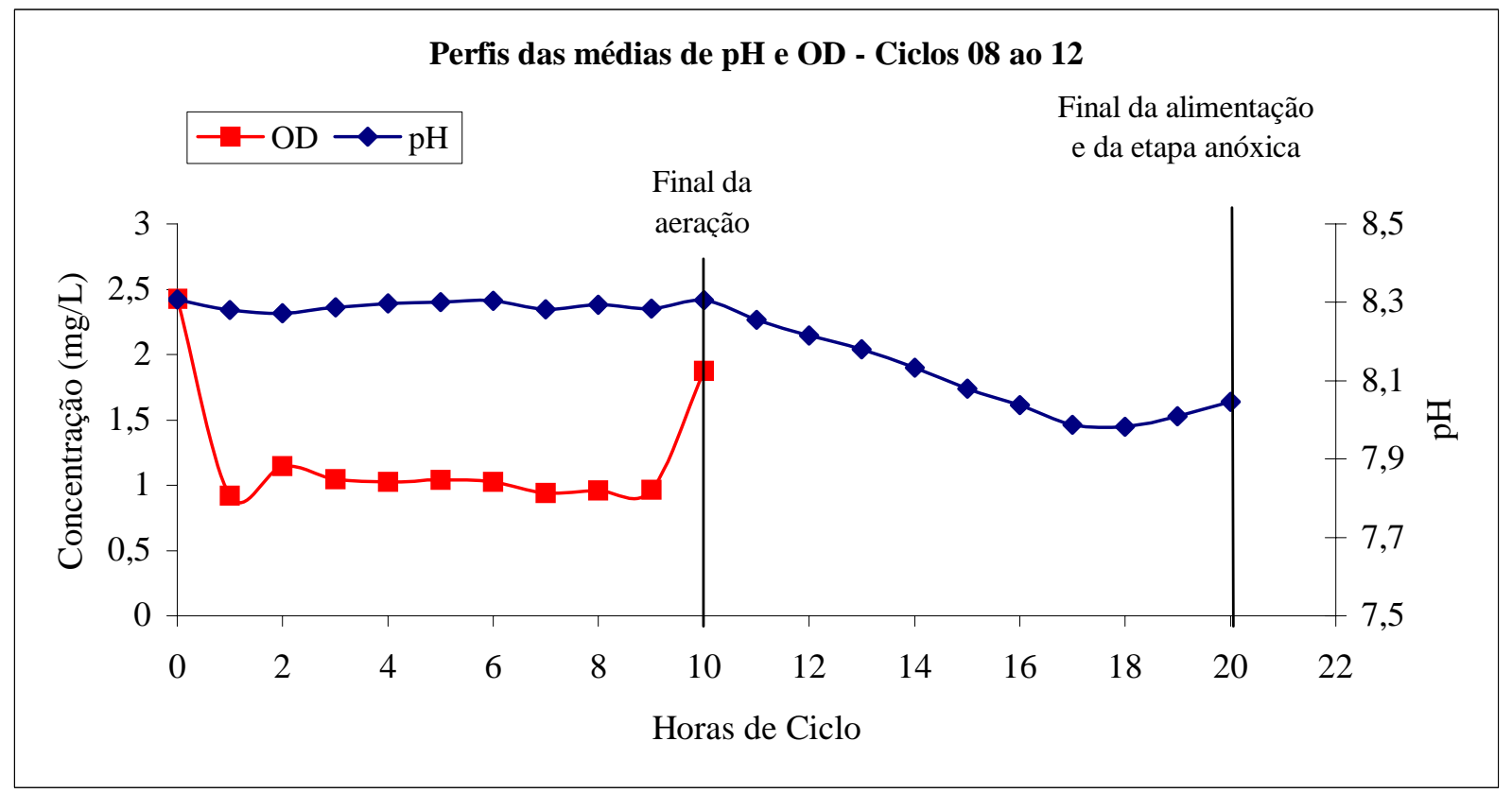

Figura 41: Perfis temporais das médias dos valores de $\mathrm{pH}$ e oxigênio dissolvido, no conteúdo do reator piloto, monitorados entre os ciclos 08 e 12.

Constatou-se entre os ciclos de tratamento 08 e 12 dessa etapa da pesquisa, que nas primeiras horas da etapa aeróbia dos ciclos ocorria uma inibição do processo de oxidação do nitrogênio amoniacal. Tal fato deveu-se a oxidação daquela quantidade de fenol que restava entre o final 
de um ciclo de tratamento e início do outro. Impactos negativos do excesso de carga orgânica ou de compostos orgânicos específicos na remoção biológica de nutrientes foram apontados em pesquisas anteriores (HOCKENBURY e GRADY JR., 1977; YUN et al., 2004); quanto ao fenol, especificamente, concentrações afluentes superiores a $400 \mathrm{mg} \mathrm{C}_{6} \mathrm{H}_{5} \mathrm{OH} / \mathrm{L}$ foram prejudiciais a nitrificação (UYGUR e KARGI, 2004).

Esse excesso de fenol, notado ao final da etapa anóxica e oxidado nas primeiras horas da etapa aeróbia, possibilitaria o aumento da carga de nitrogênio amoniacal afluente ao sistema, dada a existência de fonte de carbono para desnitrificação. Esse procedimento é desejável, uma vez que a utilização desse composto, como fonte de carbono para remoção do nitrogênio amoniacal oxidado, reduziria a demanda por $\mathrm{O}_{2}$ na etapa aeróbia dos ciclos de tratamento, e conseqüentemente, diminuiria os custos operacionais.

A tabela 24 apresenta um resumo dos resultados obtidos para a primeira etapa da segunda fase da pesquisa (concentração de nitrogênio amoniacal = $200 \mathrm{mg} \mathrm{N} / \mathrm{L}$ ). 
Tabela 24 - Resumo dos resultados da etapa 01 (nitrogênio amoniacal afluente = $200 \mathrm{mg}$ N/L) - Fase 02.

\begin{tabular}{|c|c|c|c|c|c|c|c|c|c|c|c|c|}
\hline \multirow{2}{*}{ PARÂMETROS } & \multicolumn{12}{|c|}{ CICLOS } \\
\hline & 01 & 02 & 03 & 04 & 05 & 06 & 07 & 08 & 09 & 10 & 11 & 12 \\
\hline $\begin{array}{l}\text { Carga de } \mathrm{N}-\mathrm{NH}_{3} \\
\text { (g N-NH} / \text { dia) }\end{array}$ & 0,5 & 0,5 & 1,0 & 0,9 & 1,0 & 1,0 & 1,0 & 1,0 & 1,0 & 1,0 & 1,0 & 0,9 \\
\hline $\begin{array}{l}\text { Carga de FENOL } \\
\text { (g C }{ }_{6} \mathrm{H}_{5} \mathrm{OH} / \text { dia) }\end{array}$ & 2,3 & 2,3 & 4,7 & 5,0 & 4,8 & 4,8 & 5,0 & 4,7 & 4,9 & 4,7 & 4,9 & 4,8 \\
\hline Q alimentação (ml/min) & 2,6 & 2,5 & 8,0 & 8,3 & 8,1 & 16 & 16 & 8,0 & 8,1 & 8,0 & 8,0 & 8,0 \\
\hline Temperatura Média ${ }^{\circ} \mathrm{C}$. & 32 & 32,5 & 32 & 32 & 33 & 33 & 32 & 33 & 32 & 33 & 33 & 33 \\
\hline pH (etapa aeróbia) & 8,3 & 8,3 & 8,3 & 8,3 & 8,3 & 8,3 & 8,3 & 8,3 & 8,3 & 8,3 & 8,3 & 8,3 \\
\hline SSV (mg SSV/L) & 3.420 & 3.280 & 3.510 & 2.608 & 2.808 & 3.040 & 2.945 & 2.460 & 2.230 & 2.175 & 2.445 & 2.485 \\
\hline Etapa Aeróbia (Horas) & 15 & 15 & 15 & 15 & 10 & 10 & 10 & 10 & 10 & 10 & 10 & 10 \\
\hline Etapa Anóxica (Horas) & 18 & 18 & 10 & 10 & 10 & 10 & 10 & 10 & 10 & 10 & 10 & 10 \\
\hline $\begin{array}{r}\text { Tx de nitritação esp. } \\
\text { (kg N-NH} / \text { kg SSV. dia) }\end{array}$ & 0,01 & 0,01 & 0,02 & 0,03 & 0,03 & 0,03 & 0,03 & 0,03 & 0,04 & 0,05 & 0,04 & 0,04 \\
\hline$\frac{\mathrm{N}-\mathrm{NO}_{2}}{\left(\mathrm{~N}-\mathrm{NO}_{2}^{-}+\mathrm{N}^{-}\right.}=$ & 90 & 64 & 83 & 84 & 97 & 91 & 97 & 94 & 99 & 98 & 95 & 97 \\
\hline $\begin{array}{c}\mathrm{A} / \mathrm{M} \\
\text { (kg Fenol/ kg SSV. dia) }\end{array}$ & 0,07 & 0,08 & 0,07 & 0,13 & 0,13 & 0,06 & 0,06 & 0,09 & 0,11 & 0,11 & 0,09 & 0,09 \\
\hline $\begin{array}{c}\text { Tx. de Desnitritação } \\
\text { (kg N-NO } \mathrm{NO}_{2} \text { / kg SSV .dia) }\end{array}$ & 0,01 & 0,01 & 0,03 & 0,04 & 0,03 & -- & 0,009 & 0,03 & 0,04 & 0,05 & 0,04 & 0,04 \\
\hline Remoção de $\mathrm{N}-\mathrm{NH}_{3}(\%)$ & 100 & 92 & 95 & 96 & 89 & 95 & 95 & 93 & 94 & 95 & 96 & 96 \\
\hline $\begin{array}{c}\text { Remoção de FENOL na } \\
\text { etapa anóxica (\%) }\end{array}$ & 28 & 40 & 42 & 46 & 45 & 33 & 26 & 39 & 42 & 41 & 37 & 38 \\
\hline Remoção de N oxidado (\%) & 99 & 64 & 83 & 99 & 97 & 53 & 28 & 97 & 100 & 97 & 99 & 100 \\
\hline$\frac{\mathrm{kg} \text { Fenol removido }}{\mathrm{kg} \mathrm{N} \text { oxidado removido }}$ & -- & 2,1 & 2,2 & 2,6 & 3,4 & -- & -- & 2,6 & 3,0 & 2,2 & 2,3 & 2,6 \\
\hline Amônia livre (mg/L)* & $\begin{array}{l}4,0 \mathrm{a} \\
0,8\end{array}$ & $\begin{array}{l}4,4 \mathrm{a} \\
0,4\end{array}$ & $\begin{array}{l}8,1 \mathrm{a} \\
0,4\end{array}$ & $\begin{array}{l}7,1 \mathrm{a} \\
0,3\end{array}$ & $\begin{array}{l}6,1 \mathrm{a} \\
0,5\end{array}$ & $\begin{array}{l}7,0 \mathrm{a} \\
0,4\end{array}$ & $\begin{array}{l}6,9 \mathrm{a} \\
0,3\end{array}$ & $\begin{array}{l}6,0 \mathrm{a} \\
0,4\end{array}$ & $\begin{array}{l}6,0 \mathrm{a} \\
0,4\end{array}$ & $\begin{array}{l}7,6 \text { a } \\
0,4\end{array}$ & $\begin{array}{l}6,8 \mathrm{a} \\
0,3\end{array}$ & $\begin{array}{l}6,2 \mathrm{a} \\
0,3\end{array}$ \\
\hline $\mathrm{HNO}_{2}(\mathrm{mg} / \mathrm{L})^{*}$ & $<0,002$ & $<0,007$ & $<0,001$ & $<0,001$ & $<0,001$ & $<0,001$ & $<0,001$ & $<0,001$ & $<0,001$ & $<0,001$ & $<0,001$ & $<0,001$ \\
\hline
\end{tabular}

* Concentrações calculadas de acordo com (ANTHONISEN et al., 1976) 


\subsection{2 - ETAPA 02 - CONCENTRAÇÃO AFLUENTE DE NITROGÊNIO AMONIACAL = $300 \mathrm{mg}$ N/L:}

Diante da disponibilidade de fenol, observada ao final da fase anóxica dos ciclos de tratamento daquela etapa conduzida com concentração afluente de nitrogênio amoniacal igual a $200 \mathrm{mg} \mathrm{N} / \mathrm{L}$, passou-se a estudar o comportamento dos processos de nitritação e desnitritação utilizando fenol como fonte de carbono, para concentrações afluentes de nitrogênio e fenol próximas a 300 mg N/L e 1.000 mg $\mathrm{C}_{6} \mathrm{H}_{5} \mathrm{OH} / \mathrm{L}$, respectivamente.

Durante esta nova etapa da pesquisa, o comportamento do potencial de oxi-redução foi monitorado no conteúdo do reator ao longo das diferentes etapas dos ciclos de tratamento. O consumo de alcalinizante, durante as etapas aeróbias dos ciclos, bem como, a possível recuperação de alcalinidade durante o processo de redução do nitrogênio oxidado, também foi investigado. Reduziu-se a faixa de temperatura no conteúdo do reator para valores próximos a $25^{\circ} \mathrm{C}$ do sistema com a finalidade de observar o acúmulo sustentado de $\mathrm{N}_{-} \mathrm{NO}_{2}{ }^{-}$nessa condição.

Para realização do primeiro ciclo dessa segunda etapa, programou-se a duração da etapa aeróbia em 15 horas, mantendo uma concentração de oxigênio dissolvido na massa líquida do reator próxima a 1,0 $\mathrm{mg} \mathrm{O}_{2} / \mathrm{L}$. O pH durante a etapa aeróbia foi controlado pela adição de uma solução de hidróxido de sódio e mantido próximo a 8,3. No início do primeiro ciclo da etapa 02, a concentração de SSV no conteúdo do tanque foi igual a 2.210 mg SSV/L

Ao final da fase aeróbia do ciclo de remoção para uma carga aplicada de 1,4 g N-NH$/$ dia., obteve-se uma eficiência de remoção de $\mathrm{N}-\mathrm{NH}_{3}$ de $95 \%$ com a predominância do nitrito como forma oxidada do nitrogênio amoniacal evidenciada pela relação $\mathrm{N}-\mathrm{NO}_{2}{ }^{-} /\left(\mathrm{N}_{-} \mathrm{NO}_{2}{ }^{-}+\right.$ $\mathrm{N}-\mathrm{NO}_{3}{ }^{-}$) igual a $89 \%$, mesmo com a temperatura próxima a $25^{\circ} \mathrm{C}$, portanto, abaixo daqueles valores da primeira etapa da pesquisa e de valores apontados na literatura como favoráveis ao acúmulo de $\mathrm{N}^{-\mathrm{NO}_{2}}{ }^{-}$, geralmente entre 30 e $35^{\circ} \mathrm{C}$. (TURK e MAVINIC, 1989; MULDER e 
VAN KEMPEN, 1997; VERSTRAETE e PHILIPS, 1998; KIM et al., 2003; JENICEK et al., 2004; MOSQUERA-CORRAL et al., 2005). A concentração de amônia livre calculada, nesse ciclo, variou entre 9,9 e 0,6 mg $\mathrm{NH}_{3} / \mathrm{L}$. A taxa de nitritação específica calculada foi igual a $0,04 \mathrm{~kg} \mathrm{~N}-\mathrm{NH}_{3} / \mathrm{kg} \mathrm{SSV}$. dia.

Programou-se 15 horas de duração para etapa anóxica com lançamento gradual do despejo sintético ao longo desse período. Ao término, a eficiência de remoção de nitrogênio amoniacal

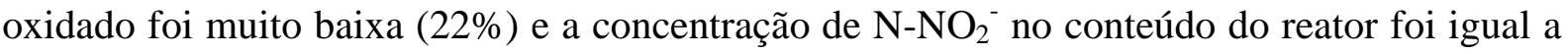
$38 \mathrm{mg} \mathrm{N}-\mathrm{NO}_{2}^{-} / \mathrm{L}$.

As figuras 42 e 43 apresentam os perfis das concentrações das espécies químicas e dos parâmetros abióticos (pH e O D.) no conteúdo do reator, ao longo desse primeiro ciclo da segunda etapa.

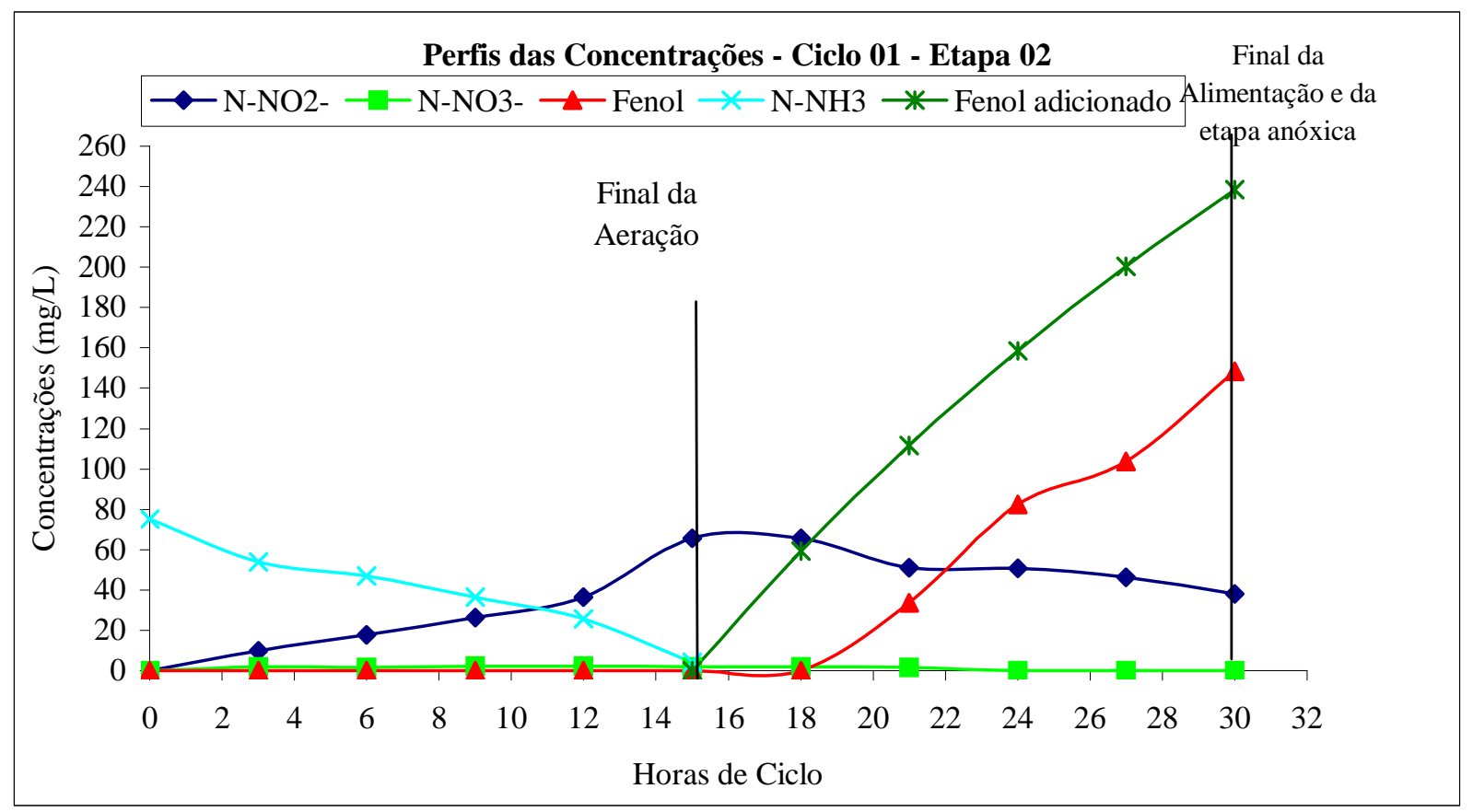

Figura 42: Perfis temporais das concentrações de $\mathrm{N}_{-} \mathrm{NO}_{2}{ }^{-}$; $\mathrm{N}-\mathrm{NO}_{3}{ }^{-}$; fenol; $\mathrm{N}-\mathrm{NH}_{3}$ no conteúdo do reator piloto - Ciclo 01 - Etapa 02. (pH na etapa aeróbia $\cong 8,3$; $\mathrm{T} \cong 25^{\circ} \mathrm{C}$ ). 


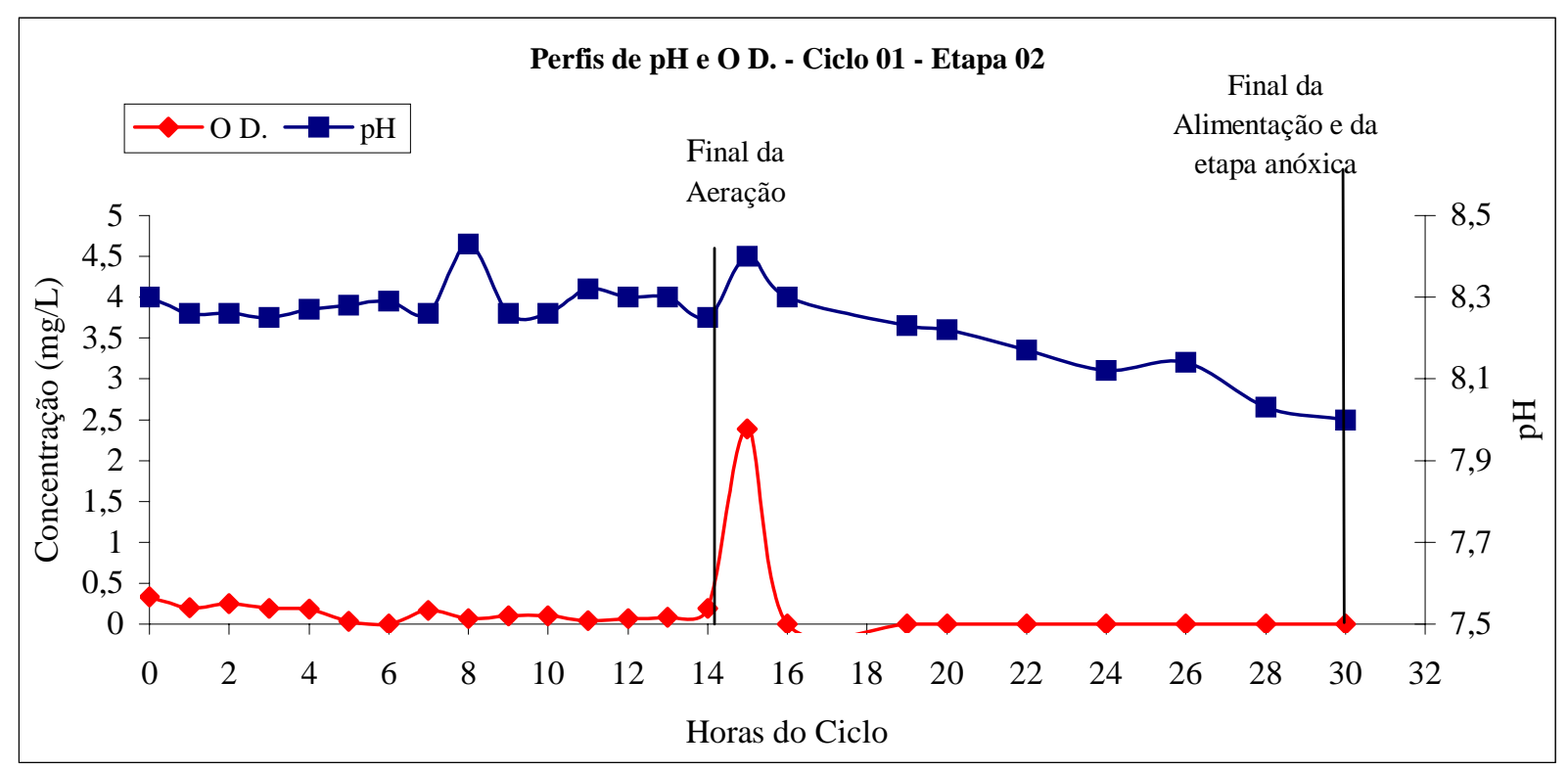

Figura 43: Perfis temporais de pH e O D. no conteúdo do reator piloto - Ciclo 01 - Etapa 02.

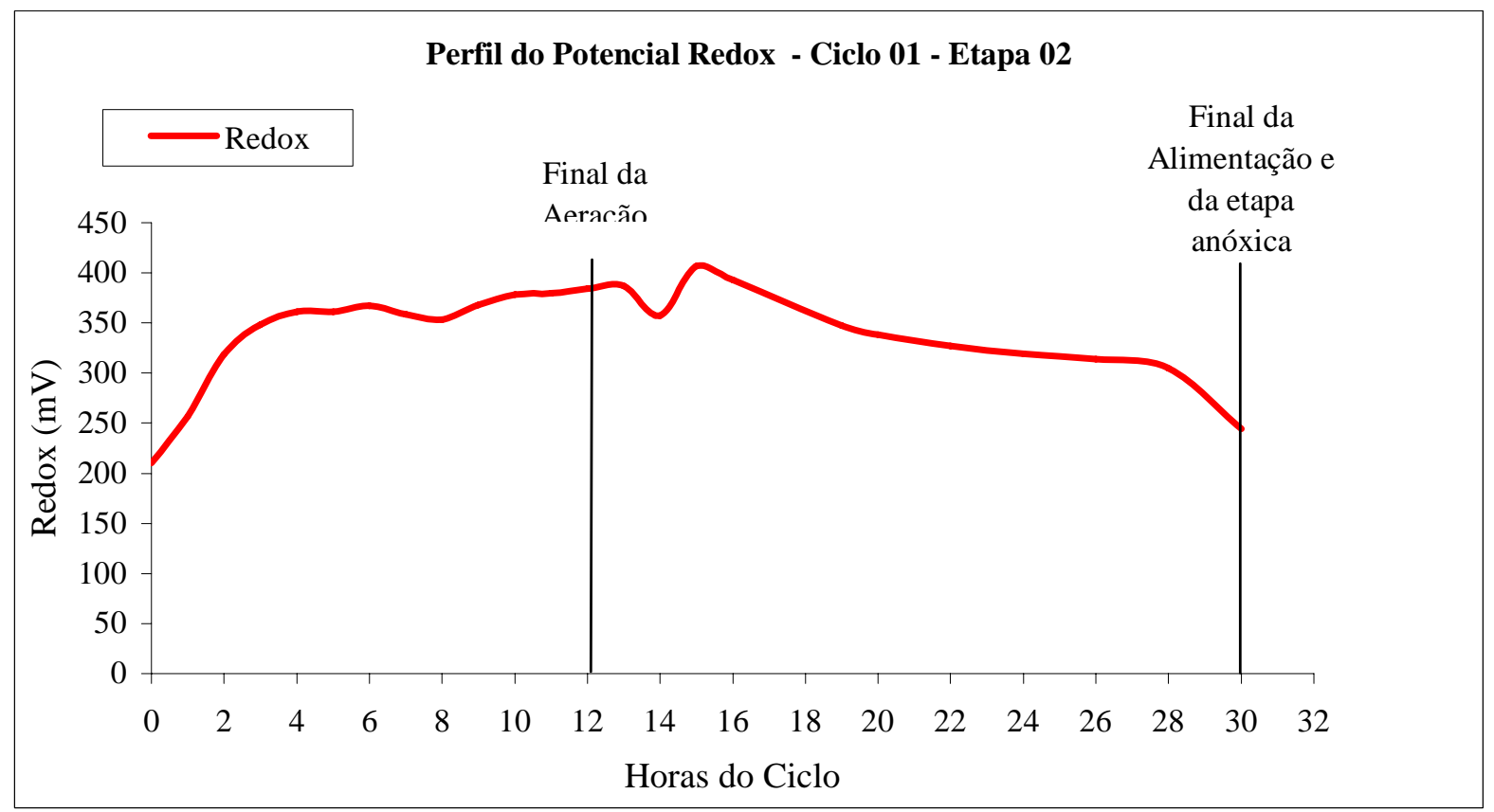

Figura 44: Perfil temporal de ORP no conteúdo do reator piloto - Ciclo 01 - Etapa 02.

Possivelmente, a baixa eficiência de remoção do nitrogênio oxidado durante o ciclo 01, deveu-se ao tempo (15 horas) insuficiente para degradação do fenol e redução do N-NOx. Para a realização do segundo ciclo, a etapa aeróbia foi programada com duração de 15 horas; entretanto, o tempo destinado à etapa anóxica foi avaliado até a redução significativa do nitrogênio amoniacal oxidado. O segundo ciclo de tratamento foi operado com uma temperatura próxima a $25^{\circ} \mathrm{C}$; valor de $\mathrm{pH}$, durante a etapa aeróbia, próximo a 8,3 e 
concentração de oxigênio dissolvido, no conteúdo do reator, próxima a $1,0 \mathrm{mg} \mathrm{O}_{2} / \mathrm{L}$. A concentração de SSV no conteúdo do reator foi de 2.275 mg SSV/L; a carga de nitrogênio amoniacal de 1,3 g N-NH 3 /dia e de fenol igual a 4,4 g $\mathrm{C}_{6} \mathrm{H}_{5} \mathrm{OH} /$ dia.

Para as condições aplicadas no segundo ciclo de tratamento, a eficiência de remoção de N$\mathrm{NH}_{3}$ foi de $96 \%$ e a relação $\mathrm{N}-\mathrm{NO}_{2}^{-} /\left(\mathrm{N}^{-} \mathrm{NO}_{2}{ }^{-}+\mathrm{N}^{-} \mathrm{NO}_{3}{ }^{-}\right)$atingiu $97 \%$ sendo que a taxa de nitritação específica foi igual a 0,03 kg N-NH 3 / kg SSV.dia.

As figuras 45 e 46 apresentam a distribuição das espécies químicas e parâmetros monitorados ao longo do ciclo de tratamento.

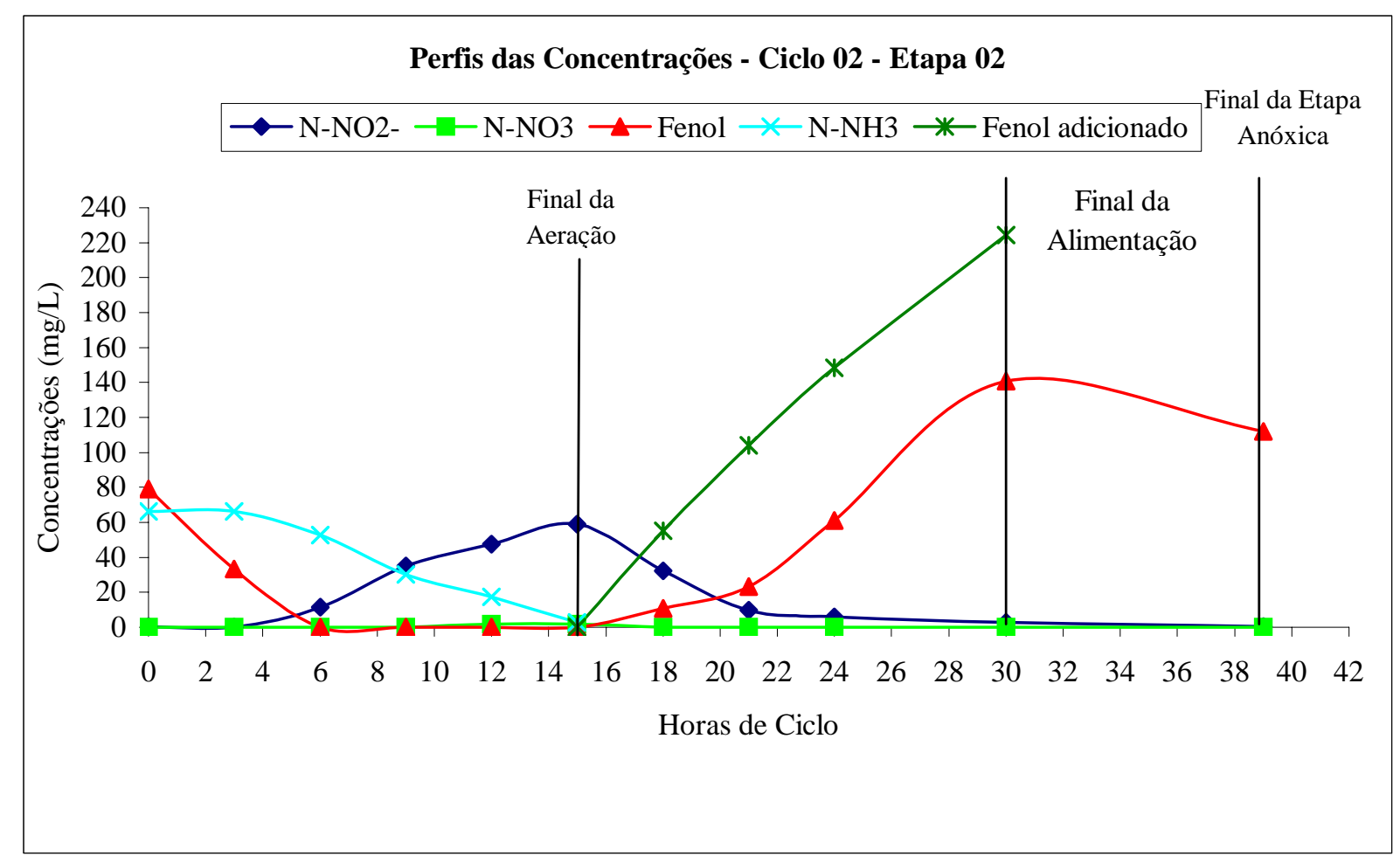

Figura 45: Perfis temporais das concentrações de $\mathrm{N}_{-} \mathrm{NO}_{2}{ }^{-} ; \mathrm{N}-\mathrm{NO}_{3}{ }^{-}$; fenol; $\mathrm{N}-\mathrm{NH}_{3}$ no conteúdo do reator piloto - Ciclo 02 - Etapa 02 (pH na etapa aeróbia $\cong 8,3 ; \mathrm{T} \cong 25^{\circ} \mathrm{C}$.). 


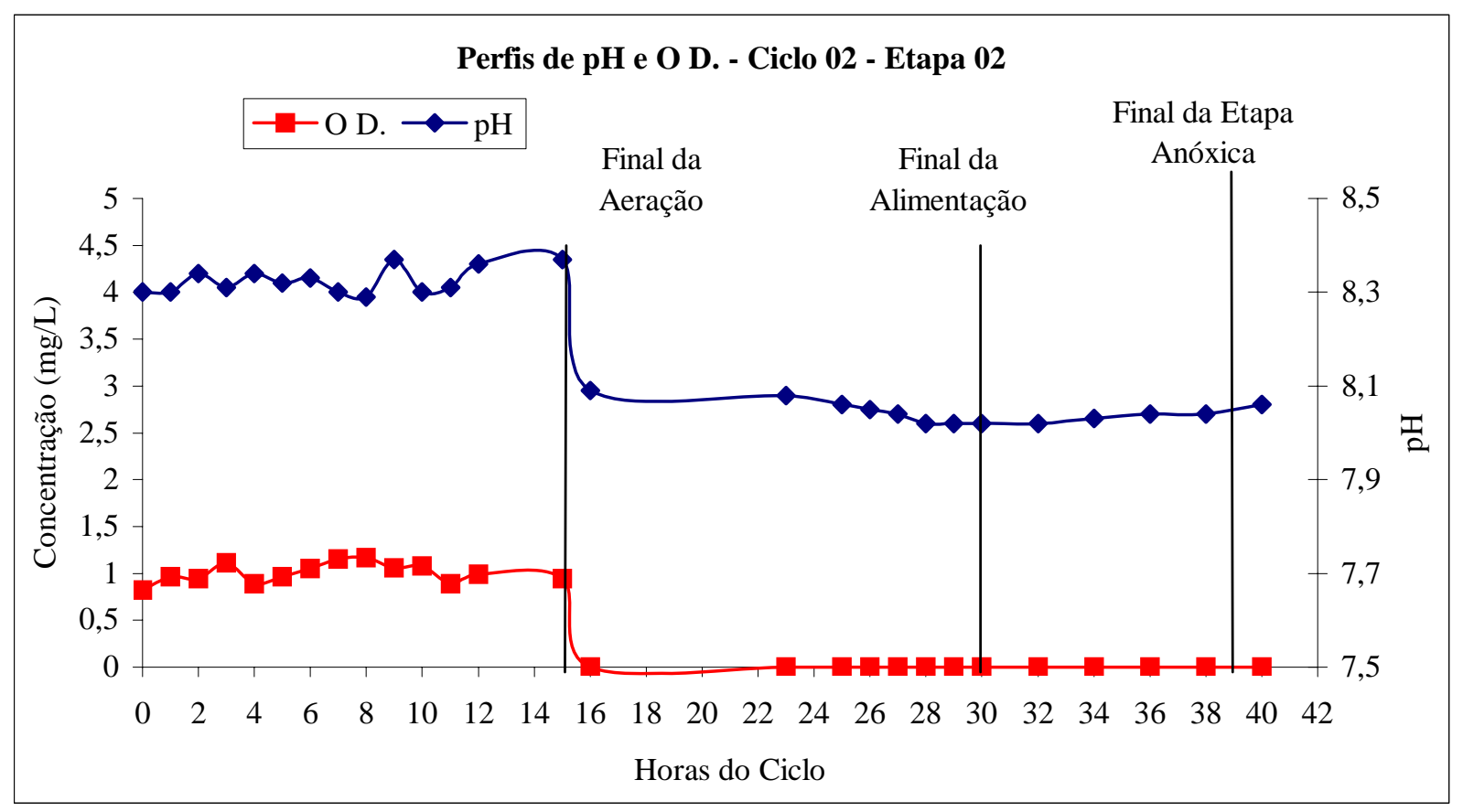

Figura 46: Perfis temporais de pH e O D. no conteúdo do reator piloto - Ciclo 02 - Etapa 02.

A aplicação do afluente ocorreu ao longo de 15 horas da etapa anóxica do ciclo de remoção, entretanto, nota-se (Figura 45) que foram necessárias 24 horas de duração dessa etapa para uma redução significativa do nitrogênio oxidado. A concentração de $\mathrm{N}_{-} \mathrm{NO}_{2}^{-}$, ao término desse intervalo de tempo, foi praticamente nula e o método analítico aplicado não acusou a presença de $\mathrm{N}^{-\mathrm{NO}_{3}}{ }^{-}$. A eficiência de remoção de fenol foi de $63 \%$ e do nitrogênio oxidado alcançou 99\%. A taxa de desnitritação específica foi igual a 0,02 kg N-NO${ }_{2}^{-} / \mathrm{kg} \mathrm{SSV.dia;}$ obteve-se uma relação A/M de 0,10 kg fenol/kg SSV.dia e, fenol removido/N-NOx removido de 3,1 kg fenol ${ }_{\text {removido }} / \mathrm{kg}$ N-NOx${ }_{\text {removido. }}$

A figura 47 mostra o perfil temporal do potencial de oxi-redução, monitorado na massa líquida do reator ao longo desse ciclo de tratamento. 


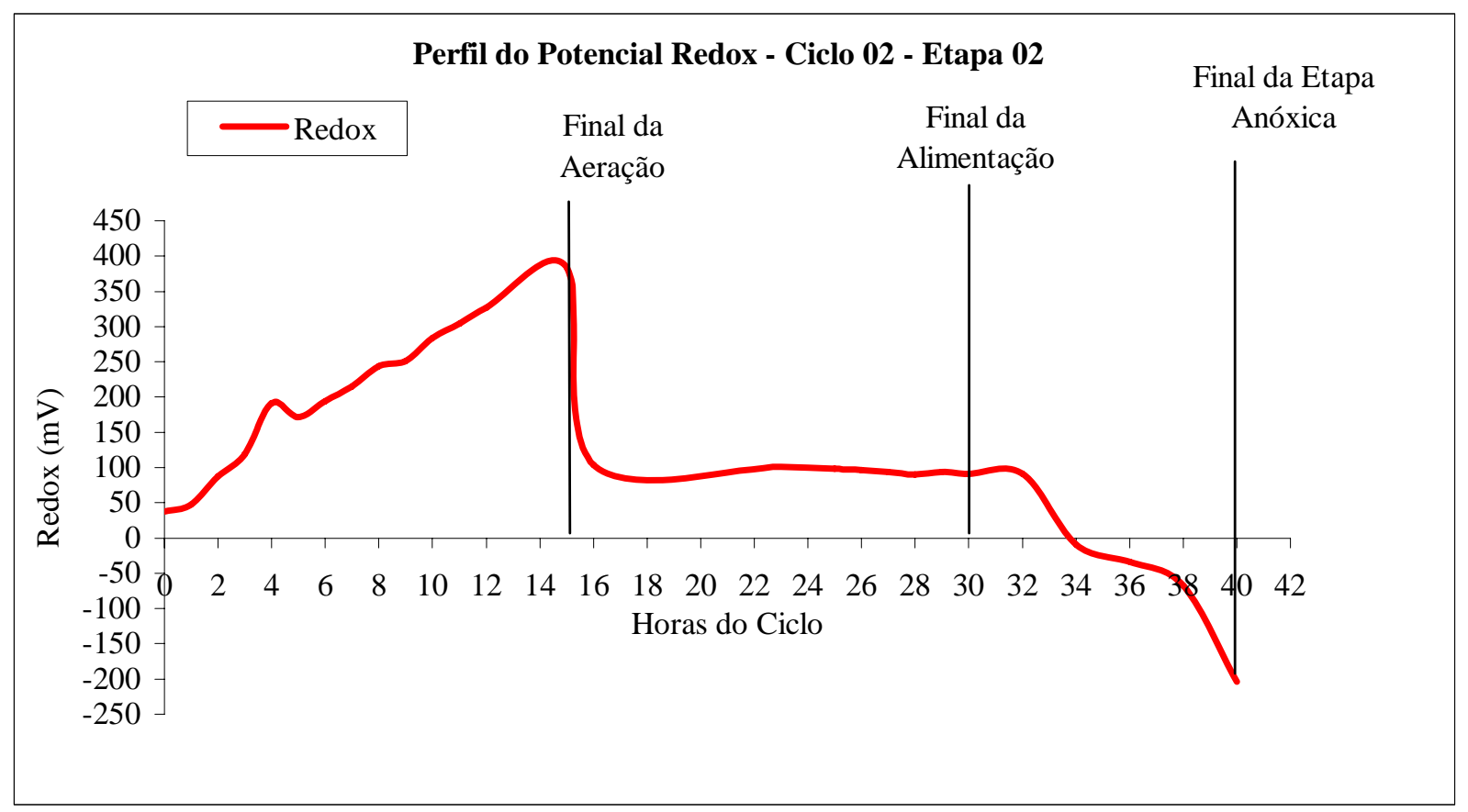

Figura 47: Perfil temporal de ORP no conteúdo do reator piloto - Ciclo 02 - Etapa 02.

Um erro na programação dos temporizadores (timers) estendeu a etapa aeróbia do ciclo 03 até 17 horas e conseqüentemente diminuiu a duração da etapa anóxica para 22 horas (15 horas com adição de afluente). As cargas de fenol e $\mathrm{N}-\mathrm{NH}_{3}$ foram, respectivamente, iguais a 4,9 g $\mathrm{C}_{6} \mathrm{H}_{5} \mathrm{OH} /$ dia e 1,4 g N-NH 3 /dia. A concentração de sólidos em suspensão voláteis, medida no início do ciclo 03, foi de $2.460 \mathrm{mg} \mathrm{SSV/L}$. Durante a operação, a temperatura variou entre 24 e $25^{\circ} \mathrm{C}$; o valor de $\mathrm{pH}$ esteve próximo a 8,3. A figura 48 apresenta o perfil das concentrações das diferentes espécies químicas no conteúdo do reator piloto ao longo do ciclo 03 de tratamento. 


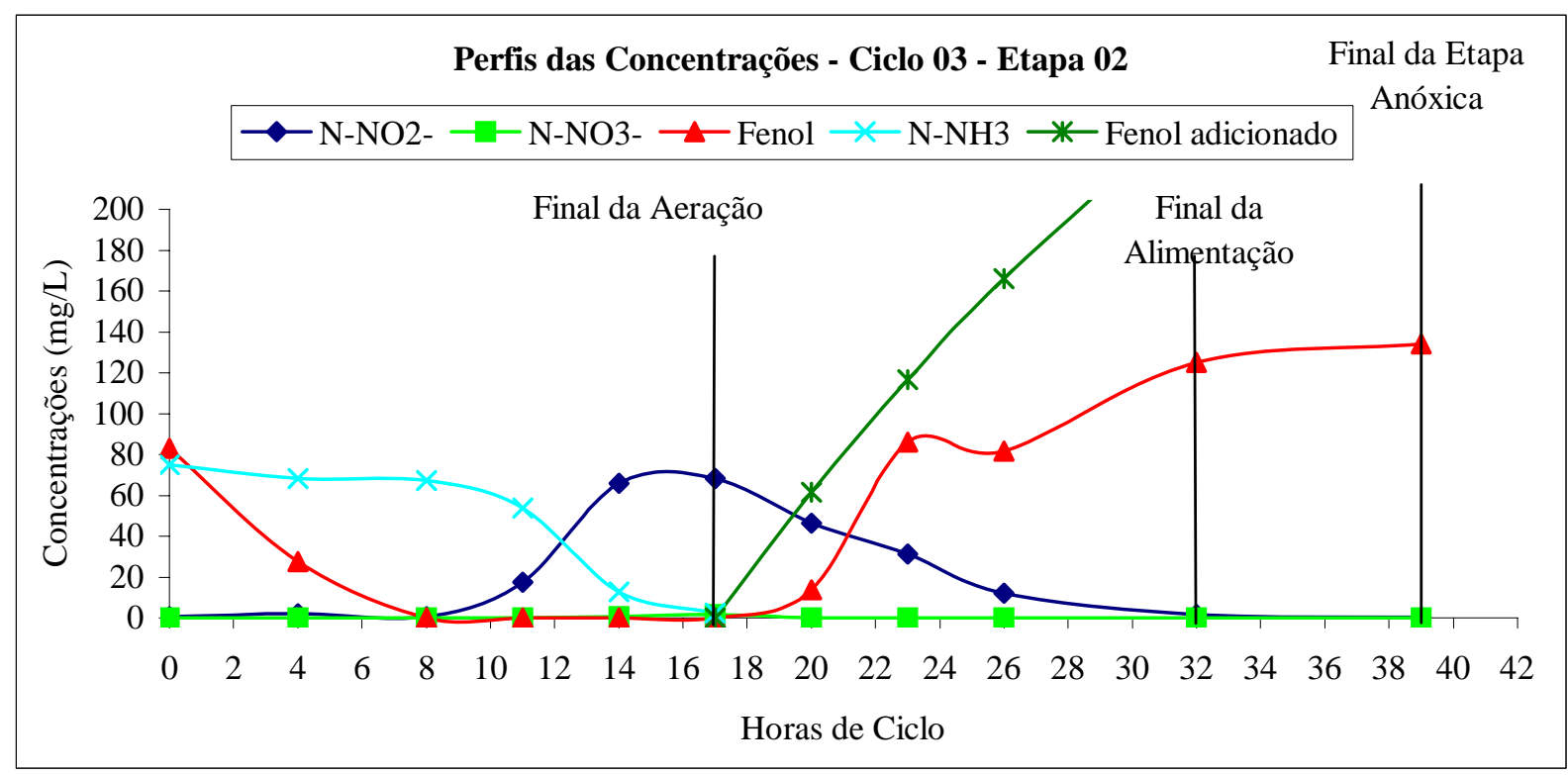

Figura 48: Perfis temporais das concentrações de $\mathrm{N}^{-\mathrm{NO}_{2}}{ }^{-} ; \mathrm{N}^{-\mathrm{NO}_{3}}{ }^{-}$; fenol; $\mathrm{N}^{-\mathrm{NH}_{3}}$ no conteúdo do reator piloto - Ciclo 03 - Etapa 02. (pH na etapa aeróbia $\cong 8,3$; $\mathrm{T} \cong 24^{\circ} \mathrm{C}$.).

O prolongamento da etapa aeróbia (17 horas) não comprometeu o acúmulo de nitrito, a relação $\mathrm{N}-\mathrm{NO}_{2}{ }^{-} /\left(\mathrm{N}^{-\mathrm{NO}_{2}}{ }^{-}+\mathrm{N}-\mathrm{NO}_{3}{ }^{-}\right)$foi igual a $98 \%$ e a eficiência de remoção de $\mathrm{N}-\mathrm{NH}_{3}$ de 97\%. A taxa de nitritação específica apresentou valor igual a 0,04 kg N-NH $/$ kg SSV.dia. A concentração de amônia livre durante essa etapa do ciclo, calculada de acordo com Anthonisen et al. (1976), variou entre 9,3 e 0,3 $\mathrm{mg} \mathrm{NH}_{3} / \mathrm{L}$, portanto próximo daquele limite (10,0 mg $\left.\mathrm{NH}_{3} / \mathrm{L}\right)$ considerado por esses pesquisadores como inibitório a todo processo de nitrificação.

As eficiências de remoção de fenol (60\%) e de N-NOx (99\%), ao final da etapa anóxica, foram bem semelhantes às do segundo ciclo. A relação $A / M$ apresentou valor de $0,10 \mathrm{~kg}$ fenol/kg SSV.dia e a taxa de desnitritação específica foi igual a 0,02 $\mathrm{kg} \mathrm{N}-\mathrm{NO}_{2}{ }^{-} / \mathrm{kgSSV}^{-d i a . ~ A ~}$ relação fenol removido / N-NOx removido = 2,9 kg fenol removido $/$ kg N-NOx removido. As figuras 49 e 50 apresentam os perfis dos parâmetros abióticos e potencial de oxi-redução monitorados durante a realização do ciclo 03 de tratamento. 


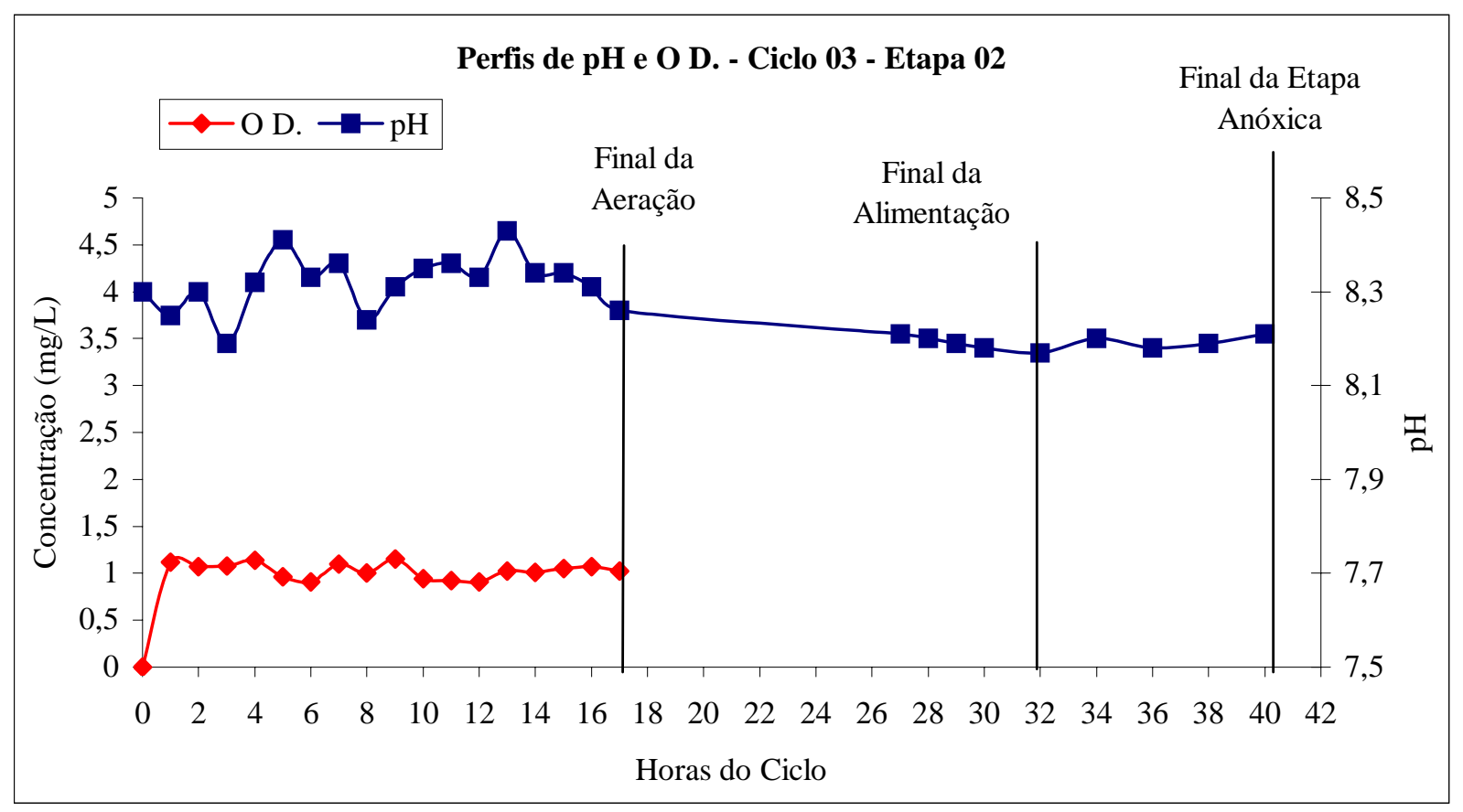

Figura 49: Perfis temporais de pH e O D. no conteúdo do reator piloto - Ciclo 03 - Etapa 02.

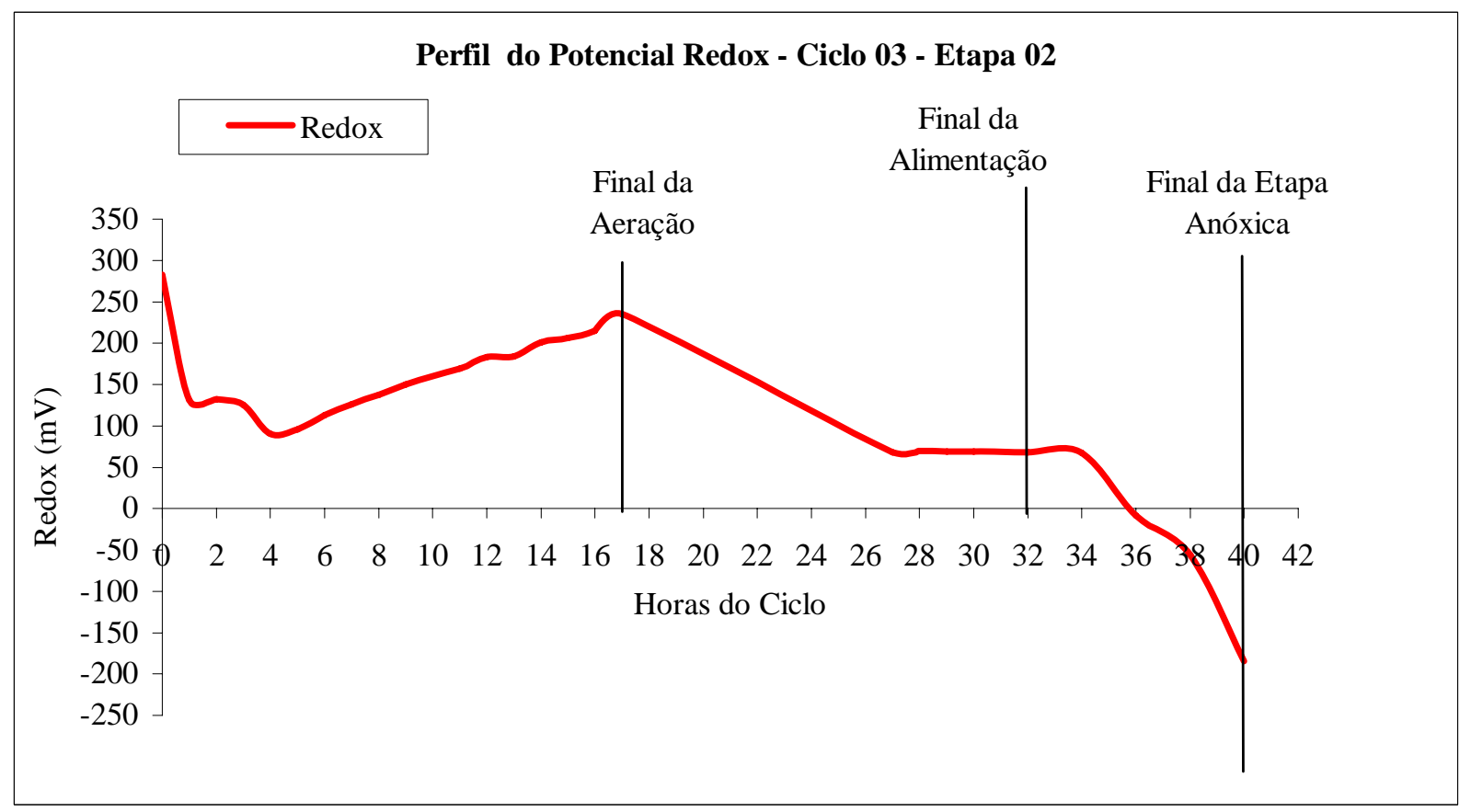

Figura 50: Perfil temporal de ORP no conteúdo do reator piloto - Ciclo 03 - Etapa 02.

Para realização dos demais ciclos (04 e 05) dessa segunda etapa da pesquisa, a etapa aeróbia durou 15 horas e a etapa anóxica, 24 horas; o lançamento do despejo, no conteúdo do reator, ocorreu durante 15 horas da fase anóxica. Não foram constatados desequilíbrios ao longo da realização desses ciclos; o $\mathrm{N}^{-\mathrm{NO}_{2}}{ }^{-}$foi a forma predominante do nitrogênio oxidado e as 
eficiências de remoção de fenol e N-NOx, ao final da etapa anóxica, variaram entre 64 e 65\% e 98 e 100\%, respectivamente. As figuras 51, 52, 53, 54, 55 e 56 apresentam os perfis das concentrações das espécies químicas, valor de pH e concentração de oxigênio dissolvido, além do perfil do potencial de oxi-redução no conteúdo do reator, ao longo desses ciclos de remoção de $\mathrm{N}-\mathrm{NH}_{3}$ e fenol.

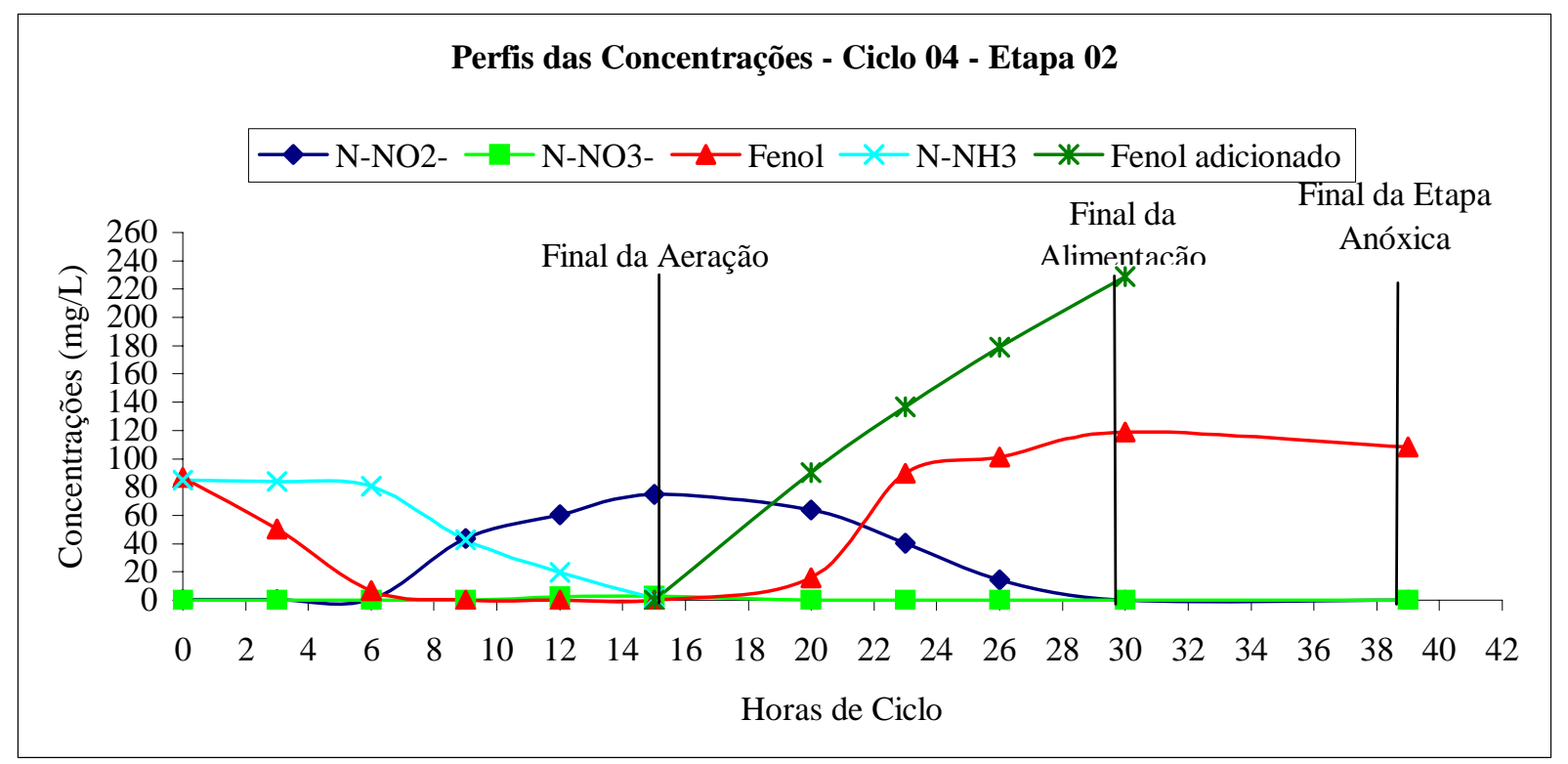

Figura 51: Perfis temporais das concentrações de $\mathrm{N}^{-\mathrm{NO}_{2}}{ }^{-}$; $\mathrm{N}-\mathrm{NO}_{3}{ }^{-}$; fenol; $\mathrm{N}^{-\mathrm{NH}_{3}}$ no conteúdo do reator piloto - Ciclo 04 - Etapa 02 . ( $\mathrm{pH}$ na etapa aeróbia $\cong 8,3 ; \mathrm{T} \cong 24^{\circ} \mathrm{C}$ ).

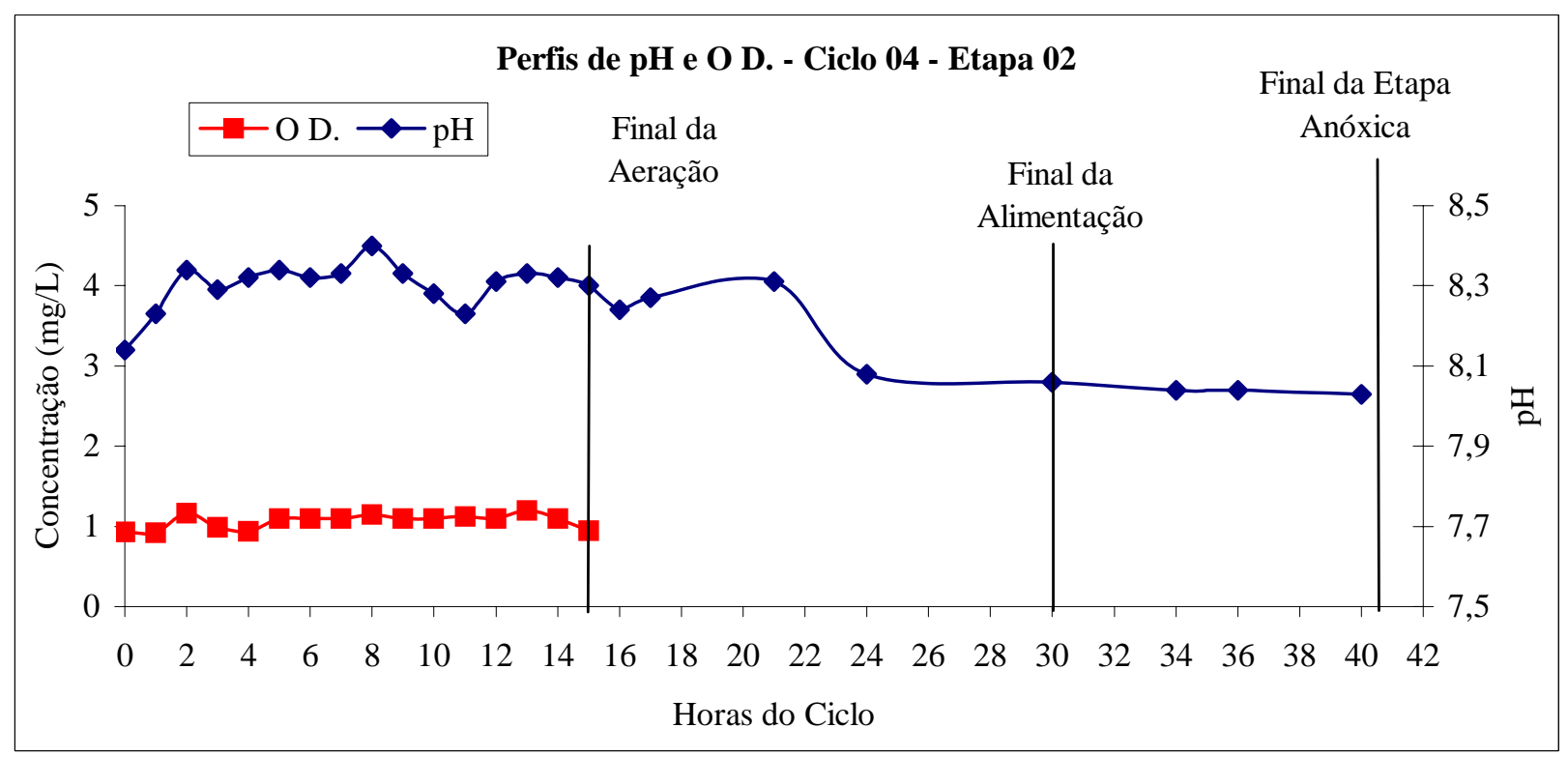

Figura 52: Perfis temporais de pH e O D. no conteúdo do reator piloto - Ciclo 04 - Etapa 02. 


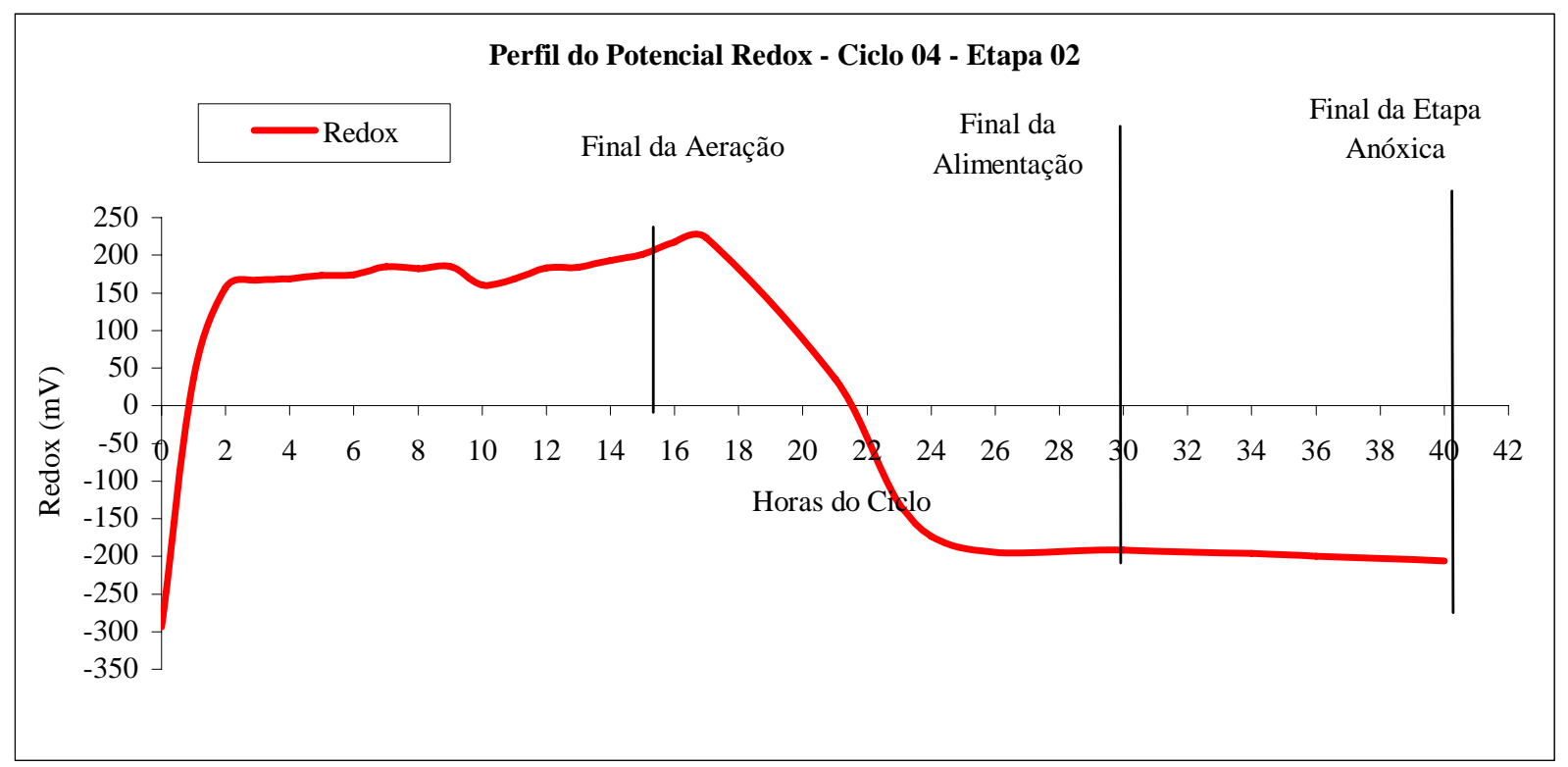

Figura 53: Perfil temporal de ORP no conteúdo do reator piloto - Ciclo 04 - Etapa 02.

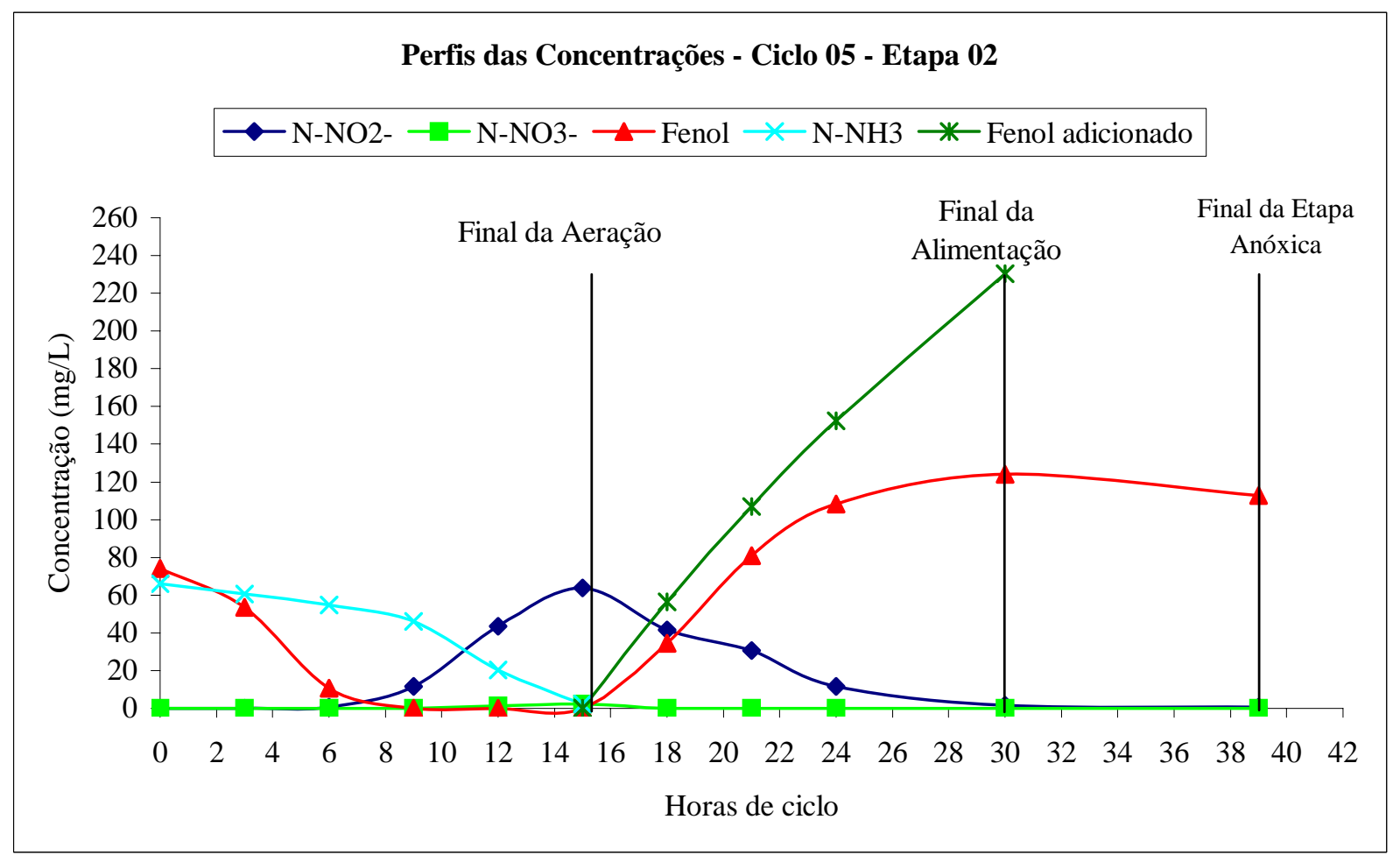

Figura 54: Perfis temporais das concentrações de $\mathrm{N}-\mathrm{NO}_{2}{ }^{-} ; \mathrm{N}-\mathrm{NO}_{3}{ }^{-}$; fenol; $\mathrm{N}_{-} \mathrm{NH}_{3}$ no conteúdo do reator piloto - Ciclo 05 - Etapa 02 (pH na etapa aeróbia $\cong 8,2 ; \mathrm{T} \cong 23^{\circ} \mathrm{C}$ ). 


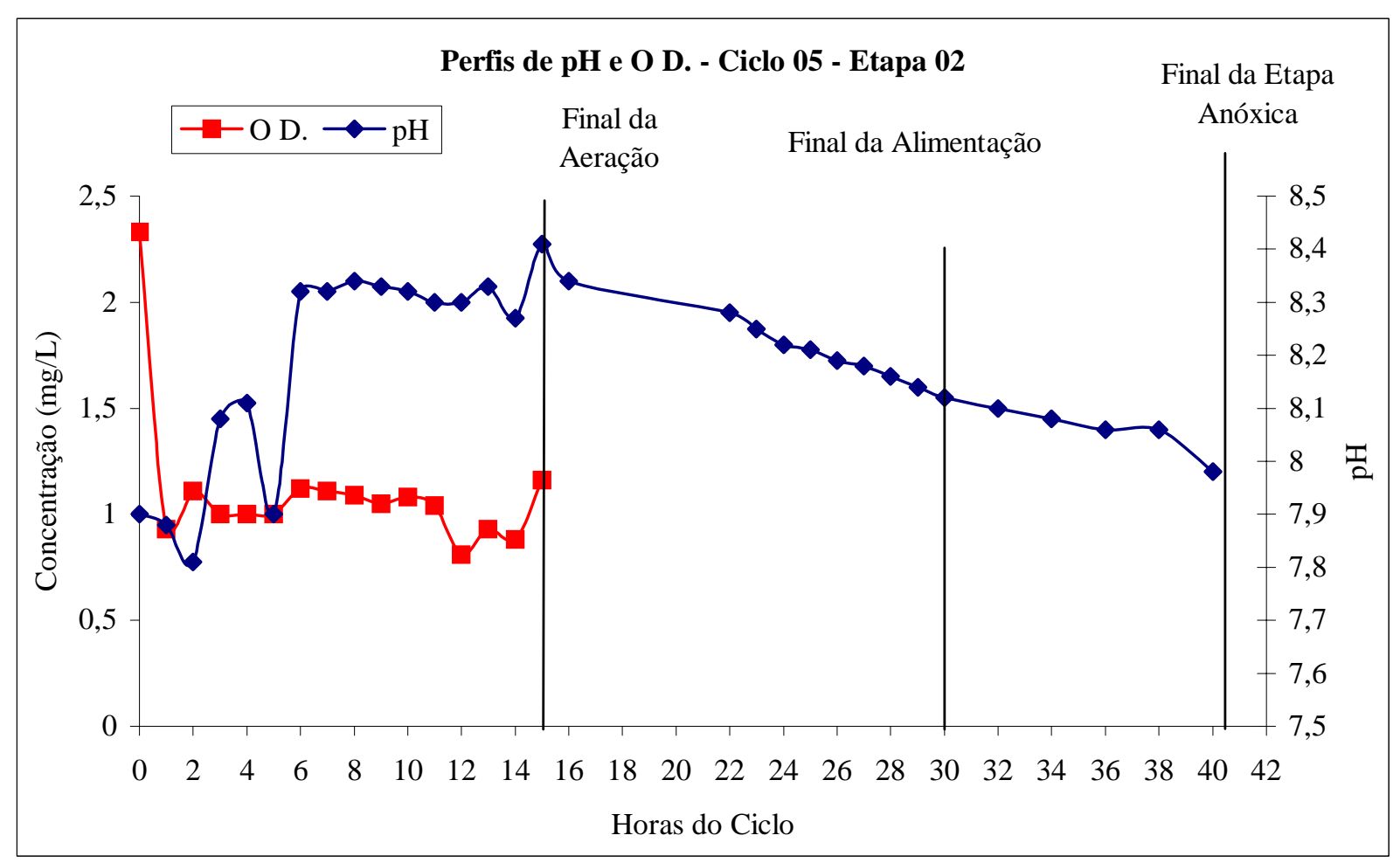

Figura 55: Perfis temporais de pH e O D. no conteúdo do reator piloto - Ciclo 05 - Etapa 02.

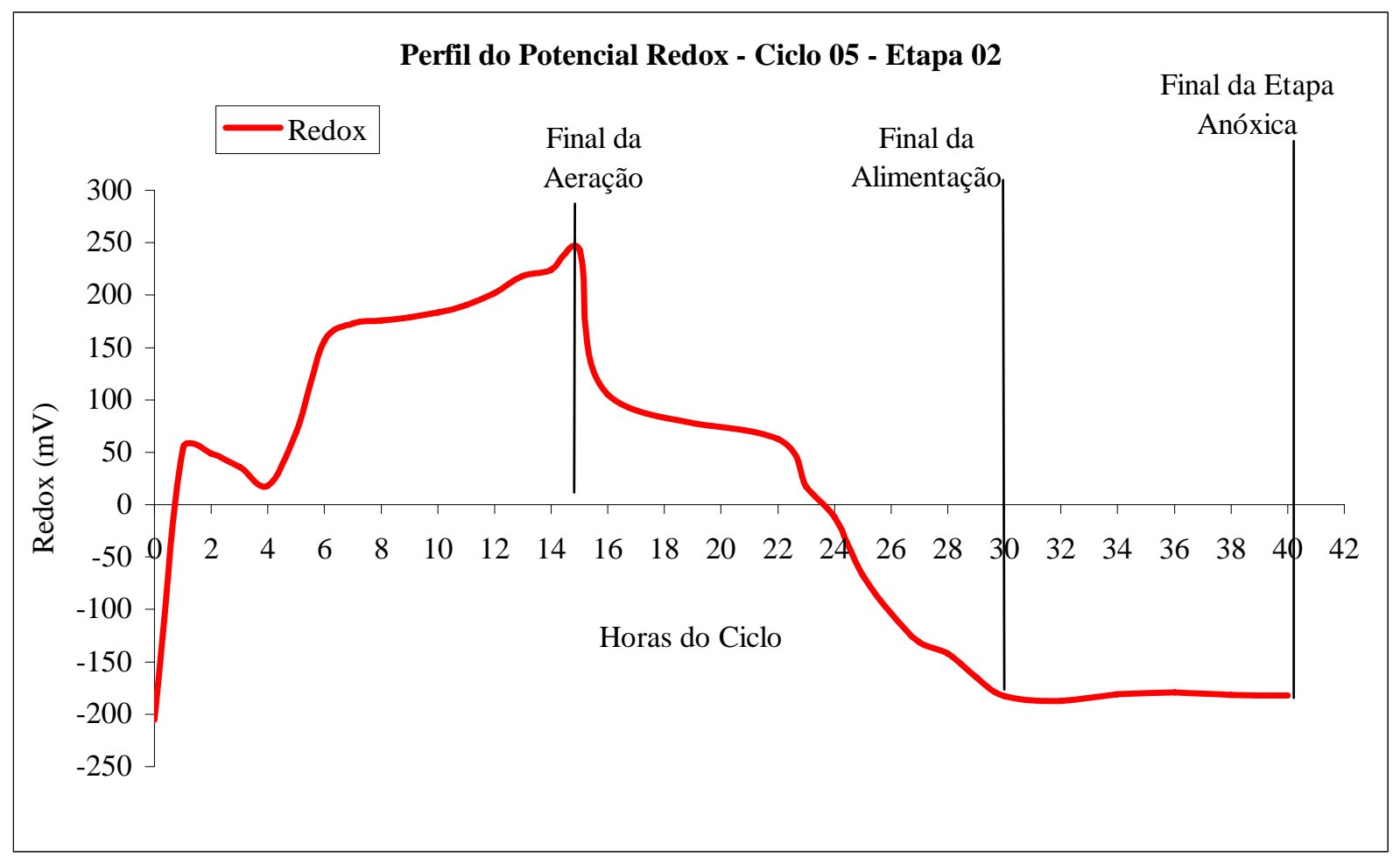

Figura 56: Perfil temporal de ORP no conteúdo do reator piloto - Ciclo 05 - Etapa 02. 
Alguns trabalhos para tentativa de implementação da automação de reatores em bateladas seqüenciais tratando águas residuárias, concluíram que o monitoramento do $\mathrm{pH}$ e do potencial de oxi-redução durante a operação do reator refletem as distintas etapas (aeróbia - anóxica) do ciclo de tratamento, e alguns pontos de inflexão das curvas de $\mathrm{pH}$ e ORP podem definir o final das reações biológicas (nitrificação e desnitrificação) (CASTELLÓ et. al., 2002; CECIL, 2003 LI et al., 2004; KIM et al., 2004; CHEN et al., 2004; ARIMA, 2005).

Durante a fase da pesquisa com concentração de nitrogênio amoniacal afluente em torno de $300 \mathrm{mg}$ N/L, o monitoramento dos perfis do potencial de oxi-redução, no conteúdo do reator ao longo dos ciclos, apresentaram uma tendência geral crescente logo no início da etapa aeróbia, mas após poucas horas ocorria uma estabilização em um valor limite. A etapa anóxica foi marcada pela redução dos valores de ORP, apresentando valores negativos quando as concentrações de nitrogênio amoniacal oxidado, no conteúdo do reator, aproximavam-se da extinção. Esse comportamento é similar ao obtido por outros pesquisadores que monitoraram perfis de ORP durante as etapas de nitrificação e desnitrificação em reatores operados em bateladas seqüenciais e associaram valores negativos de potencial redox com a extinção do N$\mathrm{NO}_{3}{ }^{-}$no conteúdo do reator, e início da fermentação anaeróbia (Figuras 04 e 06). (CYBIS, 1992; PLISSON-SAUNE et. al., 1996; CASTELLÓ et. al., 2002; CECIL, 2003; ARIMA, 2005). No primeiro ciclo dessa etapa, marcado pela inibição da etapa de desnitrificação (Figura 44) o potencial de oxi-redução diminuiu bruscamente pelo término do fornecimento de oxigênio, permanecendo aproximadamente constante em um valor positivo até o encerramento da etapa anóxica do ciclo de tratamento.

Somente através do monitoramento dos valores e perfil da curva de ORP não foi possível marcar pontos notáveis de início e término das reações biológicas (nitritação e desnitritação) nessa etapa da presente pesquisa. Como durante a etapa aeróbia dos ciclos, o pH e O.D. foram controlados próximos a valores pré-estabelecidos ( $\mathrm{pH} \cong 8,3$ e O.D. $\cong 1,0 \mathrm{mg} \mathrm{O} \mathrm{O}_{2} / \mathrm{L}$ ) para 
favorecer o acúmulo sustentado de $\mathrm{N}^{-\mathrm{NO}_{2}}{ }^{-}$, também não foi possível identificar o "vale da amônia", descrito pr alguns pesquisadores como o início e final das reações de nitrificação. (Figuras 04 , 05 e 06) (CYBIS, 1992; ARIMA, 2005).

As eficiências de remoção de fenol, durante a etapa anóxica daqueles ciclos de tratamento que não apresentaram inibição à desnitritação, nessa fase da pesquisa, oscilaram entre 63 e 67\%. Esse desempenho evidencia a existência de um excesso de fenol ao final da fase anóxica, a exemplo do ocorrido na fase da investigação conduzida com concentração de $\mathrm{N}-\mathrm{NH}_{3}$ no afluente próxima a $200 \mathrm{mg}$ N/L. Portanto, buscando investigar a possibilidade de remoção do fenol afluente (1.000 mg $\left.\mathrm{C}_{6} \mathrm{H}_{5} \mathrm{OH} / \mathrm{L}\right)$ somente na etapa anóxica dos ciclos, partiu-se para a terceira etapa dessa fase da pesquisa, conduzida com concentração no afluente de $\mathrm{N}_{-} \mathrm{NH}_{3}$ em torno de $500 \mathrm{mg} \mathrm{N} / \mathrm{L}$.

A tabela 25 apresenta um resumo dos resultados, obtidos durante os ciclos de tratamento, da fase da pesquisa conduzida com concentrações afluentes de nitrogênio amoniacal e fenol próximas a $300 \mathrm{mg} \mathrm{N} / \mathrm{L}$ e $1.000 \mathrm{mg} \mathrm{C}_{6} \mathrm{H}_{5} \mathrm{OH} / \mathrm{L}$, respectivamente. 
Tabela 25 - Resumo dos resultados da etapa $02\left(\mathrm{~N}-\mathrm{NH}_{3}\right.$ afluente $=300,0 \mathrm{mg}$ N/L) - Fase 02

\begin{tabular}{|c|c|c|c|c|c|}
\hline \multirow{2}{*}{ PARÂMETROS } & \multicolumn{5}{|c|}{ CICLOS } \\
\hline & 01 & 02 & 03 & 04 & 05 \\
\hline $\begin{array}{l}\text { Carga de } \mathrm{N}-\mathrm{NH}_{3} \\
\text { (g N-NH} / \text { dia) }\end{array}$ & 1,4 & 1,3 & 1,4 & 1,4 & 1,3 \\
\hline $\begin{array}{l}\text { Carga de Fenol } \\
\text { (g Fenol/dia) }\end{array}$ & 4,7 & 4,4 & 4,9 & 4,5 & 4,5 \\
\hline Q alimentação (ml/min) & 5,4 & 5,0 & 5,0 & 5,0 & 5,0 \\
\hline Temperatura ${ }^{\circ} \mathrm{C}$. & 25 & 25 & 24 & 24 & 23,5 \\
\hline pH médio (etapa aeróbia) & 8,3 & 8,3 & 8,3 & 8,3 & 8,2 \\
\hline $\mathrm{SSV}(\mathrm{mg} / \mathrm{L})$ & 2.210 & 2.275 & 2.460 & 2.544 & 2.604 \\
\hline Etapa Aeróbia (Horas) & 15 & 15 & 17 & 15 & 15 \\
\hline Etapa Anóxica (Horas) & 15 & 24 & 22 & 24 & 24 \\
\hline $\begin{array}{c}\text { Tx. de nitritação } \\
\text { (kg N-NH } / \text { kg SSV. dia) }\end{array}$ & 0,04 & 0,03 & 0,04 & 0,04 & 0,03 \\
\hline$\frac{\mathrm{N}-\mathrm{NO}_{2}}{\left(\mathrm{~N}-\mathrm{NO}_{2}^{-}+\mathrm{N}-\mathrm{NO}_{3}^{-}\right)}$ & 89 & 97 & 98 & 96 & 97 \\
\hline $\begin{array}{c}\mathrm{A} / \mathrm{M} \\
\text { (kg fenol/kg SSV. dia) }\end{array}$ & 0,11 & 0,10 & 0,10 & 0,09 & 0,09 \\
\hline $\begin{array}{c}\text { Tx. de desnitritação } \\
\text { (kg N-NO }{ }_{2}^{-} / \text {kg SSV .dia) }\end{array}$ & 0,005 & 0,02 & 0,02 & 0,02 & 0,02 \\
\hline Remoção de N-NH $3(\%)$ & 95 & 96 & 97 & 98 & 97 \\
\hline $\begin{array}{l}\text { Remoção de fenol na etapa } \\
\text { anóxica (\%) }\end{array}$ & 39 & 63 & 60 & 65 & 64 \\
\hline $\begin{array}{l}\text { Remoção de Nitrogênio } \\
\text { amoniacal oxidado (\%) }\end{array}$ & 22 & 99 & 99 & 100 & 98 \\
\hline $\begin{array}{c}\text { FENOL removido } \\
\text { N-NOT removido } \\
\text { (mg Fenol / mg N-NOt) }\end{array}$ & -- & 3,1 & 3,2 & 2,5 & 3,0 \\
\hline $\mathrm{NH}_{3}(\mathrm{mg} / \mathrm{L})^{*}$ & 9,9 а 0,6 & 8,2 a 0,4 & 9,3 a 0,3 & 7,0 a 0,2 & 7,4 a 0,3 \\
\hline $\mathrm{HNO}_{2}(\mathrm{mg} / \mathrm{L})^{*}$ & $<0,002$ & $<0,002$ & $<0,003$ & $<0,003$ & $<0,002$ \\
\hline
\end{tabular}




\subsection{3 - ETAPA 03 - CONCENTRAÇÃO AFLUENTE DE NITROGÊNIO AMONIACAL $\cong 500 \mathrm{mg}$ N/L:}

O primeiro ciclo da terceira etapa foi conduzido com 24 horas de fornecimento de oxigênio e 24 horas anóxicas, sendo que o lançamento de água residuária ocorreu durante 15 horas da fase anóxica do ciclo.

Ao final da fase aeróbia do ciclo de tratamento, para uma carga de 2,3 g $\mathrm{N}-\mathrm{NH}_{3} / \mathrm{dia}$ a eficiência de remoção atingiu 97\%. A taxa de nitrificação específica foi igual a 0,05 kg N$\mathrm{NH}_{3} / \mathrm{kg}$ SSV.dia, sendo que a relação $\mathrm{NO}_{2}{ }^{-} /\left(\mathrm{NO}_{2}{ }^{-}+\mathrm{NO}_{3}{ }^{-}\right)$atingiu 67\%, apresentando uma concentração de $\mathrm{N}-\mathrm{NO}_{3}{ }^{-}$, ao final da fase aeróbia do ciclo, igual a $38 \mathrm{mg} \mathrm{N}-\mathrm{NO}_{3}{ }^{-} / \mathrm{L}$. Essa elevada concentração de $\mathrm{N}-\mathrm{NO}_{3}{ }^{-}$, ao final da etapa aeróbia, aparentemente, pode ser atribuída ao valor de $\mathrm{pH}$ na massa líquida durante essa fase $(\mathrm{pH} \cong 7,8)$, ainda que, a concentração de amônia livre calculada (4,6 a $\left.0,1 \mathrm{mg} \mathrm{NH}_{3} / \mathrm{L}\right)$ se encontrasse na faixa considerada por Anthonisen et al. (1976) inibitória aos microrganismos que oxidam nitrito. Entretanto, outras pesquisas (TURK e MAVINIC, 1989; BALMELLE et al., 1992; BAE et al., 2002; GEE e KIM, 2004) apontam a necessidade da manutenção, no conteúdo do reator aeróbio, de uma concentração mínima de amônia livre (entre 4,0 e 6,0 mg NH$/ 2 / L$ ) para inibição da oxidação do $\mathrm{N}-\mathrm{NO}_{2}{ }^{-}$. Uma vez que a concentração de O.D., no conteúdo do reator, foi mantida próxima a 1,0 $\mathrm{mg} \mathrm{O} / \mathrm{L}$ a relação O.D./ $\mathrm{NH}_{3}$ variou entre 7,1 e 0,2 $\mathrm{mg} \mathrm{O}_{2} / \mathrm{mg} \mathrm{NH}_{3}$ portanto aquém do valor (< $10 \mathrm{mg} \mathrm{O}_{2} / \mathrm{mg} \mathrm{NH}_{3}$ ) considerada por Garrido et al. (1996) como favorável ao acúmulo de $\mathrm{N}-\mathrm{NO}_{2}{ }^{-}$no conteúdo do reator.

A eficiência de remoção de fenol (18\%) e a baixa remoção de nitrogênio amoniacal oxidado (17\%) indicam a ocorrência de inibição da desnitrificação, mesmo com uma taxa de aplicação volumétrica igual a $0,02 \mathrm{~kg} \mathrm{C}_{6} \mathrm{H}_{5} \mathrm{OH} / \mathrm{m}^{3}$.hora e portanto, inferior ao valor $\left(0,03 \mathrm{~kg} \mathrm{C}_{6} \mathrm{H}_{5} \mathrm{OH} /\right.$ $\mathrm{m}^{3}$.hora) obtido na primeira etapa da presente pesquisa como não inibitório aos microrganismos heterotróficos degradadores de fenol. A relação alimento/microrganismo 
(A/M), outro parâmetro considerado importante para estabilidade da desnitrificação, foi igual a 0,03 kg fenol/ kg SSV.dia, aquém da relação A/M < 0,10 kg fenol/ kg SSV.dia obtido como inibitório ao processo de redução biológica do nitrogênio oxidado (AUN, 2001).

Observando as concentrações de $\mathrm{N}_{-} \mathrm{NO}_{2}{ }^{-}$e $\mathrm{N}-\mathrm{NO}_{3}{ }^{-}$, ao longo da etapa anóxica desse primeiro ciclo, constata-se uma redução de cerca de $50 \%$ da quantidade de $\mathrm{N}^{-\mathrm{NO}_{3}}{ }^{-}$no conteúdo do reator entre 6 e 9 horas de duração da etapa anóxica. Essa diminuição do $\mathrm{N}^{-} \mathrm{NO}_{3}{ }^{-}$é acompanhada por um aumento da concentração de $\mathrm{N}^{-\mathrm{NO}_{2}}{ }^{-}\left(\cong 72 \mathrm{mg} \mathrm{N}-\mathrm{NO}_{2}{ }^{-} / \mathrm{L}\right.$ às 6 horas para $\cong 82 \mathrm{mg} \mathrm{N}-\mathrm{NO}_{2}{ }^{-} / \mathrm{L}$ às 9 horas) na massa líquida do reator; a partir desse instante ocorre inibição da desnitrificação acompanhada pelo acúmulo de fenol no conteúdo do reator piloto. Após 24 horas de duração da etapa anóxica, a concentração de $\left(\mathrm{N}^{-\mathrm{NO}_{2}}{ }^{-}+\mathrm{N}-\mathrm{NO}_{3}{ }^{-}\right)$, no conteúdo do reator, era aproximadamente igual a $100 \mathrm{mg}\left(\mathrm{N}_{-} \mathrm{NO}_{2}{ }^{-}+\mathrm{N}^{-\mathrm{NO}_{3}}{ }^{-}\right) / \mathrm{L}$. Portanto, aparentemente, essa grande quantidade de $\mathrm{N}^{-\mathrm{NO}_{2}}{ }^{-}$inibiu a atividade dos microrganismos heterotróficos degradadores de fenol.

A figura 57 apresenta as concentrações das diferentes espécies químicas monitoradas ao longo desse primeiro ciclo de tratamento conduzido com concentração afluente de $\mathrm{N}-\mathrm{NH}_{3} \cong 496 \mathrm{mg}$ $\mathrm{N}-\mathrm{NH}_{3} / \mathrm{L}$. 


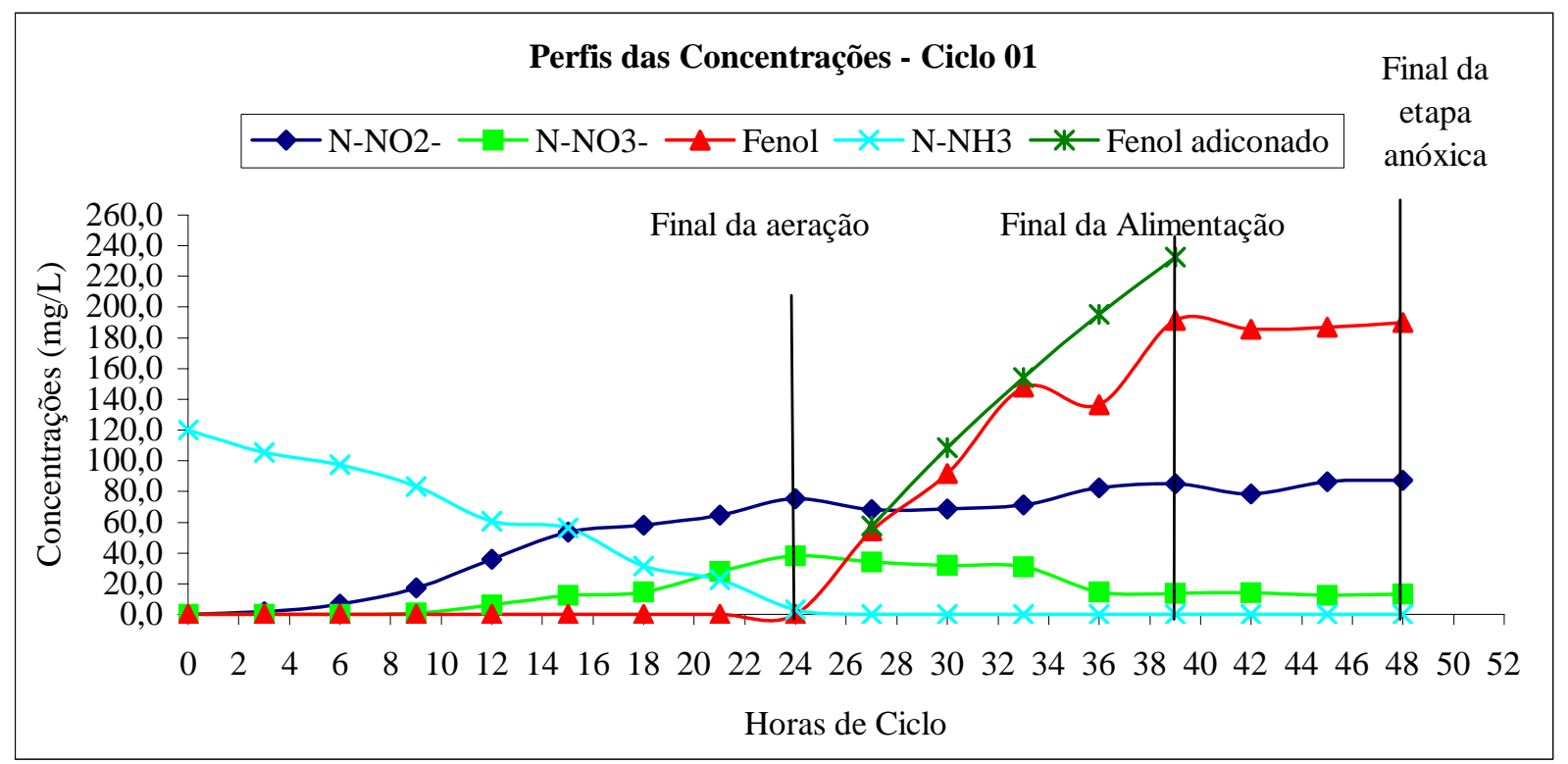

Figura 57: Perfis temporais das concentrações de $\mathrm{N}^{-\mathrm{NO}_{2}}{ }^{-} ; \mathrm{N}_{-} \mathrm{NO}_{3}{ }^{-}$; fenol; $\mathrm{N}^{-\mathrm{NH}_{3}}$ no conteúdo do reator piloto - Ciclo 01 ( $\mathrm{pH}$ na etapa aeróbia $\cong 7,8 ; \mathrm{T} \cong 25^{\circ} \mathrm{C}$ ) - Etapa 03 .

As figuras 58 e 59 apresentam os perfis dos parâmetros abióticos (pH e O.D.) e do potencial de oxi-redução monitorados no conteúdo do reator piloto ao longo do ciclo de tratamento.

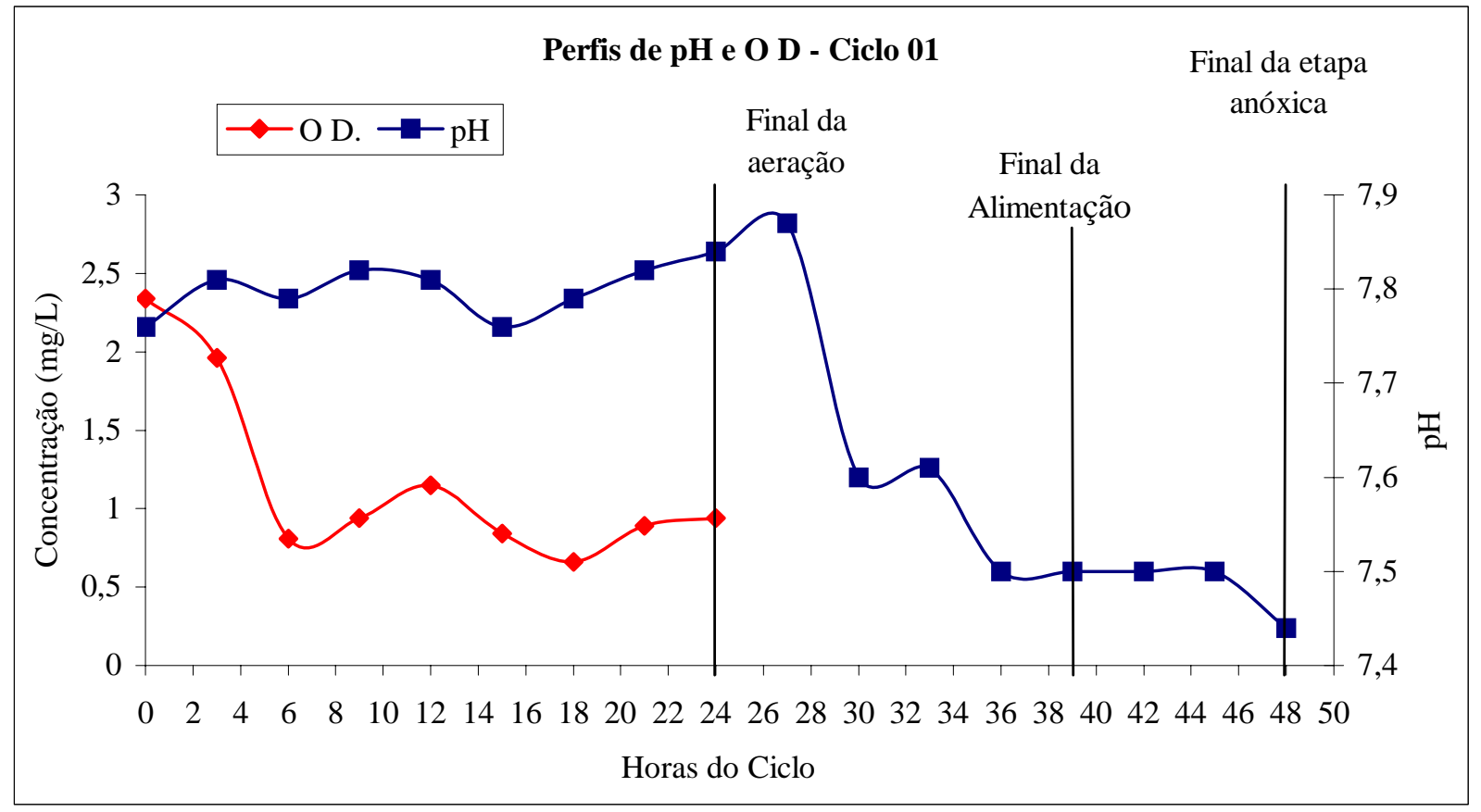

Figura 58: Perfis temporais de pH e oxigênio dissolvido no conteúdo do reator piloto - Ciclo 01 - Etapa 03. 


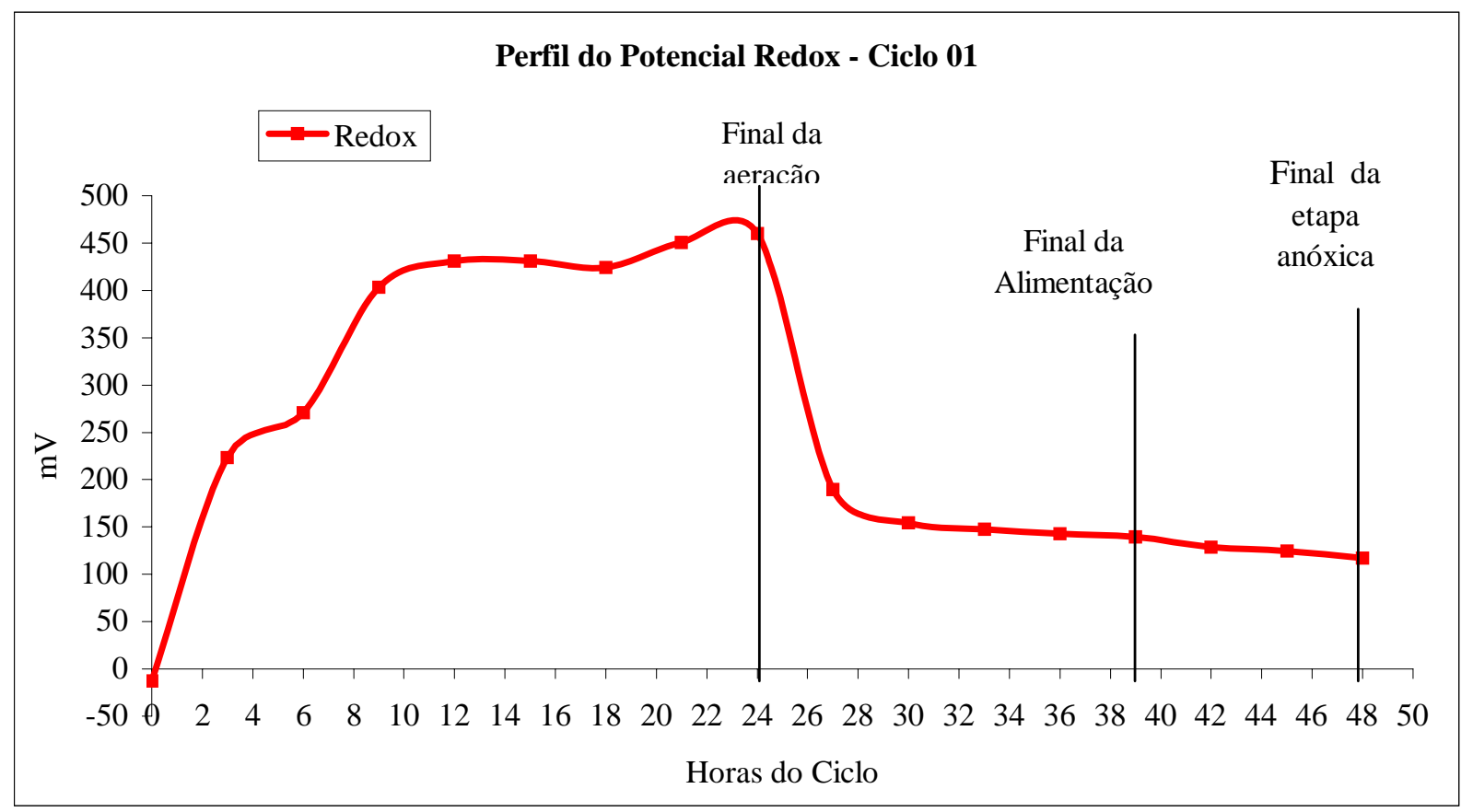

Figura 59: Perfil temporal de ORP no conteúdo do reator piloto - Ciclo 01 - Etapa 03.

Diante da inibição, observada na etapa de desnitrificação do ciclo 01 dessa terceira etapa da presente pesquisa, reduziu-se a vazão de alimentação e a aplicação do afluente estendeu-se até o final das 24 horas destinadas à fase anóxica. Outra providência, foi controlar o valor do pH, durante a etapa aeróbia, em valor aproximadamente igual a 8,3; a temperatura foi mantida em torno de $25^{\circ} \mathrm{C}$ ao longo dos ciclos de tratamento e a concentração de oxigênio dissolvido na massa líquida, durante a etapa aeróbia, foi próxima a 1,0 mg $\mathrm{O}_{2} / \mathrm{L}$ Essas condições foram aplicadas aos ciclos 02 e 03.

As figuras 60 e 61 apresentam os perfis das concentrações das espécies químicas monitoradas ao longo dos ciclos 02 e 03. 


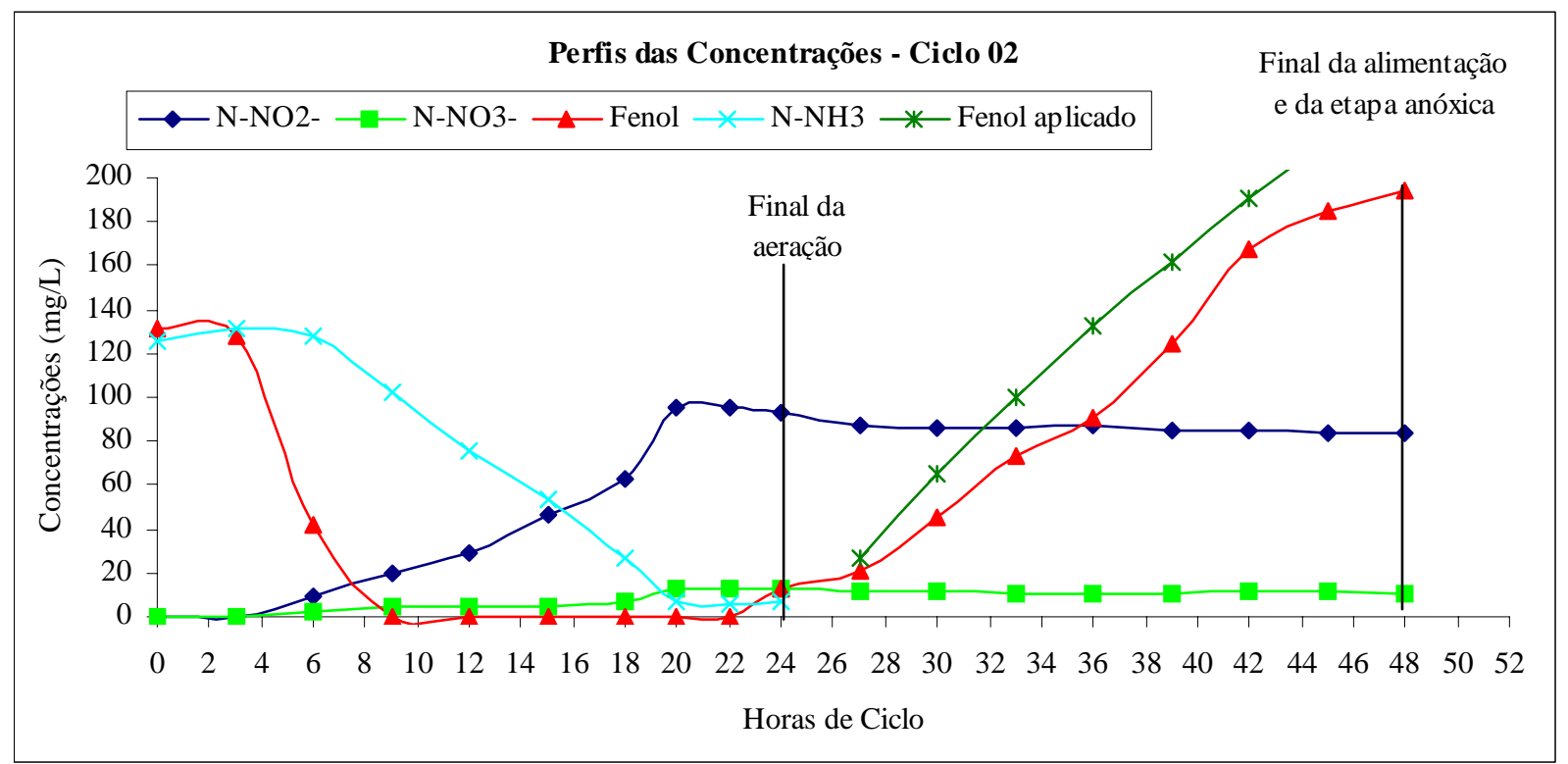

Figura 60: Perfis temporais das concentrações de $\mathrm{N}_{-\mathrm{NO}_{2}}{ }^{-}$; $\mathrm{N}-\mathrm{NO}_{3}{ }^{-}$; fenol; $\mathrm{N}^{-\mathrm{NH}_{3}}$ no conteúdo do reator piloto - Ciclo 02 - Etapa 03 . ( $\mathrm{T} \cong 25^{\circ} \mathrm{C}$.; $\mathrm{pH}$ na etapa aeróbia $\cong 8,3$ ).

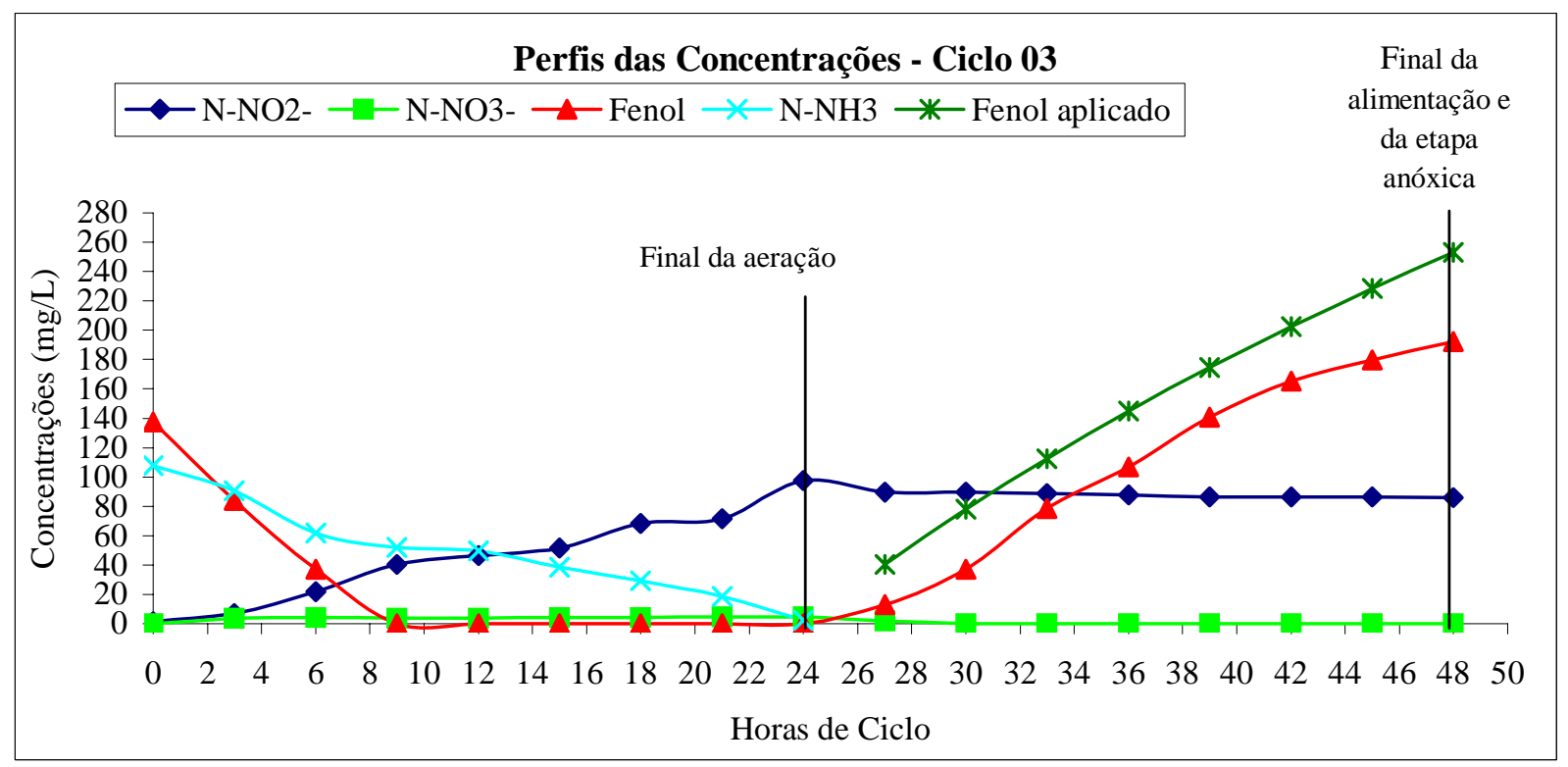

Figura 61: Perfis temporais das concentrações de $\mathrm{N}_{-} \mathrm{NO}_{2}{ }^{-}$; $\mathrm{N}-\mathrm{NO}_{3}{ }^{-}$; fenol; $\mathrm{N}-\mathrm{NH}_{3}$ no conteúdo do reator piloto - Ciclo 03 - Etapa 03. $\left(\mathrm{T} \cong 25^{\circ} \mathrm{C}\right.$; $\mathrm{pH}$ na etapa aeróbia $\cong 8,3$ )

As eficiências de remoção de $\mathrm{N}-\mathrm{NH}_{3}$ nos dois ciclos estiveram acima de 95\%, com taxas específicas de nitritação iguais a 0,05 kg N-NH$/$ kg SSV. dia; as relações $\mathrm{N}_{3} \mathrm{NO}_{2}{ }^{-} /\left(\mathrm{N}-\mathrm{NO}_{2}{ }^{-}\right.$ $+\mathrm{N}^{-\mathrm{NO}_{3}}{ }^{-}$) ao final das fases aeróbias dos ciclos 02 e 03 foram iguais a $88 \%$ e 96\%, respectivamente. A predominância do nitrito ao final das fases aeróbias (ciclo 02 = 95 mg N$\mathrm{NO}_{2}{ }^{-} / \mathrm{L}$ e ciclo $03=97 \mathrm{mg} \mathrm{N}-\mathrm{NO}_{2}{ }^{-} / \mathrm{L}$ ) possivelmente deveu-se ao valor do $\mathrm{pH}$ mantido próximo a 8,3. Esse valor permitiu a manutenção de uma concentração de amônia livre na 
massa líquida entre 16 e $0,3 \mathrm{mg} \mathrm{NH}_{3} / \mathrm{L}$, portanto, nota-se que no início da etapa aeróbia dos ciclos de remoção, a concentração de amônia livre, no conteúdo do reator, esteve acima de 10 mg $\mathrm{NH}_{3} / \mathrm{L}$ (ciclo 02 - $16 \mathrm{mg} \mathrm{NH}_{3} / \mathrm{L}$ e ciclo 03 - $15 \mathrm{mg} \mathrm{NH}_{3} / \mathrm{L}$ ). Esses valores são considerados por alguns pesquisadores inibitórios a oxidação do nitrogênio amoniacal (ANTHONISEN et al., 1976; AKERMAN, 2005); entretanto, outras pesquisas conseguiram sucesso na remoção de nitrogênio amoniacal via nitrito mesmo com concentrações de amônia livre, na massa líquida dos reatores, variando entre 14 a 32 mg NH $\mathrm{NH}_{3} \mathrm{~L}$. (WONG-CHONG e LOEHR, 1978; SAUTER e ALLEMAN, 1980; TURK e MAVINIC, 1989; JENICEK et al., 2004; DANIEL, 2005).

As remoções do nitrogênio oxidado, ao longo das fases anóxicas, apresentaram baixas eficiências (ciclo 02 = 13\% e ciclo $03=16 \%$ ), assim como as remoções de fenol (ciclo 02 e $03=24 \%$ ). Esses resultados são similares àqueles obtidos no primeiro ciclo dessa etapa da presente pesquisa (Figura 57), sugerindo, portanto, a ocorrência de inibição do processo de desnitritação.

A inibição da redução do nitrogênio oxidado pode ser oriunda da toxicidade conferida aos microrganismos heterotróficos degradadores de fenol por elevadas concentrações de nitrito e, conseqüentemente, de ácido nitroso não ionizado $\left(\mathrm{HNO}_{2}\right)$ no conteúdo do reator. Ao contrário do nitrito, $\mathrm{HNO}_{2}$ difunde rapidamente através da membrana celular dos microrganismos, uma vez dentro das células o $\mathrm{HNO}_{2}$ transforma-se em intermediários reativos (NO ou $\mathrm{NO}^{\circ}$ ) que por sua vez reagem diretamente com os centos produtores de proteínas das células, inviabilizando-as. (BAUMANN et al., 1997).

Os ciclos conduzidos com concentração de nitrogênio amoniacal afluente igual a 500 mg N/L, apresentaram concentrações entre 75 e $98 \mathrm{mg} \mathrm{N}-\mathrm{NO}_{2}{ }^{-} / \mathrm{L}$ (concentrações de ácido nitroso não ionizado variando entre 0,004 e 0,009 $\mathrm{mg} \mathrm{HNO}_{2} / \mathrm{L}$ ) no início da etapa anóxica. Investigações sobre a cinética da desnitrificação, em sistemas de lodos ativados, constataram que 
concentrações superiores a $30 \mathrm{mg} \mathrm{N}-\mathrm{NO}_{2}{ }^{-} / \mathrm{L}$ inibiram completamente o processo de desnitrificação (BECCARI et al., 1983). O estudo de viabilidade da utilização do liquor amoniacal (rico em fenol) gerado na coqueria da industria siderúrgica como fonte de carbono para desnitrificação, constatou a instabilidade do processo biológico quando a concentração atingiu $50 \mathrm{mg} \mathrm{N}-\mathrm{NO}_{2}{ }^{-} / \mathrm{L}$ no conteúdo do reator (SOGAME et al., 1996). Outros pesquisadores, investigando especificamente o comportamento da desnitritação, encontraram $50 \mathrm{mg} \mathrm{N}-\mathrm{NO}_{2}{ }^{-}$como valor limite para concentração de nitrito no conteúdo do reator, porém, eles chamam a atenção para a possibilidade de microrganismos bem aclimatados suportarem e reduzirem a $\mathrm{N}_{2}$ concentrações de $\mathrm{N}_{-} \mathrm{NO}_{2}^{-}$maiores. (CHUNG e BAE, 2002). Também, para culturas isoladas de sistemas de tratamento de águas residuárias (Pseudomonas denitrificans; Pseudomonas Fluorescens e Paracoccus denitrificans) constatou-se efeitos deletérios advindos da presença de elevadas concentrações de $\mathrm{N}_{-} \mathrm{NO}_{2}{ }^{-}$e, conseqüentemente de $\mathrm{HNO}_{2}$, para atividade da biomassa desnitrificante (ALMEIDA et al., 1995; WANG et al., 1995; BAUMANN et al., 1997; SIJBESMA et al., 2000).

Na presente pesquisa, durante a operação do sistema com concentrações de $300 \mathrm{mg}$ N/L no afluente, as concentrações de $\mathrm{N}^{-\mathrm{NO}_{2}}{ }^{-}$no início da etapa anóxica variaram entre $\cong 59 \mathrm{mg} \mathrm{N}$ $\mathrm{NO}_{2}{ }^{-}$e $\cong 70 \mathrm{mg} \mathrm{N}-\mathrm{NO}_{2}{ }^{-} / \mathrm{L}$ no conteúdo do reator piloto e estes valores não causaram inibição da desnitritação, a exemplo do primeiro ciclo da etapa com concentração de 500 mg N/L no

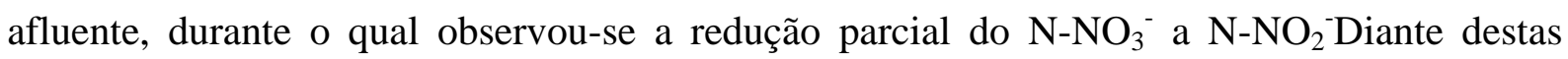
constatações, possivelmente, na presente pesquisa, concentrações superiores a $80 \mathrm{mg} \mathrm{N}^{-\mathrm{NO}_{2}}{ }^{-}$ inibiram a atividade dos microrganismos heterotróficos degradadores de fenol.

As figuras 62, 63, 64 e 65 apresentam os perfis de pH, O.D. e ORP ao longo dos ciclos 02 e 03 da terceira etapa da pesquisa. 


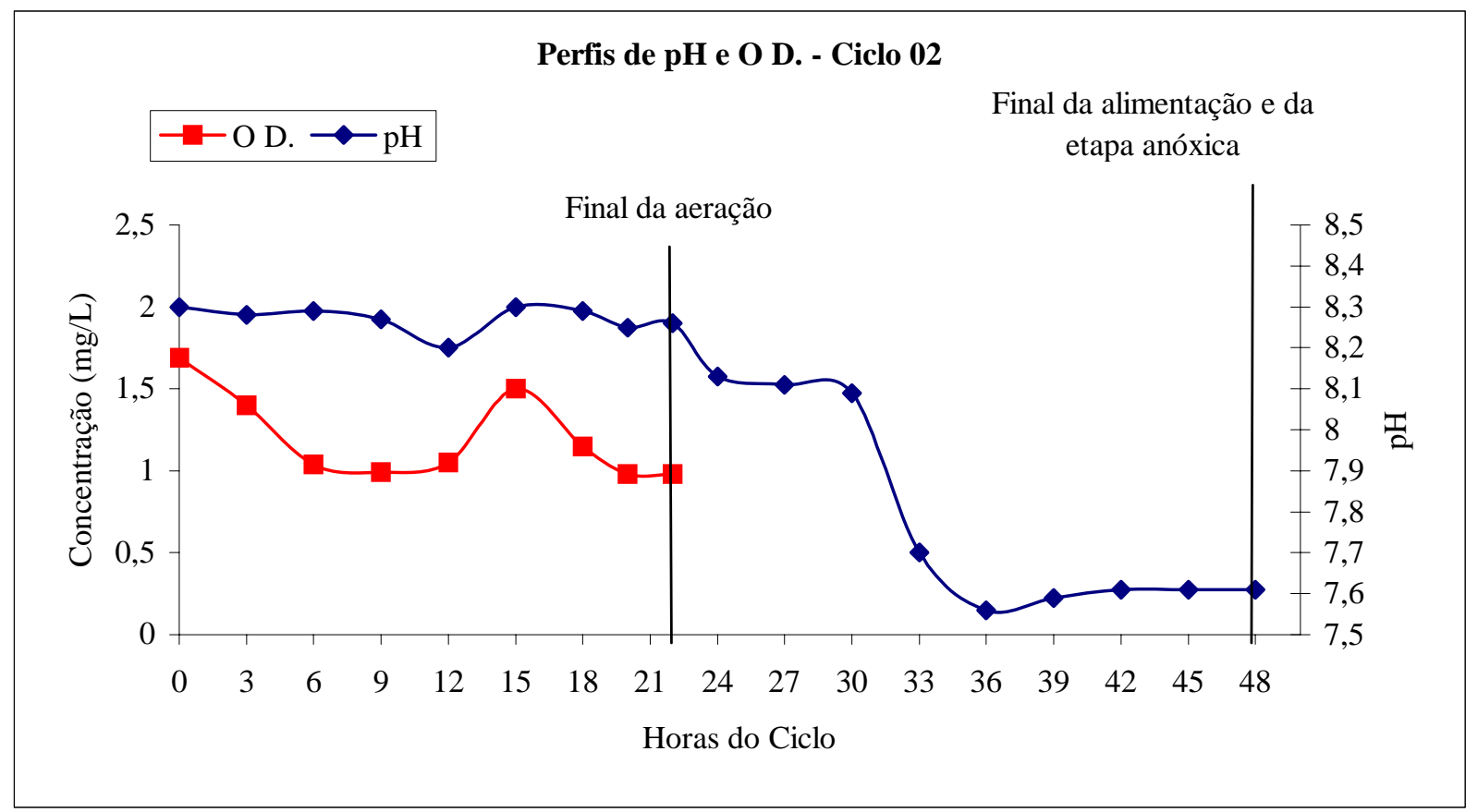

Figura 62: Perfis temporais de $\mathrm{pH}$ e oxigênio dissolvido no conteúdo do reator piloto - Ciclo 02 - Etapa 03.

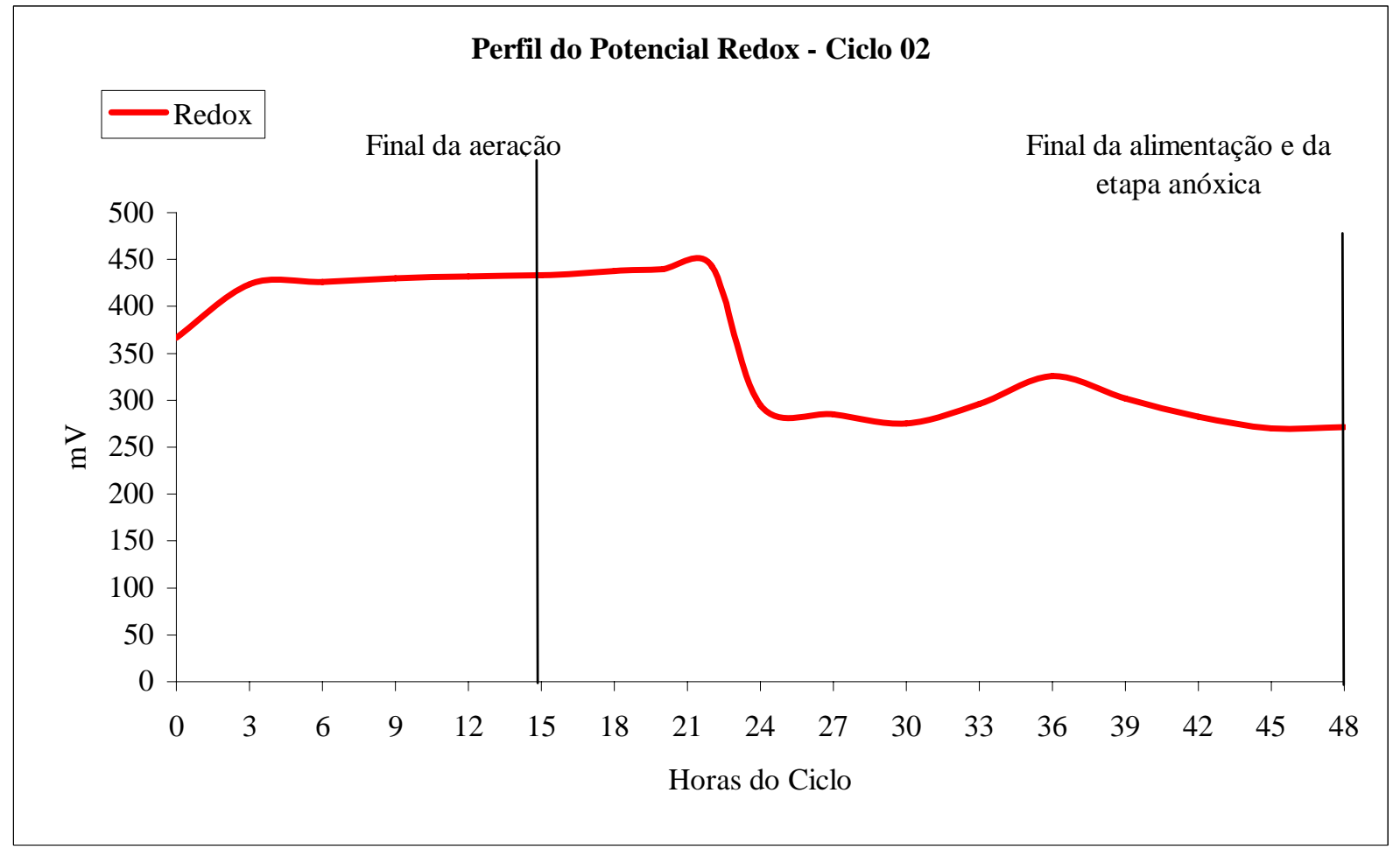

Figura 63: Perfil Temporal de ORP no conteúdo do reator piloto - Ciclo 02 - Etapa 03. 


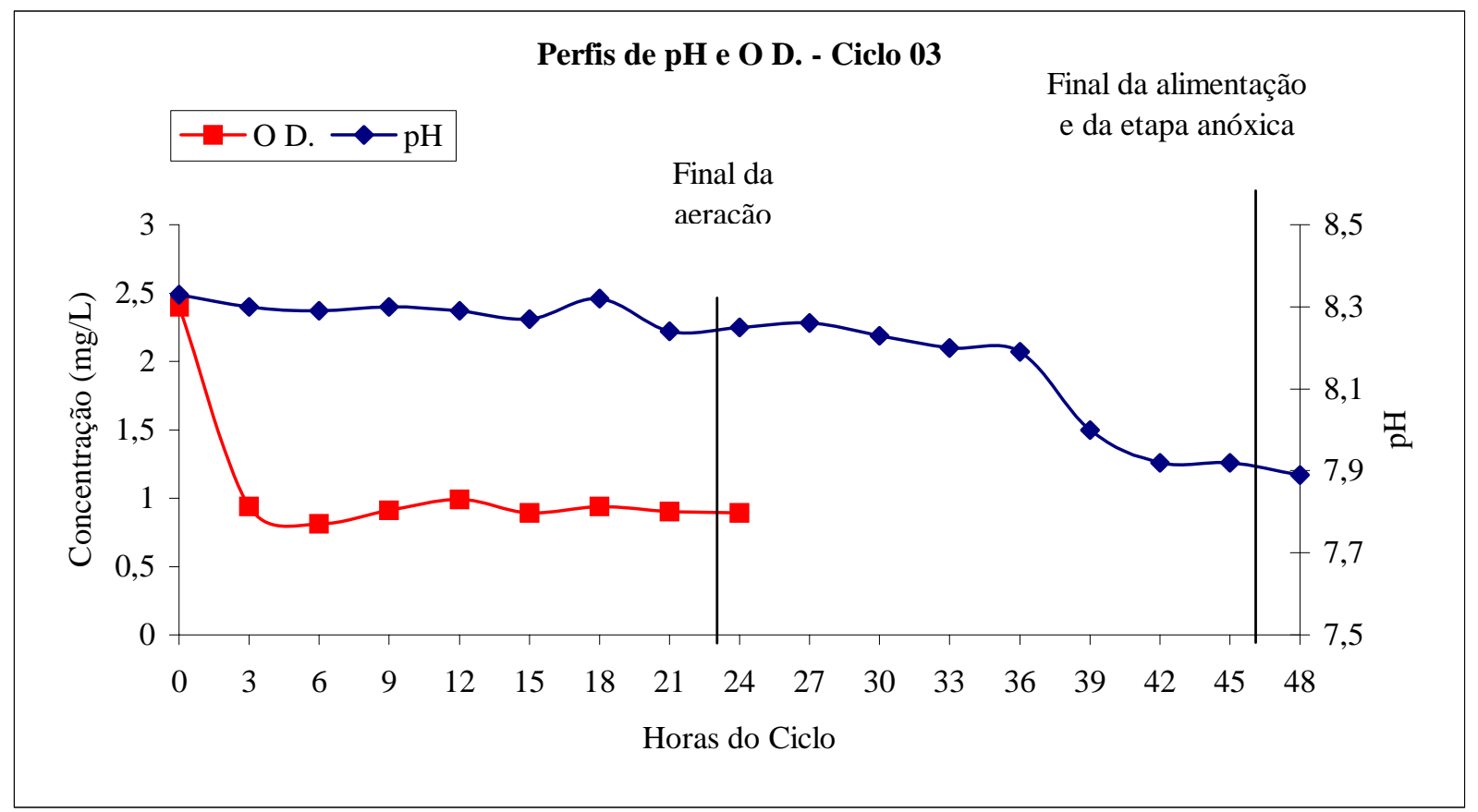

Figura 64: Perfis temporais de $\mathrm{pH}$ e oxigênio dissolvido no conteúdo do reator piloto - Ciclo 03 - Etapa 03.

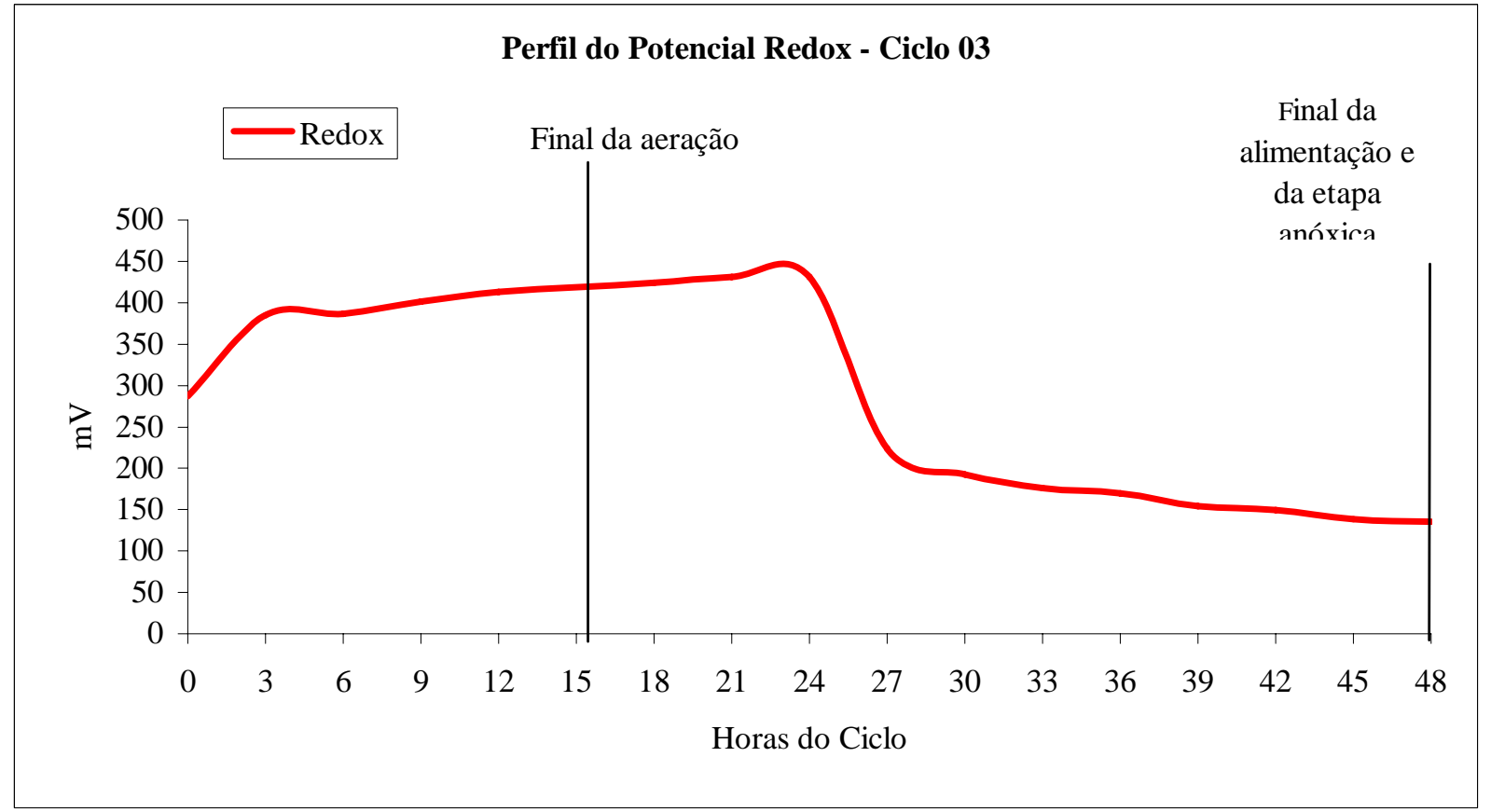

Figura 65: Perfil temporal de ORP no conteúdo do reator piloto - Ciclo 03 - Etapa 03. 
Analisando o comportamento dos gráficos de ORP no conteúdo do reator (figuras 59, 63 e 65), constata-se que o final da aeração é acompanhada por uma brusca redução nos valores do potencial redox na massa líquida, mas não foram registrados valores de ORP negativos nas etapas anóxicas dos ciclos de tratamento. Esse comportamento já havia sido notado no primeiro ciclo de tratamento da etapa da pesquisa conduzida com concentração de $\mathrm{N}-\mathrm{NH}_{3}$ no afluente próxima de 300 mg N/L, e que também fora marcado pela inibição da desnitritação. Outros trabalhos que investigaram o comportamento do potencial redox no conteúdo de reatores biológicos nas etapas de nitrificação e desnitrificação, constataram a ausência de valores negativos de ORP na massa líquida e atribuíram esse comportamento da curva de potencial redox às condições operacionais que inviabilizaram a desnitrificação biológica. (DANIEL, 2005; ARIMA, 2005). 


\subsection{BALANÇO DE ALCALINIDADE:}

\subsubsection{CONSUMO DE ALCALINIDADE DURANTE A NITRITAÇÃO:}

O consumo de alcalinidade durante a etapa aeróbia do ciclo de tratamento foi monitorado a partir da segunda etapa da pesquisa (concentração de nitrogênio amoniacal $\cong 300 \mathrm{mg}$ N/L), tal fato deveu-se a problemas de calibração da bomba dosadora da solução alcalinizante.

A tabela 26 apresenta os resultados de monitoramento da aplicação de solução alcalinizante de hidróxido de sódio. Com a finalidade de expressar os resultados em mg $\mathrm{CaCO}_{3}$, os cálculos foram realizados com base na relação $1,25 \mathrm{mg} \mathrm{CaCO}_{3} / \mathrm{mg} \mathrm{NaOH}$ dosado.

Tabela 26 - Consumo de $\mathrm{CaCO}_{3}$ durante a etapa aeróbia:

\begin{tabular}{|c|c|c|c|c|c|c|c|c|}
\hline \multirow[b]{2}{*}{ Ciclo } & \multicolumn{5}{|c|}{$\begin{array}{c}\text { Concentração de } \mathrm{N}^{-\mathrm{NH}_{3}} \\
\text { afluente: } \\
300 \mathrm{mg} \mathrm{N} / \mathrm{L} \\
\end{array}$} & \multicolumn{3}{|c|}{$\begin{array}{c}\text { Concentração de } \mathrm{N}-\mathrm{NH}_{3} \\
\text { afluente: } \\
500 \mathrm{mg} \mathrm{N} / \mathrm{L} \\
\end{array}$} \\
\hline & 01 & 02 & 03 & 04 & 05 & 01 & 02 & 03 \\
\hline$\frac{\mathrm{N}-\mathrm{NO}_{2}^{-}}{\left(\mathrm{N}-\mathrm{NO}_{2}^{-}+\mathrm{N}^{-}-\mathrm{NO}_{3}{ }^{-}\right)}$ & $89 \%$ & $97 \%$ & $98 \%$ & $96 \%$ & $97 \%$ & $66,5 \%$ & $88 \%$ & $96 \%$ \\
\hline $\mathrm{mgCaCO}_{3} / \mathrm{mgN}_{\text {oxidado }}$ & 11,0 & 12,4 & 11,2 & 8,4 & 9,6 & 10,6 & 11,4 & 9,2 \\
\hline
\end{tabular}

A média dos valores apresentados na tabela 26 é aproximadamente igual a 10,5 mgCaCO $/$ $\mathrm{mgN}_{\text {oxidado, }}$ portanto, um valor superior àquele calculado pela estequiometria $\quad(7,14 \mathrm{mg}$ $\mathrm{CaCO}_{3}$. mg N${ }^{-1}$; ver Item 3.4.1). Esse fato pode ser justificado pela manutenção do pH em um valor $(\cong 8,3)$ favorável a predominância do nitrito no conteúdo do reator, além do consumo da alcalinizante oriundo da reação de nitrificação. 
A análise de custos comparativa para implantação de um sistema que vise a remoção do nitrogênio amoniacal via nitrito não pode negligenciar esse consumo adicional de alcalinizante, principalmente em sistemas operados para tratamento de águas residuárias com baixa capacidade de tamponamento.

\subsubsection{RECUPERAÇÃO DE ALCALINIDADE DURANTE A DESNITRITAÇÃO:}

Para análise da recuperação de alcalinidade durante a fase anóxica levou-se em consideração apenas os ciclos nos quais não houve inibição do processo de desnitritação, ciclos: 02, 03, 04 e 05 da etapa realizada com concentração de nitrogênio amoniacal no afluente aproximadamente igual a $300 \mathrm{mg}$ N/L. O valor médio de alcalinidade recuperada foi igual a 1,68 mg $\mathrm{CaCO}_{3} / \mathrm{mg} \mathrm{N}_{\text {reduzido }}$, porém de acordo com os cálculos estequiométricos

(ver Item 3.4.1) esperava-se uma recuperação de 3,57 mg $\mathrm{CaCO}_{3} \cdot \mathrm{mgN}^{-1}$ reduzido. Observando os perfis temporais de $\mathrm{pH}$ correspondentes aos ciclos analisados (Figuras: 46, 49, 52 e 55) constata-se que durante a etapa anóxica ocorre uma redução do pH proveniente da adição gradual da água residuária, tal fato, possivelmente, deve-se ao comportamento do fenol em meio aquoso (Figura 66).

O lançamento gradual da água residuária fenólica ao longo da etapa anóxica (alimentação com reação), associada à liberação de íons $\mathrm{H}^{+}$oriunda da dissociação do fenol em meio aquoso, certamente, contribuiu para o consumo daquela alcalinidade que foi recuperada durante a desnitritação. Além disso antes do início da etapa anóxica descartava-se 5,0 litros de efluente nitritado (ver figura 11), cerca de $25 \%$ da massa de nitrito que não foi reduzida e portanto, não contribuiu para a recuperação da alcalinidade. 


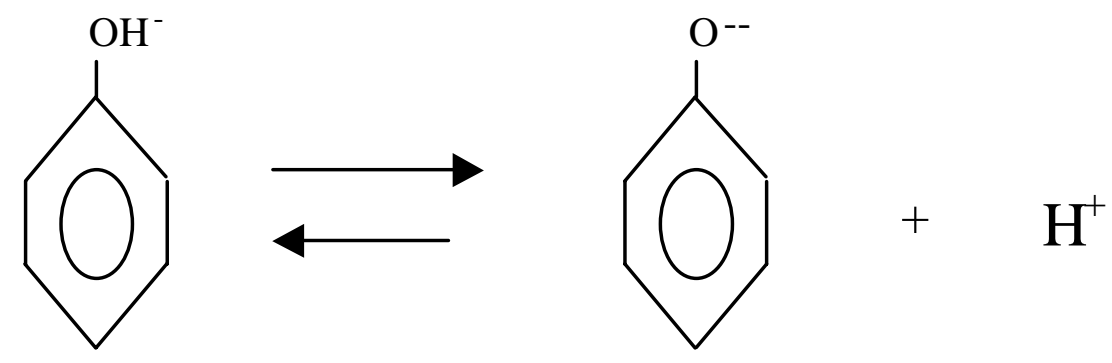

Figura 66: Dissociação do fenol em meio aquoso.

\subsection{RELAÇÃO D.Q.O/N OBTIDA DURANTE A DESNITRITAÇÃO:}

A realização das análises D.Q.O. pelo método do refluxo aberto (APHA, AWWA, WEF; 1998), apresentaram resultados erráticos ao longo da condução da pesquisa, apontados pelos valores bastantes discrepantes obtidos para relação fenol/D.Q.O. $(>6,0)$ daqueles de outros trabalhos (BETRAME, 1980; ALEM SOBRINHO et al., 1983; AUN, 2001; DOMBROSKI, 2003; SARFARAZ et al., 2004), nos quais essa relação foi próxima de 2,5 mg D.Q.O/mg fenol. Outras pesquisas utilizando água residuária sintética similar a utilizada na presente pesquisa (AUN, 2001; DOMBROSKI, 2003) já haviam apontado dificuldades na realização dessa determinação para alíquotas filtradas retiradas do conteúdo dos reatores.

A interferência de íons livres, da família dos halogênios, sofrendo oxidação e criando valores de D.Q.O. artificialmente superiores é reportada na literatura (APHA, AWWA,WEF, 1998). Usualmente essa interferência é causada por íons $\mathrm{Cl}^{-}$e minimizada, com sucesso, pela adição de sulfato de mercúrio antes da etapa de digestão; porém a presença concomitante de amônia e íons $\mathrm{Cl}^{-}$torna ineficaz a adição de sulfato de mercúrio e 
resultam em valores de D.Q.O. superiores aos efetivamente existentes nas amostras. (KIM, 1989). Outro fator de desvio, nas determinações de D.Q.O., é a excessiva concentração de nitrito no meio líquido (APHA, AWWA,WEF, 1998; SU et al., 2001) nem sempre minimizada pela adição de ácido sulfâmico em excesso.

A própria característica da pesquisa, buscando o acúmulo de $\mathrm{N}_{-} \mathrm{NO}_{2}{ }^{-}$, durante a etapa aeróbia do ciclo de tratamento, e sua remoção adicionando, durante a etapa anóxica, uma água residuária sintética constituída predominantemente por fenol e $\mathrm{NH}_{4} \mathrm{Cl}$, possivelmente, contribuiu para o insucesso e obtenção de valores discrepantes nas análises de D.Q.O. durante a desnitritação, já que a dissociação do $\mathrm{NH}_{4} \mathrm{Cl}$ em meio aquoso libera $\mathrm{Cl}^{-}$e $\mathrm{NH}_{4}{ }^{+}$. Utilizando os valores obtidos para relação fenol removido/ $\mathrm{N}-\mathrm{NO}_{2}{ }^{-}$removido durante a etapa anóxica dos ciclos de tratamento que não apresentaram inibição do processo de desnitritação, foi possível calcular, teoricamente, a relação mg D.Q.O consumida mg $\mathrm{N}-\mathrm{NO}_{2}{ }^{-}$ removido. Para a obtenção da relação fenol/D.Q.O. utilizada nos cálculos considerou-se a equação para D.Q.O. teórica de uma substância qualquer $\left(\mathrm{C}_{\mathrm{x}} \mathrm{H}_{\mathrm{y}} \mathrm{O}_{\mathrm{z}}\right)$ : (VAN HAANDEL E MARAIS, 1999).

$$
\mathrm{C}_{\mathrm{x}} \mathrm{H}_{\mathrm{y}} \mathrm{O}_{\mathrm{z}}+1 / 4(4 \mathrm{x}+\mathrm{y}-2 \mathrm{z}) \mathrm{O}_{2} \rightarrow \mathrm{x} \mathrm{CO}+\mathrm{y} / 2 \mathrm{H}_{2} \mathrm{O}
$$

Realizando os cálculos estequiométricos tem-se que a D.Q.O. teórica por grama da substância $\mathrm{C}_{\mathrm{x}} \mathrm{H}_{\mathrm{y}} \mathrm{O}_{\mathrm{z}}$ é igual a:

D.Q.O (teórica) $=8(4 \mathrm{x}+\mathrm{y}-2 \mathrm{z}) /(12 \mathrm{x}+\mathrm{y}+16 \mathrm{z}) \mathrm{g}$ D.Q.O/ g $\mathrm{C}_{\mathrm{x}} \mathrm{H}_{\mathrm{y}} \mathrm{O}_{\mathrm{z}}$ Utilizando a fórmula do fenol $\left(\mathrm{C}_{6} \mathrm{H}_{5} \mathrm{OH}\right)$ obtém-se a relação: 1 g fenol = 2,4 g D.Q.O. 
Tabela 27 - Dados para realização dos cálculos da relação D.Q.O./N teórica:

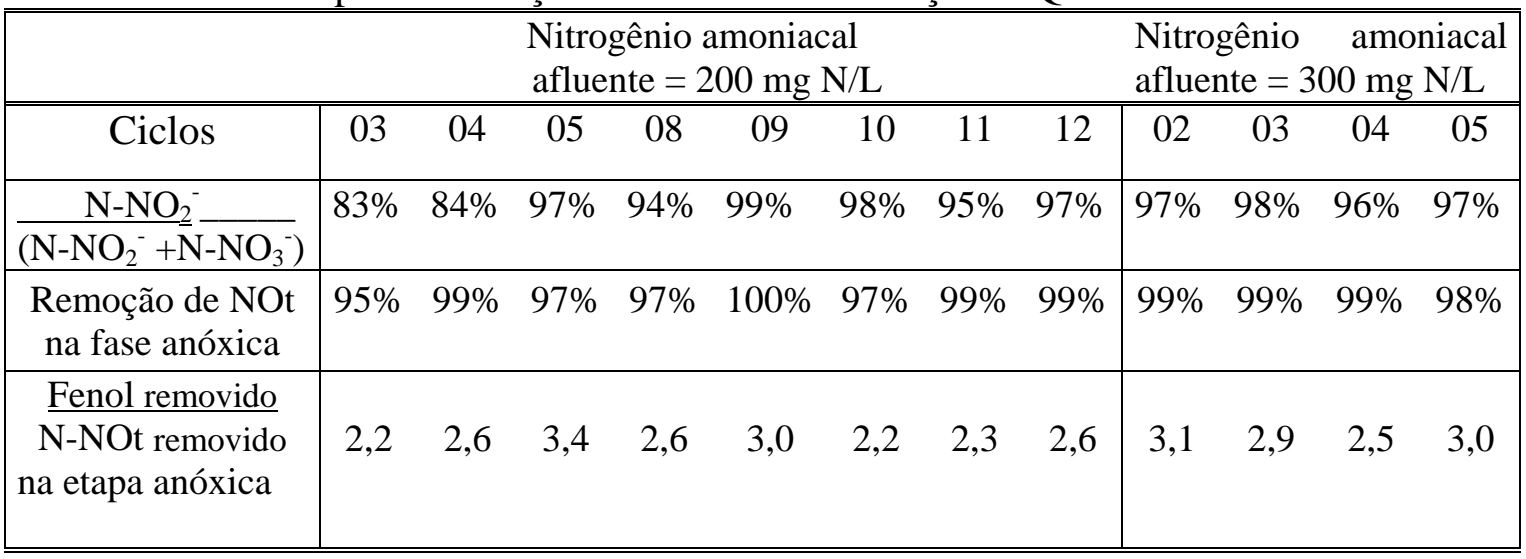

Considerando os valores da tabela 27, o valor médio da relação fenol removido/N-NOx removido, durante a etapa anóxica os ciclos de tratamento, foi igual a 2,7 g fenol removido / g N-NOx removido, o que, respeitando a relação 2,4 g D.Q.O./ g fenol, resulta em uma relação D.Q.O. removida $/ \mathrm{N}-\mathrm{NOx}$ removido $=6,5$. Portanto, o valor obtido é cerca de $20 \%$ superior ao calculado estequiometricamente (Item 3.4.3), porém, é corroborado por outros pesquisadores (D.Q.O. consumida $/ \mathrm{N}_{\text {removido }}>6,0$ ) como ideal para atingir altas eficiências de remoção biológica de nitrogênio, via nitrito. (RANDALL, BARNARD e STENSEL, 1995; CHOI et al., 2004). Além disso a relação D.Q.O. removida $/ \mathrm{N}_{\text {removido }}=6,5$ quando comparada ao valor teórico de consumo de substrato para desnitrificação (D.Q.O. consumida $/ \mathrm{N}-\mathrm{NO}_{3}{ }^{-}$ removido $\cong 8,6$ ) representa uma economia de aproximadamente $25 \%$ na necessidade de fonte de carbono para o processo, embora a economia teórica esperada para desnitritação seja igual a $40 \%$. 


\subsection{INVESTIGAÇÃO DA FORMAÇÃO DE NITROFENÓIS ATRAVÉS DO CONTATO ENTRE FENOL E NITRITO NO CONTEÚDO DO REATOR PILOTO.}

Os resultados das análises (Tabela 28) acusaram a formação de 2 e 4 - nitrofenóis, mesmo quando as condições no conteúdo do reator ( $\mathrm{pH} \cong 8,3$ e $\mathrm{T} \cong 25^{\circ} \mathrm{C}$.) não favoreciam essa reação ${ }^{6}$. Recentemente, outras pesquisas também identificaram e quantificaram 2 e 4 nitrofenóis em sistemas de tratamento de águas residuárias submetidos à temperatura ambiente $\left(\cong 23^{\circ} \mathrm{C}\right.$.), em ampla faixa de $\mathrm{pH}$ (2 a 10) e na presença ou ausência de luz. A formação de 2 - nitrofenol, através do contato entre fenol e nitrito, é imediata, enquanto a formação de 4 - nitrofenol ocorre a uma taxa mais lenta após um curto período de indução. (VIONE et al., 2002; PATNAIK e KHOURY, 2004).

Tabela 28 - Resultados das análises de compostos fenólicos:

\begin{tabular}{|c|c|c|}
\hline COMPOSTO & \multicolumn{2}{|c|}{ CONCENTRAÇÃO } \\
\hline & 24 HORAS & 36 HORAS \\
\hline 2 -NitroFenol & 2,3 mg/L & $1,43 \mathrm{mg} / \mathrm{L}$ \\
\hline 4 - Nitrofenol & 2,2 mg/L & $1,67 \mathrm{mg} / \mathrm{L}$ \\
\hline 2 - Metilfenol & 0,014 mg/L & $0,017 \mathrm{mg} / \mathrm{L}$ \\
\hline 4 - Metilfenol & 0,007 mg/L & $0,005 \mathrm{mg} / \mathrm{L}$ \\
\hline 2,4 - Diclorofenol & ND & ND \\
\hline 2,5-Diclorofenol & ND & ND \\
\hline 2,3 - Diclorofenol & ND & ND \\
\hline 2,6- Diclorofenol & ND & ND \\
\hline 2,3,5- Triclorofenol & ND & ND \\
\hline 2,3,4 -Triclorofenol & ND & ND \\
\hline 2,4,5 - Triclorofenol & ND & ND \\
\hline 2,4,6 - Triclorofenol & ND & ND \\
\hline 3,5 - Diclorofenol & ND & ND \\
\hline 2,3,6 - Triclorofenol & ND & ND \\
\hline 3,4 - Diclorofenol & ND & ND \\
\hline
\end{tabular}

ND - não detectado pelo método analítico empregado.

6 condições ácidas, baixas temperaturas $\left(\mathrm{T}<10^{\circ} \mathrm{C}\right.$.) ou foto-indução sob luz ultra-violeta. 
A análise qualitativa apresenta indícios da existência no conteúdo do reator piloto de alguns compostos intermediários da biodegradação de compostos fenólicos como 4 - nitrocatecol, cujo acúmulo transiente já havia sido observado em culturas isoladas degradando fenol e pnitrofenol. (CHO et al., 1998; THOMAS et al., 2002). Muitas classes de compostos fenólicos, a exemplo do fenol, $p$-nitrofenol, $o$-nitrofenol e $m$-nitrofenol são biodegradados apresentando o catecol como composto intermediário. (HEALY JR. e YOUNG, 1979; ZEYER e KEARNEY, 1984; CHO et al., 1998).

Ainda que exploratórias, a detecção de compostos fenólicos, nesse caso 2 e 4 - nitrofenóis, em concentrações significativas, demonstram a necessidade de avaliar-se a toxicidade do efluente final de sistemas de tratamento biológicos de águas residuárias ricas em compostos fenólicos e nitrogênio amoniacal, é importante avaliar, também, as condições de formação

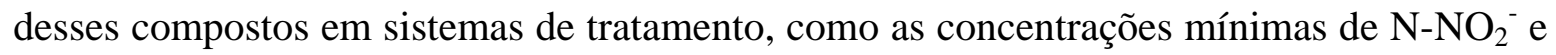
fenol, temperatura, possíveis catalisadores e faixa de pH que favoreceriam a reação.

\subsection{INVESTIGAÇÃO DA APLICAÇÃO DO ETANOL COMO FONTE DE CARBONO ALTERNATIVA AO FENOL PARA DESNITRITAÇÃO:}

Analisando a figura 11 (ver item 4.5.2) o descarte do sobrenadante foi realizado após o período aerado do ciclo de tratamento. Portanto, esse efluente, necessitava de um

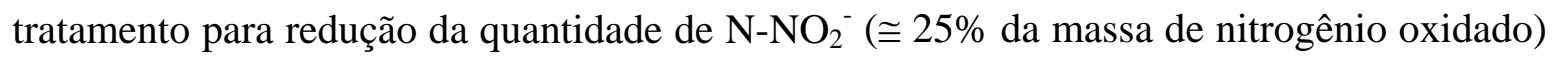
antes do descarte. Realizaram-se, então, testes exploratórios com etanol $\left(\mathrm{CH}_{3}-\mathrm{CH}_{2} \mathrm{OH}\right)$ como fonte de carbono utilizando a própria biomassa aclimatada ao fenol, apenas com a finalidade de verificar a adequação dessa fonte de carbono complementar. Outra possibilidade seria a oxidação dessa quantidade de $\mathrm{N}-\mathrm{NO}_{2}{ }^{-}$até $\mathrm{N}-\mathrm{NO}_{3}{ }^{-}$antes do descarte. 
Para realização desses testes, foram utilizados 5 litros do sobrenadante descartado após a etapa aeróbia dos ciclos realizados com concentração afluente igual a 500 mg N/L. Mantido sob refrigeração a $4^{\circ} \mathrm{C}$. e adicionado em 15 litros de lodo biológico, contando com a

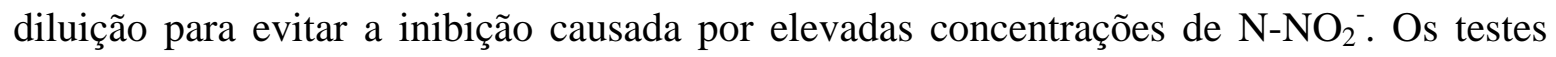
com etanol só foram realizados após o término da etapa de pesquisa da utilização de fenol como fonte de carbono para "desnitritação".

A dosagem de etanol foi igual a duas vezes o valor requerido pelos cálculos estequiométricos. Tal procedimento evitaria uma limitação da fonte de carbono para redução do nitrogênio oxidado.

$$
\mathrm{C}_{2} \mathrm{H}_{6} \mathrm{O}+3 \mathrm{NO}_{2}^{-} \rightarrow 2 \mathrm{CO}_{2}+3 \mathrm{H}_{2} \mathrm{O}+1,5 \mathrm{~N}_{2}
$$

Portanto, os cálculos estequiométricos resultam em uma relação igual a 1,1mg etanol / mg $\mathrm{N}-\mathrm{NO}_{2}^{-}$, a dosagem foi igual a 2,2 $\mathrm{mg}$ etanol / $\mathrm{mg} \mathrm{N}-\mathrm{NO}_{2}^{-}$.

A figura 67 apresenta os perfis calculados como a média das concentrações dos três testes realizados, a figura 68 apresenta os perfis médios de pH e Redox monitorados durante os testes.

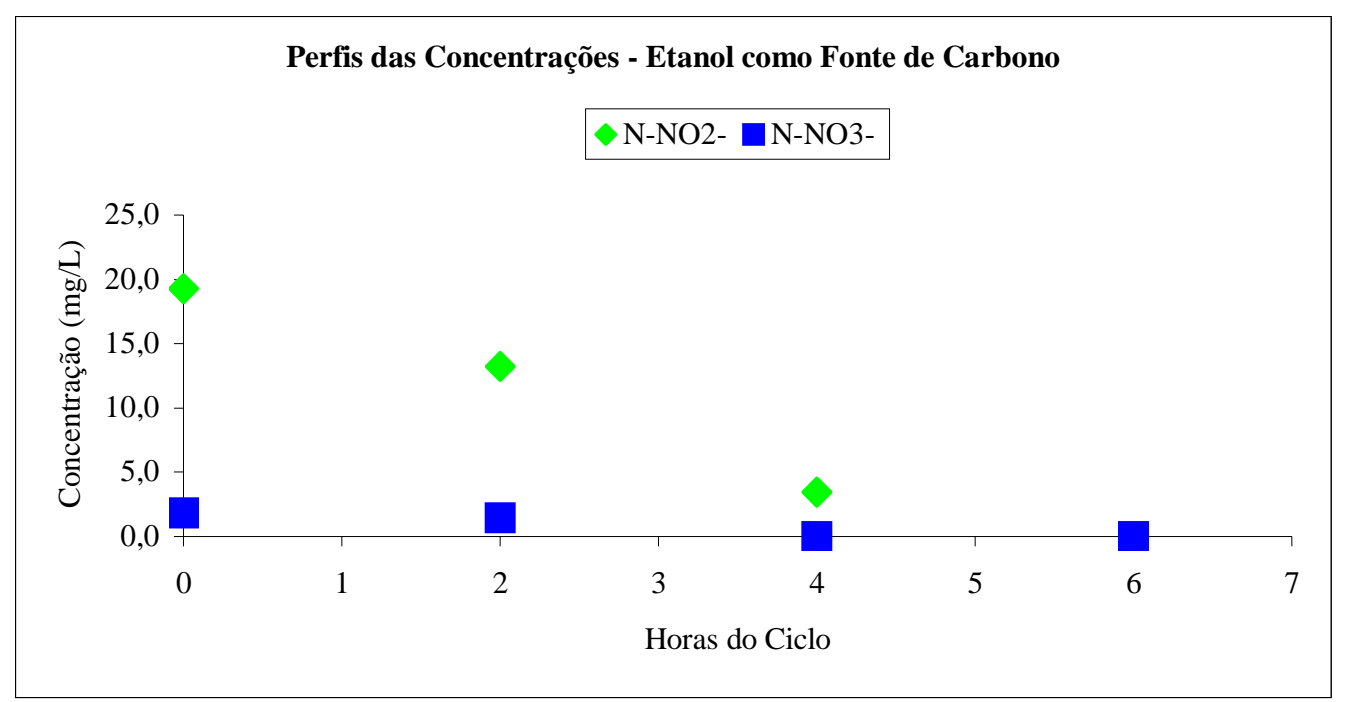

Figura 67: Perfis das concentrações de $\mathrm{N}^{-\mathrm{NO}_{2}}{ }^{-}$e $\mathrm{N}-\mathrm{NO}_{3}{ }^{-}$, calculadas como a média de três testes anóxicos utilizando etanol como fonte de carbono para "desnitritação". ( $\mathrm{T} \cong 25^{\circ} \mathrm{C}$.); 


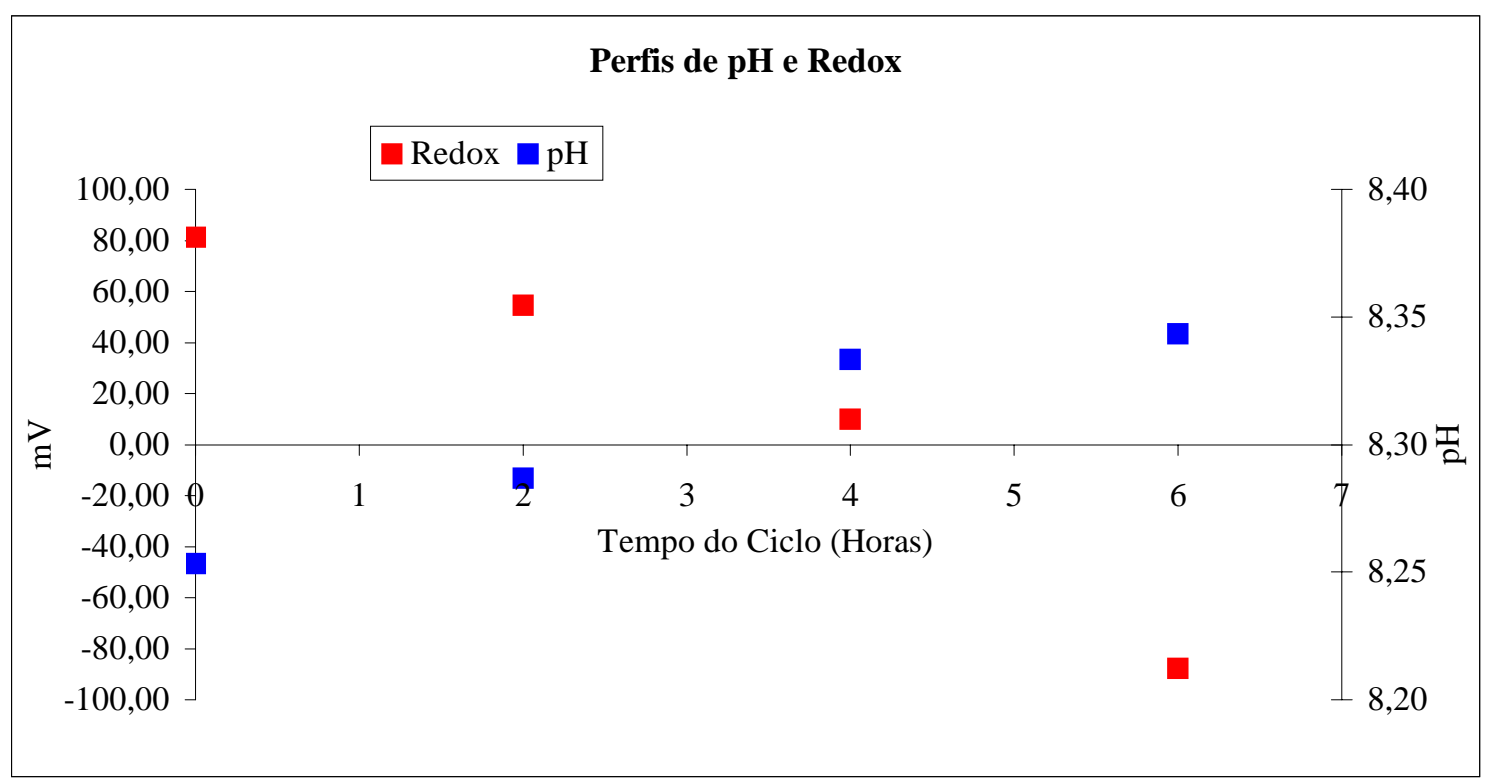

Figura 68: Perfis dos valores médios de $\mathrm{pH}$ e Redox de três testes anóxicos utilizando etanol como fonte de carbono para "desnitritação". ( $\mathrm{T} \cong 25^{\circ} \mathrm{C}$.);

O caráter exploratório desses testes permite afirmar, apenas, que o etanol pode ser utilizado como fonte de carbono para desnitritação alternativa ao fenol, sem a necessidade de um inóculo específico, nem a observação de fase de adaptação, uma vez que as eficiências de remoção de nitrogênio amoniacal oxidado foram próximas de 100\%, com a mesma biomassa aclimatada a elevadas concentrações de fenol (1.000 mg $\mathrm{C}_{6} \mathrm{H}_{5} \mathrm{OH}$ ). Tal fato, provavelmente, deve-se ao caráter de fácil assimilação do etanol pelos microrganismos heterotróficos, em cerca de quatro horas as concentrações de N-NOx, no conteúdo do reator, eram próximas de 3,0 mg N-NOx/L, conforme constatado na figura 67.

Esse excelente desempenho também ficou refletido no comportamento das curvas de potencial oxi-redução e pH, monitorados durante os testes. A curva de potencial redox apresentou um perfil similar a outros sistemas desnitrificantes eficientes, com valor final negativo (- 87,7 mV), evidenciando a baixa concentração iônica do meio (CASTELLÓ et. al., 2002; CECIL, 2003; ARIMA, 2005). 


\section{CONCLUSÕES:}

A presente pesquisa permitiu concluir que:

- Para concentrações afluentes da ordem de 200; 300 e 500 mg N/L, as condições para predominância do nitrito, como forma oxidada do nitrogênio, no conteúdo do reator piloto (20 litros) operado em bateladas seqüenciais foram: valor do $\mathrm{pH} \cong 8,3$ associado à extensão do período aeróbio do ciclo de tratamento que garantisse uma concentração mínima de amônia livre (> 0,3 mg $\mathrm{NH}_{3} / \mathrm{L}$ ) na massa líquida do reator ao final da etapa aeróbia. Com estas condições, a relação $\mathrm{N}^{-\mathrm{NO}_{2}}{ }^{-} /\left(\mathrm{N}_{-} \mathrm{NO}_{2}^{-}+\mathrm{N}-\mathrm{NO}_{3}{ }^{-}\right)$ao longo da pesquisa variou entre 89 e $99 \%$.

- Concentrações de amônia livre da ordem de 16 mg $\mathrm{NH}_{3} / \mathrm{L}$ e de ácido nitroso livre entre 0,001 e 0,009 $\mathrm{HNO}_{2} / \mathrm{L}$ no conteúdo do reator piloto não inibiram a oxidação do nitrogênio amoniacal.

- Mantendo uma concentração de 1,0 mg $\mathrm{O}_{2} / \mathrm{L}$ durante a etapa aeróbia, as remoções de $\mathrm{N}-\mathrm{NH}_{3}$ variaram entre: 89 e 98\% com concentrações no afluente próximas a 200 mg N/L ao longo de nove ciclos de remoção; 95 e 98\% para concentrações no afluente da ordem de 300 mg N/L durante a realização de cinco ciclos de tratamento e 95 e 97\% com concentrações no afluente próximas a $500 \mathrm{mg}$ N/L, no decorrer de três ciclos de tratamento. Para temperaturas entre 23,5 e $33^{\circ} \mathrm{C}$. e concentrações de sólidos em suspensão voláteis no conteúdo do reator piloto entre 2.175 e $3.420 \mathrm{mg}$ SSV/L, as

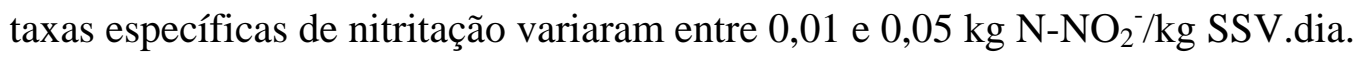


- Fenol, em concentrações no afluente próximas a 1.000 mg $\mathrm{C}_{6} \mathrm{H}_{5} \mathrm{OH} / \mathrm{L}$, mostrou-se adequado como única fonte de carbono para remoção de nitrogênio, via nitrito, para concentrações afluentes da ordem de 200 e 300 mg N/L, com alimentação contínua ao longo de parte da etapa anóxica. As eficiências de remoção do nitrogênio oxidado variaram entre 97 e 100\%, utilizando taxas de aplicação volumétricas próximas a 0,03 $\mathrm{kg}$ fenol $/ \mathrm{m}^{3}$.hora.. As taxas de desnitritação específicas variaram entre 0,01 e 0,05 kg $\mathrm{N}-\mathrm{NO}_{2}^{-}$/ kg SSV .dia; a relação alimento/microrganismo (A/M) esteve compreendida entre 0,06 e 0,13 kg fenol / kg SSV. dia.

- As eficiências de remoção de fenol ao longo da etapa anóxica variaram entre 37 e 67\%, resultando em valores entre 2,1 e 3,2 g fenol removido/g N-NOx removido, correspondendo teoricamente a um valor médio para relação DQO/N, efetivamente consumida durante a etapa anóxica, igual a 6,5 D.Q.O. removida/N-NOx removido. Este valor quando comparado ao valor teórico de consumo de substrato para desnitrificação

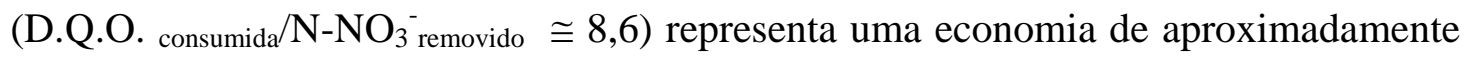
25\% na necessidade de fonte de carbono para o processo, ainda que a economia teórica esperada fosse igual a $40 \%$.

- Concentrações iguais ou superiores a $80 \mathrm{mg} \mathrm{N}-\mathrm{NO}_{2}{ }^{-} / \mathrm{L}$ no conteúdo do reator piloto inviabilizaram a utilização do fenol (1.000 mg $\mathrm{C}_{6} \mathrm{H}_{5} \mathrm{OH} / \mathrm{L}$ no afluente) como fonte de carbono para os microrganismos heterotróficos, durante a etapa anóxica. Para valor da relação alimento/microrganismos igual a 0,06 kg fenol / kg SSV. dia, taxas de aplicação volumétricas da ordem de $0,07 \mathrm{~kg}$ fenol $/ \mathrm{m}^{3}$.hora também inibiram a ocorrência da desnitritação no conteúdo do reator piloto. 
- Investigações exploratórias da formação de nitrofenóis no conteúdo do reator piloto durante a etapa com concentração no afluente próxima a $500 \mathrm{mg} \mathrm{N} / \mathrm{L}$, revelaram a

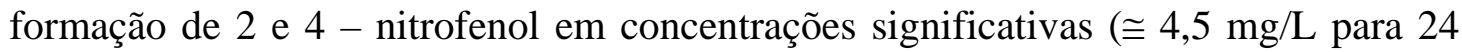
horas e 3,0 mg/L para 36 horas de contato entre o $\mathrm{N}^{-\mathrm{NO}_{2}}{ }^{-}$e fenol) ainda que as condições na massa líquida do reator biológico $\left(\mathrm{pH} \cong 8,3\right.$ e temperatura $\cong 25^{\circ} \mathrm{C}$.) não favorecessem essa reação. 


\section{SUGESTÕES PARA FUTURAS PESQUISAS:}

Para futuras pesquisas visando a remoção biológica do nitrogênio amoniacal utilizando fenol como fonte de carbono em etapa anóxica, recomenda-se:

- Observar as condições para predominância do nitrito como nitrogênio oxidado, em sistemas biológicos de tratamento de águas residuárias, à temperaturas inferiores a $20^{\circ} \mathrm{C}$ no conteúdo do reator.

- Estudar a tratabilidade de águas residuárias ricas em fenol e nitrogênio amoniacal, utilizando sistemas biológicos de tratamento com biomassa aderida.

- Uma melhor investigação das condições de formação e remoção de nitrofenóis em sistemas biológicos de tratamento de águas residuárias, a exemplo de águas residuárias das unidades de destilação do carvão em indústrias siderúrgicas, inclusive com realização de ensaios de toxicidade e toxidez.

- A obtenção de parâmetros cinéticos para degradação do fenol em meio anóxico, tanto para culturas isoladas, quanto para culturas mistas, cultivadas em suspensão na massa líquida ou imobilizadas em meio suporte, pode ajudar na definição de parâmetros de projeto. 


\section{REFERÊNCIAS BIBLIOGRÁFICAS}

ABELING, U.; SEYFRIED, C. F. Anaerobic-aerobic treatment of high-strength ammonium wastewater. Nitrogen removal via nitrite. Water Science and Technology, Londres, v. 26, n. 56, p. 1007 - 1015, 1992.

AKERMAN, A. Feasibility of nitrate-shunt (nitritation) on landfill leachate.. Tese (Mestrado) - Instituto de Tecnologia, Universidade de Lund. Lund (Suécia), 2005. Disponível em: http:// www.sysav.se/upload/ovright. Acesso em: 14 de set. de 2005.

ALEM SOBRINHO, P.; GARCIA JÚNIOR, A. D.; RODENAS, M. DE L. A. Tratamento de águas residuárias com elevadas concentrações de fenóis pelo processo de lodos ativados. In: CONGRESSO BRASILEIRO DE ENGENHARIA SANITÁRIA E AMBIENTAL, 12. Balneário Camboriú, 1983. Anais. p. 7,1 - 7,13.

ALMEIDA, J. S.; JÚLIO, S. M.; REIS, M. A. M.; CARRONDO, M. J. T. Nitrite inhibition of denitrification by Pseudomonas fluorescens. Biotechnology and Bioengineering, v. 46, n. 3, p. $194-201,1995$.

AL-OBAIDI, U.; MOODIE, R. B. The nitrous acid-catalysed nitration of phenol. Journal of the Chemical Society, p. 467 - 472, 1985.

AMERICAN PUBLIC HEALTH ASSOCIATION (APHA); AMERICAN WATER WORKS ASSOCIATION (AWWA); WATER ENVIRONMENT FEDERATION (WEF). Standard methods for the examination of water and wastewater. 20.ed., Washington, 1998.

ANTHONISEN, A.C.; LOEHR, R. C.; PRAKASAM, T. B. S.; SRINATH, E.G. Inhibition of nitrification by ammonia and nitrous acid. Journal of Water Pollution Control Federation, v. 48, n. 5, p. 835 - 852, mai. 1976.

ANTHONY, R. M.; BREIMHURST, L. H. Determining maximum influent concentrations of priority polluants for treatment plants. Journal of Water Pollution Contro Federation, v. 53, n. 10, p. 1457-1468, out. 1981.

ARIMA, G. A. Otimização de reator seqüencial em batelada para remoção biológica de carbono e nitrogênio com controle difuso. 2005. 182p. Tese (Doutorado) - Instituto de Pesquisas Hidráulicas, Universidade Federal do Rio Grande do Sul. 
ARORA, M. L.; BARTH, E. F.; UMPHRES, M. B. Technology evaluation of sequencing batch reactors. Journal of Water Pollution Contro Federation, v. 57, n. 8, p. 867-875, aug. 1985.

AUN, M. V. Contribuição ao estudo da desnitrificação utilizando fenol como fonte de carbono. 2001. 171p. Dissertação (Mestrado) - Escola Politécnica, Universidade de São Paulo. São Paulo, 2001.

BAE, W.; BAEK, S.; CHUNG, J..; LEE, Y. Optimal operational factors for nitrite accumulation in batch reactors. Biodegradation, v. 12, p. 359-366, 2002.

BALMELLE, B.; NGUYEN, K. M.; CAPDEVILLE, B.; CORNIER, J. C.; DEGUIN, A. Study of factors controlling nitrite build-up in biological processes for water nitrification. Water Science and Technology, Londres, v. 26, n. 5-6, p. 1017 - 1025, 1992.

BAUMANN, B.; VAN DER MEER, J. R.; SNOZZI, M.; ZEHNDER, J. B. Inhibition of denitrification activity but not of mRNA induction in Paracoccus denitrificans by nitrite at a suboptimal pH. Antonie van Leeuwenhoek. v.72 p. 183-189, 1997.

BECCARI, M.; PASSINO, M.; RAMADORI, R.; TANDOI, V. Kinetics of dissimilatory of nitrate and nitrite reduction in suspended growth culture. Journal of WPCF, v. 55, p. 58 - 69, 1983.

BLACKALL, L. L. A sumary of recent microbial discoveries in biological nutrient removal from wastewater. Biodegradation, v. 10, n. 3, p. 29 - 31, 2000.

BRAILE, P. M.; CAVALCANTI, J. E. W. A. Manual de tratamento de águas residuárias industriais. São Paulo, ABES, 1993.

BRASIL. Ministério do Meio Ambiente. Conselho Nacional do Meio Ambiente. Resolução $\mathrm{n}^{\circ}$ 357 de 17 de março de 2005. Dispõe sobre a classificação dos corpos de água e diretrizes ambientais para o seu enquadramento, bem como estabelece as condições e padrões de lançamento de efluentes, e dá outras providências. Diário Oficial da União, 18 mar. 2005.

CAMPOS, J. L.; GARRIDO-FERNANDEZ, J. M.; MENDEZ, R.; LEMA, J. M. Nitrification at high ammonia loading rates in a activated sludge unit. Bioresource Technology, n. 68, p. 141 148, 1999. 
CASTELLÓ, E.; GHISLIERI, D.; ONO, A.; BORZACCONI, L. Optimización del funcionamiento de un SBR para la remoción de materia orgánica y nutrientes. In: CONGRESSO INTERAMERICANO DE INGENIARÍA SANITARIA Y AMBIENTAL. 28., 2002. Cancún. México.

CECIL, D. Controlling nirogen removal using redox and ammonium sensors. Water Science and Technology, Londres v. 47, n. 11, p. 109-114, 2003.

CHANG, Y. J.; NISHIIO, N.; NAGAI, S. Characteristics of granular methanogenic sludge grown on phenol synthetic medium and methanogenic fermentation of phenolic wastewater in a UASB reactor. Journal Fermetation Bioengineering, v. 79, n. 4, p. 348 - 353, 1995.

CHEN, M.; KIM, J-H; KISHIDA, N.; NISHIMURA, O.; SUDO, R. Enhaced nitrogen removal using $\mathrm{C} / \mathrm{N}$ load adjustment and real-time control strategy in sequencing batch reactors for swine wastewater treatment. Water Science and Technology, Londres v. 49, n. 5-6, p. 309 - 314, 2004.

CHO, Y-G; YOON, J-H; PARK, Y-H; LEE, S-T. Simultaneous degradation of p-nitrophenol and phenol by a newly isolated Nocardioides sp. Journal of genetic applied microbiology. v. 44, p. 303 - 309, 1998.

CHOI, E.; YUN, Z.; CHUNG, T. H. Strong nitrogenous and agro-wastewater: current technological overview and future direction. Water Science and Technology, Londres v. 49, n. 5-6, p. 1- 5, 2004.

CHUNG, J.; BAE, W. Nitrite reduction by a mixed culture under conditions relevant to shortcut biological nitrogen removal. Biodegradation, v. 13, p. 163-170, 2002.

COLLINS, G. ; FOY, C.; MCHUGH, S.; MAHONY, T.; O'FLAHERTY V. Anaerobic biological treatment of phenolic watewater at $15-18^{\circ} \mathrm{C}$. Water Research, Oxford, v. 39, n. 08, p. 1614 - 1620, 2005.

DA COSTA, A. J. P.; Estudo de tratabilidade de água residuária sintética simulando despejo líquido de coquerias. São Paulo, 1999. Tese (Doutorado) - Escola Politécnica, Universidade de São Paulo.

DAIMS, H. Novel Nitrospira-like bacteria as dominant nitrite-oxidizers in biofilms from wastewater treatments plants: diversity and in-situ phisiology. Water Science and Technology, Londres, v. 41, n. 4-5, p. 85- 90, 2000. 
DANIEL, L. M. C. Remoção de Nitrogênio via nitrito em reator operado em bateladas seqüenciais contendo biomassa imobilizada e aeração intermitente. 2005. 102p. Tese (Doutorado) - Escola de Engenharia de São Carlos, Universidade de São Paulo.

DOMBROSKI, S. A. G. Nitrificação e desnitrificação de água residuária de coqueria utilizando fonte interna de carbono. 2003. 420p. Tese (Doutorado) - Escola Politécnica, Universidade de São Paulo. São Paulo, 2003.

DWYER, D. F.; KRUMME, M. L.; BOYD, A. S.; TIEDJE J. M. Kinetics of Phenol biodegradation by an immobilized methanogenic consortium. Applied Environment Microbiology. v.46, n.1, p. 50 - 54, July., 1983.

ECKENFELDER, W. W. Developing industrial water pollution control programs. Lancaster, Technomic Publishing Company, 1997.

EIROA, M.; VILAR A.; AMOR, L.; KENNES, C.; VEIGA, M. C. Biodegradation and effect of formaldehyde and phenol on the denitrification process. Water Research, Oxford, v. 39, p. 449455, 2005.

FANG, H. H. P.; CHEN, T.; LI Y. Y.; CHUI, H. K. Degradation of Phenol in wastewater in a Upflow Anaerobic Sludge Blanket Reactor. Water Research, Oxford, v. 30, n. 6, p. 1353 1360, 1996.

FANG, H. H. P.; LIU, Y; KE, S. Z.; ZHANG, T. Anaerobic degradation of phenol in wastewater at ambient temperature. Water Science and Technology, Londres, v. 49, n. 1, p. 95 - 102, 2004.

FURUMAI, H.; TAGUI, H.; TUJITA, K. Effects of pH and alkalinity on sulfur denitrification in a biological granular filter. Water Science and Technology, Londres, v. 34, n. 1 - 2, p. 355 362, 1996.

FUX, C. ; SIEGRIST, H. Nitrogen removal from sludge digester liquids by nitrification/denitrification or partial nitritation/anammox: environmental and economical considerations. Water Science and Technology, Londres, v. 50, n. 10, p. 19-26, 2004. 
GARRIDO, J. M.; VAN BENTHUM, W. A. J.; VAN LOOSDRECHT, M. C. M.; HEIJNEN, J. $\mathrm{J}$. Influence of dissolved oxygen concentration on nitrite accumulation in a biofilm airlift suspension reactor. Biotechnology and Bioengineering, v. 53, p. 168 - 178, 1996.

GANCZARCZYK, J. J. Second-stage activated sludge treatment of coke-plant effluents. Water Research, Oxford, v. 13, p. 337 - 342, 1979.

GEE, C. S.; KIM J. S. Nitrite accumulation followed by denitrification using sequencing batch reactor. Water Science and Technology, Londres, v. 49, n. 5 - 6, p. 47 - 55, 2004.

GÓRSKA, S. J.; CICHON, A.; MIKSCH, C. Nitrogen removal from wastewater with high ammonia nitrogen concentration vi shorter nitrification and denitrification. Water Science and Technology, Londres, v. 36, n. 10, p. 73 - 78, 1997.

GREENFIELD, J. H.; NEUFELD, R. D. Quantification of the influece of steel industry trace organic substances on biological nitrification. In: INDUSTRIAL WASTE CONFERENCE, 36., Lafayette, 1981. Proceedings. Lafayette: Ann Arbor Science, p. 772 - 783, 1982.

GRUNDITZ, C.; DALHAMMAR, G. Development of nitrification inhibition assays using pure cultures of Nitrossomonas and Nitrobacter. Water Research, Oxford, v. 35, n. 2, p. 433 - 440, 2001.

HANAKI, K.; WANTAIN, C.; OHGAKI, S. Nitrification at low levels of dissolved oxygen with and without organic loading in a suspended-growth reactor. Water Research, Oxford, v. 24, n. 3, p. 297 - 302, 1990.

HEALY, JR. J. B; YOUNG, L. Y. Catechol and phenol degradation by a methanogenic population of bacteria. Applied Environment Microbiology. v.35, n.1, p. 216 - 218, Jan., 1978.

HEALY, JR. J. B; YOUNG, L. Y. Anaerobic biodegradation of eleven aromatic compounds to Methane. Applied Environment Microbiology. v.38, n.1, p. 84-89, July, 1979.

HELMER, C.; TROMM, C.; HIPPEN, A.; ROSENWINKEL K.-H.; SEYFRIED C.-F.; KUNST, Single stage biological nitrogen removal by nitritation and anaerobic ammonium oxidation in biofilm systems. Water Science and Technology, Londres, v. 43, n. 1, p. 311 - 320, 2001.

HOCKENBURY, M. R.; GRADY JR., C. P. L. Inhibition of nitrification-effects of selected organic compounds. Journal WPCF, p. 769 - 777, May, 1977. 
HOLUB, W.; PRZYTOCKA-JUSIAK, M.; BLASZCZYK, M.; MYCIELSKI, R. Nitrite as agent selecting anaerobic phenol degrading microflora in petroleum refining sediments. Water Research, v. 34, n. 4, p. $1354-1358,2000$.

HOWARTH, R., W., Human acceleration of the nitrogen cycle: drivers, consequences, and steps toward solutions. Water Science and Technology, Londres, v. 49, n. 5-6, p. 7 - 13, 2004.

HWANG, I. S.; MIN, K. S.; CHOI, E.; YUN, Z. Nitrogen removal from piggery waste using the combined SHARON and ANAMMOX process. Water Science and Technology, Londres, v. 52, n. 10-11, p. 487 - 494, 2005.

INTERNATIONAL AGENCY FOR RESEARCH ON CANCER. Monographs on the evaluation of carcinogenic risks to humans. . Disponível em $\leq$ http://www.iarc.fr $>$ Acesso em: 06 jul. 2005.

JENICEK, P.; SVEHIA, P.; ZABRANSKA, J.; DOHANYOS, M.. Factors affecting nitrogen removal by nitritation/denitritation. Water Science and Technology, Londres, v. 49, n. 5 - 6, p. $73-79,2004$.

JETTEN M. S. M.; STROUS, M.; VAN DE PAS-SCHOONEN, K. T.; SCHALK, J.; VAN DONGEN, G. J. M. U.; VAN DE GRAAF, A. A.; LOGEMANN, S.; MUYZER, G.; VAN LOOSDRECHT, M. C. M.; KUENEN G. J. The anaerobic oxidation of ammonium. Microbiology Reviews, v. 22, n. 5, p. $421-437,1999$.

JONES, D. D.; SPEAKE, J. L.; WHITE, J.; GAUTHIER, J. J. Biological treatment of highstrength coke-plant wastewater. In: INDUSTRIAL WASTE CONFERENCE, 38., West Lafayette, 1983. Proceedings. West Lafayette, Boston: Butterworth Publishers , p. 561 - 570, 1983.

JOO S-H, KIM D-J, YOO I-K, PARK K \& CHA G-C. Partial nitrification in an upflow biological aerated filter by $\mathrm{O}_{2}$ limitation. Biotechnology Letters. v. 22, p. 937-940, 2000.

KADIYALA, V.; SMETS, B. F.; CHANDRAN, K.; SPAIN, J. C. High afinity p-nitrophenol oxidation by Bacillus sphaericus JS905. FEMS Microbiology Letters, v. 166, p. 115 - 120, 1998. 
KAMIYAMA, H. Lodo ativado por batelada (LAB): suas vantagens no tratamento de esgotos em comunidades de médio e pequeno porte (Parte 1). Revista do DAE, v.46, n.157, out/dez. 1988.

KIBRET, M.; SOMITSCH, W.; ROBRA, K. H. Characterization of a phenol degrading mixed population by enzime assay. Water Research, Oxford, v. 34, n. 4, p. 1127 - 1134, 2000.

KIKUGAWA, K.; KATO, T. Formation of a mutagenic diazoquinone by interaction of phenol with nitrite. Food Chemical Toxicology, v. 26, n. 3, p. 209-214, 1988.

KIM J. D.; CHANG, D. I.; LEE D. W.; HAN I. K.; YOO, G. C. CHA. Nitrification of high strength ammonia wastewater and nitrite accumulation characteristics. Water Science and Technology, Londres, v. 47, n. 11, p. 45 - 51, 2003.

KIM, J. H.; CHEN, M; KISHIDA, N.; SUDO, R. Integrated real-time control strategy for nitrogen removal in swine wastewater treatment using sequencing batch reactors. Water Research, Oxford, v. 38, n. 8, p. 3340 - 3348, 2004.

KIM, R. B. Effect of ammonia on COD analysis. Journal of Water Pollution Control Federation, v.61, n. 5, p - 614-617, Mai. 1989.

KOSTENBADER, P. D.; FLECKSTEINER, J. W. Biological oxidation of coke plant weak ammonia liquor. Journal of Water Pollution Control Federation, v.41, n. 2, p - 199-207, Feb. 1969.

KULKARNI, M.; CHAUDHARI, A. Biodegradation of $p$ - nitrophenol by Pseudomonas putida. Bioresource Technology. n. 97, p. 982 - 988, 2006.

KUMARAN, P.; PARUCHURI, L. Y. Kinetics of phenol biotransformation. Water Research, Oxford, v. 31, n. 1, p. 11 - 22, 1997.

LAI, E.; SENKPIEL S.; SOLLEY D.; KELLER J. Nitrogen removal of high strength wastewater via nitritation/denitritation using a sequencing batch reactor. Water Science and Technology, Londres, v. 50, n. 10, p. 27-33, 2004.

LAY, J. J.; CHENG, S.S. Influence of hydraulic loading rate on UASB reactor treating phenolic watewater. Journal Environmental Engineering. v. 124. n. 9, p. 829 - 837, 1998. 
LEE, D. S.; JEON, C. O.; PARK, J. M. Biological nitrogen removal with enhanced phosphate uptake in sequencing batch reactor using single sludge system. Water Research, Oxford, v. 35, n. 16, p. 3968 - 3976, 2001.

LEE, M. W.; PARK, Y. J. PARK, J. M.; CHUN, H. D. Control of external carbon addition in biological nitrogen removal process for the treatment of coke-plant wastewater. Water Environment Research, v.73, n.4, p. 415 - 425, Jul/Aug. 2001.

LESLEY, A. R.; KUENEN, J. G. Aerobic denitrification: a controversy revived. Archives of Microbiology, Delft, v. 139, p. 351-354, 1984.

LI, P. H. Y.; RODDICK, F. A.; HOBDAY, M. D. Bioregeneration involving a Coal-based adsorbent used for removing nitrophenol from water. Journal of Chemical Technology and Biotechnology. v. 73, p. 405 - 413, 1998.

LI, Y. Z.; PENG, C. Y.; PENG, Y. Z.; WANG, P. Nitrogen removal from pharmaceutical manufacturing wastewater via nitrite and the process optimization with on-line control. Water Science and technology, Londres, v. 50, n. 06, p. 25-30, 2004.

LLOYD, D; BODDY, L; DAVIES, K. J. P. Persistence of bacterial denitrification capacity under aerobic conditions: The rule rather than the exception. FEMS Microbiology Ecology, v. 45, n. 3, p. 185-190, 1987.

MAURET, M. P. E.; PUECH-COSTES, E.; MAURETTE, M. T.; BAPTISTE, P. Application of experimental research methodology to the study of nitrification in mixed culture. Water Science and technology, Londres, v. 34, n. 01, p. 245-252, 1996.

MADIGAN, M. T.; MARTINKO, J. M.; PARKER, J. Brock Biology of Microorganisms. $8^{\text {a. }}$ edição. New Jersey. Prentice Hall, 1997.

MEHROTRA, I.; KUMAR, P.; GALI, V. Treatment of phenolic wastewater using UASB reactor. In: NATIONAL CONFERENCE ON BIOLOGICAL TREATMENT OF WASTEWATER AND WASTE AIR, Trinvadrum, India, 2003.

METCALF \& EDDY INC. Wastewater engineering: Treatment and Reuse. Revisão de George Tchobanoglous, Franklin Burton e David Stensel. 4. ed. New York: McGraw-Hill, 2003. 
MORITA, D. M.; Tratabilidade de águas residuárias contendo poluentes perigosos - estudo de caso. São Paulo, 1993. Tese (Doutorado) - Escola Politécnica, Universidade de São Paulo.

MORITA, D. M.; LEITE, J. V.; DA COSTA, A. J. M.; FERRARESI, G. N.; ALEM SOBRINHO, P. Avaliação da toxicidade do fenol ao tratamento biológico de águas residuárias de coqueria pelo método "fed-batch reactor" modificado. In: CONGRESSO BRASILEIRO DE ENGENHARIA SANITÁRIA E AMBIENTAL, 19., Foz do Iguaçú, 1997. Anais. p. 187 - 199.

MORRISON, R. T.; BOYD, R. N. Organic Chemistry. Sixth edition. New Jersey. Prentice-Hall International editors, 1992.

MOSQUERA-CORRAL, A.; BARZ, T.; DAPENA, A.; CAMPOS, J.L.; MENDEZ, R. Partial nitrification in a SHARON reactor in the presence of salts and organic carbon compounds. Process Biochemistry, v. 40, p. 3109 - 3118, 2005.

MUENCH, E. V.; LANT, P.; KELLER, J. Simultaneous nitrification and denitrification in bench-scale sequencing batch reactors. Water Research, v. 30, n. 2, p. 277-284, 1996.

MULDER, A.; VAN DE GRAAF, A.A.; ROBERTSON, L.A.; KUENEN, J.G. Anaerobic ammonium oxidation discovered in a denitrifying fluidized bed reactor. FEMS Microbiology Ecology, v.16, p.177-84, 1995.

MULDER, J. W.; VAN KEMPEN, R. N-removal by SHARON. Water Quality International, v. 2, p. $30-31,1997$.

MULDER, J. W.; VAN LOOSDRECHT, M. C.; HELLINGA, C.; VAN KEMPEN, R. Full-scale application of the SHARON process for treatment of rejection water of digested sludge dewatering. Water Science and Technology, Londres, v. 43, n. 11, p. 127 - 134, 2001.

NOOPHAN, P.; FIGUEROA, L. A.; MUNAKATA-MARR, J. Nitrite oxidation inhibition by hidroxylamine: experimental and model evaluation. Water Science and Technology, Londres, v. 50, n. 6, p. $295-304,2004$.

PATNAIK, P.; KHOURY, J. N. Reaction of phenol with íon nitrite: Pathways of formation of nitrophenols in environmental waters. Water Research, v. 38, p. 206 - 210; 2004. 
PENG, Y.; MA, Y.; WANG, S.; WANG, X. Fuzzy control of nitrogen removal in predenitrification process using ORP. Water Science and Technology, Londres, v. 52, n. 12, p. $161-171,2005$.

PHILIPS, S.; LAANBROEK, H. J.; VERSTRAETE, W. Origin, cause and effects of increased nitrite concentrations in aquatic environments. Reviews in Environmental Science and Biotechnology, n. 01, p. 115 - 141, 2002.

PIVELI, R. P.; KATO, M. T. Qualidade das águas e poluição: aspectos físico-químicos. $1^{\mathrm{a}}$ edição. São Paulo. Associação Brasileira de Engenharia Sanitária e Ambiental (ABES). 2006.

PLISSON-SAUNE, S.; CAPDEVILLE, B.; MAURET, M.; DEGUIN, A.; BAPTISTE, P. Realtime control of nitrogen removal using three ORP bending-points: signification, control strategy and results. Water Science and Technology, Londres, v. 33, n. 1, p. 275 - 280, 1996.

POCHANA, K.; KELLER, J. Study of factors affecting simultaneous nitrification and denitrification (SND). Water Science and Technology, Vol. 39, no. 6, pp. 61-68, 1999

POLLICE, A.; TANDOI, V.; LESTINGI, C. Influence of aeration and sludge retention time on ammonium oxidation to nitrite and nitrate. Water Research, v.36, p.2541-46, 2002.

PRAKASAM, T. B. S.; LOEHR, R.C. Microbial nitrification and denitrification in concentrated wastes. Water Research, n. 6, p. 859-869, 1972.

PUZNAVA, N.; PAYRAUDEAU, M.; THORNBERG, D. Simultaneous nitrification and denitrification in biofilters with real time aeration control. Water Science and Technology, Londres, v. 43, n. 1, p. 269 - 276, 2001.

RANDALL, C. W. The environmental, economic and societal consequences of inadequate nitrogen pollution controls. Water Science and Technology, Londres, v. 49, n. 5-6, p. 23 - 33, 2004.

RANDALL, C. W.; BARNARD, J. L.; STENSEL H. D. Design and retrofit of wastewater treatment plants for biological nutrient removal. Lancaster, Technomic Publishing Company, 1995. 
RHEE, S.; LEE, J.J.; LEE, S. Nitrite accumulation in a sequencing batch reactor during the aerobic phase of biological nitrogen removal. Biotechnology Letters, Vol 19, No 2, p. 195-198, Fev. 1997.

RUIZ, G.; JEISON, D.; CHAMY, R. Nitrification with high nitrite accumulation for the treatment of wastewater with high ammonia concentration. Water Research, Oxford, v. 37, p. 1371 - 1377, 2003.

SANTOS, S. G. Utilização de Metanol, Etanol e Metano como doadores de elétrons para a desnitrificação. 2003. Tese (Doutorado) Escola de Engenharia de São Carlos. Universidade de São Paulo. São Carlos, 2003.

SÃO PAULO (Estado) Decreto $n^{\circ} 8.468$ de 08 de setembro de 1976. Aprova o regulamento da Lei n $^{\circ} 997$ de 31 de maio de 1976, que dispõe sobre a prevenção e o controle da poluição do meio ambiente. Legislação estadual: controle de poluição ambiental, São Paulo, CETESB, 1991.

SÃO PAULO (Estado). Secretaria do Meio Ambiente. Resolução SMA-3 de 22 de fevereiro de 2000. Implementa o controle ecotoxicológico de efluentes líquidos do Estado de São Paulo. Gabinete do Secretário, São Paulo, 22 de fev. 2000.

SARFARAZ, S.; THOMAS S.; TEWARI, U. K.; IYENGAR, L. Anoxic treatment of phenolic wastewater in sequencing batch reactor. Water Research, Oxford, v. 38, n. 4, p. 965 - 971, 2004.

SAUTER, L. J.; ALLEMAN, J. E. A streamlined approach to biological nitrogen removal. Journal of Environmental Engineering. p. 296 - 306, 1980.

SAWYER, C. N.; Mc CARTY, P. L.; PARKIN, G. F. Chemistry for environmental engineering. 4 ed. New-York: McGraw-Hill, 1994.

SIJBESMA, W. F. H.; ALMEIDA, J. S.; REIS M. A. M.; SANTOS, H. Metabolic engineering and cell physiology uncoupling effect of nitrite during denitrification by Pseudomonas Fluorescens. Biotechnology and Bioengineering, v. 52, n. 01, p. 176 - 182, 2000.

SOGAME, S.; AKIYAMA, M.; HONDA, T.; HASEGAWA, T. Application of biological denitrification method for cokeoven wastewater treatment. Journal of the Iron and Steel Institute of Japan, v 82, n 5, p. 447-452, May, 1996. 
STOVER, L. E.; KINCANNON D. F. Biological treatability of specific organic compounds found in chemical industry wastewaters. Journal of Water Pollution Contro Federation, v. 55, n. 1, p. 97-109, jan. 1983.

STUVEN, R.; BOCK, E. Nitrification and denitrification as a source for $\mathrm{NO}$ and $\mathrm{NO}_{2}$ production in high-strength wastewater. Water Research, Oxford, v. 35, n. 8, p. 1905 - 1914, 2001.

SU, J.-J.; LIU, B.-Y.; CHANG, Y.-C. Identifying an interfering factor on chemical oxygen demand (COD) determination in piggery wastewater and eliminating the factor by an indigenous Pseudomonas stutzeri strain. Letters in Applied Microbiology, n. 33, p. 440 - 444, 2001.

SUESCUN, J.; OSTOLAZA, X.; GARCIA-SANZ, M.; AYESA, E. Real-time strategies for predenitrification-nitrification control activaded sludge plants biodegradation control. Water Science and Technology, Londres, v. 43, n. 1, p. 209 - 216, 2001.

SUIDAN, M. T.; NAJM, J. N.; PFEFFER, J.; VANG, Y.T. Anaerobic biodegradation of Phenol: inhibition kinetics and system stability. Journal of Environmental Engineering, Nova York, v. 114, n. 6, p. 1359 - 1376, 1988.

TABAK, H. H.; QUAVE, S. A.; MASHNI, C.I.; BARTH, E. F. Biodegradability studies with organic priority polluant compounds. Journal of Water Pollution Control Federation, v. 53, n. 10, p. 1503-1518, out. 1981.

TAY, J. H.; HE, Y. X.; YAN, Y. G. Improved anaerobic degradation of phenol with supplemental glucose. Journal Environmental Engineering, v. 127, n.1, p. 38 - 45, 2001.

THIRD, K.A.; PAXMAN, J.; SCHMID, M.; STROUS, M.; JETTEN, M. S. M.; CORDRUWISCH, R. Treatment of nitrogen-rich wastewater using partial nitrification and Anammox in the CANON process. Water Science and Technology, Londres, v. 52, n. 4, p. 47 - 54, 2005.

THOMAS, S.; SARFARAZ, S.; MISHRA, L. C.; IYENGAR, L. Degradation of phenol and phenolic compounds by a defined denitrifying bacterial culture. World Journal of Microbiology and Biotechnology. n. 18, p. 57 - 63, 2002.

TURK, O.; MAVINIC, D.S. Maintaining nitrite build-up in a system acclimated to free ammonia. Water Research, Oxford, v. 23, n. 11, p. 1383 - 1388, 1989. 
TURNEY, T. A.; WRIGHT, G. A. Nitrous acid and nitrosation. Chemical Reviews, v. 59, n. 3 p. $497-513,1959$.

UNITED STATES DEPARTMENT OF LABOR; OCCUPATIONAL SAFETY AND HEALTH ADMINISTRATION. Limits for air contaminants. Disponível em < http://www.osha.gov> Acesso em: 06 jul. 2005.

UNITED STATES ENVIRONMENT PROTECT AGENCY. Toxicological review of phenol. Washington, D.C., set. 2002. Disponível em: < http://www.usepa.gov/iris $>$. Acesso em 06 jul. 2005.

UNITED STATES ENVIRONMENT PROTECT AGENCY. Phenol analisys in water. Washington, D.C. Disponível em: < http://www.usepa.gov/sw-846/main.htm. Acesso em 16 abr. 2006.

UYGUR, A.; KARGI, F. Phenol inhibition of biological nutrient removal in a four-step sequencing batch reactor. Process Biochemistry, v. 39, p. 2123 - 2128, 2004.

VAN BENTHUM, W. Integrated nitrification and denitrification in biofilm airlift reactors: biofilm development, process design and hydrodynamics. Delft, 1998. Tese (Doutorado) Universidade Técnica de Delft, Holanda, 1998.

VAN HAANDEL, A.; MARAIS, G. O comportamento do sistema de lodo ativado - teoria e aplicações para projeto e operação. Campina Grande: Epgraf, 1999.

VAN KEMPEN, R.; TEN HAVE, C. C. R.; MEIJER, S. C. F.; MULDER, J. W.; DUIN, J. O. J; UIJTERLINDE, C. A.; VAN LOOSDRECHT, M. C. M. SHARON process evaluated for improved wastewater treatment plant nitrogen effluent quality. Water Science and Technology, Londres, v. 52, n. 4, p. 55 - 62, 2005.

VEERESH G.S., KUMAR P.; MEHROTRA I. Treatment of phenol and cresols in upflow anaerobic sludge blanket (UASB) process: a review. Water Research, Oxford, v. 39, n. 1, p. 154 - 170, Jan. 2005.

VERSTRAETE W.; VANSTAEN, H.; VOETS, J. P. Adaptation to nitrification of activated sludge systems treating highly nitrogenous waters. Journal of Water Pollution Control Federation, v. 49, p. 1604-1608, 1977. 
VERSTRAETE, W.; PHILIPS, S. Nitrification/denitrification processes and technologies in new contexts. Enviromental Pollution. v. 102, p. 717-726, 1998.

VILLAS BÔAS, D. M. Bactérias degradadoras de fenol em sistemas de lodos ativados. São Paulo, 1998. Tese (Doutorado) - Escola Politécnica, Universidade de São Paulo.

VIONE, D.; MAURINO, V.; MINERO, C.; PELIZZETI, E. New processes in the environmental chemistry of nitrite: nitration of phenol upon nitrite photoinduced oxidation. Environmental Science and Technology, v. 36, n. 04, p. 669 - 676, 2002.

VOLCKE, E. I. P.; VAN HULLE, S. W. H.; DONCKELS, B. M. R.; VAN LOOSDRECHT M. C. M.; VANROLLEGHEM, P. A. Coupling the SHARON process with Anammox: Model-based scenario analysis with focus on operating costs. Water Science and Technology, Londres, v. 52, n. 4, p. $107-115,2005$.

VON SPERLING, M. Princípios do tratamento biológico de águas residuárias: lodos ativados. $2^{\mathrm{a}}$ edição. Belo Horizonte: DESA, UFMG, 2002. 4v.

WANG, B.; HE, S.; WANG, L.; SHUO, L. Simultaneous nitrification and de-nitrification in MBR. Water Science and Technology, Londres, v. 52, n. 10, p. 435 - 442, 2005.

WANG, J-H; BALTZIS, B. C.; LEWANDOWSKI, G. A. Fundamental denitrification kinetics studies with Pseudomona denitrificans. Biotechnology and Bioengineering, v. 47, n. 1, p. 26 41, 1995.

WANG, S. Y.; GAO, D. W.; PENG, Y. Z.; YANG, Q. Nitrification-denitrification via nitrite for nitrogen removal from high nitrogen soybean wastewater with on-line fuzzy control. Water Science and Technology, Londres, v. 49, n. 5 - 6, p. 121 - 127, 2004.

WONG-CHONG, G. M.; LOEHR, R. C. Kinetics of microbial nitrification. Nitrite-nitrogen oxidation. Water Research, Oxford, v. 12, n. 8, p. 605 - 609, 1978.

WYFFELS, S.; BOECKX, P.; PYNAERT, K.; ZHANG, D.; VAN CLEEMPUT, O.; CHEN, G.; VERSTRAETE, W. Nitrogen removal from sludge reject water by a two-stage oxygen-limited autotrophic nitrification denitrification process. Water Science and Technology, Londres, v. 49, n. 5 -6, p. $57-64,2004$. 
YAMAGISHI, T.; LEITE, J.; UEDA, S.; YAMAGUCHI, F.; SUWA, Y.. Simultaneous removal of phenol and ammonia by an actived sludge process with cross-flow filtration. Water Research, Oxford, v. 35, n. 13, p. 3089-3096, 2001.

YANG, L.; ALLEMAN, J. E. Investigation of batchwise nitrite build-up by an enriched nitrification culture. Water Science and Technology, Londres, v. 26, n. 5-6, p. 997-1005, 1992.

YANG, R. D.; HUMPHREY, A. E. Pseudomonas putida: Dynamics and steady state of phenol biodegradation in pure and mixed cultures. Biotechnology and Bioengineering, v. 17, n.8, p. 1211 - 1233, 1975.

YI, Q.; YIBO, W.; HUIMING, Z. Efficacy of pre-treatment methods in the activated sludge removal of refractory compounds in coke-plant wastewater. Water Research, Oxford, v. 28, n. 3, p. 701-7046, 1994.

YIBO, W.; MIN, Z.; YI, Q. Biological treatment of coke-plant wastewater for COD and $\mathrm{NH}_{3}-\mathrm{N}$ removal. Water Science and Technology, Londres, v. 23, n. 10 - 12, p. 1883 - 1892, 1991.

YOO, H.; AHN, K.; LEE, K.; KWAK, Y.; SONG, K. Nitrogen removal from synthetic wastewater by simultaneous nitrification and denitrification (SND) via nitrite in an intermittentlyaerated reactor. Water Resource, v. 33, n. 1, p. 145 - 154, 1999.

YUN, Z.; JUNG, Y.-H.; LIM, B.-R.; CHOI, E.; MIN, K. S. The stability of nitrite nitrification with strong nitrogenous wastewater: effects of organic concentration and microbial diversity. Water Science and Technology, Londres, v. 49, n. 5-6, p. 89 - 96, 2004.

ZDRADEK, C. P. Seleção de linhagens oxidadoras de amônio e remoção de nitrogênio via nitrito em reator descontínuo alimentado (SBR) sob condições de limitação de oxigênio. Florianópolis, 2005. Tese (Doutorado) - Programa de Pós-Graduação em Engenharia Química, Universidade Federal de Santa Catarina.

ZEYER, J.; KEARNEY, P. C. Degradation of o-Nitrophenol and $m$-Nitrophenol by a Pseudomonas putida. Journal of agricultural food chemistry. v. 32, p. 238 - 242, 1984. 
ANEXO A - Fotos do sistema de lodos ativados em escala piloto ( volume útil de 20 litros) operado durante a presente pesquisa em bateladas seqüenciais, instalado no Laboratório de Saneamento da Escola Politécnica da USP.
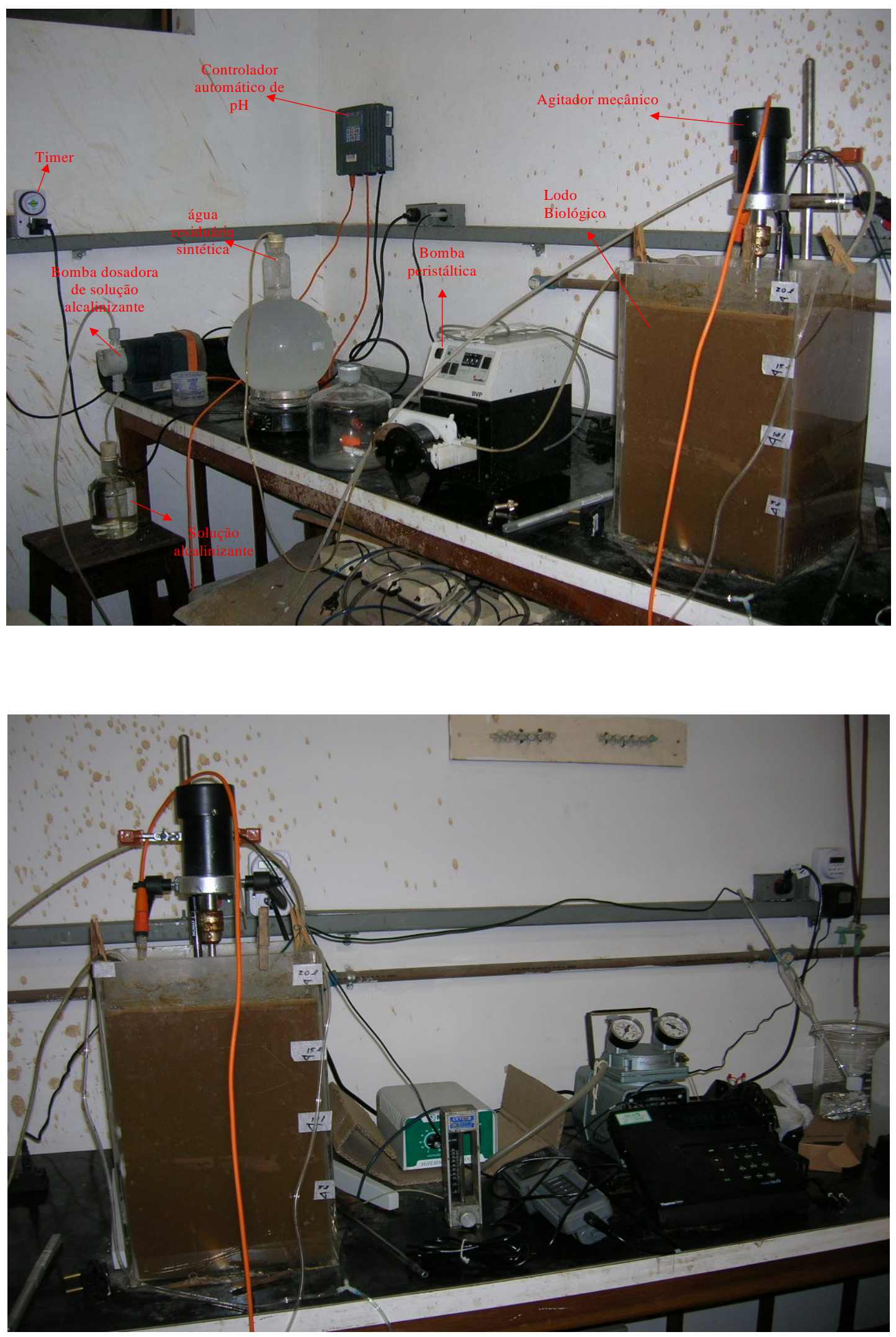
ANEXO B - Concentrações de N-NH$H_{3}$, fenol, $\mathrm{N}_{-\mathrm{NO}_{2}}{ }^{-}, \mathrm{N}-\mathrm{NO}_{3}{ }^{-} \cdot \mathrm{NH}_{3}$ e $\mathrm{HNO}_{2}$ no conteúdo do reator piloto ao longo dos ciclos de tratamento.

ANEXO B1 - Etapa 01 - Concentração no afluente em torno de 200 mg N/L

\begin{tabular}{l} 
Etapa 01 - Ciclo 01 \\
Q alim. - 2,6 mL/min \\
Concentração de N-NH3 afluente - \\
Concentração de Fenol afluente - \\
\cline { 2 - 11 }
\end{tabular}

Etapa 01 - Ciclo02

Q alim. - $\quad 2,5 \mathrm{~mL} / \mathrm{min}$

Concentração de N-NH3 afluente -

$203 \mathrm{mg} \mathrm{N} / \mathrm{L}$

\begin{tabular}{|c|c|c|c|c|c|c|c|c|c|c|c|c|}
\hline \multicolumn{7}{|c|}{ Concentração de Fenol afluente - } & \multicolumn{6}{|c|}{ Anóxico } \\
\hline \multirow[b]{2}{*}{ Horas do ciclo } & \multicolumn{6}{|c|}{ Aerado } & \multicolumn{5}{|c|}{ Alimentação } & \multirow[b]{2}{*}{33} \\
\hline & 0 & 3 & 6 & 9 & 12 & 15 & 18 & 21 & 24 & 27 & 30 & \\
\hline & & & & & & & & & & & & \\
\hline mg N-NO2-/L & 0 & 4,6 & 12,6 & 18,8 & 24,6 & 20,2 & 22,8 & 13,9 & 5,8 & 0,0 & 0,0 & 0,0 \\
\hline mg N-NO3-/L & 0 & 1,1 & 3,1 & 5,1 & 7,0 & 11,2 & 3,3 & 2,1 & 0,4 & 0,3 & 0 & 0 \\
\hline mg C6H5OH/L & 23,6 & 0,1 & 0,1 & 0,1 & 0,1 & 0,1 & 0,1 & 32,9 & 23,0 & 16,9 & 13,0 & 28,3 \\
\hline mg N-NH3/L & 26,8 & 21,4 & 17,6 & 10,9 & 4,8 & 2,2 & 4,5 & 4,5 & 4,5 & 4,5 & 4,5 & 4,5 \\
\hline mg NH3/L & 4,4 & 3,5 & 2,9 & 1,8 & 0,8 & 0,4 & & & & & & \\
\hline mg HNO2/L & 0,000 & 0,001 & 0,002 & 0,003 & 0,005 & 0,007 & & & & & & \\
\hline Fenol aplicado & & & & & & 0 & 29,8 & 58,0 & 84,6 & 109,7 & 133,6 & \\
\hline
\end{tabular}

Etapa 01 - Ciclo 03

Q alim. - $\quad 8,0 \mathrm{~mL} / \mathrm{min}$

Concentração de N-NH3 afluente -

$207 \mathrm{mg} \mathrm{N} / \mathrm{L}$

Concentração de Fenol afluente -

$973 \mathrm{mg} \mathrm{C} 6 \mathrm{H} 5 \mathrm{OH} / \mathrm{L} \quad$ Anóxico

\begin{tabular}{|c|c|c|c|c|c|c|c|c|c|c|}
\hline & \multicolumn{6}{|c|}{ Aerado } & \multicolumn{4}{|c|}{ Alimentação } \\
\hline Horas do ciclo & 0 & 3 & 6 & 9 & 12 & 15 & 18 & 21 & 24 & 25 \\
\hline mg N-NO2-/L & 0 & 2,9 & 6,3 & 12,0 & 28,4 & 40,8 & 24,2 & 11,3 & 6,3 & 1,9 \\
\hline mg N-NO3-/L & 0 & 1,6 & 2,4 & 3,3 & 6,2 & 8,2 & 9,8 & 2,3 & 0,6 & 0,8 \\
\hline $\mathrm{mg} \mathrm{C6H5OH/L}$ & 32,4 & 0,1 & 0,1 & 0,1 & 0,1 & 0,1 & 27,9 & 45,8 & 91,0 & 139,0 \\
\hline mg N-NH3/L & 48,3 & 29,7 & 20,5 & 9,5 & 3,5 & 2,6 & 2,6 & 2,6 & 2,6 & 2,6 \\
\hline mg NH3/L & 8,1 & 5,0 & 3,4 & 1,6 & 0,6 & 0,4 & & & & \\
\hline $\mathrm{mg} \mathrm{HNO} 2 / \mathrm{L}$ & 0,000 & 0,000 & 0,000 & 0,000 & 0,001 & 0,001 & & & & \\
\hline Fenol aplicado & & & & & & 0 & 85,2 & 156,7 & 217,6 & 235,9 \\
\hline
\end{tabular}


Etapa 01 - Ciclo 04
Q alim. -
$8,3 \mathrm{~mL} / \mathrm{min}$

Concentração de N-NH3 afluente -

$189 \mathrm{mg} \mathrm{N} / \mathrm{L}$

Concentração de Fenol afluente -

$1012 \mathrm{mg} \mathrm{C} 6 \mathrm{H} 5 \mathrm{OH} / \mathrm{L}$

\begin{tabular}{|c|c|c|c|c|c|c|c|c|c|c|}
\hline \multicolumn{7}{|c|}{ Concentração de Fenol afluente - } & \multicolumn{4}{|c|}{ Anóxico } \\
\hline & \multicolumn{6}{|c|}{ Aerado } & \multicolumn{4}{|c|}{ Alimentação } \\
\hline Horas do ciclo & 0 & 3 & 6 & 9 & 12 & 15 & 18 & 21 & 24 & 25 \\
\hline mg N-NO2-/L & 0 & 3,3 & 7,0 & 10,5 & 31,0 & 38,4 & 18,5 & 7,9 & 2,0 & 0,0 \\
\hline mg N-NO3-/L & 0,1 & 1,0 & 3,0 & 2,9 & 4,0 & 7,2 & 2,9 & 1,0 & 0,9 & 0,5 \\
\hline $\mathrm{mg} \mathrm{C} 6 \mathrm{H} 5 \mathrm{OH} / \mathrm{L}$ & 40,6 & 0,1 & 0,1 & 0,1 & 0,1 & 0,1 & 29,2 & 62,3 & 86,0 & 137,0 \\
\hline mg N-NH3/L & 42,7 & 34,7 & 22,0 & 18,4 & 2,6 & 1,8 & 1,8 & 1,8 & 1,8 & 1,8 \\
\hline mg NH3/L & 7,1 & 5,8 & 3,6 & 3,1 & 0,4 & 0,3 & & & & \\
\hline mg HNO2/L & 0,000 & 0,000 & 0,000 & 0,000 & 0,001 & 0,001 & & & & \\
\hline Fenol aplicado & & & & & & 0 & 91,7 & 168,1 & 232,8 & 252,2 \\
\hline
\end{tabular}

Etapa $01-$ Ciclo 05

Q alim.- $\quad 8,1 \mathrm{~m} \mathrm{~L} / \mathrm{m}$ in

Concentração de N-N H 3 a fluente -

$198 \mathrm{~m} \mathrm{~g} \mathrm{~N} / \mathrm{L}$

Concentração de Fenol afluente -

$981 \mathrm{mg} \mathrm{C} 6 \mathrm{H} 5 \mathrm{OH} / \mathrm{L}$

\begin{tabular}{|c|c|c|c|c|c|c|c|c|}
\hline & & & & & & An & ico & \\
\hline & & A e & do & & & Alime & t a çã 0 & \\
\hline Horas do ciclo & 0 & 3 & 6 & 10 & 12 & 15 & 18 & 20 \\
\hline m g N - N O $2-/ L$ & 0,8 & 3,1 & 9,8 & 32,6 & 21,7 & 7,5 & 0,2 & 0,0 \\
\hline m g $\mathrm{N}-\mathrm{N}$ O $3-/ \mathrm{L}$ & 1,4 & 1,5 & 1,2 & 0,9 & 3,0 & 1,2 & 0,8 & 0,9 \\
\hline $\mathrm{mg} \mathrm{C} 6 \mathrm{H} 5 \mathrm{OH} / \mathrm{L}$ & 47,6 & 0,1 & 0,1 & 0,0 & 54,5 & 61,3 & 94,0 & 126,0 \\
\hline m g N-N H $3 / \mathrm{L}$ & 36,9 & 20,9 & 17,6 & 3,1 & 3,1 & 3,1 & 3,1 & 3,1 \\
\hline m g N H 3/L & 6,1 & 3,5 & 2,9 & 0,5 & & & & \\
\hline m g $\mathrm{H} \mathrm{N} \mathrm{O} 2 / \mathrm{L}$ & 0,000 & 0,000 & 0,000 & 0,001 & & & & \\
\hline Fenol aplicado & & & & 0 & 59,7 & 136,8 & 201,9 & 240,1 \\
\hline
\end{tabular}

Etapa $01-$ Ciclo 06
Q alim.-
$16,0 \mathrm{~m} \mathrm{~L} / \mathrm{m}$ in

Concentração de N-N H 3 afluente -

$208 \mathrm{mg} \mathrm{N} / \mathrm{L}$

C oncentração de Fenol afluente -

$994 \mathrm{mg} \mathrm{C} 6 \mathrm{H} 5 \mathrm{OH} / \mathrm{L}$

\begin{tabular}{|c|c|c|c|c|c|c|c|c|}
\hline \multirow{3}{*}{ Horas do ciclo } & \multirow{2}{*}{\multicolumn{4}{|c|}{ Aerado }} & \multicolumn{4}{|c|}{ Anóxico } \\
\hline & & & & & \multicolumn{2}{|c|}{ A limentação } & \multirow[b]{2}{*}{18} & \multirow[b]{2}{*}{20} \\
\hline & 0 & 3 & 6 & 10 & 12 & 15 & & \\
\hline m g $\mathrm{N}-\mathrm{N} \mathrm{O} 2-/ \mathrm{L}$ & 2,4 & 5,5 & 14,1 & 36,4 & 28,4 & 20,6 & 18,3 & 18,5 \\
\hline $\mathrm{mg} \mathrm{N}-\mathrm{NOO} 3-/ \mathrm{L}$ & 0,9 & 1,3 & 3,9 & 3,7 & 3,0 & 0,8 & 0,9 & 0,9 \\
\hline $\mathrm{mg} \mathrm{C6H5OH/L}$ & 38,7 & 0,0 & 0,0 & 0,0 & 31,7 & 162,0 & 166,0 & 163,0 \\
\hline $\mathrm{m} \mathrm{g} \mathrm{N}-\mathrm{N} \mathrm{H} \mathrm{3/L}$ & 42,5 & 32,7 & 11,5 & 2,4 & 2,4 & 2,4 & 2,4 & 2,4 \\
\hline $\mathrm{mg} \mathrm{N} \mathrm{H} 3 / \mathrm{L}$ & 7,0 & 5,4 & 1,9 & 0,4 & & & & \\
\hline $\mathrm{mg} \mathrm{H} \mathrm{N} \mathrm{O} 2 / \mathrm{L}$ & 0,000 & 0,000 & 0,000 & 0,001 & & & & \\
\hline Fenol aplicado & & & & 0 & 59,6 & 136,7 & & \\
\hline
\end{tabular}


Etapa $01-$ Ciclo 07

Q alim.- $\quad 16,0 \mathrm{~m} \mathrm{~L} / \mathrm{m}$ in

Concentração de N-N H 3 afluente -

$204 \mathrm{mg} \mathrm{N} / \mathrm{L}$

Concentração de Fenol afluente -

$1011 \mathrm{mg} \mathrm{C} 6 \mathrm{H} 5 \mathrm{OH} / \mathrm{L}$

\begin{tabular}{|c|c|c|c|c|c|c|c|c|}
\hline \multirow{3}{*}{ Horas do ciclo } & & & & & \multicolumn{4}{|c|}{ Anóxico } \\
\hline & \multicolumn{4}{|c|}{ Aerado } & \multicolumn{2}{|c|}{ A limentação } & \multirow[b]{2}{*}{18} & \multirow[b]{2}{*}{20} \\
\hline & 0 & 3 & 6 & 10 & 12 & 15 & & \\
\hline $\mathrm{mg} \mathrm{N}-\mathrm{N} \mathrm{O} 2-/ \mathrm{L}$ & 0 & 0 & 16,6 & 37,1 & 28,2 & 27,2 & 25,3 & 27,0 \\
\hline m g N-NO3-/L & 0,6 & 0,2 & 1,6 & 1,0 & 0,8 & 1,0 & 0,9 & 1,1 \\
\hline $\mathrm{mg} \mathrm{C} 6 \mathrm{H} 5 \mathrm{OH} / \mathrm{L}$ & 154,6 & 71,6 & 0,0 & 0,0 & 34,6 & 179,0 & 182,0 & 185,8 \\
\hline $\mathrm{mg} \mathrm{N}-\mathrm{NH} 3 / \mathrm{L}$ & 41,7 & 29,4 & 11,5 & 2,0 & 2,0 & 2,0 & 2,0 & 2,0 \\
\hline $\mathrm{mg} \mathrm{NH3/L}$ & 6,9 & 4,9 & 1,9 & 0,3 & & & & \\
\hline $\mathrm{mg} \mathrm{H} \mathrm{NO} 2 / \mathrm{L}$ & 0,000 & 0,000 & 0,001 & 0,001 & & & & \\
\hline Fenol aplicado & & & & 0 & 117,3 & 249,7 & & \\
\hline
\end{tabular}

Etapa 01 - Ciclo 08

$\mathrm{Q}$ alim.- $\quad 8,0 \mathrm{~m} \mathrm{~L} / \mathrm{m}$ in

Concentração de N-NH3 afluente -

$206 \mathrm{mg} \mathrm{N} / \mathrm{L}$

Concentração de Fenol afluente -

$984 \mathrm{mg} \mathrm{C} 6 \mathrm{H} 5 \mathrm{OH} / \mathrm{L}$

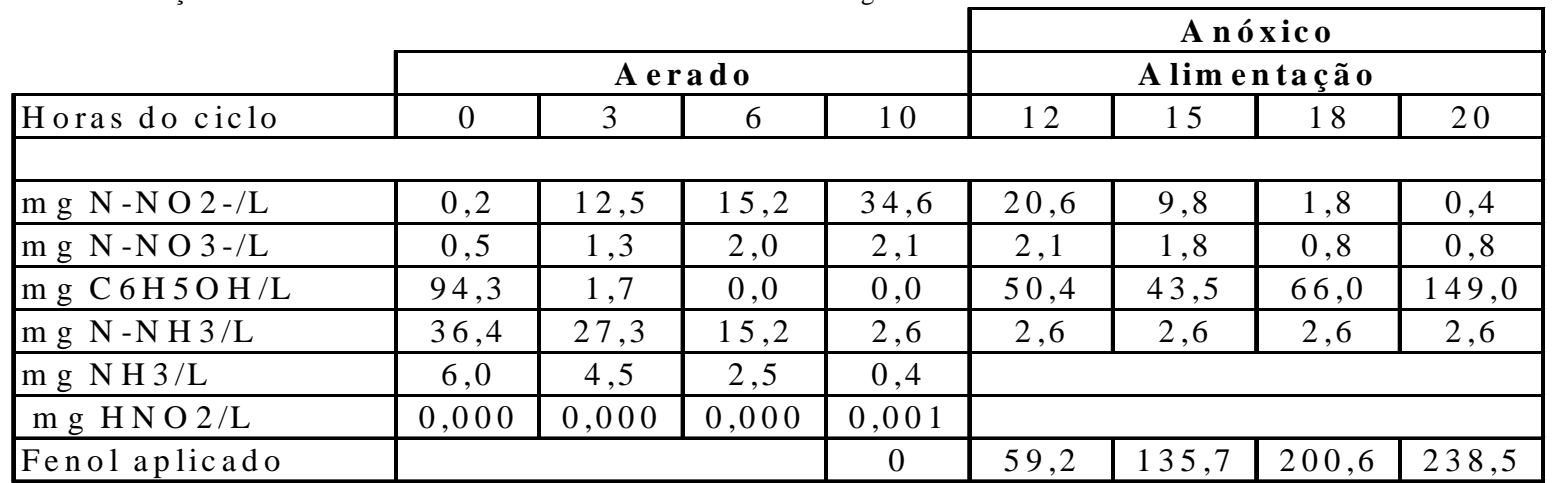

Etapa 01 - Ciclo 09
$\mathrm{Q}$ alim . -
$8,1 \mathrm{~m} \mathrm{~L} / \mathrm{m}$ in

Concentração de N-N H 3 afluente -

$207 \mathrm{mg} \mathrm{N} / \mathrm{L}$

Concentração de Fenol afluente -

$1.016 \mathrm{mg} \mathrm{C} 6 \mathrm{H} 5 \mathrm{OH} / \mathrm{L}$

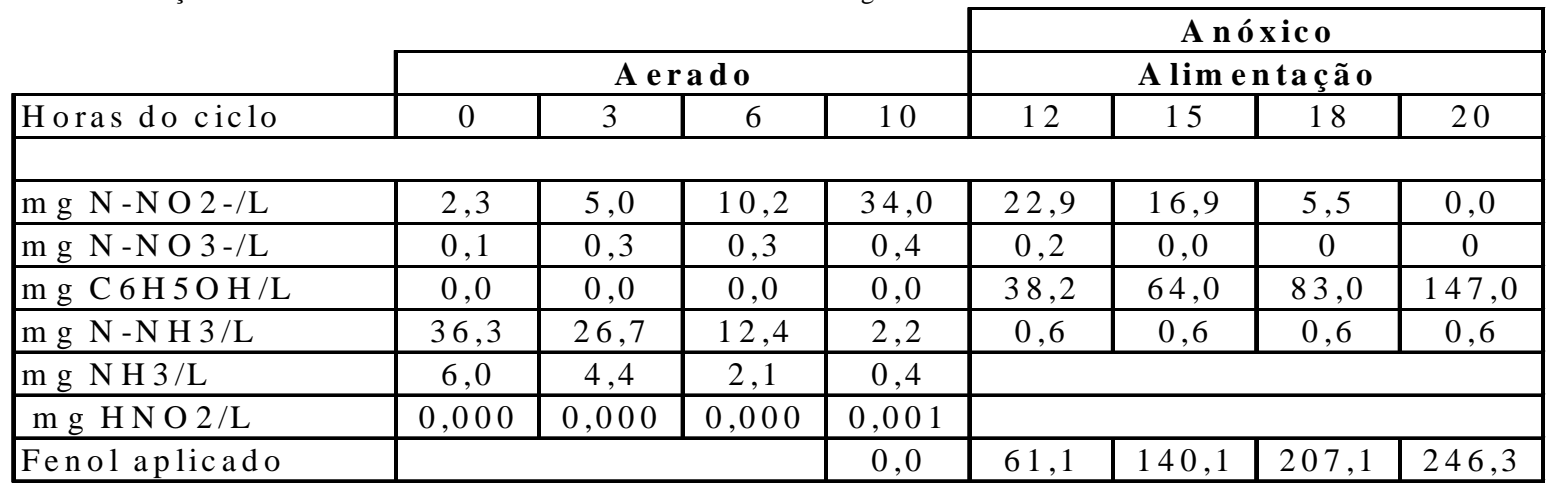


Etapa $01-$ Ciclo 10

Q alim.- $\quad 8,0 \mathrm{~m} \mathrm{~L} / \mathrm{m}$ in

Concentração de N-NH3 afluente - $209 \mathrm{mg} \mathrm{N} / \mathrm{L}$

Concentração de Fenol afluente -

$981 \mathrm{mg} \mathrm{C} 6 \mathrm{H} 5 \mathrm{OH} / \mathrm{L}$

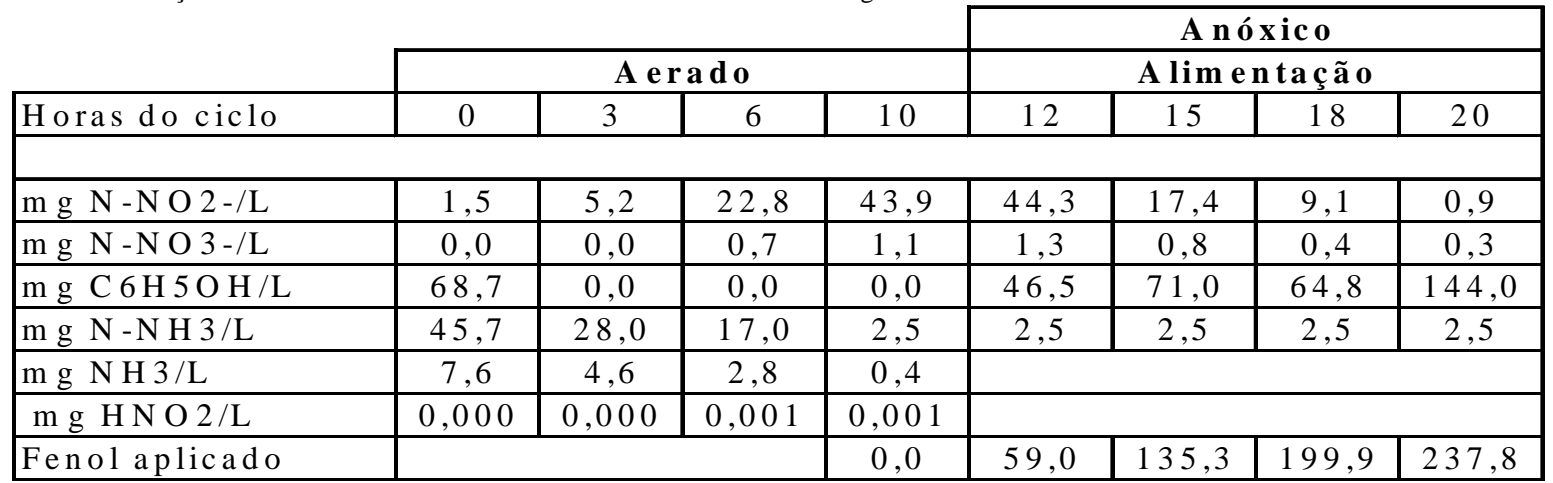

Etapa $01-$ Ciclo 11

Q alim.- $\quad 8,0 \mathrm{~m} \mathrm{~L} / \mathrm{m}$ in

Concentração de N-N H 3 afluente -

$211 \mathrm{mg} \mathrm{N} / \mathrm{L}$

Concentração de Fenol afluente -

$1014 \mathrm{mg} \mathrm{C} 6 \mathrm{H} 5 \mathrm{OH} / \mathrm{L}$

\begin{tabular}{|c|c|c|c|c|c|c|c|c|}
\hline & & & & & & An & ico & \\
\hline & & A e 1 & do & & & Alime & ta çã o & \\
\hline Horas do ciclo & 0 & 3 & 6 & 10 & 12 & 15 & 18 & 20 \\
\hline m g N - N O 2-/L & 0,8 & 4,6 & 27,2 & 38,5 & 38,6 & 16,1 & 5,7 & 0,4 \\
\hline $\mathrm{mg} \mathrm{N}-\mathrm{N} \mathrm{O} 3-/ \mathrm{L}$ & 0,2 & 0,2 & 2,5 & 1,9 & 0,9 & 0,7 & 0,8 & 0,2 \\
\hline 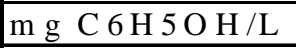 & 72,3 & 0,0 & 0,0 & 0,0 & 40,5 & 45,1 & 76,0 & 159,0 \\
\hline m g N-N H 3/L & 41,0 & 23,0 & 6,5 & 1,8 & 1,2 & 1,2 & 1,2 & 1,2 \\
\hline $\mathrm{mg} \mathrm{NH3/L}$ & 6,8 & 3,8 & 1,1 & 0,3 & & & & \\
\hline $\mathrm{m} \mathrm{g} \mathrm{H} \mathrm{N} \mathrm{O} 2 / \mathrm{L}$ & 0,000 & 0,000 & 0,001 & 0,001 & & & & \\
\hline Fenol aplicado & & & & 0,0 & 61,0 & 139,9 & 206,7 & 245,8 \\
\hline
\end{tabular}

Etapa $01-$ Ciclo 12

$\mathrm{Q}$ alim.- $\quad 8,0 \mathrm{~m} \mathrm{~L} / \mathrm{m}$ in

Concentração de N-N H 3 afluente -

Concentração de Fenol afluente -

$194 \mathrm{mg} \mathrm{N} / \mathrm{L}$

$991 \mathrm{mg} \mathrm{C} 6 \mathrm{H} 5 \mathrm{OH} / \mathrm{L}$

\begin{tabular}{|c|c|c|c|c|c|c|c|c|}
\hline & & & & & & A n & xico & \\
\hline & & A e & ado & & & Alime & t ta ção & \\
\hline Horas do ciclo & 0 & 3 & 6 & 10 & 12 & 15 & 18 & 20 \\
\hline m g N $-\mathrm{N} \mathrm{O} 2-/ \mathrm{L}$ & 1,6 & 5,3 & 8,3 & 35,0 & 23,6 & 18,8 & 8,0 & 0,0 \\
\hline m g $\mathrm{N}-\mathrm{N} O 3-/ \mathrm{L}$ & 0,0 & 0,5 & 1,0 & 1,0 & 1,0 & 0,6 & 0,4 & 0,1 \\
\hline $\mathrm{mg} \mathrm{C6H5OH/L}$ & 59,4 & 0,0 & 0,0 & 0,0 & 54,1 & 55,0 & 46,4 & 152,0 \\
\hline m g N-N H $3 / \mathrm{L}$ & 37,4 & 24,1 & 10,4 & 1,7 & 1,7 & 1,7 & 1,7 & 1,7 \\
\hline $\mathrm{m} \mathrm{g} \mathrm{N} \mathrm{H} \mathrm{3/L}$ & 6,2 & 4,0 & 1,7 & 0,3 & & & & \\
\hline $\mathrm{mg} \mathrm{HNO} 2 / \mathrm{L}$ & 0,000 & 0,000 & 0,000 & 0,001 & & & & \\
\hline Fenol aplicado & & & & 0,0 & 59,6 & 136,7 & 202,0 & 240,2 \\
\hline
\end{tabular}


ANEXO B2 - Etapa 02 - Concentração no afluente em torno de 300 mg N/L

Etapa 02 - Ciclo 01

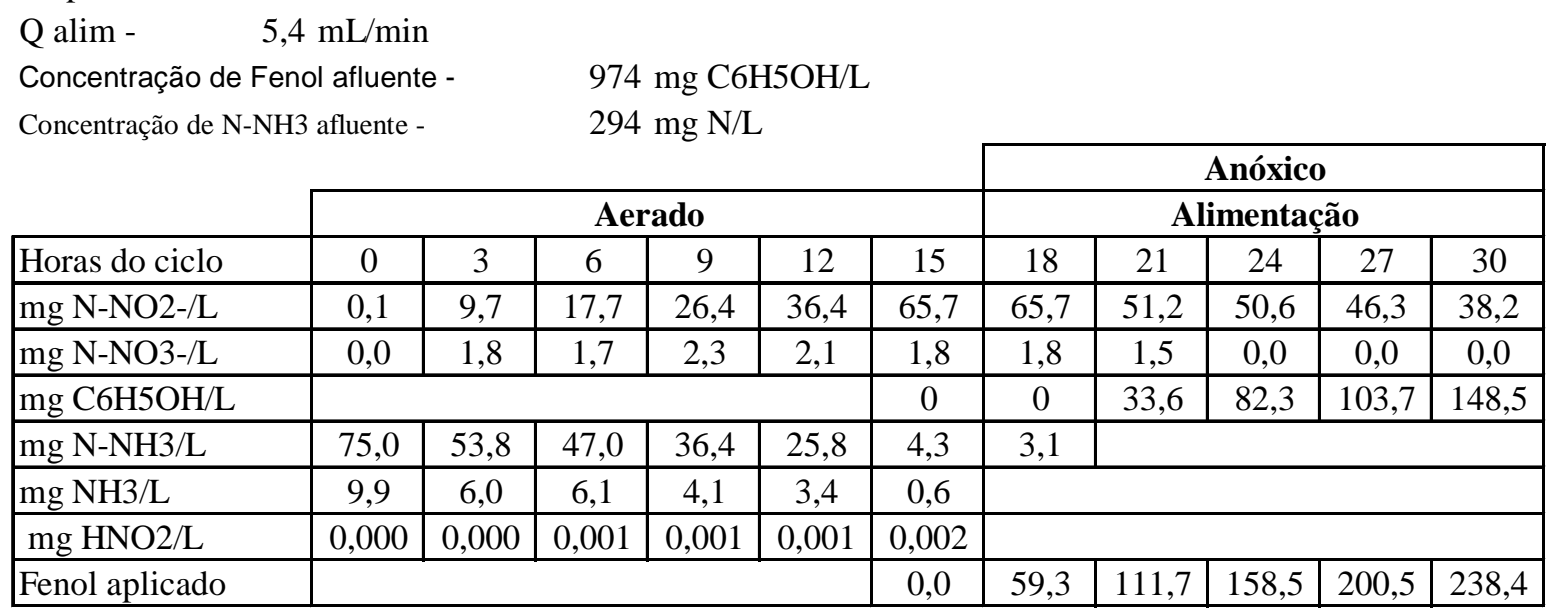

Etapa 02 - Ciclo 02

Q alim - $\quad 5,0 \mathrm{~mL} / \mathrm{min}$

Concentração de Fenol afluente -

Concentração de N-NH3 afluente -

$972 \mathrm{mg} \mathrm{C6H5OH/L}$

$284 \mathrm{mg} \mathrm{N} / \mathrm{L}$

\begin{tabular}{|c|c|c|c|c|c|c|c|c|c|c|c|}
\hline \multirow{3}{*}{ Horas do ciclo } & & \multicolumn{5}{|c|}{ Anóxico } \\
\hline & \multicolumn{6}{|c|}{ Aerado } & \multicolumn{4}{|c|}{ Alimentação } & \multirow[b]{2}{*}{39} \\
\hline & 0 & 3 & 6 & 9 & 12 & 15 & 18 & 21 & 24 & 30 & \\
\hline mg N-NO2-/L & 0,5 & 0,1 & 11,5 & 35,1 & 47,6 & 59,0 & 32,1 & 9,8 & 5,7 & 2,9 & 0,4 \\
\hline mg N-NO3-/L & 0,0 & 0,0 & 0,0 & 0,0 & 1,7 & 1,6 & 0 & 0 & 0 & 0 & 0 \\
\hline mg C6H5OH/L & 97,9 & 33,4 & 0 & 0 & 0 & 0 & 10,7 & 23,3 & 61,0 & 140,9 & 112,0 \\
\hline mg N-NH3/L & 66,1 & 66,1 & 52,6 & 30,2 & 17,4 & 2,9 & 2,9 & & & & \\
\hline mg NH3/L & 8,2 & 8,3 & 6,9 & 4,3 & 2,4 & 0,4 & & & & & \\
\hline mg HNO2/L & 0,000 & 0,000 & 0,000 & 0,001 & 0,002 & 0,002 & & & & & \\
\hline Fenol aplicado & & & & & & 0 & 55,0 & 104,1 & 148,3 & 224,3 & \\
\hline
\end{tabular}

Etapa 02 - Ciclo 03

Q alim - $\quad 5,0 \mathrm{~mL} / \mathrm{min}$

Concentração de Fenol afluente -

Concentração de N-NH3 afluente -

$1.089 \mathrm{mg} \mathrm{C} 6 \mathrm{H} 5 \mathrm{OH} / \mathrm{L}$

$306 \mathrm{mg} \mathrm{N} / \mathrm{L}$

\begin{tabular}{|c|c|c|c|c|c|c|c|c|c|c|c|}
\hline \multicolumn{7}{|c|}{ 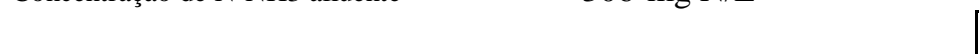 } & \multicolumn{5}{|c|}{ Anóxico } \\
\hline & \multicolumn{6}{|c|}{ Aerado } & \multicolumn{4}{|c|}{ Alimentação } & \multirow[b]{2}{*}{39} \\
\hline Horas do ciclo & 0 & 3 & 6 & 9 & 12 & 15 & 18 & 21 & 24 & 30 & \\
\hline mg N-NO2-/L & 0,6 & 2,1 & 0,7 & 17,3 & 65,7 & 68,1 & 46,4 & 31,2 & 12,0 & 1,6 & 0,4 \\
\hline mg N-NO3-/L & 0 & 0 & 0 & 0 & 0,6 & 1,6 & 0 & 0 & 0 & 0 & 0 \\
\hline mg C6H5OH/L & 134,1 & 27,5 & 0 & 0 & 0 & 0 & 13,8 & 86,2 & 81,6 & 125,0 & 111,3 \\
\hline mg N-NH3/L & 75,0 & 68,3 & 67,2 & 53,8 & 12,9 & 2,5 & 2,5 & & & & \\
\hline mg NH3/L & 9,3 & 8,8 & 6,9 & 7,1 & 1,6 & 0,3 & & & & & \\
\hline mg HNO2/L & 0,000 & 0,000 & 0,000 & 0,001 & 0,002 & 0,003 & & & & & \\
\hline Fenol aplicado & & & & & & 0 & 61,6 & 116,7 & 166,1 & 251,3 & \\
\hline
\end{tabular}


Etapa 02 - Ciclo 04

Q alim - $\quad 5,0 \mathrm{~mL} / \mathrm{min}$

Concentração de Fenol afluente -

$992 \mathrm{mg} \mathrm{C6H5OH/L}$

Concentração de N-NH3 afluente -

$321 \mathrm{mg} \mathrm{N} / \mathrm{L}$

\begin{tabular}{|c|c|c|c|c|c|c|c|c|c|c|c|}
\hline \multirow{3}{*}{ Horas do ciclo } & \multirow{2}{*}{\multicolumn{6}{|c|}{ Aerado }} & \multicolumn{5}{|c|}{ Anóxico } \\
\hline & & & & & & & \multicolumn{4}{|c|}{ Alimentação } & \multirow[b]{2}{*}{39} \\
\hline & 0 & 3 & 6 & 9 & 12 & 15 & 20 & 23 & 26 & 30 & \\
\hline mg N-NO2-/L & 0,3 & 0,3 & 0,3 & 43,7 & 60,7 & 68,7 & 63,8 & 40,4 & 14,3 & 0,1 & 0,1 \\
\hline mg N-NO3-/L & 0 & 0 & 0 & 0 & 2,34 & 2,77 & 0 & 0 & 0 & 0 & 0 \\
\hline mg C6H5OH/L & 147,0 & 50,4 & 6,9 & 0 & 0 & 0 & 15,7 & 89,9 & 101,3 & 118,9 & 108,2 \\
\hline mg N-NH3/L & 85,1 & 84,0 & 80,6 & 42,6 & 19,6 & 1,5 & 1,5 & & & & \\
\hline mg NH3/L & 7,0 & 9,5 & 9,7 & 5,2 & 2,3 & 0,2 & & & & & \\
\hline mg HNO2/L & 0,000 & 0,000 & 0,000 & 0,002 & 0,002 & 0,003 & & & & & \\
\hline Fenol aplicado & & & & & & 0 & 90,2 & 136,8 & 178,9 & 228,9 & \\
\hline
\end{tabular}

Etapa 02 - Ciclo 05

Q alim - $\quad 5,0 \mathrm{~mL} / \mathrm{min}$

Concentração de Fenol afluente -

Concentração de N-NH3 afluente -

998 mg C6H5OH/L

$284 \mathrm{mg} \mathrm{N} / \mathrm{L}$

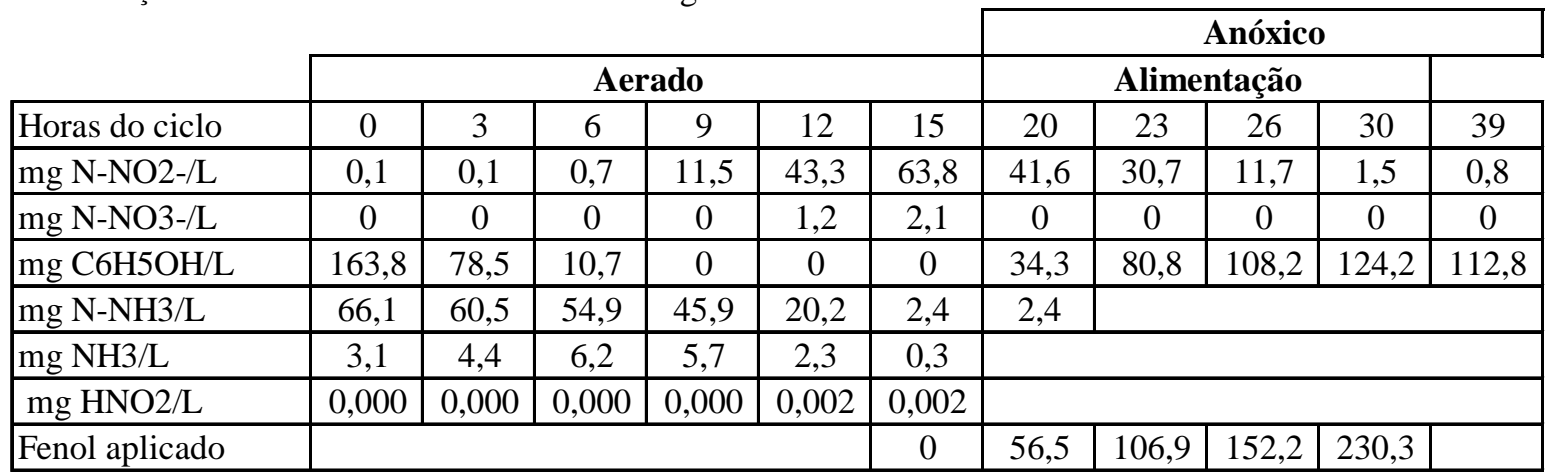


ANEXO B3 - Etapa 03 - Concentração no afluente em torno de 500 mg N/L

Etapa 03 - Ciclo 01

$$
\text { Q alim - } \quad 5,2 \mathrm{~mL} / \mathrm{min}
$$

Concentração de Fenol afluente -

$978 \mathrm{mg} \mathrm{C} 6 \mathrm{H} 5 \mathrm{OH} / \mathrm{L}$

Concentração de N-NH3 afluente -

495,6 mg N/L

\begin{tabular}{|c|c|c|c|c|c|c|c|c|c|c|c|c|c|c|c|c|c|}
\hline & & & & & & & & & & \multicolumn{5}{|c|}{ Alimentação } & & & \\
\hline & \multicolumn{9}{|c|}{ Aerado } & & & & & óxico & & & \\
\hline Horas do ciclo & 0 & 3 & 6 & 9 & 12 & 15 & 18 & 21 & 24 & 27 & 30 & 33 & 36 & 39 & 42 & 45 & 48 \\
\hline mg N-NO2-/L & 0,2 & 1,6 & 6,8 & 17,3 & 35,9 & 53,4 & 58,2 & 64,8 & 75,4 & 68,3 & 68,7 & 71,5 & 82,3 & 84,9 & 78,5 & 86,3 & 87,1 \\
\hline mg N-NO3-/L & 0 & 0 & 0 & 0,92 & 6,34 & 12,5 & 14,7 & 28,1 & 38 & 33,9 & 32,1 & 31,1 & 14,5 & 13,9 & 14,1 & 12,6 & 13,4 \\
\hline $\mathrm{mg} \mathrm{C} 6 \mathrm{H} 5 \mathrm{OH} / \mathrm{L}$ & 0 & 0 & 0 & 0 & 0 & 0 & 0 & 0 & 0 & 54,5 & 91,5 & 147,8 & 136,4 & 191,2 & 185,6 & 186,7 & 190,2 \\
\hline mg N-NH3/L & 119,8 & 105,3 & 97,4 & 83,4 & 60,5 & 56,3 & 31,4 & 22,6 & 3,1 & 3,1 & & & & & & & \\
\hline mg NH3/L & 4,6 & 4,2 & 4,0 & 3,8 & 2,6 & 2,2 & 1,3 & 1,0 & 0,1 & & & & & & & & \\
\hline mg HNO2/L & 0,000 & 0,000 & 0,001 & 0,002 & 0,004 & 0,007 & 0,007 & 0,007 & 0,008 & & & & & & & & \\
\hline Fenol aplicado & & & & & & & & & & 57,4 & 108,5 & 154,2 & 195,3 & 232,6 & & & \\
\hline
\end{tabular}

Etapa 03 - Ciclo 02

Q alim - $\quad 3,5 \mathrm{~mL} / \mathrm{min}$

Concentração de Fenol afluente -

Concentração de N-NH3 afluente -

$989 \mathrm{mg} \mathrm{C6H5OH/L}$

$515,2 \mathrm{mg} \mathrm{N} / \mathrm{L}$

\begin{tabular}{|c|c|c|c|c|c|c|c|c|c|c|c|c|c|c|c|c|c|c|}
\hline \multirow[b]{3}{*}{ Horas do ciclo } & \multirow{2}{*}{\multicolumn{9}{|c|}{ Aerado }} & \multicolumn{9}{|c|}{ Alimentação } \\
\hline & & & & & & & & & & \multicolumn{9}{|c|}{ Anóxico } \\
\hline & 0 & 3 & 6 & 9 & 12 & 15 & 18 & 20 & 22 & 24 & 27 & 30 & 33 & 36 & 39 & 42 & 45 & 48 \\
\hline mg N-NO2-/L & 0,0 & 0,1 & 9,5 & 19,6 & 28,6 & 46,4 & 62,4 & \begin{tabular}{|l|}
95,6 \\
\end{tabular} & \begin{tabular}{|l|}
94,8 \\
\end{tabular} & 92,9 & 87,5 & 85,8 & 86,4 & 87,3 & 85,2 & 84,6 & 83,9 & 84,3 \\
\hline mg N-NO3-/L & 0,0 & 0,0 & 2,3 & 4,1 & 5,2 & 4,1 & 7,5 & 12,3 & 12,9 & 12,3 & 11,9 & 12,1 & 10,2 & 10,3 & 10,4 & 11,1 & 11,4 & 10,7 \\
\hline $\mathrm{mg} \mathrm{C} 6 \mathrm{H} 5 \mathrm{OH} / \mathrm{L}$ & $\mid 131,0$ & 128,4 & 42,1 & 0,0 & 0,0 & 0,0 & 0,0 & 0,0 & 0,0 & 13,0 & 20,7 & 45,4 & 73,1 & 90,7 & 124,3 & 167,3 & 184,5 & 194,7 \\
\hline mg N-NH3/L & 125,4 & 131,0 & 128,2 & 102,5 & 76,2 & 53,8 & 27,2 & 6,9 & 5,9 & 6,9 & & & & & & & & \\
\hline mg NH3/L & 15,5 & 15,5 & 15,5 & 11,9 & 7,6 & 6,6 & 3,3 & 0,8 & 0,7 & & & & & & & & & \\
\hline mg HNO2/L & 0,000 & 0,000 & 0,000 & 0,001 & 0,001 & 0,002 & 0,002 & 0,004 & 0,004 & & & & & & & & & \\
\hline \begin{tabular}{|l|} 
Fenol aplicado \\
\end{tabular} & & & & & & & & & & 26,9 & 64,7 & 99,6 & 132,0 & 162,1 & 190,1 & 216,3 & 240,9 & \\
\hline
\end{tabular}


Etapa 03 - Ciclo 03

Q alim - $\quad 3,5 \mathrm{~mL} / \mathrm{min}$

Concentração de Fenol afluente -

Concentração de N-NH3 afluente -

$1.006 \mathrm{mg}$ C6H5OH/L

$503 \mathrm{mg} \mathrm{N} / \mathrm{L}$

\begin{tabular}{|c|c|c|c|c|c|c|c|c|c|c|c|c|c|c|c|c|c|c|c|}
\hline \multirow{3}{*}{\multicolumn{2}{|c|}{ Homas dosicts }} & & & & & & & & & & \multicolumn{9}{|c|}{ Alimentação } \\
\hline & & \multicolumn{9}{|c|}{ Aerado } & \multicolumn{9}{|c|}{ Anóxico } \\
\hline & & 0 & 3 & 6 & 9 & 12 & 15 & 18 & 20 & 22 & 24 & 27 & 30 & 33 & 36 & 39 & 42 & 45 & 48 \\
\hline NO2- & $(\mathrm{mg} / \mathrm{L})$ & 1,4 & 7,1 & 22,0 & 40,4 & 46,4 & 51,4 & 68,3 & 71,5 & 97,4 & 89,6 & 89,4 & 88,7 & 87,9 & 86,1 & 86,3 & 86,5 & 86,1 & 84,3 \\
\hline NO3- & $(\mathrm{mg} / \mathrm{L})$ & 0 & 3,8 & 4,2 & 3,9 & 3,9 & 4,1 & 4,3 & 4,8 & 4,6 & 1,9 & 0 & 0 & 0 & 0 & 0 & 0 & 0 & 0 \\
\hline Fenol & $(\mathrm{mg} / \mathrm{L})$ & 137,4 & 84,1 & 37,3 & 0 & 0 & 0 & 0 & 0 & 0 & 13,2 & 37,4 & 78,5 & 106,7 & 140,8 & 165,3 & 179,5 & 192,4 & 192,37 \\
\hline $\mathrm{NH} 4+$ & $(\mathrm{mg} / \mathrm{L})$ & 107,5 & 90,7 & 61,6 & 52,1 & 49,6 & 38,7 & 29,4 & \begin{tabular}{|l|}
18,6 \\
\end{tabular} & 2,5 & 2,5 & & & & & & & & \\
\hline NH3 & $(\mathrm{mg} / \mathrm{L})$ & 15,1 & 11,2 & 7,2 & 6,5 & 6,1 & 4,9 & 3,6 & 2,0 & 0,3 & & & & & & & & & \\
\hline $\mathrm{HNO}_{2}^{-2}$ & $(\mathrm{mg} / \mathrm{L})$ & 0,000 & 0,000 & 0,001 & 0,001 & 0,002 & 0,002 & 0,002 & 0,003 & 0,004 & & & & & & & & & \\
\hline \multicolumn{2}{|c|}{ Fenol Aplicado } & & & & & & & & & & 40,5 & 78,0 & 112,6 & 144,7 & 174,6 & 202,5 & 228,6 & 253,0 & \\
\hline
\end{tabular}


ANEXO C - Análise qualitativa de compostos fenólicos utilizando cromatografia gasosa acoplada a espectrômetro de massa.

ANEXO C1 - Amostra retirada do conteúdo do reator com 24 horas anóxicas

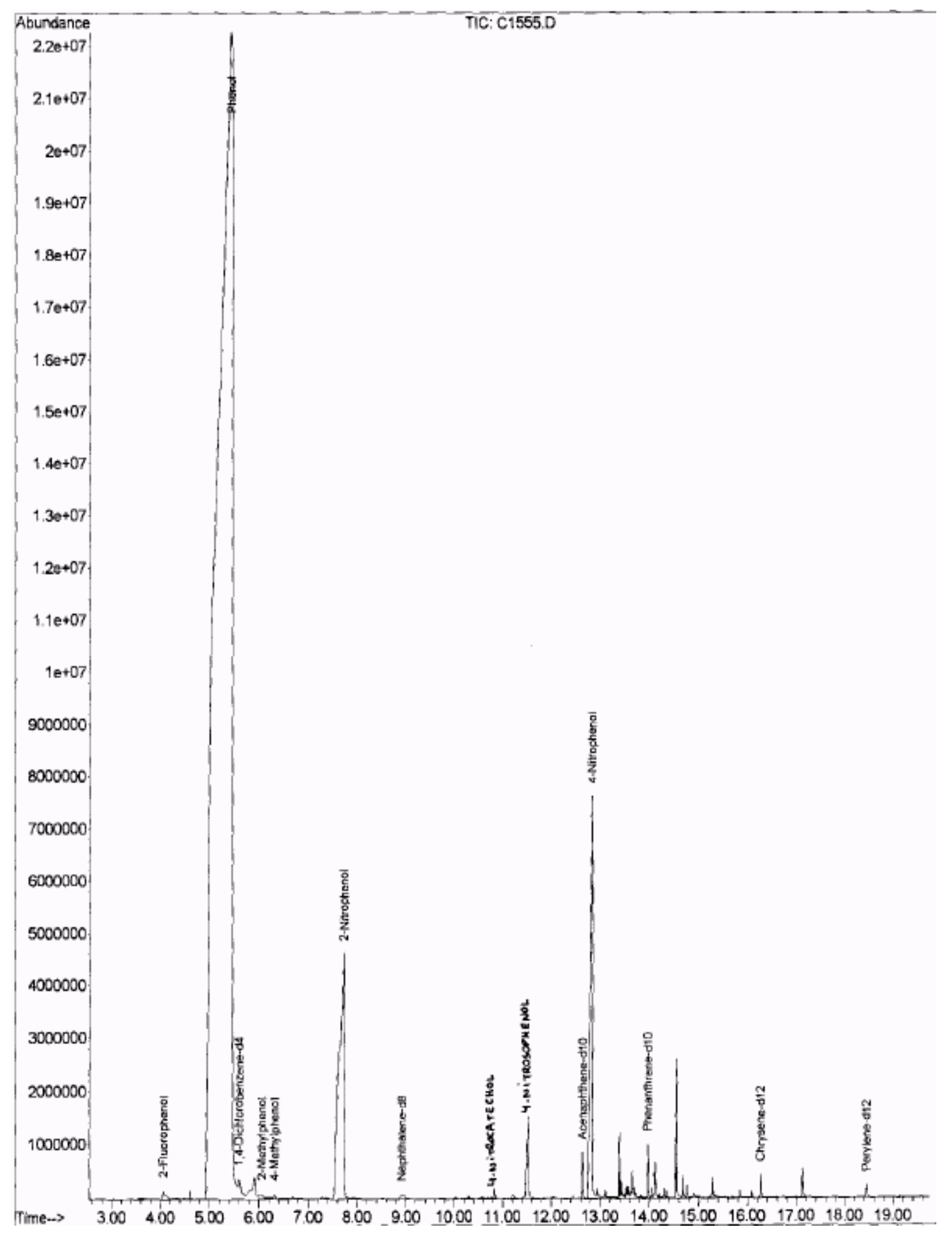


ANEXO C2 - Amostra retirada do conteúdo do reator com 36 horas anóxicas:

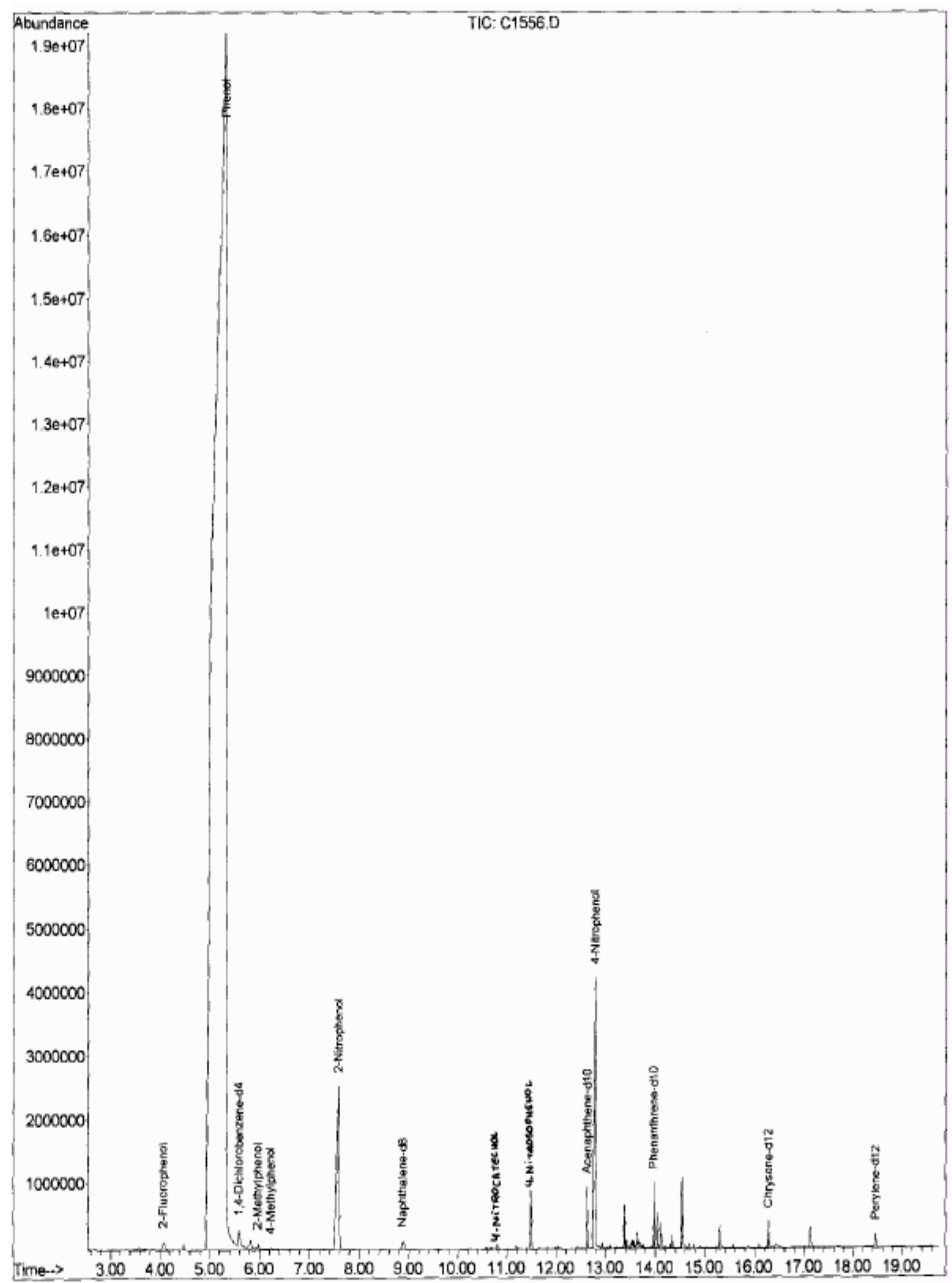


ANEXO D - Cálculos

ANEXO D1 - Concentração no afluente em torno de 200 mg N/L CICLO 01:

Concentração de Sólidos em Suspensão Voláteis =

Carga de N-NH3 = $461 \mathrm{mg} \mathrm{N}-\mathrm{NH} 3 /$ dia

$3420 \mathrm{mg} / \mathrm{L}$

Carga de Fenol = $2307 \mathrm{mg}$ fenol/dia

Volumes retirados para realização de análises:

Etapa Aeróbia $=\quad 0,2$ Litros

Etapa Anóxica $=\quad 0,6$ Litros

Início da Etapa Aeróbia:

Massa de N-NH3 =

454 mg N-NH3

0 mg N-NO2-

Massa de N-NO2- =

0 mg N-NO3-

Início da Etapa Anóxica:

14 mg N-NO2-

Massa de N-NO2- =

47 mg N-NO3-

Massa de N-NO3- =

$47 \mathrm{mg} \mathrm{N}-\mathrm{NO} 3$
$0 \mathrm{mg}$ fenol

Final da Etapa Aeróbia

Massa de N-NH3 =

Massa de N-NO2- =

Massa de N-NO3- =

Final da Etapa Anóxica

Massa de N-NO2- =

Massa de N-NO3- =

Massa de Fenol =

0 mg N-NH3

414 mg N-NO2-

47 mg N-NO3-

Cálculos das Eficiências

Remoção de N-NH3 =

Relação N-NO2- / (N-NO2- + N-NO3-) =

0 mg N-NO2-

0 mg N-NO3-

$2114 \mathrm{mg}$ fenol

$100 \%$

$90 \%$

0,01 kg N-NH3 / kg SSV.dia

$28 \%$

$100 \%$

$586 \mathrm{mg}$

$165 \mathrm{mg}$

$421 \mathrm{mg}$

$1171 \mathrm{mg}$

$358 \mathrm{mg}$

$814 \mathrm{mg}$

$1757 \mathrm{mg}$

$600 \mathrm{mg}$

$1157 \mathrm{mg}$

$2343 \mathrm{mg}$

$945 \mathrm{mg}$

$1398 \mathrm{mg}$

$2928 \mathrm{mg}$

$2114 \mathrm{mg}$

$814 \mathrm{mg}$

$2928 \mathrm{mg}$

$814 \mathrm{mg}$

$0,07 \mathrm{~kg}$ fenol$/ \mathrm{Kg}$ SSV.dia

0,01 kg (N-NO3- + N-NO2-)/kgSSV.dia

0,01 kg N-NO2- / kg SSV.dia

$1,8 \mathrm{~kg}$ fenol / kg N-NO2-

Taxa de desnitrificação =

Taxa de "desnitritação" =

Relação Fenol/ N-NO2- = 
CICLO 02:

Concentração de Sólidos em Suspensão Voláteis =

Carga de $\mathrm{N}-\mathrm{NH} 3=$

$457 \mathrm{mg} \mathrm{N}-\mathrm{NH} 3 / \mathrm{dia}$

Carga de Fenol =

$2304 \mathrm{mg}$ fenol/dia

Volumes retirados para realização de análises:

Etapa Aeróbia $=\quad 0,2$ Litros

Etapa Anóxica $=\quad 0,6$ Litros

Início da Etapa Aeróbia:

Massa de $\mathrm{N}-\mathrm{NH} 3=$

Massa de N-NO2- =

$456 \mathrm{mg} \mathrm{N}-\mathrm{NH} 3$

Massa de N-NO3- =

$0 \mathrm{mg} \mathrm{N}-\mathrm{NO} 2$

$0 \mathrm{mg} \mathrm{N}-\mathrm{NO} 3-$

Início da Etapa Anóxica:

Massa de N-NO2- =

$340 \mathrm{mg} \mathrm{N}-\mathrm{NO} 2-$

Massa de N-NO3- =

$189 \mathrm{mg} \mathrm{N}-\mathrm{NO} 3$

Massa de fenol =
$3280 \mathrm{mg} / \mathrm{L}$

Final da Etapa Aeróbia

Massa de $\mathrm{N}-\mathrm{NH} 3=$

$37 \mathrm{mg} \mathrm{N}-\mathrm{NH} 3$

Massa de N-NO2- =

$340 \mathrm{mg} \mathrm{N}-\mathrm{NO} 2$

Massa de N-NO3- =

189 mg N-NO3-

Final da Etapa Anóxica

Massa de N-NO2- =

Massa de N-NO3- =

Massa de fenol =

$0 \mathrm{mg} \mathrm{N}-\mathrm{NO} 2$

$0 \mathrm{mg} \mathrm{N}-\mathrm{NO} 3$

$1649 \mathrm{mg}$ fenol

\section{Cálculos das Eficiências}

Remoção de $\mathrm{N}-\mathrm{NH} 3=$

Relação N-NO2- / (N-NO2- + N-NO3-) =

Taxa de Nitrificação =

Eficiência de Remoção do fenol =

Eficiência de remoção de N-Nox =

Remoção de Fenol:

3 hs.

Massa de Fenol Aplicada =

Massa de Fenol Final $=$

Massa de Fenol Utilizada =

6 hs. Massa de Fenol Aplicada =

Massa de Fenol Final $=$

Massa de Fenol Utilizada =

9 hs. $\quad$ Massa de Fenol Aplicada =

Massa de Fenol Final =

Massa de Fenol Utilizada $=$

12 hs.

Massa de Fenol Aplicada =

Massa de Fenol Final $=$

Massa de Fenol Utilizada $=$

18 hs. Massa de Fenol Aplicada =

Massa de Fenol Final =

Massa de Fenol Utilizada $=$

Massa Total de Fenol $=$

Massa de Fenol utilizada $=$

Relação Alimento/Microrganismos =

Taxa de desnitrificação =

Taxa de "desnitritação" =

Relação Fenol/ N-NO2- =
$92 \%$

$64 \%$

$0,01 \mathrm{~kg} \mathrm{~N}-\mathrm{NH} 3 / \mathrm{Kg}$ SSV.dia

$40 \%$

$100 \%$

$551 \mathrm{mg}$

$1 \mathrm{mg}$

$549 \mathrm{mg}$

$1101 \mathrm{mg}$

$527 \mathrm{mg}$

$575 \mathrm{mg}$

$1652 \mathrm{mg}$

$380 \mathrm{mg}$

$1272 \mathrm{mg}$

$2203 \mathrm{mg}$

$869 \mathrm{mg}$

$1334 \mathrm{mg}$

$2754 \mathrm{mg}$

$1649 \mathrm{mg}$

$1105 \mathrm{mg}$

$2754 \mathrm{mg}$

$1105 \mathrm{mg}$

$0,08 \mathrm{~kg}$ fenol $/ \mathrm{kg}$ SSV.dia

0,01 kg (N-NO3- + N-NO2-)/kgSSV.dia

0,01 kg N-NO2- / kg SSV.dia

2,1 kg fenol / kg (N-NO2- + N-NO3-) 
CICLO 03:

Concentração de Sólidos em Suspensão Voláteis =

Carga de $\mathrm{N}-\mathrm{NH} 3=$

$994 \mathrm{mg} \mathrm{N}-\mathrm{NH} 3 / \mathrm{dia}$

Carga de Fenol = $4670 \mathrm{mg}$ fenol/dia

Volumes retirados para realização de análises:

$\begin{array}{lr}\text { Etapa Aeróbia }= & 0,5 \text { Litros } \\ \text { Etapa Anóxica }= & 1 \text { Litros }\end{array}$

Início da Etapa Aeróbia:

Massa de $\mathrm{N}-\mathrm{NH} 3=$

Massa de N-NO2- =

$966 \mathrm{mg} \mathrm{N}-\mathrm{NH} 3$

Massa de N-NO3- =

Início da Etapa Anóxica:

Massa de N-NO2- =

Massa de N-NO3- =

0 mg N-NO3-

Massa de fenol $=$

796 mg N-NO2

$160 \mathrm{mg} \mathrm{N}-\mathrm{NO} 3$

$0 \mathrm{mg}$ fenol
Final da Etapa Aeróbia

Massa de $\mathrm{N}-\mathrm{NH} 3=$

Massa de N-NO2- =

Massa de N-NO3- =

Final da Etapa Anóxica

Massa de N-NO2- =

Massa de N-NO3- =

Massa de fenol =
$51 \mathrm{mg} \mathrm{N}-\mathrm{NH} 3$

$796 \mathrm{mg} \mathrm{N}-\mathrm{NO} 2$

$160 \mathrm{mg} \mathrm{N}-\mathrm{NO} 3-$

$35 \mathrm{mg} \mathrm{N}-\mathrm{NO} 2$

$15 \mathrm{mg} \mathrm{N}-\mathrm{NO} 3$

$2697 \mathrm{mg}$ fenol

Cálculos das Eficiências

Remoção de $\mathrm{N}-\mathrm{NH} 3=$

Relação N-NO2- / (N-NO2- + N-NO3-) =

Taxa de Nitrificação =

Eficiência de Remoção do fenol =

Eficiência de remoção de N-Nox =

Remoção de Fenol:

Massa de Fenol Aplicada $=$

Massa de Fenol Final =

Massa de Fenol Utilizada $=$

6 hs. $\quad$ Massa de Fenol Aplicada =

Massa de Fenol Final =

Massa de Fenol Utilizada =

9 hs. $\quad$ Massa de Fenol Aplicada =

Massa de Fenol Final =

Massa de Fenol Utilizada =

10 hs. $\quad$ Massa de Fenol Aplicada =

Massa de Fenol Final $=$

Massa de Fenol Utilizada $=$

$83 \%$

$0,02 \mathrm{~kg} \mathrm{~N}-\mathrm{NH} 3 / \mathrm{kg} \mathrm{SSV}$.dia

$42 \%$

$95 \%$

$1401 \mathrm{mg}$

$457 \mathrm{mg}$

$945 \mathrm{mg}$

$2802 \mathrm{mg}$

$810 \mathrm{mg}$

$1992 \mathrm{mg}$

$4203 \mathrm{mg}$

$1731 \mathrm{mg}$

$2473 \mathrm{mg}$

$4670 \mathrm{mg}$

$2697 \mathrm{mg}$

$1974 \mathrm{mg}$

Massa Total de Fenol $=$

$4670 \mathrm{mg}$

Massa de Fenol utilizada =

$1974 \mathrm{mg}$

Relação Alimento/Microrganismos =

Taxa de desnitrificação =

Taxa de "desnitritação" =

Relação Fenol/ N-NO2- =

$0,07 \mathrm{~kg}$ fenol $/ \mathrm{kg}$ SSV.dia

0,03 kg (N-NO3- + N-NO2-)/kgSSV.dia

$0,03 \mathrm{~kg} \mathrm{~N}-\mathrm{NO} 2-$ / kg SSV.dia

2,2 kg fenol / kg (N-NO2- + N-NO3-) 
CICLO 04:

Concentração de Sólidos em Suspensão Voláteis = Carga de $\mathrm{N}-\mathrm{NH} 3=$ $941 \mathrm{mg} \mathrm{N}-\mathrm{NH} 3 / \mathrm{dia}$

Carga de Fenol = $5040 \mathrm{mg}$ fenol/dia

Volumes retirados para realização de análises:
Etapa Aeróbia $=$
0,5 Litros

Etapa Anóxica =

1 Litros

Início da Etapa Aeróbia:

Massa de $\mathrm{N}-\mathrm{NH} 3=$

Massa de N-NO2- =

$854 \mathrm{mg} \mathrm{N}-\mathrm{NH} 3$

$0 \mathrm{mg} \mathrm{N}-\mathrm{NO} 2$

Massa de N-NO3- =

$2 \mathrm{mg} \mathrm{N}-\mathrm{NO} 3$

Início da Etapa Anóxica:

Massa de N-NO2- =

Massa de N-NO3- =

749 mg N-NO2-

Massa de fenol =

$2608 \mathrm{mg} / \mathrm{L}$

Final da Etapa Aeróbia

Massa de $\mathrm{N}-\mathrm{NH} 3=$

Massa de N-NO2- =

$35 \mathrm{mg} \mathrm{N}-\mathrm{NH} 3$

Massa de N-NO3- =

Final da Etapa Anóxica

Massa de N-NO2- =

Massa de N-NO3- =

Massa de fenol =

0 mg N-NO2-

$9 \mathrm{mg} \mathrm{N}-\mathrm{NO} 3$

$2710 \mathrm{mg}$ fenol

Cálculos das Eficiências

Remoção de N-NH3 =

Relação N-NO2- / (N-NO2- + N-NO3-) =

$96 \%$

$84 \%$

$0,03 \mathrm{~kg} \mathrm{~N}-\mathrm{NH} 3 / \mathrm{kg} \mathrm{SSV}$.dia

$46 \%$

Eficiência de Remoção do fenol =

Eficiência de remoção de N-Nox =

Remoção de Fenol:

3 hs.

Massa de Fenol Aplicada $=$

Massa de Fenol Final $=$

$1512 \mathrm{mg}$

$478 \mathrm{mg}$

Massa de Fenol Utilizada $=\quad 1034 \mathrm{mg}$

6 hs. $\quad$ Massa de Fenol Aplicada =

Massa de Fenol Final =

$3024 \mathrm{mg}$

$1108 \mathrm{mg}$

Massa de Fenol Utilizada $=\quad 1916 \mathrm{mg}$

9 hs. Massa de Fenol Aplicada =

$4536 \mathrm{mg}$

Massa de Fenol Final $=\quad 1658 \mathrm{mg}$

Massa de Fenol Utilizada $=\quad 2878 \mathrm{mg}$

10 hs. Massa de Fenol Aplicada $=$

Massa de Fenol Final =

$5040 \mathrm{mg}$

Massa de Fenol Utilizada =

$2710 \mathrm{mg}$

$2330 \mathrm{mg}$

Massa Total de Fenol $=$

$5040 \mathrm{mg}$

Massa de Fenol Final $=$

$2710 \mathrm{mg}$

Relação Alimento/Microrganismos =

Taxa de desnitrificação =

Taxa de "desnitritação" =

Relação Fenol/ N-NO2- =

$0,13 \mathrm{~kg}$ fenol $/ \mathrm{kg}$ SSV.dia

0,04 kg (N-NO3- + N-NO2-)/kgSSV.dia

0,04 kg N-NO2- / kg SSV.dia

3,1 kg fenol / kg (N-NO2- + N-NO3-) 
CICLO 05:

Concentração de Sólidos em Suspensão Voláteis =

Carga de $\mathrm{N}-\mathrm{NH} 3=$

$962 \mathrm{mg} \mathrm{N}-\mathrm{NH} 3 / \mathrm{dia}$

Carga de Fenol = $4768 \mathrm{mg}$ fenol/dia

Volumes retirados para realização de análises:

$\begin{array}{lr}\text { Etapa Aeróbia }= & 0,5 \text { Litros } \\ \text { Etapa Anóxica }= & 1 \text { Litros }\end{array}$

Início da Etapa Aeróbia:

Massa de $\mathrm{N}-\mathrm{NH} 3=$

Massa de N-NO2- =

$738 \mathrm{mg} \mathrm{N}-\mathrm{NH} 3$

Massa de N-NO3- =

$16 \mathrm{mg} \mathrm{N}-\mathrm{NO} 2-$

Início da Etapa Anóxica:

Massa de N-NO2- =

Massa de N-NO3- =

28 mg N-NO3-

Massa de fenol =

$636 \mathrm{mg} \mathrm{N}-\mathrm{NO} 2$

$17 \mathrm{mg} \mathrm{N}-\mathrm{NO} 3$

$0 \mathrm{mg}$ fenol
Final da Etapa Aeróbia

Massa de $\mathrm{N}-\mathrm{NH} 3=$

Massa de N-NO2- =

Massa de N-NO3- =

$60 \mathrm{mg} \mathrm{N}-\mathrm{NH} 3$ $636 \mathrm{mg} \mathrm{N}-\mathrm{NO} 2$

17 mg N-NO3-

Final da Etapa Anóxica

Massa de N-NO2- =

Massa de N-NO3- =

Massa de fenol =
$0 \mathrm{mg} \mathrm{N}-\mathrm{NO} 2$

$17 \mathrm{mg} \mathrm{N}-\mathrm{NO} 3$

$2633 \mathrm{mg}$ fenol

Cálculos das Eficiências

Remoção de $\mathrm{N}-\mathrm{NH} 3=$

Relação N-NO2- / (N-NO2- + N-NO3-) =

$89 \%$

$97 \%$

$0,03 \mathrm{~kg} \mathrm{~N}-\mathrm{NH} 3 / \mathrm{kg} \mathrm{SSV}$.dia

$45 \%$

Eficiência de Remoção do fenol =

Eficiência de remoção de N-Nox =

Remoção de Fenol:

2 hs.

Massa de Fenol Aplicada $=$

Massa de Fenol Final =

Massa de Fenol Utilizada $=$

5 hs. Massa de Fenol Aplicada =

Massa de Fenol Final =

Massa de Fenol Utilizada $=$

8 hs. Massa de Fenol Aplicada =

Massa de Fenol Final =

Massa de Fenol Utilizada =

10 hs.

Massa de Fenol Aplicada $=$

Massa de Fenol Final =

Massa de Fenol Utilizada $=$

Massa Total de Fenol =

Massa de Fenol Final =

Relação Alimento/Microrganismos =

Taxa de desnitrificação =

Taxa de "desnitritação" =

Relação Fenol/ N-NO2- =
$97 \%$

$954 \mathrm{mg}$

$865 \mathrm{mg}$

$89 \mathrm{mg}$

$2384 \mathrm{mg}$

$1057 \mathrm{mg}$

$1327 \mathrm{mg}$

$3814 \mathrm{mg}$

$1747 \mathrm{mg}$

$2067 \mathrm{mg}$

$4768 \mathrm{mg}$

$2633 \mathrm{mg}$

$2135 \mathrm{mg}$

$4768 \mathrm{mg}$

$2633 \mathrm{mg}$

$0,12 \mathrm{~kg}$ fenol $/ \mathrm{kg}$ SSV.dia

0,03 kg (N-NO3- + N-NO2-)/kgSSV.dia

0,03 kg N-NO2- / kg SSV.dia

$3,4 \mathrm{~kg}$ fenol / kg (N-NO2- + N-NO3-) 
CICLO 06:

Concentração de Sólidos em Suspensão Voláteis = Carga de $\mathrm{N}-\mathrm{NH} 3=$ 998 mg N-NH3/dia

Carga de Fenol = $4771 \mathrm{mg}$ fenol/dia

Volumes retirados para realização de análises:
Etapa Aeróbia $=$
0,5 Litros

Etapa Anóxica =

1 Litros

Início da Etapa Aeróbia:

Massa de $\mathrm{N}-\mathrm{NH} 3=$

Massa de N-NO2- =

$850 \mathrm{mg} \mathrm{N}-\mathrm{NH} 3$

Massa de N-NO3- =

18 mg N-NO3-

Início da Etapa Anóxica:

Massa de N-NO2- =

Massa de N-NO3- =

$710 \mathrm{mg} \mathrm{N}-\mathrm{NO} 2$

Massa de Fenol =

$2 \mathrm{mg} \mathrm{N}-\mathrm{NO} 3$

$0 \mathrm{mg}$ fenol

Cálculos das Eficiências

Remoção de $\mathrm{N}-\mathrm{NH} 3=$

Relação N-NO2- / (N-NO2- + N-NO3-) =

Taxa de Nitrificação =

Eficiência de Remoção do fenol =

Eficiência de remoção de N-Nox =

Remoção de Fenol:

Massa de Fenol Aplicada =

Massa de Fenol Final =

Massa de Fenol Utilizada =

5 hs. Massa de Fenol Aplicada =

Massa de Fenol Final =

Massa de Fenol Utilizada $=$

8 hs. Massa de Fenol Aplicada =

Massa de Fenol Final =

Massa de Fenol Utilizada =

10 hs.

Massa de Fenol Aplicada =

Massa de Fenol Final $=$

Massa de Fenol Utilizada $=$

Massa Total de Fenol $=$

Massa de Fenol utilizada =

Relação Alimento/Microrganismos =

Taxa de desnitrificação =

Taxa de "desnitritação" =

Relação Fenol/ N-NO2- =
$3040 \mathrm{mg} / \mathrm{L}$

Final da Etapa Aeróbia

Massa de $\mathrm{N}-\mathrm{NH} 3=$

$46 \mathrm{mg} \mathrm{N}-\mathrm{NH} 3$

Massa de N-NO2- =

$710 \mathrm{mg} \mathrm{N}-\mathrm{NO} 2$

Massa de N-NO3- =

72 mg N-NO3-

Final da Etapa Anóxica

Massa de N-NO2- =

Massa de N-NO3- =

Massa de Fenol =

$351 \mathrm{mg} \mathrm{N}-\mathrm{NO} 2$

$18 \mathrm{mg} \mathrm{N}-\mathrm{NO} 3$

$3211 \mathrm{mg}$ fenol
$95 \%$

$91 \%$

$0,03 \mathrm{~kg} \mathrm{~N}-\mathrm{NH} 3 / \mathrm{kg}$ SSV.dia

$33 \%$

$53 \%$

$1908 \mathrm{mg}$

$534 \mathrm{mg}$

$1375 \mathrm{mg}$

$4771 \mathrm{mg}$

$3191 \mathrm{mg}$

$1580 \mathrm{mg}$

$4771 \mathrm{mg}$

$3287 \mathrm{mg}$

$1484 \mathrm{mg}$

$4771 \mathrm{mg}$

$3211 \mathrm{mg}$

$1560 \mathrm{mg}$

$4771 \mathrm{mg}$

$1560 \mathrm{mg}$

$0,06 \mathrm{~kg}$ fenol $/ \mathrm{kg}$ SSV.dia

0,02 kg (N-NO3- + N-NO2-)/kgSSV.dia

0,01 kg N-NO2- / kg SSV.dia

$3,8 \mathrm{~kg}$ fenol / kg (N-NO2- + N-NO3-) 
CICLO 07:

Concentração de Sólidos em Suspensão Voláteis = Carga de $\mathrm{N}-\mathrm{NH} 3=$ 1004 mg N-NH3/dia

Carga de Fenol = $4974 \mathrm{mg}$ fenol/dia

Volumes retirados para realização de análises:
Etapa Aeróbia $=$
0,5 Litros

Etapa Anóxica =

1 Litros

Início da Etapa Aeróbia:

Massa de $\mathrm{N}-\mathrm{NH} 3=$

Massa de N-NO2- =

$834 \mathrm{mg} \mathrm{N}-\mathrm{NH} 3$

Massa de N-NO3- =

Início da Etapa Anóxica:

Massa de N-NO2- =

Massa de N-NO3- =

$723 \mathrm{mg} \mathrm{N}-\mathrm{NO} 2$

Massa de Fenol =

$19 \mathrm{mg} \mathrm{N}-\mathrm{NO} 3$

$0 \mathrm{mg}$ fenol
$2945 \mathrm{mg} / \mathrm{L}$

Final da Etapa Aeróbia

Massa de $\mathrm{N}-\mathrm{NH} 3=$

Massa de N-NO2- =

$39 \mathrm{mg} \mathrm{N}-\mathrm{NH} 3$

Massa de N-NO3- =

$19 \mathrm{mg} \mathrm{N}-\mathrm{NO3}-$

Final da Etapa Anóxica

Massa de N-NO2- =

Massa de N-NO3- =

Massa de Fenol =

$514 \mathrm{mg} \mathrm{N}-\mathrm{NO} 2$

$20 \mathrm{mg} \mathrm{N}-\mathrm{NO} 3$

$3661 \mathrm{mg}$ fenol

Cálculos das Eficiências

Remoção de $\mathrm{N}-\mathrm{NH} 3=$

Relação N-NO2- / (N-NO2- + N-NO3-) =

$97 \%$

Taxa de Nitrificação =

Eficiência de Remoção do fenol =

Eficiência de remoção de N-Nox =

Remoção de Fenol:

Massa de Fenol Aplicada =

Massa de Fenol Final $=$

Massa de Fenol Utilizada $=$

5 hs. Massa de Fenol Aplicada =

Massa de Fenol Final =

Massa de Fenol Utilizada =

8 hs. $\quad$ Massa de Fenol Aplicada =

Massa de Fenol Final =

Massa de Fenol Utilizada =

10 hs. $\quad$ Massa de Fenol Aplicada =

Massa de Fenol Final $=$

Massa de Fenol Utilizada $=$

$0,03 \mathrm{~kg} \mathrm{~N}-\mathrm{NH} 3 / \mathrm{kg} \mathrm{SSV}$.dia

$26 \%$

$28 \%$

$1990 \mathrm{mg}$

$584 \mathrm{mg}$

$1405 \mathrm{mg}$

$4974 \mathrm{mg}$

$3548 \mathrm{mg}$

$1426 \mathrm{mg}$

$4974 \mathrm{mg}$

$3604 \mathrm{mg}$

$1371 \mathrm{mg}$

$4974 \mathrm{mg}$

$3661 \mathrm{mg}$

$1313 \mathrm{mg}$

Massa Total de Fenol $=$

$4974 \mathrm{mg}$

Massa de Fenol utilizada =

$1313 \mathrm{mg}$

Relação Alimento/Microrganismos =

Taxa de desnitrificação =

Taxa de "desnitritação" =

Relação Fenol/ N-NO2- =

$0,06 \mathrm{~kg}$ fenol $/ \mathrm{kg}$ SSV.dia

0,01 kg (N-NO3- + N-NO2-)/kgSSV.dia

0,01 kg N-NO2- / kg SSV.dia

$6,30 \mathrm{~kg}$ fenol / kg (N-NO2- + N-NO3-) 
CICLO 08:

Concentração de Sólidos em Suspensão Voláteis = Carga de $\mathrm{N}-\mathrm{NH} 3=$ 989 mg N-NH3/dia

Carga de Fenol = $4723 \mathrm{mg}$ fenol/dia

Volumes retirados para realização de análises:
Etapa Aeróbia $=$
0,5 Litros

Etapa Anóxica =

1 Litros

Início da Etapa Aeróbia:

Massa de $\mathrm{N}-\mathrm{NH} 3=$

Massa de N-NO2- =

$728 \mathrm{mg} \mathrm{N}-\mathrm{NH} 3$

Massa de N-NO3- =

$9 \mathrm{mg} \mathrm{N}-\mathrm{NO} 3$

Início da Etapa Anóxica:

Massa de N-NO2- =

Massa de N-NO3- =

$675 \mathrm{mg} \mathrm{N}-\mathrm{NO} 2-$

Massa de Fenol =

$1 \mathrm{mg} \mathrm{N}-\mathrm{NO} 3$

$0 \mathrm{mg}$ fenol
$2460 \mathrm{mg} / \mathrm{L}$

Final da Etapa Aeróbia

Massa de $\mathrm{N}-\mathrm{NH} 3=$

Massa de N-NO2- =

$51 \mathrm{mg} \mathrm{N}-\mathrm{NH} 3$

Massa de N-NO3- =

$41 \mathrm{mg} \mathrm{N}-\mathrm{NO} 3$

Final da Etapa Anóxica

Massa de N-NO2- =

Massa de N-NO3- =

Massa de Fenol =

$8 \mathrm{mg} \mathrm{N}-\mathrm{NO} 2-$

$15 \mathrm{mg} \mathrm{N}-\mathrm{NO} 3$

$2831 \mathrm{mg}$ fenol

Cálculos das Eficiências

Remoção de N-NH3 =

Relação N-NO2- / (N-NO2- + N-NO3-) =

Taxa de Nitrificação =

Eficiência de Remoção do fenol =

Eficiência de remoção de N-Nox =

Remoção de Fenol:

2 hs.

Massa de Fenol Aplicada = Massa de Fenol Final =

Massa de Fenol Utilizada =

5 hs. Massa de Fenol Aplicada =

Massa de Fenol Final =

Massa de Fenol Utilizada $=$

8 hs. Massa de Fenol Aplicada =

Massa de Fenol Final =

Massa de Fenol Utilizada =

10 hs.

Massa de Fenol Aplicada $=$

Massa de Fenol Final =

Massa de Fenol Utilizada $=$

Massa Total de Fenol =

Massa de Fenol Final =

Relação Alimento/Microrganismos =

Taxa de desnitrificação =

Taxa de "desnitritação" =

Relação Fenol/ N-NO2- =
$93 \%$

$94 \%$

$0,03 \mathrm{~kg} \mathrm{~N}-\mathrm{NH} 3 / \mathrm{kg} \mathrm{SSV}$.dia

$39 \%$

$97 \%$

$945 \mathrm{mg}$

$799 \mathrm{mg}$

$145 \mathrm{mg}$

$2362 \mathrm{mg}$

$749 \mathrm{mg}$

$1613 \mathrm{mg}$

$3779 \mathrm{mg}$

$1224 \mathrm{mg}$

$2555 \mathrm{mg}$

$4723 \mathrm{mg}$

$2891 \mathrm{mg}$

$1833 \mathrm{mg}$

$4723 \mathrm{mg}$

$2891 \mathrm{mg}$

$0,09 \mathrm{~kg}$ fenol $/ \mathrm{kg}$ SSV.dia

0,04 kg (N-NO3- + N-NO2-)/kgSSV.dia

$0,03 \mathrm{~kg} \mathrm{~N}-\mathrm{NO} 2-$ / kg SSV.dia

$2,6 \mathrm{~kg}$ fenol / kg (N-NO2- + N-NO3-) 
CICLO 09:

Concentração de Sólidos em Suspensão Voláteis = Carga de $\mathrm{N}-\mathrm{NH} 3=$ 994 mg N-NH3/dia

Carga de Fenol = $4877 \mathrm{mg}$ fenol/dia

Volumes retirados para realização de análises:
Etapa Aeróbia $=$
0,5 Litros

Etapa Anóxica =

1 Litros

Início da Etapa Aeróbia:

Massa de $\mathrm{N}-\mathrm{NH} 3=$

Massa de N-NO2- =

Massa de N-NO3- =

$725 \mathrm{mg} \mathrm{N}-\mathrm{NH} 3$

$47 \mathrm{mg} \mathrm{N}-\mathrm{NO} 2$

$3 \mathrm{mg} \mathrm{N}-\mathrm{NO} 3$

Início da Etapa Anóxica:

Massa de N-NO2- =

Massa de N-NO3- =

663 mg N-NO2-

Massa de Fenol =

$7 \mathrm{mg} \mathrm{N}-\mathrm{NO} 3$

$0 \mathrm{mg}$ fenol
$2230 \mathrm{mg} / \mathrm{L}$

Final da Etapa Aeróbia

Massa de $\mathrm{N}-\mathrm{NH} 3=$

Massa de N-NO2- =

Massa de N-NO3- =

$43 \mathrm{mg} \mathrm{N}-\mathrm{NH} 3$ $663 \mathrm{mg} \mathrm{N}-\mathrm{NO} 2$

$7 \mathrm{mg} \mathrm{N}-\mathrm{NO} 3-$

Final da Etapa Anóxica

Massa de N-NO2- =

Massa de N-NO3- =

Massa de Fenol =

0 mg N-NO2-

$0 \mathrm{mg} \mathrm{N}-\mathrm{NO} 3$

$2852 \mathrm{mg}$ fenol

Cálculos das Eficiências

Remoção de N-NH3 =

Relação N-NO2- / (N-NO2- + N-NO3-) =

Taxa de Nitrificação =

Eficiência de Remoção do fenol =

Eficiência de remoção de N-Nox =

Remoção de Fenol:

2 hs.

Massa de Fenol Aplicada =

Massa de Fenol Final =

Massa de Fenol Utilizada $=$

5 hs. Massa de Fenol Aplicada =

Massa de Fenol Final =

Massa de Fenol Utilizada $=$

8 hs. $\quad$ Massa de Fenol Aplicada =

Massa de Fenol Final =

Massa de Fenol Utilizada =

10 hs.

Massa de Fenol Aplicada =

Massa de Fenol Final =

Massa de Fenol Utilizada $=$

Massa Total de Fenol $=$

Massa de Fenol Final =

Relação Alimento/Microrganismos =

Taxa de desnitrificação =

Taxa de "desnitritação" =

Relação Fenol/ N-NO2- =
$94 \%$

$99 \%$

0,04 kg N-NH3 / kg SSV.dia

$42 \%$

$100 \%$

$975 \mathrm{mg}$

$606 \mathrm{mg}$

$369 \mathrm{mg}$

$2438 \mathrm{mg}$

$1101 \mathrm{mg}$

$1338 \mathrm{mg}$

$3901 \mathrm{mg}$

$1539 \mathrm{mg}$

$2363 \mathrm{mg}$

$4877 \mathrm{mg}$

$2852 \mathrm{mg}$

$2025 \mathrm{mg}$

$4877 \mathrm{mg}$

$2852 \mathrm{mg}$

$0,11 \mathrm{~kg}$ fenol $/ \mathrm{kg}$ SSV.dia

0,04 kg (N-NO3- + N-NO2-)/kgSSV.dia

0,04 kg N-NO2- / kg SSV.dia

$3,0 \mathrm{~kg}$ fenol / kg (N-NO2- + N-NO3-) 
CICLO 10:

Concentração de Sólidos em Suspensão Voláteis = Carga de $\mathrm{N}-\mathrm{NH} 3=$ 1003 mg N-NH3/dia

Carga de Fenol = $4709 \mathrm{mg}$ fenol/dia

Volumes retirados para realização de análises:
Etapa Aeróbia $=$
0,5 Litros

Etapa Anóxica =

1 Litros

Início da Etapa Aeróbia:

Massa de $\mathrm{N}-\mathrm{NH} 3=$

Massa de N-NO2- =

Massa de N-NO3- =

$914 \mathrm{mg} \mathrm{N}-\mathrm{NH} 3$

$30 \mathrm{mg} \mathrm{N}-\mathrm{NO} 2$

$0 \mathrm{mg} \mathrm{N}-\mathrm{NO} 3$

Início da Etapa Anóxica:

Massa de N-NO2- =

856 mg N-NO2-

Massa de N-NO3- =

$21 \mathrm{mg} \mathrm{N}-\mathrm{NO} 3$

Massa de Fenol =

$0 \mathrm{mg}$ fenol
$2175 \mathrm{mg} / \mathrm{L}$

Final da Etapa Aeróbia

Massa de $\mathrm{N}-\mathrm{NH} 3=$

Massa de N-NO2- =

Massa de N-NO3- =

$48 \mathrm{mg} \mathrm{N}-\mathrm{NH} 3$

$856 \mathrm{mg} \mathrm{N}-\mathrm{NO} 2-$

$21 \mathrm{mg} \mathrm{N}-\mathrm{NO} 3-$

Final da Etapa Anóxica

Massa de N-NO2- =

Massa de N-NO3- =

Massa de Fenol =

$16 \mathrm{mg} \mathrm{N}-\mathrm{NO} 2-$

$6 \mathrm{mg} \mathrm{N}-\mathrm{NO} 3$ -

$2794 \mathrm{mg}$ fenol

Cálculos das Eficiências

Remoção de $\mathrm{N}-\mathrm{NH} 3=$

Relação N-NO2- / (N-NO2- + N-NO3-) =

Taxa de Nitrificação =

Eficiência de Remoção do fenol =

Eficiência de remoção de N-Nox =

Remoção de Fenol:

2 hs.

Massa de Fenol Aplicada =

Massa de Fenol Final $=$

Massa de Fenol Utilizada =

5 hs.

Massa de Fenol Aplicada =

Massa de Fenol Final $=$

Massa de Fenol Utilizada =

8 hs. Massa de Fenol Aplicada =

Massa de Fenol Final =

Massa de Fenol Utilizada =

10 hs.

Massa de Fenol Aplicada $=$

Massa de Fenol Final =

Massa de Fenol Utilizada $=$

Massa Total de Fenol $=$

Massa de Fenol Final =

Relação Alimento/Microrganismos =

Taxa de desnitrificação =

Taxa de "desnitritação" =

Relação Fenol/ N-NO2- =
$95 \%$

$98 \%$

0,05 kg N-NH3 / kg SSV.dia

$41 \%$

$97 \%$

$942 \mathrm{mg}$

$737 \mathrm{mg}$

$204 \mathrm{mg}$

$2354 \mathrm{mg}$

$1222 \mathrm{mg}$

$1132 \mathrm{mg}$

$3767 \mathrm{mg}$

$1202 \mathrm{mg}$

$2565 \mathrm{mg}$

$4709 \mathrm{mg}$

$2794 \mathrm{mg}$

$1915 \mathrm{mg}$

$4709 \mathrm{mg}$

$2794 \mathrm{mg}$

$0,11 \mathrm{~kg}$ fenol $/ \mathrm{kg}$ SSV.dia

0,05 kg (N-NO3- + N-NO2-)/kgSSV.dia

0,05 kg N-NO2- / kg SSV.dia

$2,2 \mathrm{~kg}$ fenol / kg (N-NO2- + N-NO3-) 
CICLO 11:

Concentração de Sólidos em Suspensão Voláteis = Carga de $\mathrm{N}-\mathrm{NH} 3=$ 1013 mg N-NH3/dia

Carga de Fenol = $4867 \mathrm{mg}$ fenol/dia

Volumes retirados para realização de análises:
Etapa Aeróbia $=$
0,5 Litros

Etapa Anóxica =

1 Litros

Início da Etapa Aeróbia:

Massa de $\mathrm{N}-\mathrm{NH} 3=$

Massa de N-NO2- =

Massa de N-NO3- =

$820 \mathrm{mg} \mathrm{N}-\mathrm{NH} 3$

$15 \mathrm{mg} \mathrm{N}-\mathrm{NO} 2$

$3 \mathrm{mg} \mathrm{N}-\mathrm{NO} 3-$

Início da Etapa Anóxica:

Massa de N-NO2- =

751 mg N-NO2-

Massa de N-NO3- =

$37 \mathrm{mg} \mathrm{N}-\mathrm{NO} 3$

Massa de Fenol =

$0 \mathrm{mg}$ fenol
$2445 \mathrm{mg} / \mathrm{L}$

Final da Etapa Aeróbia

Massa de $\mathrm{N}-\mathrm{NH} 3=$

Massa de N-NO2- =

Massa de N-NO3- =

$24 \mathrm{mg} \mathrm{N}-\mathrm{NH} 3$

751 mg N-NO2-

37 mg N-NO3-

Final da Etapa Anóxica

Massa de N-NO2- =

Massa de N-NO3- =

Massa de Fenol =

$7 \mathrm{mg} \mathrm{N}-\mathrm{NO} 2-$

$4 \mathrm{mg} \mathrm{N}-\mathrm{NO} 3$

$3085 \mathrm{mg}$ fenol

Cálculos das Eficiências

Remoção de $\mathrm{N}-\mathrm{NH} 3=$

Relação N-NO2- / (N-NO2- + N-NO3-) =

Taxa de Nitrificação =

Eficiência de Remoção do fenol =

Eficiência de remoção de N-Nox =

Remoção de Fenol:

2 hs.

Massa de Fenol Aplicada =

Massa de Fenol Final =

Massa de Fenol Utilizada =

5 hs.

Massa de Fenol Aplicada =

Massa de Fenol Final $=$

Massa de Fenol Utilizada =

8 hs. $\quad$ Massa de Fenol Aplicada =

Massa de Fenol Final =

Massa de Fenol Utilizada $=$

10 hs.

Massa de Fenol Aplicada $=$

Massa de Fenol Final =

Massa de Fenol Utilizada $=$

Massa Total de Fenol $=$

Massa de Fenol Final =

Relação Alimento/Microrganismos =

Taxa de desnitrificação =

Taxa de "desnitritação" =

Relação Fenol/ N-NO2- =
$96 \%$

$95 \%$

0,04 kg N-NH3 / kg SSV.dia

$37 \%$

$99 \%$

$973 \mathrm{mg}$

$642 \mathrm{mg}$

$331 \mathrm{mg}$

$2434 \mathrm{mg}$

$775 \mathrm{mg}$

$1658 \mathrm{mg}$

$3894 \mathrm{mg}$

$1409 \mathrm{mg}$

$2485 \mathrm{mg}$

$4867 \mathrm{mg}$

$3085 \mathrm{mg}$

$1783 \mathrm{mg}$

$4867 \mathrm{mg}$

$3085 \mathrm{mg}$

$0,09 \mathrm{~kg}$ fenol $/ \mathrm{kg}$ SSV.dia

0,04 kg (N-NO3- + N-NO2-)/kgSSV.dia

0,04 kg N-NO2- / kg SSV.dia

2,3 kg fenol / kg (N-NO2- + N-NO3-) 
CICLO 12:

Concentração de Sólidos em Suspensão Voláteis = Carga de $\mathrm{N}-\mathrm{NH} 3=$ $931 \mathrm{mg} \mathrm{N}-\mathrm{NH} 3 / \mathrm{dia}$

Carga de Fenol = $4757 \mathrm{mg}$ fenol/dia

Volumes retirados para realização de análises:
Etapa Aeróbia $=$
0,5 Litros

Etapa Anóxica =

1 Litros

Início da Etapa Aeróbia:

Massa de $\mathrm{N}-\mathrm{NH} 3=$

Massa de N-NO2- =

Massa de N-NO3- =

$747 \mathrm{mg} \mathrm{N}-\mathrm{NH} 3$

$32 \mathrm{mg} \mathrm{N}-\mathrm{NO} 2$

$0 \mathrm{mg} \mathrm{N}-\mathrm{NO} 3-$

Início da Etapa Anóxica:

Massa de N-NO2- =

Massa de N-NO3- =

$683 \mathrm{mg} \mathrm{N}-\mathrm{NO} 2-$

Massa de Fenol =

$20 \mathrm{mg} \mathrm{N}-\mathrm{NO} 3$

$0 \mathrm{mg}$ fenol
$2485 \mathrm{mg} / \mathrm{L}$

Final da Etapa Aeróbia

Massa de $\mathrm{N}-\mathrm{NH} 3=$

Massa de N-NO2- =

Massa de N-NO3- =

$33 \mathrm{mg} \mathrm{N}-\mathrm{NH} 3$ $683 \mathrm{mg} \mathrm{N}-\mathrm{NO} 2-$

20 mg N-NO3-

Final da Etapa Anóxica

Massa de N-NO2- =

Massa de N-NO3- =

Massa de Fenol =

$0 \mathrm{mg} \mathrm{N}-\mathrm{NO} 2-$

$2 \mathrm{mg} \mathrm{N}-\mathrm{NO} 3$

$2888 \mathrm{mg}$ fenol

Cálculos das Eficiências

Remoção de $\mathrm{N}-\mathrm{NH} 3=$

Relação N-NO2- / (N-NO2- + N-NO3-) =

Taxa de Nitrificação =

Eficiência de Remoção do fenol =

Eficiência de remoção de N-Nox =

Remoção de Fenol:

Massa de Fenol Aplicada $=$

Massa de Fenol Final $=$

Massa de Fenol Utilizada =

5 hs. Massa de Fenol Aplicada =

Massa de Fenol Final $=$

Massa de Fenol Utilizada =

8 hs. $\quad$ Massa de Fenol Aplicada =

Massa de Fenol Final $=$

Massa de Fenol Utilizada =

10 hs.

Massa de Fenol Aplicada =

Massa de Fenol Final $=$

Massa de Fenol Utilizada $=$

Massa Total de Fenol $=$

Massa de Fenol utilizada $=$

Relação Alimento/Microrganismos =

Taxa de desnitrificação =

Taxa de "desnitritação" =

Relação Fenol/ N-NO2- =

$96 \%$

$97 \%$

0,04 kg N-NH3 / kg SSV.dia

$38 \%$

$100 \%$

$951 \mathrm{mg}$

$858 \mathrm{mg}$

$93 \mathrm{mg}$

$2378 \mathrm{mg}$

$945 \mathrm{mg}$

$1433 \mathrm{mg}$

$3805 \mathrm{mg}$

$860 \mathrm{mg}$

$2945 \mathrm{mg}$

$4757 \mathrm{mg}$

$2949 \mathrm{mg}$

$1808 \mathrm{mg}$

$4757 \mathrm{mg}$

$2949 \mathrm{mg}$

$0,09 \mathrm{~kg}$ fenol $/ \mathrm{kg}$ SSV.dia

0,04 kg (N-NO3- + N-NO2-)/kgSSV.dia

0,03 kg N-NO2- / kg SSV.dia

2,6 kg fenol / kg (N-NO2- + N-NO3-) 
ANEXO D2 - Concentração no afluente em torno de 300 mg N/L

\section{Ciclo 01}

Concentração de Sólidos em Suspensão Voláteis =

Carga de N-NH3 = $1429 \mathrm{mg} \mathrm{N}-\mathrm{NH} 3 /$ dia

Carga de Fenol = $\quad 4734 \mathrm{mg}$ fenol/dia

Volumes retirados para realização de análises:

Etapa Aeróbia $=\quad 0,4$ litros

Etapa Anóxica $=\quad 0,1$ litros

Início da Etapa Aeróbia:

$\begin{array}{lr}\text { Massa de N-NH3 = } & 1126 \mathrm{mg} \mathrm{N}-\mathrm{NH3} \\ \text { Massa de N-NO2- = } & 1 \mathrm{mg} \mathrm{N}-\mathrm{NO}- \\ \text { Massa de N-NO3- }= & 0 \mathrm{mg} \mathrm{N}-\mathrm{NO3}-\end{array}$

Massa de N-NO3- =

$0 \mathrm{mg} \mathrm{N}-\mathrm{NO} 3-$

Início da Etapa Anóxica

Massa de N-NO2- =

Massa de N-NO3- =

Massa de Fenol $=$
$2210 \mathrm{mg} / \mathrm{L}$

Final da Etapa Aeróbia

Massa de N-NH3 = $62 \mathrm{mg} \mathrm{N}-\mathrm{NH} 3$

Massa de N-NO2- = $960 \mathrm{mg} \mathrm{N}-\mathrm{NO}^{-}$

Massa de N-NO3- = $27 \mathrm{mg} \mathrm{N}-\mathrm{NO} 3-$

Final da Etapa Anóxica

Massa de N-NO2- =

Massa de N-NO3- =

Massa de Fenol =
$744 \mathrm{mg} \mathrm{N}-\mathrm{NO} 2-$

$65 \mathrm{mg} \mathrm{N}-\mathrm{NO} 3-$

$2879 \mathrm{mg}$ fenol

\section{Cálculos das Eficiências}

Remoção de $\mathrm{N}-\mathrm{NH} 3=$

Relação N-NO2- / (N-NO2- + N-NO3-) =

$62 \mathrm{mg} \mathrm{N}-\mathrm{NO} 3$

$0 \mathrm{mg}$ fenol

$94 \%$

$89 \%$

0,04 kg N-NH3 / kg SSV.dia

$39 \%$

$22 \%$

Eficiência de Remoção do fenol =

Remoção de Fenol:

3 hs. $\quad$ Massa de Fenol Aplicada $=$

$947 \mathrm{mg}$

Massa de Fenol Final $=$

$0 \mathrm{mg}$

$947 \mathrm{mg}$

$1893 \mathrm{mg}$

6 hs. Massa de Fenol Aplicada =

$555 \mathrm{mg}$

$1338 \mathrm{mg}$

$2840 \mathrm{mg}$

$1437 \mathrm{mg}$

$1403 \mathrm{mg}$

$3787 \mathrm{mg}$

$1909 \mathrm{mg}$

12 hs. Massa de Fenol Aplicada =

Massa de Fenol Final $=$

$1878 \mathrm{mg}$

$4734 \mathrm{mg}$

15 hs. Massa de Fenol Aplicada $=$

$\begin{array}{ll}\text { Massa de Fenol Final }= & 2879 \mathrm{mg} \\ \text { Massa de Fenol Utilizada }= & 1855 \mathrm{mg}\end{array}$

Massa Total de Fenol $=$

$4734 \mathrm{mg}$

Massa Final de Fenol =

$2879 \mathrm{mg}$

Relação Alimento/Microrganismos =

$0,11 \mathrm{~kg}$ fenol $/ \mathrm{kg}$ SSV.dia

Taxa de desnitrificação =

Taxa de "desnitritação" =

Relação Fenol/ N-NO2- =

0,01 kg (N-NO3- + N-NO2-)/kgSSV.dia

0,005 kg N-NO2- / kg SSV.dia

n.d $\mathrm{kg}$ fenol / kg (N-NO2- + N-NO3-) 
Ciclo 02

Concentração de Sólidos em Suspensão Voláteis =

Carga de $\mathrm{N}-\mathrm{NH} 3=$

$1278 \mathrm{mg} \mathrm{N}-\mathrm{NH} 3 /$ dia

Carga de Fenol = $4374 \mathrm{mg}$ fenol/dia

Volumes retirados para realização de análises:

Etapa Aeróbia $=\quad 0,25$ litros

Etapa Anóxica $=\quad 0,14$ litros

Início da Etapa Aeróbia:

Massa de $\mathrm{N}-\mathrm{NH} 3=$

Massa de N-NO2- =

$991 \mathrm{mg} \mathrm{N}-\mathrm{NH} 3$

$7 \mathrm{mg} \mathrm{N}-\mathrm{NO} 2$

Massa de N-NO3- =

$0 \mathrm{mg} \mathrm{N}-\mathrm{NO} 3-$

Início da Etapa Anóxica:

Massa de N-NO2- =

Massa de N-NO3- =

Massa de Fenol =
$2275 \mathrm{mg} / \mathrm{L}$

Final da Etapa Aeróbia

Massa de $\mathrm{N}-\mathrm{NH} 3=$

Massa de N-NO2- =

Massa de N-NO3- =

$43 \mathrm{mg} \mathrm{N}-\mathrm{NH} 3$

$870 \mathrm{mg} \mathrm{N}-\mathrm{NO} 2-$

$24 \mathrm{mg} \mathrm{N}-\mathrm{NO} 3-$

Final da Etapa Anóxica

Massa de N-NO2- =

Massa de N-NO3- =

Massa de Fenol =
9 mg N-NO2-

$0 \mathrm{mg} \mathrm{N}-\mathrm{NO} 3-$

$1637 \mathrm{mg}$ fenol

\section{Cálculos das Eficiências}

Remoção de N-NH3 =

Relação N-NO2- / (N-NO2- + N-NO3-) =

Taxa de Nitrificação =

Eficiência de Remoção do fenol =

Eficiência de remoção de N-Nox =

$24 \mathrm{mg} \mathrm{N}-\mathrm{NO} 3$

$96 \%$

$97 \%$

0,03 kg N-NH3 / kg SSV.dia

$63 \%$

$99 \%$

\section{Remoção de Fenol:}

3 hs.

Massa de Fenol Aplicada =

$875 \mathrm{mg}$

$168 \mathrm{mg}$

$707 \mathrm{mg}$

$1750 \mathrm{mg}$

Massa de Fenol Utilizada =

Massa de Fenol Final =

Massa de Fenol Utilizada $=$

9 hs.

Massa de Fenol Aplicada =

Massa de Fenol Final =

Massa de Fenol Utilizada =

15 hs.

Massa de Fenol Aplicada =

Massa de Fenol Final =

Massa de Fenol Utilizada =

24 hs. Massa de Fenol Aplicada =

Massa de Fenol Final $=$

Massa de Fenol Utilizada $=$

Massa Total de Fenol $=$

Massa Final de Fenol

Relação Alimento/Microrganismos =

Taxa de desnitrificação =

Taxa de "desnitritação" =

Relação Fenol/ N-NO2- =
$385 \mathrm{mg}$

$1364 \mathrm{mg}$

$2624 \mathrm{mg}$

$1063 \mathrm{mg}$

$1561 \mathrm{mg}$

$4374 \mathrm{mg}$

$2073 \mathrm{mg}$

$2301 \mathrm{mg}$

$4374 \mathrm{mg}$

$1637 \mathrm{mg}$

$2737 \mathrm{mg}$

$4374 \mathrm{mg}$

$1637 \mathrm{mg}$

$0,10 \mathrm{~kg}$ fenol $/ \mathrm{kg}$ SSV.dia

0,02 kg (N-NO3- + N-NO2-)/kgSSV.dia

0,02 kg N-NO2- / kg SSV.dia

3,1 kg fenol / kg (N-NO2- + N-NO3-) 
Ciclo 03

Concentração de Sólidos em Suspensão Voláteis =

Carga de $\mathrm{N}-\mathrm{NH} 3=$

1377 mg N-NH3/dia

Carga de Fenol = 4900,5 mg fenol/dia

Volumes retirados para realização de análises:

$\begin{array}{ll}\text { Etapa Aeróbia }= & 0,2 \text { litros } \\ \text { Etapa Anóxica }= & 0,1 \text { litros }\end{array}$

Início da Etapa Aeróbia:

Massa de $\mathrm{N}-\mathrm{NH} 3=$

Massa de N-NO2- =

Massa de N-NO3- =

$1126 \mathrm{mg} \mathrm{N}-\mathrm{NH} 3$

$10 \mathrm{mg} \mathrm{N}-\mathrm{NO} 2$

$0 \mathrm{mg} \mathrm{N}-\mathrm{NO} 3-$

Início da Etapa Anóxica:

Massa de N-NO2- =

Massa de N-NO3- =

1007 mg N-NO2-

$36 \mathrm{mg} \mathrm{N}-\mathrm{NO} 3$

Massa de Fenol =
$2460 \mathrm{mg} / \mathrm{L}$

Final da Etapa Aeróbia

Massa de $\mathrm{N}-\mathrm{NH} 3=$

Massa de N-NO2- =

Massa de $\mathrm{N}-\mathrm{NO} 3-=$

$36 \mathrm{mg} \mathrm{N}-\mathrm{NH} 3$ 1007 mg N-NO2-

$24 \mathrm{mg} \mathrm{N}-\mathrm{NO} 3-$

Final da Etapa Anóxica

Massa de N-NO2- =

Massa de N-NO3- =

Massa de Fenol =

$7 \mathrm{mg} \mathrm{N}-\mathrm{NO} 2$

$0 \mathrm{mg} \mathrm{N}-\mathrm{NO} 3$

$1975 \mathrm{mg}$ fenol

Cálculos das Eficiências

Remoção de N-NH3 =

Relação N-NO2- / (N-NO2- + N-NO3-) =

Taxa de Nitrificação =

Eficiência de Remoção do fenol =

Eficiência de remoção de N-Nox =

$97 \%$

$98 \%$

0,04 kg N-NH3 / kg SSV.dia

$60 \%$

$99 \%$

$980 \mathrm{mg}$

$216 \mathrm{mg}$

$764 \mathrm{mg}$

$1960 \mathrm{mg}$

$1427 \mathrm{mg}$

$534 \mathrm{mg}$

$2940 \mathrm{mg}$

$1424 \mathrm{mg}$

$1517 \mathrm{mg}$

$4901 \mathrm{mg}$

$2404 \mathrm{mg}$

$2496 \mathrm{mg}$

$4901 \mathrm{mg}$

$1975 \mathrm{mg}$

$2925 \mathrm{mg}$

$4901 \mathrm{mg}$

$1975 \mathrm{mg}$

Massa Total de Fenol $=$

Massa Final de Fenol

$0,10 \mathrm{~kg}$ fenol $/ \mathrm{kg} \mathrm{SSV.dia}$

0,02 kg (N-NO3- + N-NO2-)/kgSSV.dia

0,02 kg N-NO2- / kg SSV.dia

$2,9 \mathrm{~kg}$ fenol / kg (N-NO2- + N-NO3-)

Taxa de desnitrificação =

Taxa de "desnitritação" =

Relação Fenol/ N-NO2- = 
Ciclo 04

Concentração de Sólidos em Suspensão Voláteis =

Carga de $\mathrm{N}-\mathrm{NH} 3=$

1445 mg N-NH3/dia

Carga de Fenol = $4464 \mathrm{mg}$ fenol/dia

Volumes retirados para realização de análises:

$\begin{array}{ll}\text { Etapa Aeróbia }= & 0,3 \text { litros } \\ \text { Etapa Anóxica }= & 0,2 \text { litros }\end{array}$

Início da Etapa Aeróbia:

Massa de $\mathrm{N}-\mathrm{NH} 3=$

Massa de N-NO2- =

Massa de N-NO3- =

$1277 \mathrm{mg} \mathrm{N}-\mathrm{NH} 3$

$4 \mathrm{mg} \mathrm{N}-\mathrm{NO} 2$ -

$0 \mathrm{mg} \mathrm{N}-\mathrm{NO} 3$ -

Início da Etapa Anóxica:

Massa de N-NO2- =

Massa de N-NO3- =

Massa de Fenol =

$$
\begin{aligned}
& 1100 \text { mg N-NO2- } \\
& 21 \text { mg N-NO3- } \\
& 0 \text { mg fenol }
\end{aligned}
$$

$2544 \mathrm{mg} / \mathrm{L}$

\section{Final da Etapa Aeróbia}

Massa de $\mathrm{N}-\mathrm{NH} 3=$

Massa de N-NO2- =

Massa de N-NO3- =

Final da Etapa Anóxica

Massa de N-NO2- =

Massa de N-NO3- =

Massa de Fenol =

$21 \mathrm{mg} \mathrm{N}-\mathrm{NH} 3$

$1100 \mathrm{mg} \mathrm{N}-\mathrm{NO} 2-$

$41 \mathrm{mg} \mathrm{N}-\mathrm{NO} 3$

2 mg N-NO2-

0 mg N-NO3-

$1574 \mathrm{mg}$ fenol

\section{Cálculos das Eficiências}

Remoção de $\mathrm{N}-\mathrm{NH} 3=$

Relação N-NO2- / (N-NO2- + N-NO3-) =

Taxa de Nitrificação =

Eficiência de Remoção do fenol =

0,04 kg N-NH3 / kg SSV.dia

$65 \%$

Eficiência de remoção de N-Nox =

$100 \%$

Remoção de Fenol:

$\begin{array}{rlr}3 \text { hs. } & \text { Massa de Fenol Aplicada }= & 1488 \mathrm{mg} \\ & \text { Massa de Fenol Final }= & 255 \mathrm{mg} \\ & \text { Massa de Fenol Utilizada }= & 1233 \mathrm{mg} \\ 6 \text { hs. } & \text { Massa de Fenol Aplicada }= & 2381 \mathrm{mg} \\ & \text { Massa de Fenol Final }= & 1539 \mathrm{mg} \\ 9 \text { hs. } & \text { Massa de Fenol Utilizada }= & 842 \mathrm{mg} \\ & \text { Massa de Fenol Aplicada }= & 3274 \mathrm{mg} \\ 15 \text { hs. } & \text { Massa de Fenol Final }= & 1824 \mathrm{mg} \\ & \text { Massa de Fenol Utilizada }= & 1450 \mathrm{mg} \\ & \text { Massa de Fenol Aplicada }= & 4464 \mathrm{mg} \\ 24 \text { hs. } & \text { Massa de Fenol Final }= & 2273 \mathrm{mg} \\ & \text { Massa de Fenol Utilizada }= & 2191 \mathrm{mg} \\ & \text { Massa de Fenol Aplicada }= & 4464 \mathrm{mg} \\ & \text { Massa de Fenol Final }= & 1574 \mathrm{mg} \\ & \text { Massa de Fenol Utilizada }= & 2890 \mathrm{mg}\end{array}$

Massa Total de Fenol $=\quad 4464 \mathrm{mg}$

Massa Final de Fenol $\quad 1574 \mathrm{mg}$

$0,09 \mathrm{~kg}$ fenol $/ \mathrm{kg}$ SSV.dia

Taxa de desnitrificação =

0,02 kg (N-NO3- + N-NO2-)/kgSSV.dia

$0,02 \mathrm{~kg} \mathrm{~N}-\mathrm{NO} 2-$ / kg SSV.dia

2,5 kg fenol / kg (N-NO2- + N-NO3-) 
Ciclo 05

Concentração de Sólidos em Suspensão Voláteis =

Carga de $\mathrm{N}-\mathrm{NH} 3=$

$1,278 \mathrm{mg} \mathrm{N}-\mathrm{NH} 3 /$ dia

Carga de Fenol =

4,491 $\mathrm{mg}$ fenol/dia

Volumes retirados para realização de análises:

$\begin{array}{ll}\text { Etapa Aeróbia }= & 0,3 \text { litros } \\ \text { Etapa Anóxica }= & 0,2 \text { litros }\end{array}$

Início da Etapa Aeróbia:

Massa de $\mathrm{N}-\mathrm{NH} 3=$

Massa de N-NO2- =

$991 \mathrm{mg} \mathrm{N}-\mathrm{NH} 3$

Massa de N-NO3- =

$2 \mathrm{mg} \mathrm{N}-\mathrm{NO} 2$

$0 \mathrm{mg} \mathrm{N}-\mathrm{NO} 3$

Início da Etapa Anóxica:

Massa de N-NO2- =

Massa de N-NO3- =

Massa de Fenol =
$2604 \mathrm{mg} / \mathrm{L}$

Final da Etapa Aeróbia

Massa de $\mathrm{N}-\mathrm{NH} 3=$

Massa de N-NO2- =

Massa de N-NO3- =

$34 \mathrm{mg} \mathrm{N}-\mathrm{NH} 3$ 936 mg N-NO2-

$31 \mathrm{mg} \mathrm{N}-\mathrm{NO} 3$

Final da Etapa Anóxica

Massa de N-NO2- =

Massa de N-NO3- =

Massa de Fenol =

\author{
$16 \mathrm{mg} \mathrm{N}-\mathrm{NO} 2$ \\ $0 \mathrm{mg} \mathrm{N}-\mathrm{NO} 3-$ \\ $1633 \mathrm{mg}$ fenol
}

Cálculos das Eficiências

Remoção de N-NH3 =

Relação N-NO2- / (N-NO2- + N-NO3-) =

Taxa de Nitrificação =

Eficiência de Remoção do fenol =

0,03 kg N-NH3 / kg SSV.dia

$64 \%$

Eficiência de remoção de N-Nox =

$98 \%$

Remoção de Fenol:

$\begin{array}{rlr}3 \text { hs. } & \text { Massa de Fenol Aplicada }= & 898 \mathrm{mg} \\ & \text { Massa de Fenol Final }= & 531 \mathrm{mg} \\ 6 \text { hs. } & \text { Massa de Fenol Utilizada }= & 368 \mathrm{mg} \\ & \text { Massa de Fenol Aplicada }= & 1796 \mathrm{mg} \\ & \text { Massa de Fenol Final }= & 1318 \mathrm{mg} \\ 9 \text { hs. } & \text { Massa de Fenol Utilizada }= & 478 \mathrm{mg} \\ & \text { Massa de Fenol Aplicada }= & 2695 \mathrm{mg} \\ & \text { Massa de Fenol Final }= & 1861 \mathrm{mg} \\ 15 \text { hs. } & \text { Massa de Fenol Utilizada }= & 833 \mathrm{mg} \\ & \text { Massa de Fenol Aplicada }= & 4491 \mathrm{mg} \\ 24 \text { hs. } & \text { Massa de Fenol Final }= & 2358 \mathrm{mg} \\ & \text { Massa de Fenol Utilizada }= & 2133 \mathrm{mg} \\ & \text { Massa de Fenol Aplicada }= & 4491 \mathrm{mg} \\ & \text { Massa de Fenol Final }= & 1633 \mathrm{mg} \\ & \text { Massa de Fenol Utilizada }= & 2858 \mathrm{mg}\end{array}$

Massa Total de Fenol = $\quad 4491 \mathrm{mg}$

Massa Final de Fenol 1633 mg

Relação Alimento/Microrganismos =

$0,09 \mathrm{~kg}$ fenol $/ \mathrm{kg}$ SSV.dia

Taxa de desnitrificação =

Taxa de "desnitritação" =

Relação Fenol/ N-NO2- =

0,02 kg (N-NO3- + N-NO2-)/kgSSV.dia

0,02 kg N-NO2- / kg SSV.dia

$3,0 \mathrm{~kg}$ fenol / kg (N-NO2- + N-NO3-) 
ANEXO D3 - Concentração no afluente em torno de 500 mg N/L

\section{Ciclo 01}

Concentração de Sólidos em Suspensão Voláteis = Carga de N-NH3 = 2319,4 mg N-NH3/dia

Carga de Fenol = $\quad 4577,0 \mathrm{mg} \mathrm{fenol} / \mathrm{dia}$

Volumes retirados para realização de análises:

Etapa Aeróbia $=\quad 0,4$ Litros

Etapa Anóxica $=\quad 0,2$ Litros

Início da Etapa Aeróbia:

Massa de N-NH3

$2397 \mathrm{mg} \mathrm{N}-\mathrm{NH} 3$

Massa de N-NO2- =

$0 \mathrm{mg} \mathrm{N}-\mathrm{NO} 2$

Massa de N-NO3- =

0 mg N-NO3-

Início da Etapa Anóxica:

Massa de N-NO2- =

Massa de N-NO3- =

$1476 \mathrm{mg} \mathrm{N}-\mathrm{NO} 2$

744 mg N-NO3-

Massa de Fenol $=$
$2370 \mathrm{mg} / \mathrm{L}$

Final da Etapa Aeróbia

Massa de $\mathrm{N}-\mathrm{NH} 3=$

Massa de N-NO2- =

Massa de N-NO3- =

Final da Etapa Anóxica

Massa de N-NO2- =

Massa de N-NO3- =

Massa de Fenol =

259 mg N-NO3-

$3771 \mathrm{mg}$ fenol
$61 \mathrm{mg} \mathrm{N}-\mathrm{NH} 3$

1476 mg N-NO2-

744 mg N-NO3-
1685 mg N-NO2-

\section{Cálculos das Eficiências}

Remoção de N-NH3 =

Relação N-NO2- / (N-NO2- + N-NO3-) =

Taxa de Nitrificação =

Eficiência de Remoção do fenol =

Eficiência de remoção de N-Nox =

Remoção de Fenol:

\begin{tabular}{|c|c|c|}
\hline \multirow[t]{3}{*}{3 hs. } & Massa de Fenol Aplicada $=$ & $915 \mathrm{mg}$ \\
\hline & Massa de Fenol Final $=$ & 866 \\
\hline & Massa de Fenol Utilizada $=$ & 50 \\
\hline \multirow[t]{3}{*}{6 hs. } & Massa de Fenol Aplicada $=$ & 1831 \\
\hline & Massa de Fenol Final = & 1541 \\
\hline & Massa de Fenol Utilizada $=$ & 290 \\
\hline \multirow[t]{3}{*}{9 hs. } & Massa de Fenol Aplicada $=$ & 2746 \\
\hline & Massa de Fenol Final $=$ & 2628 \\
\hline & Massa de Fenol Utilizada $=$ & 118 \\
\hline \multirow[t]{3}{*}{12 hs. } & Massa de Fenol Aplicada $=$ & 3662 \\
\hline & Massa de Fenol Final = & 2553 \\
\hline & Massa de Fenol Utilizada $=$ & 1108 \\
\hline \multirow[t]{3}{*}{15 hs. } & Massa de Fenol Aplicada $=$ & 4577 \\
\hline & Massa de Fenol Final $=$ & 3758 \\
\hline & Massa de Fenol Utilizada $=$ & 81 \\
\hline \multirow[t]{3}{*}{$18 \mathrm{hs}}$. & Massa de Fenol Aplicada = & 4577 \\
\hline & Massa de Fenol Final = & 3822 \\
\hline & Massa de Fenol Utilizada $=$ & 755 \\
\hline \multirow[t]{3}{*}{21 hs. } & Massa de Fenol Aplicada $=$ & 4577 \\
\hline & Massa de Fenol Final $=$ & 4019 \\
\hline & Massa de Fenol Utilizada $=$ & 558 \\
\hline \multirow[t]{3}{*}{24 hs. } & Massa de Fenol Aplicada $=$ & 4577 \\
\hline & Massa de Fenol Final = & 3771 \\
\hline & Massa de Fenol Utilizada $=$ & 806 \\
\hline \multicolumn{2}{|c|}{ Massa Total de Fenol aplicada = } & 4577,04 \\
\hline \multicolumn{2}{|c|}{ Massa final de Fenol $=$} & 3771 \\
\hline \multicolumn{2}{|c|}{ Massa Total de Fenol utilizada $=$} & 806 \\
\hline
\end{tabular}

$97 \%$

$66 \%$

0,05 kg N-NH3 / kg SSV.dia

$18 \%$

$17 \%$

$15 \mathrm{mg}$

$6 \mathrm{mg}$

$\mathrm{mg}$

$541 \mathrm{mg}$

$290 \mathrm{mg}$

$118 \mathrm{mg}$

$553 \mathrm{mg}$

mg

$758 \mathrm{mg}$

$819 \mathrm{mg}$

$4577 \mathrm{mg}$

$\mathrm{mg}$

$577 \mathrm{mg}$

$019 \mathrm{mg}$

$558 \mathrm{mg}$

$71 \mathrm{mg}$

$806 \mathrm{mg}$

$3771 \mathrm{mg}$

$0,03 \mathrm{~kg}$ fenol/kg SSV.dia

0,00 kg (N-NO3- + N-NO2-)/kgSSV.dia

0,00 kg N-NO2- / kg SSV.dia

Relação Alimento/Microrganismos =

Taxa de desnitrificação =

Taxa de desnitritação = 
Ciclo 02

Concentração de Sólidos em Suspensão Voláteis = Carga de N-NH3 $=\quad 2596,608 \mathrm{mg} \mathrm{N}-\mathrm{NH} 3 /$ dia Carga de Fenol = $\quad 4984,56 \mathrm{mg}$ fenol/dia Volumes retirados para realização de análises:
Etapa Aeróbia =
0,6 Litros

Etapa Anóxica $=$

0,3 Litros

Início da Etapa Aeróbia:

Massa de $\mathrm{N}-\mathrm{NH} 3=$

Massa de N-NO2- =

$2509 \mathrm{mg} \mathrm{N}-\mathrm{NH} 3$

Massa de N-NO3- =

$0 \mathrm{mg} \mathrm{N}-\mathrm{NO} 2$

$0 \mathrm{mg} \mathrm{N}-\mathrm{NO} 3$

Início da Etapa Anóxica:

Massa de N-NO2- =

Massa de N-NO3- =

1839 mg N-NO2-

Massa de Fenol =

$15 \mathrm{mg} \mathrm{N}-\mathrm{NO} 3$

$0 \mathrm{mg}$ fenol

Cálculos das Eficiências:

Remoção de N-NH3 =

Relação N-NO2- / (N-NO2- + N-NO3-) =

Taxa de Nitrificação =

Eficiência de Remoção do fenol =

Eficiência de remoção de N-Nox =

Remoção de Fenol:

3 hs.

Massa de Fenol Aplicada $=$

Massa de Fenol Final =

Massa de Fenol Utilizada $=$

6 hs. Massa de Fenol Aplicada =

Massa de Fenol Final =

Massa de Fenol Utilizada =

9 hs. $\quad$ Massa de Fenol Aplicada =

Massa de Fenol Final =

Massa de Fenol Utilizada $=$

12 hs.

Massa de Fenol Aplicada =

Massa de Fenol Final $=$

Massa de Fenol Utilizada $=$

15 hs. Massa de Fenol Aplicada =

Massa de Fenol Final =

Massa de Fenol Utilizada =

18 hs. Massa de Fenol Aplicada =

Massa de Fenol Final =

Massa de Fenol Utilizada $=$

21 hs. Massa de Fenol Aplicada =

Massa de Fenol Final =

Massa de Fenol Utilizada $=$

24 hs.

Massa de Fenol Aplicada $=$

Massa de Fenol Final =

Massa de Fenol Utilizada =

Massa Total de Fenol aplicada $=$

Massa final de Fenol =

Massa Total de Fenol utilizada =
$2277 \mathrm{mg} / \mathrm{L}$

Final da Etapa Aeróbia

Massa de $\mathrm{N}-\mathrm{NH} 3=$

Massa de N-NO2- =

Massa de N-NO3- =

$115 \mathrm{mg} \mathrm{N}-\mathrm{NH} 3$

1839 mg N-NO2-

$250 \mathrm{mg} \mathrm{N}-\mathrm{NO} 3-$

Final da Etapa Anóxica

Massa de N-NO2- =

Massa de N-NO3- =

Massa de Fenol =

$1614 \mathrm{mg} \mathrm{N}-\mathrm{NO} 2$

$113 \mathrm{mg} \mathrm{N}-\mathrm{NO} 3$

$3617 \mathrm{mg}$ fenol 
Ciclo 03

Concentração de Sólidos em Suspensão Voláteis = Carga de $\mathrm{N}-\mathrm{NH} 3=$ 2535 mg N-NH3/dia

Carga de Fenol = $5070 \mathrm{mg}$ fenol/dia

Volumes retirados para realização de análises:
Etapa Aeróbia $=$
0,8 Litros

Etapa Anóxica =

0,2 Litros

Início da Etapa Aeróbia:

Massa de $\mathrm{N}-\mathrm{NH} 3=$

Massa de N-NO2- =

Massa de N-NO3- =

$2150 \mathrm{mg} \mathrm{N}-\mathrm{NH} 3$

$28 \mathrm{mg} \mathrm{N}-\mathrm{NO} 2$

$0 \mathrm{mg} \mathrm{N}-\mathrm{NO} 3-$

Início da Etapa Anóxica:

Massa de N-NO2- =

1875 mg N-NH3

Massa de N-NO3- =

$48 \mathrm{mg} \mathrm{N}-\mathrm{NO} 2$

Massa de Fenol =
$2265 \mathrm{mg} / \mathrm{L}$

Final da Etapa Aeróbia

Massa de $\mathrm{N}-\mathrm{NH} 3=$

Massa de N-NO2- =

Massa de $\mathrm{N}-\mathrm{NO} 3-=$

$47 \mathrm{mg} \mathrm{N}-\mathrm{NH} 3$

1875 mg N-NO2-

89 mg N-NO3-

Final da Etapa Anóxica

Massa de N-NO2- =

Massa de N-NO3- =

Massa de Fenol =
$1640 \mathrm{mg} \mathrm{N}-\mathrm{NH} 3$

$47 \mathrm{mg} \mathrm{N}-\mathrm{NO} 2-$

3850 mg N-NO3-

Cálculos das Eficiências

Remoção de N-NH3 =

Relação N-NO2- / (N-NO2- + N-NO3-) =

Taxa de Nitrificação =

Eficiência de Remoção do fenol =

Eficiência de remoção de N-Nox =

Remoção de Fenol:

3 hs.

Massa de Fenol Aplicada =

Massa de Fenol Final $=$

Massa de Fenol Utilizada =

6 hs. Massa de Fenol Aplicada =

Massa de Fenol Final =

Massa de Fenol Utilizada =

9 hs. Massa de Fenol Aplicada =

Massa de Fenol Final =

Massa de Fenol Utilizada =

12 hs. Massa de Fenol Aplicada =

Massa de Fenol Final $=$

Massa de Fenol Utilizada $=$

15 hs. Massa de Fenol Aplicada =

Massa de Fenol Final =

Massa de Fenol Utilizada $=$

18 hs. Massa de Fenol Aplicada =

Massa de Fenol Final $=$

Massa de Fenol Utilizada $=$

21 hs. Massa de Fenol Aplicada $=$

Massa de Fenol Final =

Massa de Fenol Utilizada $=$

24 hs.

Massa de Fenol Aplicada $=$

Massa de Fenol Final $=$

Massa de Fenol Utilizada $=$

Massa Total de Fenol aplicada $=$

Massa final de Fenol $=$

Massa Total de Fenol utilizada $=$

Relação Alimento/Microrganismos =

Taxa de desnitrificação =
$98 \%$

$95 \%$

0,05 kg N-NH3 / kg SSV.dia

$24 \%$

$16 \%$

$634 \mathrm{mg}$

$206 \mathrm{mg}$

$428 \mathrm{mg}$

$1268 \mathrm{mg}$

$607 \mathrm{mg}$

$661 \mathrm{mg}$

$1901 \mathrm{mg}$

$1323 \mathrm{mg}$

$578 \mathrm{mg}$

$2535 \mathrm{mg}$

$1867 \mathrm{mg}$

$669 \mathrm{mg}$

$3169 \mathrm{mg}$

$2552 \mathrm{mg}$

$617 \mathrm{mg}$

$3803 \mathrm{mg}$

$3100 \mathrm{mg}$

$703 \mathrm{mg}$

$4436 \mathrm{mg}$

$3479 \mathrm{mg}$

$957 \mathrm{mg}$

$5070 \mathrm{mg}$

$3850 \mathrm{mg}$

$1220 \mathrm{mg}$

$5070 \mathrm{mg}$

$3850 \mathrm{mg}$

$1220 \mathrm{mg}$

0,04 kg fenol/kg SSV.dia

0,00 kg (N-NO3- + N-NO2-)/kgSSV.dia 